\title{
Support of an Asthma/COPD service for general practitioners in daily care
}

Citation for published version (APA):

Lucas, A. E. M. (2012). Support of an Asthma/COPD service for general practitioners in daily care.

[Doctoral Thesis, Maastricht University]. Maastricht University. https://doi.org/10.26481/dis.20120907al

Document status and date:

Published: 01/01/2012

DOI:

10.26481/dis.20120907al

Document Version:

Publisher's PDF, also known as Version of record

\section{Please check the document version of this publication:}

- A submitted manuscript is the version of the article upon submission and before peer-review. There can be important differences between the submitted version and the official published version of record.

People interested in the research are advised to contact the author for the final version of the publication, or visit the DOI to the publisher's website.

- The final author version and the galley proof are versions of the publication after peer review.

- The final published version features the final layout of the paper including the volume, issue and page numbers.

Link to publication

\footnotetext{
General rights rights.

- You may freely distribute the URL identifying the publication in the public portal. please follow below link for the End User Agreement:

www.umlib.nl/taverne-license

Take down policy

If you believe that this document breaches copyright please contact us at:

repository@maastrichtuniversity.nl

providing details and we will investigate your claim.
}

Copyright and moral rights for the publications made accessible in the public portal are retained by the authors and/or other copyright owners and it is a condition of accessing publications that users recognise and abide by the legal requirements associated with these

- Users may download and print one copy of any publication from the public portal for the purpose of private study or research.

- You may not further distribute the material or use it for any profit-making activity or commercial gain

If the publication is distributed under the terms of Article $25 \mathrm{fa}$ of the Dutch Copyright Act, indicated by the "Taverne" license above, 

Voor papa 
The research presented in this thesis was conducted at the School for Public Health and Primary Care: CAPHRI, Department General Practice of Maastricht University. CAPHRI participates in the Netherlands School of Primary Care Research CaRe. CAPHRI was classified as 'excellent' by the external evaluation committee of leading international experts that reviewed CAPHRI in December 2010

\section{AEM Lucas,}

Cover, design \& Layout: planpuur. Utrecht

Print: Drukkerij Gildeprint, Enschede

ISBN: 978-94-6108-321-0

From 2004-2007 the study was supported by an unrestricted grant from "Picasso," an initiative of the Research School CAPHRI, Pfizer Inc. and Boehringer Ingelheim Inc. 


\section{Support of an Asthma/COPD service for General Practitioners in daily care}

Proefschrift

ter verkrijging van de graad van doctor aan de Universiteit Maastricht,

op gezag van de Rector Magnificus, prof. dr. L.L.G. Soete, volgens het besluit van het College van Decanen,

in het openbaar te verdedigen op

vrijdag 7 september 2012 om 12.00 uur

doo

Anna Elisabeth Maria Lucas geboren ter Swalmen 
Promotor: Prof.

Co-promotores:

Beoordelingscommissie:
Dr. C.P. van Schayck

Dr. F.W.J.M. Smeenk Dr. I.J.M. Smeele

Prof. Dr. GJ Wesseling

Dr. J Muris

Prof. Dr. T. Van der Molen 
2 The validity of diagnostic support of an Asthma/COPD

service in primary care

Br.J Gen Pract 2007. 57(544): p. 892-6.

3 Diagnostic assessments of spirometry and medical history data by respiratory specialists supporting primary care: are they reliable?

Prim Care Resp J 2009. 18(3): p. 177-184.

$4 \quad$ Overtreatment with inhaled corticosteroids and diagnostic problems in primary care patients, an exploratory study Fam Pract 2008. 25(2): p. 86-91.

5 Diagnostic accuracy of primary care Asthma/COPD working hypotheses, a real life study

Respiratory Medicine 2012 106(8): p. 1158-1163.

6 Diagnostic advice by Astma/COPD-services and its usefulness to reduce diagnostic uncertainty for respiratory problems in primary care Submitted

7 Consultation performance of general practitioners when supported by an Asthma/COPDC-service BMC Research Notes 2012, 5:368

10 Samenvatting

voor de praktijk: De complexe weg naar de diagnose Astma/COPD Twijfel aan de diagnose Astma/COPD? 


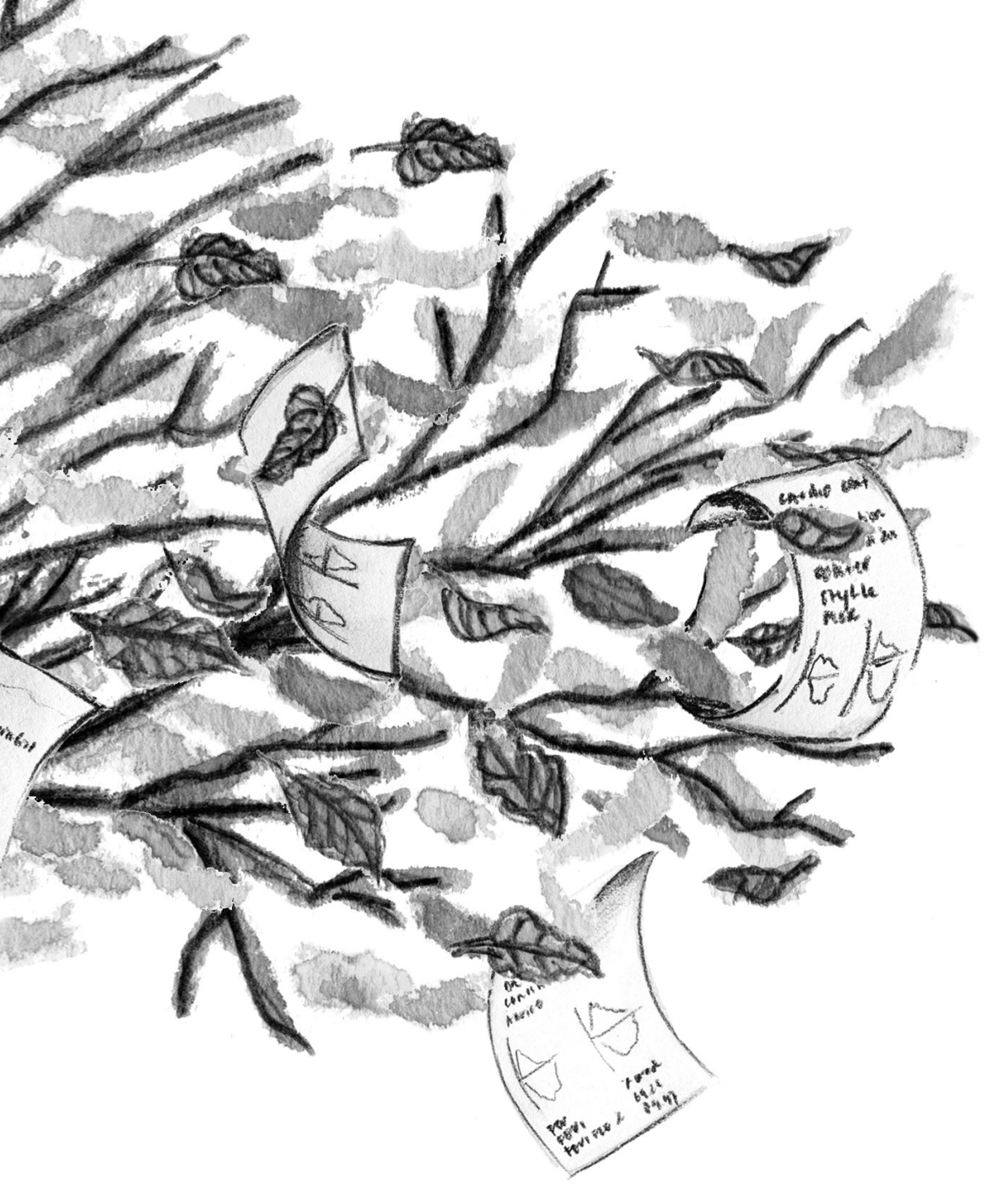

Chapter 1

Introduction 


\section{Support of an Asthma/COPD service offered to General Practitioners} delivering care to patients with respiratory problems

The study was conducted amongst GPs in and around Eindhoven, the Netherlands. Eindhoven has had an AC-service since May 2001, currently serving more than 300 family practices. From May 2004 until December 2007 GPs were asked to participate in the study, which involved entering a regular partnership with the AC-service and agreeing to have their patients answer evaluation questions. 33 GPs and 947 patients participated. No special protocols were written to ensure the study evaluated real, everyday care.

\section{Introduction}

Asthma/COPD services offer support to General Practitioners (GPs) who have to diagnose and monitor asthma and COPD patients and perform consultations in which they address all the issues advocated in the guidelines for asthma/COPD disease management. The ultimate aim of this support is to help improve the patients' quality of life. This thesis addresses the issues that need to be understood to evaluate the intervention of the Astma/COPD-service and its quality, in preparation for future research into the impact of support on patient outcome.

In this introduction, to understand the context of an AC-service, we first outline the development of diagnostic guidelines and of models for disease management and related evidence. In addition, we will describe the asthma/COPD-service and the way patients enroll in this service and in our study in more detail. Our research questions are answered in the subsequent chapters of this thesis and are introduced at the end of this section.

\section{Development of diagnostic guidelines and facilities}

As early as 1975, the National Science foundation published a consensus report stating the importance of spirometry to confirm the diagnosis of COPD and promoting a multidisciplinary approach to patient care. Non-physicians became involved in the overall management of the disease which focused on quality of life, patient education smoking cessation, immunization, nutritional support, and the importance of social and community factors in optimally managing COPD. A systematic respiratory care program and follow-up was advocated, although - as was true for all relevant guidelines before 2000 - there was no evidence to support these recommendations ${ }^{[1]}$.

Before the first evidence based guidelines were published in 2001 by the Global Initiative for Chronic Obstructive Lung Disease (GOLD) ${ }^{[2]}$, the American Thoracic Society (ATS), the European Respiratory Society (ERS) and the British Thoracic society (BTS) published influential guidelines for the diagnosis and management of COPD in $1995^{[3-5]}$. Although these guidelines differed in spirometry criteria for severity of COPD, they gave a boost to the worldwide development of national guidelines for COPD $^{[6]}$, as did the GINA guidelines for astma ${ }^{[7]}$.

In the Netherlands the first primary care guidelines were published in 1992 in which "asthma" and "COPD" were combined under the umbrella term "CARA". In 1997, the new Dutch guidelines differentiated COPD from astma and definitively introduced 
spirometry as a primary care facility, which was further developed in revisions of the guidelines in 2001 and $2007^{[8,9]}$. The guidelines were very welcome, since they finally provided clear diagnostic and management criteria. However, the diagnostic requirements, i.e. spirometry, were recognized as complicated and not always feasible. For this reason, asthma/COPD services were founded, the first one in 1995 in Breda ${ }^{[10]}$, that facilitated the performance of spirometry and added an interpretation service, while GPs retained responsibility for the final diagnosis and the care process for their patients.

A spirometry service was also available for GPs at the Diagnostic Center Eindhoven, an institution offering all kinds of primary care diagnostic facilities and services to GPs. This service developed from a facility that only performed spirometry to an institution that delivered protocolized diagnostic assessment of spirometry and written medical history data by consulting pulmonologists. By May 2001, it was officially called an Asthma/COPD-service.

Facilities to support diagnostic assessment for patients with respiratory complaints are also developed in other countries. All services provide spirometry tests that are assessed by especially interested and trained general practitioners ${ }^{[1]}$ or respiratory specialists ${ }^{[12]}$. Some services only interpret the spirometry results ${ }^{[13]}$, others include $\mathrm{x}$-ray and $\mathrm{O} 2$-saturation ${ }^{[14]}$ or use medical history data ${ }^{[15]}$. Consulting respiratory specialists collect data by actually seeing the patient ${ }^{[16]}$ or by only assessing paper information $^{[17]}$. Computerized data assessment is also used on a wide scale ${ }^{[18,19]}$.

A lot of research was done to find evidence for the best model to support primary care $^{[20-22]}$. The conclusion always was that the diagnostic process in asthma/COPD was complicated, and just adding spirometry to medical interview and examination was not sufficient ${ }^{[23,24]}$. Diagnostic support remained necessary: only when GPs were well equipped and facilitated in their own office, and when they were well trained in performing spirometry and in interpreting the results, there was no diagnostic quality advantage of expert spirometry assessment by respiratory specialist or by computerized assessment ${ }^{[12,18,19,25,26]}$. Real life research projects show that this ideal situation is hardly ever reached. The diagnostic process of asthma and COPD in primary care needs quality improvement and quality sustainment ${ }^{[27-32]}$ and should benefit from a centrally-directed, quality-controlled, diagnostic support service for GPs.

\section{Development of models for disease management}

Guidelines do not only provide instructions for diagnostic methods, they also focus on disease management, pharmacotherapy and issues improving the quality of life of astma and COPD-patients. Patient education is important to increase knowledge about the disease, the circumstances that influence disease symptoms and the consequences for future health. Patients should also be educated about medication and inhaling techniques, and about the importance of compliance to therapy. For astma patients dealing with allergies and self-management of medication is especially important. Life style recommendations such as smoking cessation, physical condition, and nutrition concern all patients but COPD patients in particular. Continued coaching is important and follow-up recommendations are given in all guidelines, the frequency of which depends on the disease burden and gravity.

In the past decades strategies are examined to determine "best practice" for disease management and implementation of guidelines. Focus was on supporting GPs (giving information and instruction about guidelines, providing management instruments, decision support and feedback ${ }^{[32-36)}$ ), on educating patients (information, educational materials, e-health ${ }^{[37-41]}$ ), on multidisciplinary revision of tasks (task delegation, nurse $\operatorname{clini}^{[42,43]}$ ), on financial regulations (DBC ${ }^{[44]}$ ), and on computerized support of protocolized disease management ${ }^{[19,36]}$. The aim of all these strategies is to improve patient outcome (inhalation technique, compliance, self-management, dyspnoea, stop smoking) and ultimately to improve patients' quality of life by implementing the best medical care.

In the Eindhoven region, the asthma/COPD-service was developed by GPs and lung specialists as part of an integrated disease management model. By meeting social and political requirements for quality care, GPs could better structure their care process by delegating diagnostic and follow-up spirometry to the AC-service and use the information provided by the AC-service for the patient's personal disease management. At the same time, practice nurses were introduced in primary care practices. The cooperation of GPs, practice nurses and the AC-service improved the asthma/COPD process management, as well as patient education and care ${ }^{[45]}$. 


\section{Asthma/COPD service: diagnostic and therapeutic disease manage- ment support}

The astma/COPD service evaluated in this thesis is part of the Diagnostic Cente Eindhoven which was founded in 1986 (since 2010 it is called "Diagnostiek voor U") as a private diagnostic institution. The Diagnostic Center Eindhoven serves more than 300 general practitioners and other health care professionals in the Eindhoven region by offering laboratory tests, $x$-ray, ultrasound, function test like exercise electrocardiography, spirometry, etc. ${ }^{[46]}$. Specialists from the regional hospitals cooperate by offering diagnostic assessments and feedback, training for employees and "clients", and by quality assessment and maintenance of the various services.

In the mid nineties the Diagnostic center Eindhoven first founded a Support Service for Diabetes, which set the example for the asthma/COPD-service in 2001. Both services support GPs in diagnosing their patients as well as and in monitoring their disease. For these purposes patients can be referred to the Diagnostic Center Eindhoven to have all relevant diagnostic tests performed and reported.

For the supposed diabetes patient, blood samples are collected (HbA1c, glucose, creatinin, cholesterol, etc.) and fundus photography and extensive podological examinations are performed. A detailed report of the results is sent to the GP.

For the supposed asthma/COPD patient at first only a lung function test was available performed according to ATS/ERS standards by trained lung function assistants using Welch Allyn spirometers and software. Reversibility tests were included and flow volume curves and figures were sent to the GP (figure1).

In contrast to diabetes, it is complicated to understand the diagnostic test results in asthma/COPD. Therefore pulmonologists of the regional hospitals were asked to perform diagnostic assessments. Furthermore, a medical history form was developed to facilitate their assessments (figure 2a, 2b), making it possible to assess not only the quality and results of the spirometry but also to assess a clinical diagnosis. When invited to visit the AC-service, the patients were asked to fill out this form at home and bring it to the lung function assistant who performed spirometry.

To complete the diagnostic process the GP could ask for an allergy test (dermatological or a Phadiatop/ RAST), for a (pro-)BNP-test to exclude heart failure and/or for a chest $x$-ray to exclude lung cancer and other specific lung diseases.
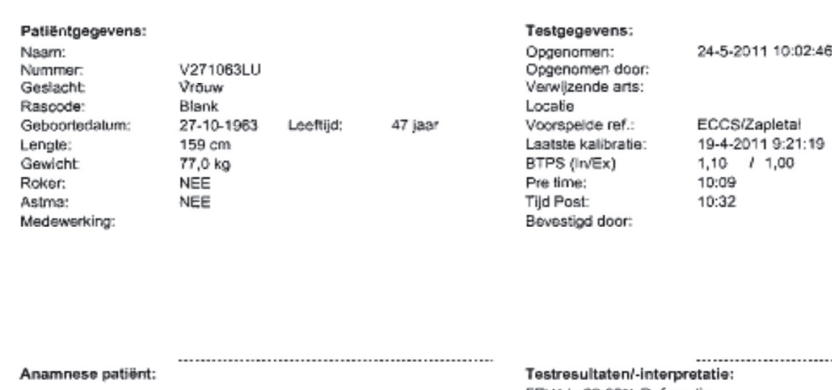

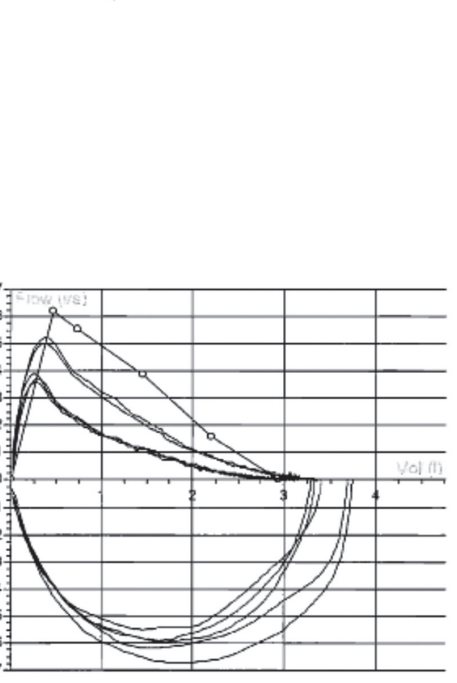

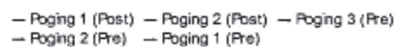

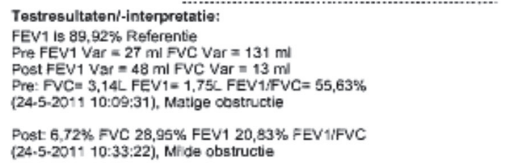

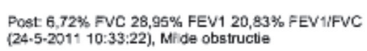
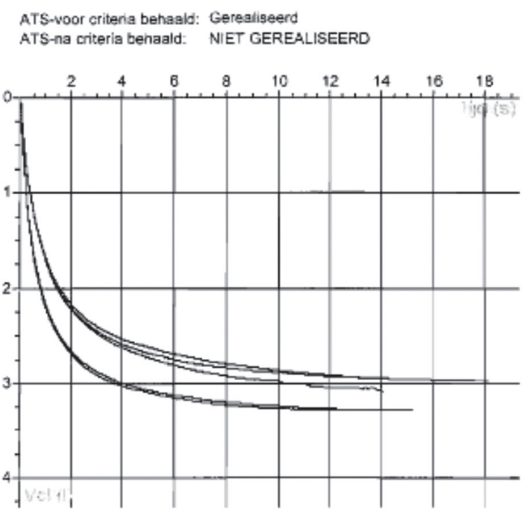

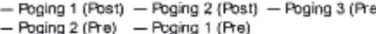

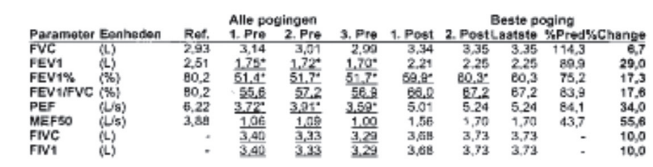


Figure 2a: Medical history form page 1

(brought to the AC-service by the patient after filling it in at home)
Figure 2b: Medical history form page 2

(brought to the AC-service by the patient after filling it in at home)

\section{MEDICAL HISTORY QUESTIONNAIRE}

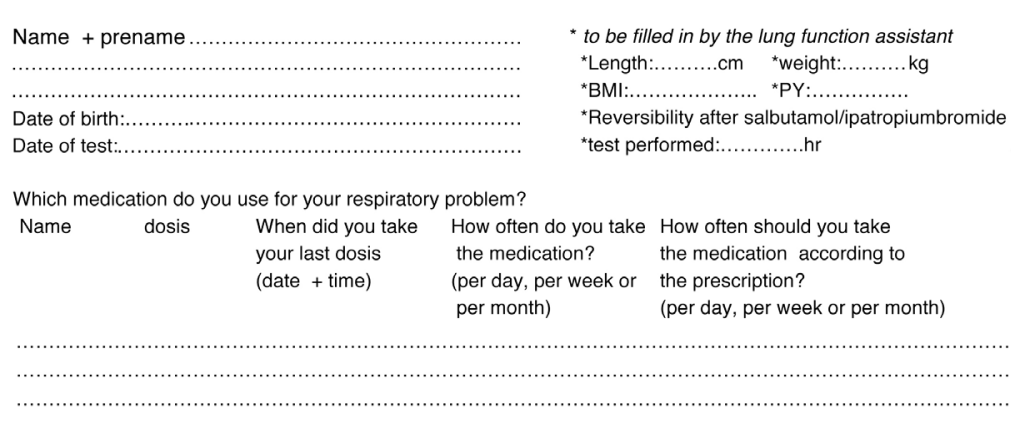

Do you use other medication? Please list below.
1. A A youvising a pumonay

Are you visiting a pulmonary
specialist, or have you visited one specialist, or
in the past?

2. Are you visting a heart specialist or have you visited one in the past??

3. Did you ever have a Chest X-ray performed?

4. Did you ever have a lung
function performed?

5. Did you ever have eczema, haytever, allergy, asthma, bronchitis?
6. do pulmonary problems occur

8. Which hobbies do you

have?

9. Do you smoke, or have you ever = mark the right answer. If you have questions, please ask the - No

Yes: when was to bs O No

Yes: when was the last time? For what reason.......
In which hospital? In which hosp

O Yes: when was the last time? In which

No Yes: when was the last time?

O No $O$ yes, please mark the right item

O No O yes O No

O Yes, how much do you or did you smoke and for how many year ....igarettes/day, during........year, I stopped (date): :.............

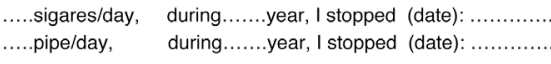
The following is filled in by the biometrist who performs the test.

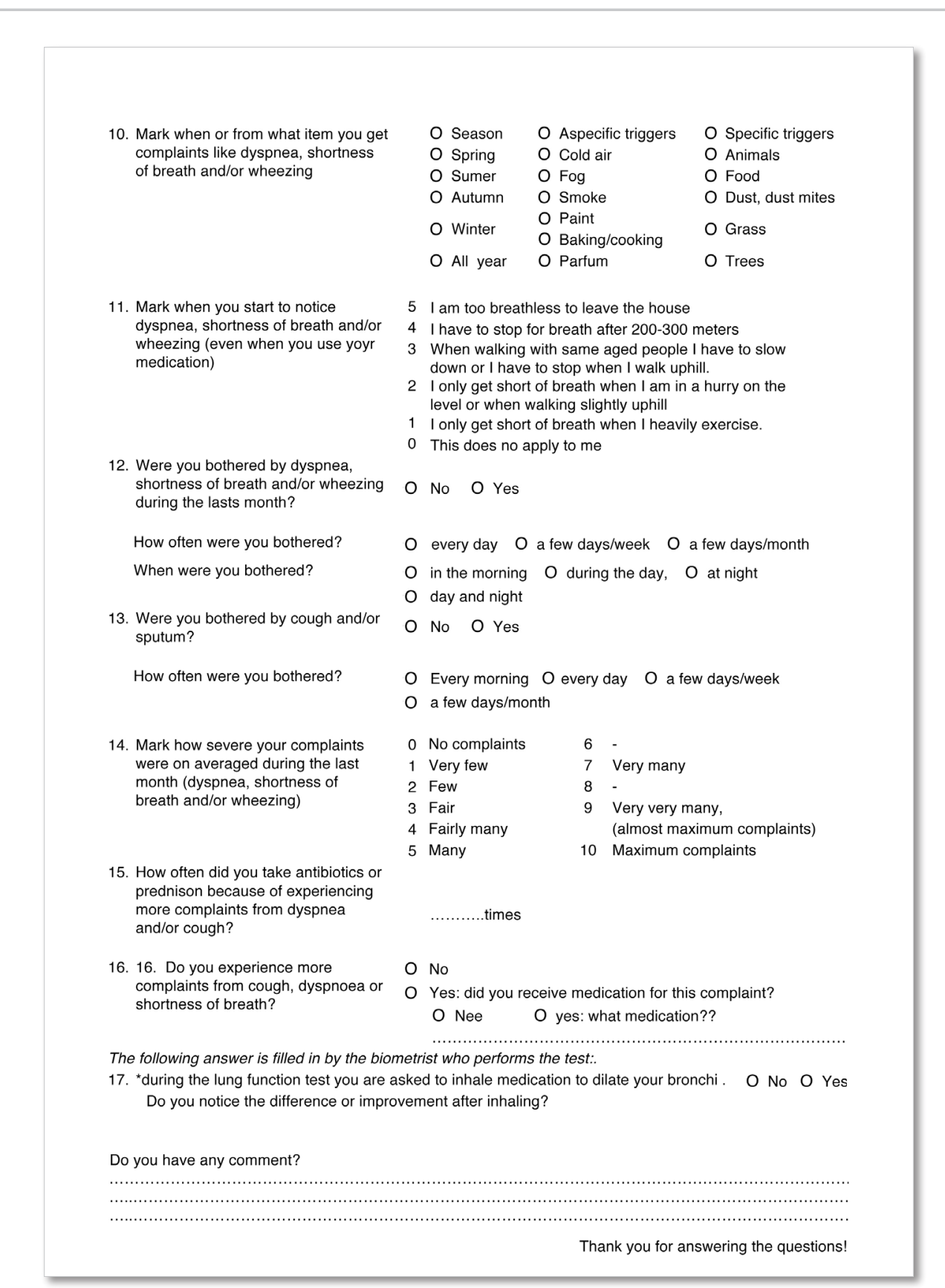




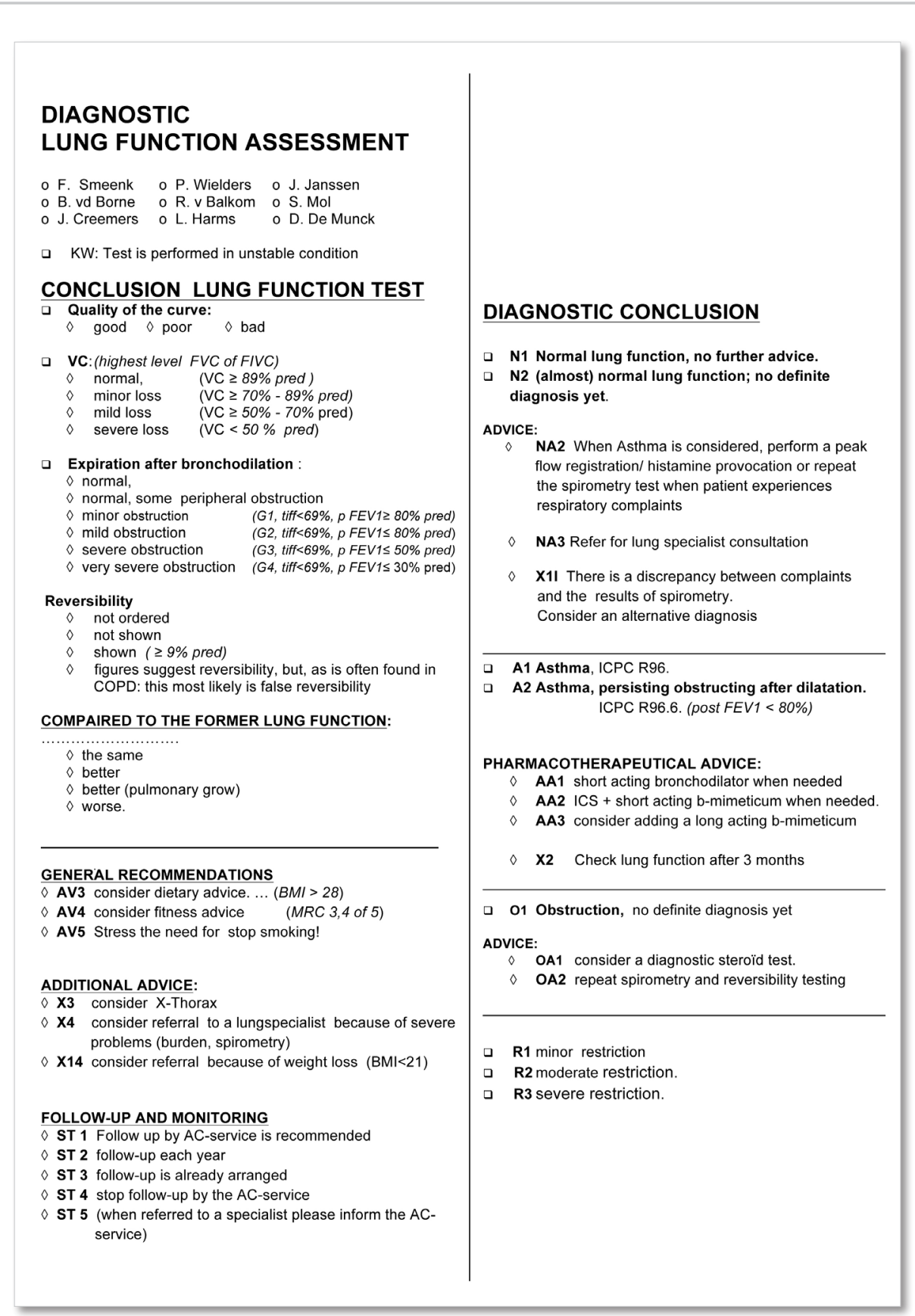

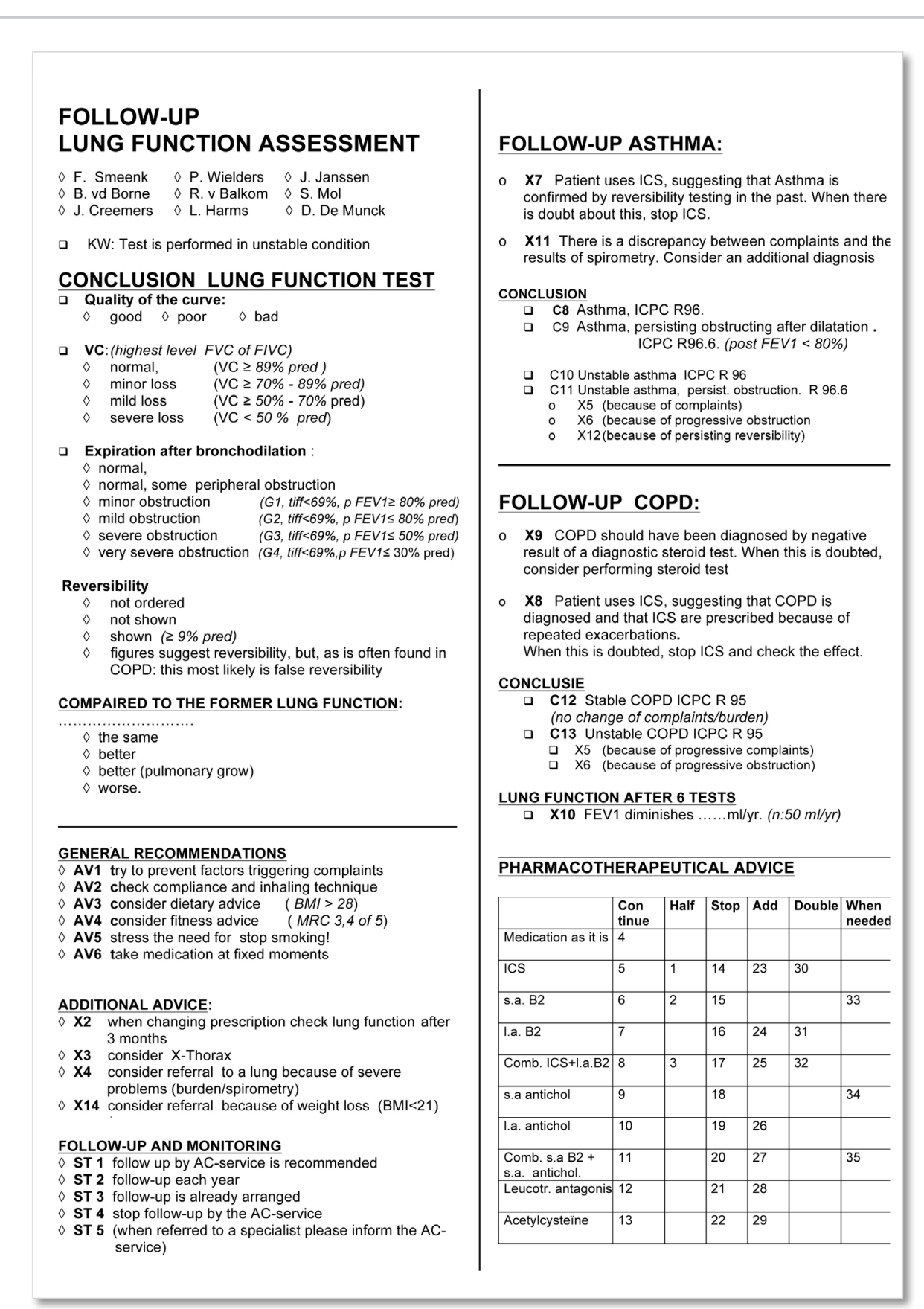


All these written data enabled the pulmonologists to conduct detailed diagnostic interpretations. Protocols were developed to facilitate these assessments and to ensure concordance in assessments of different lung specialists. In addition to criteria for the interpretation of spirometry results and categories for the assessed diagnoses, recommendations for further diagnostic examinations were developed by pulmonologists together with especially interested GPs (chapter 5). Furthermore, advice for medical treatment and improving life style was added (chapter 7 ).

Four protocols became available for the assessing pulmonologist to be used in case of:

1. New patients not diagnosed before (figure 3)

2. Follow-up of patients diagnosed with astma and/or COPD (figure 4)

3. Patients needing a spirometry check-up after change of medication

4. Patients who had had a steroid test as was advocated at the time (prednisolon 30 $\mathrm{mg} /$ day, 10 days, to identify asthma and/or patient's personal best lung function

It was (and is) not always obvious whether a patient can be considered to be a "new" patient, or a follow-up patient, for example patients using ICS without having had a lung function test (chapter 4). In case of doubt, pulmonologists could choose the assessment form that they thought was suitable. The asthma/COPD service together with its consultants put effort in improving the assessment procedure, including the assessment forms, inspired by the results of this evaluation study, which in 2011 led to one assessment form for all assessments (added as Addendum at the end of this chapter).

\section{Further developments}

Until 2011 the routing of performing spirometry, assessments and reporting results was time consuming: every day the spirometry, medical history forms, and assessment forms were brought to the pulmonologists' office and collected a few days later. Then, the diagnostic conclusions and advice were transcribed in Welch Allyn software. A report was written by the Asthma/COPD service and sent to the GPs. (figure 5).

In 2011 electronic data communication became possible between the asthma/ COPD-service and the primary care practices. The development of tele-communication between asthma/COPD-service and pulmonologists should further fasten the delivered service and improve the incorporation of test results in patient records and their availability in daily care.

Figure 5: Report sent to the GP (in Dutch, for English examples: see chapter 3 and 8)

Cardio Control Workstatio

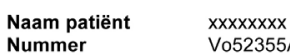

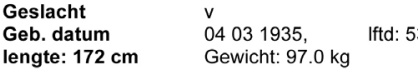
Beoordeling door de longarts: Dr. XXXXX. Voor informatie te be dienst op tel.no..... Kwalititit van de curve: redelijk, acceptabel Vitale capaciteit: Normaal
Uitademing: Matige obstructio Reversibilititit: Kwantitatiet lijkt er sprake van van b-mimetica, maar dit kan vals positief $z$ in vanwege een volumen response zoals voorkom

CONCLUSIE: COPD GOLD 2

ADVIES: indien verdenking bestaat op astma/hyperreactivititit overeweeg herhalen van de
longfunctie bij toename klachten of verwijs naar de
longarts voor een histamineprovocatietest

" overweeg dieetadviezen (BMl is t hoog) "overweeg extra aandacht voor conditie (MRC) " controleer de compliance, medicatie dagelijts

Patiënte is opgenomen in de AC-dienst voor jaarlijkse follow-up en zal over een jaar worden
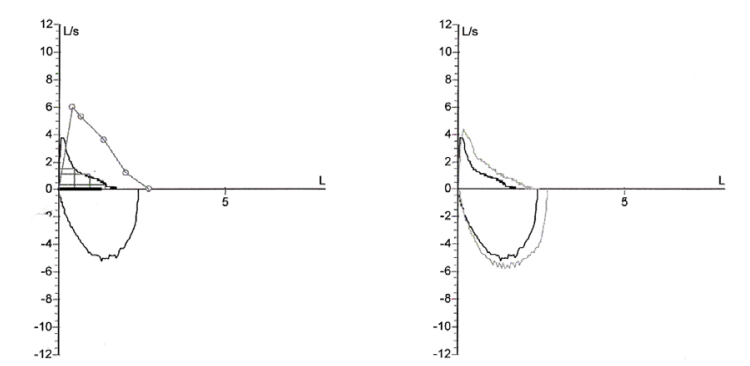

Diagnostiek voor U

Adres
Postcode $\begin{array}{ll}\text { tum longfunctie } & 0105 \text { 2008, 9:07:27 } \\ \text { Jometrist } & \text { JPO }\end{array}$ Notities: huisarts: YYrYY, adres: tel...
Code 83093, incl. revers. Reden: DIAGNOSIS ANAMNESE Eekend bij longarts: Ja (broer had tbc)
Eerder X-Thorax: 15 jaar geleden voorgeschiedenis - Hooikoorts, bronchitis
familie geschiedenis: positief Tamilie geschiedenis: positief
Roken: gestopt in 1996, PY: 22 Beroep: nvt. Hobby: tekenen en schilderen
Uittokkende factoren: aspecifieke en specifieke Uitrokken
Prikkels MRC: 3 (loopt langzamer dan leeftidgenoten)
Klachten: vooral in vooriaar en najaar Kachten vooral overdag Klachtenfrequentie: dagel
Hoesten, weinig slijm Klachtenscore: 4 (matig) (Max=10, BORG) Exacerbaties in het afgelopen jaar: éen (predn.) voorgeschreven longmedicatie: tiotropium 1 d Compliance: gebruilik alleen bijit klachten, omorbiditititit hypothyr. Cardiovasc.
Comedicatie Euthyrax. Acetosal. Furosemite

\begin{tabular}{|c|c|c|c|c|c|}
\hline $\begin{array}{l}\text { Parameter } \\
\text { FVC }\end{array}$ & $\begin{array}{c}1^{\text {st }} \text { try } \\
1.87\end{array}$ & $\begin{array}{l}\text { Predicted } \\
270\end{array}$ & $\begin{array}{c}\text { \% pred. } \\
69299\end{array}$ & $\begin{array}{l}2 e \text { try } \\
244\end{array}$ & \% diff. \\
\hline Fivc & 2.41 & & $\begin{array}{l}8.49 \\
84.47\end{array}$ & 2.66 & \\
\hline $\begin{array}{l}\text { FEV1 } \\
\text { FEV1/FVC \% }\end{array}$ & $\begin{array}{r}1.26 \\
67.38\end{array}$ & $\begin{array}{l}2.26 \\
83770\end{array}$ & 55.90 & $\begin{array}{l}1.61 \\
65.98\end{array}$ & $\begin{array}{l}15.48 \\
{ }^{1} .46\end{array}$ \\
\hline FEV1/FINC \% & 52.28 & $\begin{array}{l}0.0 .103 \\
79.93\end{array}$ & $\begin{array}{l}85.40 \\
65.40\end{array}$ & $\begin{array}{l}60.24 \\
60.24\end{array}$ & 9.98 \\
\hline FEF50 & 1.08 & 3.53 & 30.62 & 1.16 & 2.26 \\
\hline
\end{tabular}




\section{Asthma/COPD service: logistic disease management support}

The Diabetes Service also set an example for the asthma/COPD service in offering effective logistic disease management support (screening practice registers, providing feedback about monitored data ${ }^{[47]}$ ). Currently, this logistic support entails screening practice records to find patients eligible for monitoring, maintaining a yearly call system for follow-up, providing education in performing and interpreting spirometry and assisting in meetings between pulmonologists and general practitioners by offering feedback on assessments performed at the AC-service ${ }^{[48]}$

\section{Asthma/COPD service: selecting the right patients to enroll}

GPs can refer their patients for diagnostic assessment when they have visited the office because of respiratory complaints suspicious for asthma or COPD. This case finding does not always take place consistently. Patients might visit their GP and present their complaints in an unspecified manner ${ }^{[49,50]}$ and GPs do not always recognize respiratory complaints as caused by or connected with an obstructive disease ${ }^{[51]}$. Also, many COPD patients can be discovered by screening populations that have not discussed their respiratory problems ye ${ }^{[52-56]}$. It should be stressed that GPs could pay more attention to the possibility of COPD in older patients that smoke and cough for some time since about $50 \%$ of them might suffer from COPD ${ }^{[57-59]}$. These are the patients eligible for referral to the asthma/COPD service.

GPs seem to diagnose astma more easily than COPD when patients visit the office for respiratory complaints. That means: GPs show (too) few restraints in treating their patients with astma medication when there are symptoms of asthma ${ }^{[00-62]}$. GPs should perform diagnostic tests before diagnosing, let alone treating, patients as asthma patients. These patients also are eligible for referral to the asthma/COPD service.

The number of COPD resp. astma patients discovered through office visits each year (i.e. the incidence of COPD and asthma) is around 0,2\% resp. 0,6\% of the population $^{[8,9]}$, which means 5 resp. 15 new patients each year in a standardized (Dutch) practice of 2350 patient. However, these figures are only correct when al patients are found. When GPs start cooperating with an AC-service and are reorganizing their disease management, this is most often not the case. First, the practice population needs to be screened to get a good view on possible asthma and COPDpatients that should have regular care according to the professional standards. The AC-service assists in screening when asked by the general practitioner. A trained nurse selects patients with an ICPC-code for asthma (R96) or COPD (R95) or bronchitis (R91) registered in their medical file kept by the GP (International Classification of Primary Care ${ }^{[63]}$, and patients who received a prescription for lung medication with ATC-code R03. (American Thoracic Coding ${ }^{[64)}$ ). The nurse does the first check to remove patients from the list for which the registration was not correct, according to the clinical information in the rest of the patient's file. GPs do a final check.

Patients on the list after selection by the GP are referred to the AC-service to be newly diagnosed or to have their assumed diagnose (working hypothesis) checked. When asthma or COPD is confirmed, patients can be called for yearly follow-up, on their GP's request.

Before we started the study this thesis describes, we examined the necessity of selecting patients by an AC-service nurse practitioner or the GP after screening medical records for ICPC- and ATC-codes. The table below shows the results: in 4 randomly chosen practices only one third of the patients remained eligible for monitoring by the Asthma/COPD service based on a plausible working hypothesis Asthma or COPD.

Table 1: Screening of medical records for ICPC-codes (R95, R96, R91) in the past 4 years and for inhaled medication (ATC R03A/B) in the last 2 years, and the GPs' validity check

\begin{tabular}{ccc}
\hline N Patients in the practice & $\begin{array}{c}\text { Screening medical records } \\
\text { N patients selected, } \\
\text { \%prevalence }\end{array}$ & $\begin{array}{c}\text { Selection made by nurse and GP } \\
\text { N patients eligible for AC-care, } \\
\% \text { prevalence }\end{array}$ \\
\hline 2236 & $160=7,1 \%$ & $60=2,6 \%$ \\
7180 & $574=7,9 \%$ & $212=2,9 \%$ \\
2550 & $316=12,3 \%$ & $111=4,3 \%$ \\
2431 & $247=10,1 \%$ & $84=3,4 \%$ \\
\hline
\end{tabular}




\section{Selection of asthma/COPD patients for the study}

When our evaluation project was to begin (May 2004), 99 practices in the Eindhoven region were eligible to start the cooperation with the asthma/COPD service and were waiting for the nurse to start screening their medical records. GPs were asked to take part in our evaluation project, and 33 of them agreed. After randomization 17 practices started the cooperation with the astma/COPD service one after the other. For the other 16 practices the cooperation was postponed.

Participation in the study started with regular screening of the medical records by the astma/COPD-service to find patients eligible for asthma/COPD-care. All selected patients were eligible for the GPs new disease management program (i.e. monitoring by the GP in cooperation with the asthma/COPD service), and every patient was asked to participate in the study. This meant receiving the usual care and answering questionnaires about their GP's consultation performance after office visits.

Epidemiological figures differ for the prevalence of asthma and even more for COPD. According to the Dutch professional standards the prevalence in the Netherlands is 20/1000 (2\%) resp. 28/1000 (2.8\%) patients, which means 50 COPD and 70 asthma patients in each standardized practice. It is clear that we could not discover all these eligible patients in our study practices. Although very important we did not address the topic of under-diagnosis in our research project but concentrated on the patients already diagnosed as asthma or COPD by their GPs and on the value of the asthma/ COPD service in supporting GPs to improve the diagnostic accurateness.

\section{This Thesis}

The asthma/COPD-service was started because of a need for support felt by GPs who experienced diagnostic problems when delivering care for their asthma/COPDpatients. They had to find a way to manage the care process better for the benefit of their patients and to meet the obligations of medical society and public policy.

Protocols were based on guidelines, on research data and on common sense of all participants. Satisfaction about the support of the Asthma/COPD-service was high, 10.000 patients visit the service each year. However, the support procedure, being intensive and costly, had not yet been evaluated on its results. Our research was intended to fill this shortcoming and the final question of our research was: do patients of GPs who cooperate with the AC-service experience benefits of their GP's supported care?
Before examining this final question we had to examine in detail how the support of the AC-service intervened in GPs' usual care. Many questions were raised from: "Who are the right persons to be enrolled in the AC-service?" to "What is the value of the information from the AC-service?" and "What happens with this information when sent to the GP?" It turned out that we had to evaluate the intervention itself, instead of considering it as a tool to examine changes in patients well being. This is how this thesis is formed:

- In this introduction chapter we described the AC-service and how it was founded. We also described the first problem that can bias the evaluation of the effect on patients' wellbeing: do the right patients visit the AC-service and how are they found?

- Chapter 2 describes whether the procedure of assessing a patient's diagnosis from written data (spirometry, medical history) is a valid assessment method. The concordance between "paper" assessments of the pulmonologist (based on written patient data and spirometry) and 'live" assessments (when actually seeing the patient in an office consultation) was examined, to answer the question: is it possible to assess the right diagnosis without actually seeing the patient?

- In chapter 3 (repeated) assessments of five different respiratory specialists are compared to answer the question GPs are very interested in ${ }^{[65]}$ : do the diagnostic assessments have good intra- and inter-observer reliability?

- Chapter 4 describes one of the problems encountered when screening practices and when studying the validity and reliability of assessments: the use of inhaled corticosteroids ICS) by patients who are not yet diagnosed as asthma patients. This often incorrectly labels patients with a diagnosis of asthma and generates pharmaceutical costs, but also causes diagnostic problems for the consulting pulmonologists of the AC-service. How often does incorrect use of ICS occur, and how big is the diagnostic problem caused?

- In chapter 5 is explored how accurate working hypotheses of GPs are when these were re-assessed by the AC-service and whether this accurateness is influenced by the arguments GPs have for their hypotheses. In other words: is a referral to the AC-service useful for all patients or is it possible to make a selection based on the arguments for patients' working hypotheses?

- Chapter 6 describes the stability of the diagnoses when assessed again at follow-up and the meaning of diagnostic advice given by pulmonologists in case of doubt at the first visit to the AC-service. The question is: How long does it take before GPs can be certain of their patient's diagnosis and can this process be shortened by following diagnostic advice? 
- Chapter 7 examines whether GPs use not only the diagnosis and diagnostic advice but also the other information reported by the AC-service, which can support GPs' patient education and treatment, important in self-management strategies.

- In chapter 8 and chapter 9, our results are discussed and summarized and put into a wider context, including recommendations for future research and for daily practice at the $\mathrm{AC}$-service and in primary care.

The last chapters are two articles in Dutch, written for the "praktijkondersteuners" (practice nurses) ${ }^{[6,67]}$. These enthusiastic and ambitious nurses have become key stakeholders of the astma/COPD care in primary care practices. The way they developed their profession and their position is commendable, and I am convinced that they can stimulate their GPs to improve those aspects of the asthma/COPD disease management that were so difficult for them during our study. The last two articles are a tribute to these fine professionals. 


\section{Literature}

1. Hodgkin JE, Balchum O, Kass I, Glaser EM, Miller WF, Haas A, et al.Chronic obstructive airway diseases. Current concepts in diagnosis and comprehensive care. JAMA 1975. 232(12): 1243-60.

2. GOLD, The Global Initiative for Chronic Obstructive Pulmonary Disease. 2009.

3. American Thoracic Society Official Statement. Standardization of Spirometry. 1994 Update. Am J Respir Crit Care Med 1995. 152(3):1107-36.

4. Siafakas NM, Vermeire P, Pride NB, Paoletti P, Gibson J, Howard P, et al. Optimal assessment and management of chronic obstructive pulmonary disease (COPD). The European Respiratory Society Task Force. Eur Resp J 1995. 8(8): 1398-1420.

5. BTS guidelines for the management of chronic obstructive pulmonary disease.The COPD Guidelines Group of the Standards of Care Committee of the BTS. Thorax 1997.52(suppl5): s1-28.

6. Pierson, D. Clinical practice guidelines for chronic obstructive pulmonary disease: a review and comparison of current resources. Respir Care 2006. 51(3): 277-88.

7. O'Byrne P.Global guidelines for asthma management: summary of the current status and future challenges. Pol Arch Med Wewn 2010. 120(12): 511-7.

8. Smeele IJM, Van Weel C, Van Schayck CP, Van der Molen T, Thoonen B, Schermer T, et al.Standard of the Dutch College of General Practitioners on COPD (NHG-Standaard COPD, article in Dutch). Huisarts Wet 2007(8): 362-370.

9. Geijer RMM, Chavannes.N., Muris JWM, Sachs APE, Schermer T, Smeele IJM, et al. Standard of the Dutch College of General Practitioners on asthma (NHG-Standaard Astma bij volwassenen,article in Dutch). Huisarts Wet 2007(11): 537-551.

10. Smeele I, Djamin R., Hennekam M., Papieren Consultatie. Med Contact 2002(57): 43.

11. Jones R, Whittaker M, Hanney K, Shackell B. A pilot study of a mobile spirometry service in primary care. Prim Care Respir J 2005. 14(3):169-71.

12. Walker P, Mitchell P, Diamantea F, Warburton CJ, Davies L., Effect of primary-care spirometry on the diagnosis and management of COPD. Eur Respir J 2006. 28(5): 945-952.

13. Averame G, Bonavia M, Ferri P, Moretti AM, Fogliani V, Cricelli C et al. Office spirometry can improve the diagnosis of obstructive airway disease in primary care setting. Respir Med 2009. 103(6): 866-872.

14. Hassett R, Meade K, Partridge MR. Enhancing the accuracy of respiratory diagnoses in primary care: a report on the establishment of a Community Respiratory Assessment Unit. Prim Care Respir J 2006.15(6): 354-361.

15. Vaughn R, Maclntyre D, An outreach Spirometry service for Greater Glasgow health board: does it help in diagnosis. Eur Respir J, 2004. 24 (suppl. 48): 182s.

16. Wolfenden H, Bailey L, Murphy K, Partridge MR. Use of an open access spirometry service by general practitioners. Prim Care Respir J 2006. 15(4): 252-255.

17. Denis J, Smeele IJ, van Hessen PAW Asthma/COPD service improves diagnosis and montoring in primary care. Eur Respir J, 2005. 26(suppl.49): p. 178s.

18. Kuilboer MM, van Wijk MA, Mosseveld M, van der Does E, Ponsioen BP, de Jongste JC, et al. Feasibility of AsthmaCritic, a decision-support system for asthma and COPD which generates patient-specific feedback on routinely recorded data in general practice. Fam Pract 2002. 19(5): 442-447.

19. Poels P, Schermer TRJ,Thoonen BPA, Jacobs JE, Akkermans RP, de Vries Robbe PF, et al. Spirometry expert support in family practice: a cluster-randomised trial. Prim Care Respir $J$ 2009. 18(3): 189-197. 
20. Worth A, Pinnock H, Fletcher M, Hoskins G, Levy ML, Sheikh A. Systems for the management of respiratory disease in primary care - an international series: United Kingdom. Prim Care Respir J 2011. 20(1): 23-32.

21. Glasgow N. Systems for the management of respiratory disease in primary care - an international series: Australia. Prim Care Respir J 2008. 17(1): 19-25.

22. Bonavia M, Averame G., Canonica W, Cricelli C, Fogliani V, Grassi C, et al. Feasibility and validation of telespirometry in general practice: The Italian "Alliance" study. Respir Med 2009 103(11): 1732-37.

23. Abramson M, Schattner RL, Sulaiman D, Birch K, Simpson P, Del Colle E, et al. Do spirometry and regular follow-up improve health outcomes in general practice patients with asthma or COPD? A cluster randomised controlled trial. Med J Aust. 2010. 193(2): 104-109.

24. Chavez PC, Shokar NK. Diagnosis and management of chronic obstructive pulmonary disease (COPD) in a primary care clinic. copd 2009 6(6): 446-51.

25. Yawn, B., Enright PL, Lemanske RF, Israel E, Pace W, Wollan P, Boushey H, Spirometry Can Be Done in Family Physicians' offices and Alters Clinical Decisions in Management of Asthma and COPD. Chest 2007. 132(4): 1162-1168.

26. Poels PJP, Schermer TRJ, Akkermans RP, Jacobs A, van den Bogart-Jansen M. Bottema BJAM, van Weel C. General practitioners' needs for ongoing support for the interpretation of spirometry tests. Eur J Gen Pract 2007. 13(1): 16-19.

27. Lusuardi M, De Benedetto F, Paggiaro P, Sanguinetti CM, Brazzola G, Ferri P, Donner CF. A Randomized Controlled Trial on Office Spirometry in Asthma and COPD in Standard General Practice. Chest 2006. 129(4): 844-852.

28. Bolton CE, lonescu AA, Edwards PH, Faulkner TA, Edwards SM, Shale DJ. Attaining a correct diagnosis of COPD in general practice. Respir Med 2005. 99(4): 493-500.

29. Schneider A, Hörlein E, Wartner E, Schumann I, Henningsen P, Linde K. Unlimited access to health care - impact of psychosomatic co-morbidity on utilisation in German general practices. BMC Family Practice 2011. 12(1): 51

30. Walters JA, Hansen EC, Johns DP, Blizzard EL, Walters EH, Wood-Baker R. A mixed methods study to compare models of spirometry delivery in primary care for patients at risk of COPD. Thorax, 2008. 63(5): 408-414.

31. Upton J, Madoc-Sutton H, Sheikh A, Frank TL, Walker S, Fletcher M.National survey on the roles and training of primary care respiratory nurses in the UK in 2006: are we making progress? Prim Care Respir J 2007. 16(5): 284-290.

32. Oei SM, Thien FC, Schattner RL, Sulaiman ND, Birch K, Simpson P, et al. Effect of spirometry and medical review on asthma contro in patients in general practice : A randomised controlled trial. Respirology 2011. 16(5): 803-810.

33. Cranston JM, Crockett AJ, Moss JR, Pegram RW, Stocks NP. Models of chronic disease management in primary care for patients with mild-to-moderate asthma or COPD: a narrative review. Med J Aust 2008. 188(8 suppl): s50-2.

34. Foster JA, Yawn BP, Maziar A, Jenkins T, Rennard SI, Casebeer L. Enhancing COPD management in primary care settings. MedGenMed. 2007. 9(3): 24

35. Meulepas MA, Lucas AEM, Jacobs EJ, Smeele IJM, Smeenk FWJM, Bottema BJAM, Grol RP. Effectiviness of organisational interventions to improve the management of chronic obstructive lung diseases in primary care. Thesis: Evaluation of a chronic care model for primary care, Centre of Quality of Care Research UMC St Radboud Nijmegen \& UM Maastricht, 2007. ISBN 978-90-76014-17-3: 22-36.

36. Roshanov PS, Misra S, Gerstein HC, Garg AX, Sebaldt RJ, Mackay JA, et al., Computerized clinical decision support systems for chronic disease management: A decision-makerresearcher partnership systematic review. Implement Sci 2011. 6(1): 92.
37. Wofford J, Stevens S, Brown K, Teaching asthma self-assessment through computer-assisted patient education: a pilot study. Prim Care Respir J 2011. 20(2): 218-218.

38. Roberts N, Partridge M. Evaluation of a paper and electronic pictorial COPD action plan. Chron Respir Dis 2011. 8(1): 31-40.

39. Gallefoss $F$. The effects of patient education in COPD in a 1 year follow-ip randomised controlled trial. Patient Educ Couns. 2004. 52(3):259-66.

40. Effing T, Monninkhof EM, van der Valk PD, van der Palen J, van Herwaarden CL, Partidge MR, et al. Self-management education for patients with chronic obstructive pulmonary disease. Cochrane Database Syst Rev. 2007 Oct 17;(4):CD002990.

41. Hesselink AE, Penninx BW, van der Windt DA, van Duin BJ, de Vries P, Twisk JW, et ab, Effectiveness of an education programme by a general practice assistant for asthma and COPD patients: results from a randomised controlled trial. Patient Educ Couns 2004. 55(1): $121-128$.

42. Dierick-van Daele AT, Spreeuwenberg C, Derckx EW, van Leeuwen Y, Toemen T, Legius M, et al. The value of nurse practitioners in Dutch general practices. Qual Prim Care 2010. 18(4) $231-41$

43. Rootmensen GN, van Keimpema AR, Looysen EE, van der Schaaf L, de Haan RJ, Jansen HM The effects of additional care by a pulmonary nurse for asthma and COPD patients at a respiratory outpatient clinic: results from a double blind, randomized clinical trial. Patient Educ Couns 2008. 70(2):179-86.

44. DBC: diagnose Behandel Combinatie, http://www.dbconderhoud.nl.

45. Meulepas MA, Jacobs .J, Lucas AE, Smeenk FW, Smeele I, Bottema BJ, Grol RP., The feasibility of a primary care model for the management of COPD. Prim Care Respir J 2006. 15(6) $337-41$

46. Diagnostiek voor U, 25 jaar voor u, Jaarverslag 2010. http://www.diagnostiekvooru.nl/, 2011.

47. Meulepas MA, Braspenning J, de Grauw WJ, Lucas AE, Harms L, Akkermans RP, Grol RP. Logistic support service improves processes and outcomes of diabetes care in general practice. Fam Pract 2007. 24(1): 20-5

48. Smeele I, Hennekam M, Wind $\mathrm{H}$, Verstijnen M, Kamphuis $\mathrm{H}$. Astma-COPD praktijkinventarisatie. Tijdschr voor Praktijkondersteuning 2008. 3(3): 67-69.

49. van Weel, C. Underdiagnosis of asthma and COPD: is the general practitioner to blame? Monaldi Arch Chest Dis, 2002. 57(1):. 65-8.

50. Elliott A, McAteer A, Hannaford P. Revisiting the symptom iceberg in today's primary care: results from a UK population survey. BMC Family Practice 2011. 12(1): 16.

51. van Schayck CP, van Der Heijden FM, van Den Boom G, Tirimanna PR, van Herwaarden CL. Underdiagnosis of asthma: is the doctor or the patient to blame? The DIMCA project. Thorax 2000. 55(7): 562-565.

52. Dirven JA, Muris JW, van Schayck CP. COPD Screening in General Practice Using a Telephone Questionnaire. COPD 2010. 7(5): 352-359.

53. Bednarek M, Maciejewski J, Wozniak M, Kuca P, Zielinski J. Prevalence, severity and underdiagnosis of COPD in the primary care setting. Thorax 2008. 63(5): 402-407.

54. Danielsson P, Sif Ólafsdóttir I, Benediktsdóttir B, Gíslason T, Janson C. The prevalence of COPD in Uppsala, Sweden - The Burden of Obstructive Lung Disease (BOLD) study: Cross-sectional Population-based Study. Clin Respir J. 2011 Jun 8. doi: 10.1111/.1752-699X.2011.00257x. [Epub ahead of print, 2011.

55. Tinkelman DG, Price DB, Nordyke RJ, Halbert RJ. Misdiagnosis of COPD and asthma in primary care patients 40 years of age and over. J Asthma 2006. 43(1): 75 - 80.

56. Broekhuizen BD, Sachs AP, Hoes AW, Moons KG, van den Berg JW, Dalinghaus WH, et al Undetected chronic obstructive pulmonary disease and asthma in people over 50 years with persistent cough. Br J Gen Pract 2010. 60(576):489-94 
57. Tinkelman DG, Price D, Nordyke RJ, Halbert RJ. COPD screening efforts in primary care: what is the yield? Prim Care Respir J 2007. 16(1): 41-48.

58. van Schayck CP, Chavannes NH. Detection of asthma and chronic obstructive pulmonary disease in primary care. Eur Respir J Suppl 2003. 39:16s-22s. Review.

59. Albers M, Schermer T, Molema J, Kloek C, Akkermans R, Heijdra Y, van Weel, C. Do family physicians' records fit guideline diagnosed COPD? Fam Practice 2009. 26(2): 81-87.

60. Luks VP, Vandemheen KL, Aaron SD. Confirmation of asthma in an era of overdiagnosis. Eur Respir J 2010. 36(2):255-60

61. Pakhale S, Sumner A, Coyle D, Vandemheen K, Aaron S. (Correcting) misdiagnoses of asthma: a cost effectiveness analysis. BMC Pulm Med 2011. 11(1): 27.

62. Menckeberg TT, Bouvy ML, Bracke M, Hugtenburg JG, Lammers JW, Raaijmakers JA.Patients' understanding of the reasons for starting and discontinuing inhaled corticosteroids. $\mathrm{Br} \mathrm{J}$ Clin Pharmacol 2008. 66(2): 255-60.

63. International Classification of Primary Care: short titles and Dutch subtitles. Utrecht;Nederlands Huisartsen Genootschap; 1995. 1995

64. WHO, The Anatomical Therapeutical Chemical Classification System with Daily Doses (ATC-DDD).http://www.who.int/classifications/atcddd/en/. 2007.

65. Lucas A, Smeenk F., Smeele I, Brouwer T, van Schayck O Het klopt heel aardig!' Validiteit van het diagnostisch advies dat astma/COPD-diensten aan huisartsen geven (article in Dutch). Huisarts Wet 2008. 51(10): 479-84.

66. Lucas AEM, The complexe route to the diagnosis asthma or COPD (articel in Dutch). Tijdschr v Praktijkondersteuning 2011. 6(1): 17-22.

67. Lucas AEM, Uncertainty about the diagnosis Astma/COPD (article in Dutch). Tijdschrift v Praktijkondersteuning 2011. 6(7): 49-54. 
Addendum: Actual Assessment form in 2011, Dutch version. (2 pages)

\begin{tabular}{|c|c|c|c|}
\hline & \multicolumn{3}{|c|}{ 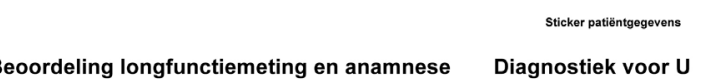 } \\
\hline \multicolumn{4}{|l|}{ Longartsen } \\
\hline 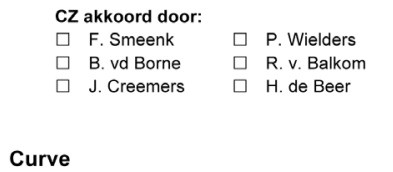 & $\begin{array}{l}\text { MMC akkoord door: } \\
\text { 口. J.Janssen } \\
\text { M. M. Henten } \\
\text { D D. de Munck } \\
\text { D M. Youssef-EI Soud }\end{array}$ & $\begin{array}{lll}\text { d door: } & \\
\text { the } & \square & \text { R. Aleva } \\
\text { ten } & \square & \text { G.Jonker } \\
\text { nck } & \square & \text { S. Mol } \\
\text { ef-El Soud } & & \end{array}$ & 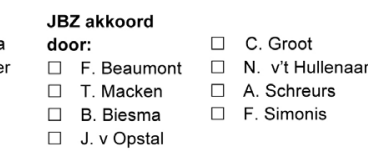 \\
\hline $\begin{array}{l}\text { Kwalitieit curve } \\
\square 1 \text { Goed } \\
\square 2 \text { Matig, we beoordeelbar } \\
\square 3 \text { Slecht, niet goed beoordeelbaar }\end{array}$ & \multicolumn{2}{|c|}{ 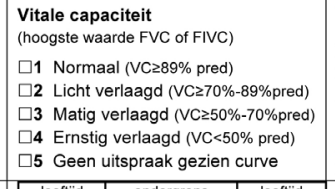 } & $\begin{array}{l}\text { Reversibiliteit } \\
\square 1 \text { Niet aangevrraagd } \\
\square 2 \text { Niet aangetoond } \\
\square 3 \text { Aangetoond ( } 12 \% \text { pré en toename 200ml) } \\
\square 4 \text { Waarschijlijk vals positief } \\
\square 5 \text { N Niet uitgevoerd div.m. inname eigen med. } \\
\square 6 \text { Geen uitspraak over gedaan worden }\end{array}$ \\
\hline 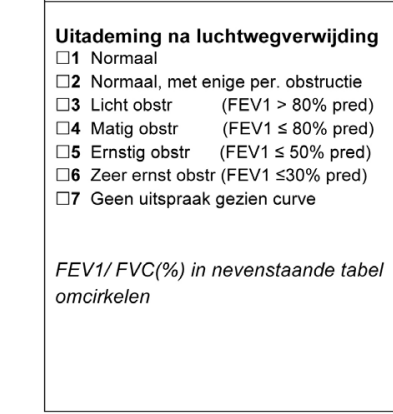 & \begin{tabular}{|c|} 
Ieetijid \\
veouven \\
25 \\
$26-31$ \\
$32-36$ \\
$37-41$ \\
$42-46$ \\
$47-52$ \\
$53-57$ \\
$58-62$ \\
$63-68$ \\
$69-73$ \\
$74-78$ \\
$79-80$ \\
$>80$ \\
$>80$ \\
\end{tabular} & 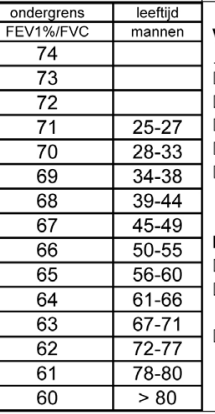 & 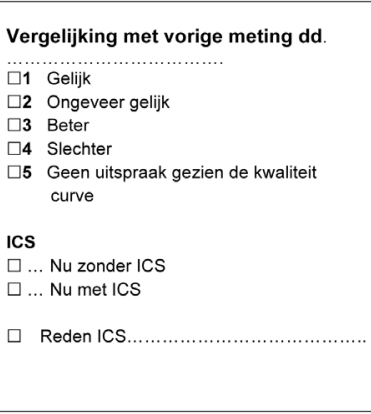 \\
\hline \multicolumn{4}{|c|}{ Eerder gestelde diagnose $(n)$ in het verleden } \\
\hline \multicolumn{2}{|c|}{ 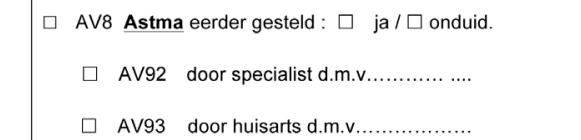 } & \multicolumn{2}{|c|}{$\begin{array}{l}\square \text { AVg copD eerder gesteld: } \quad \square \text { ja } / \square \text { onduid. } \\
\square \text { AV92 door specialist d.m.v......................... } \\
\square \text { AV93 door huisarts d.m.v.................. }\end{array}$} \\
\hline \multicolumn{4}{|l|}{ (Vrijwel) normale longfunctie, restrictie } \\
\hline 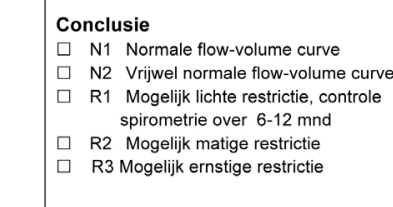 & & 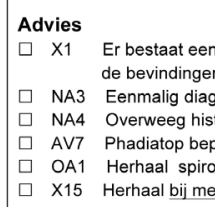 & $\begin{array}{l}\text { nn discrepantie tussen klachten en } \\
\text { en, overweeg alternatieve diagnose } \\
\text { gnosostich consult lognarts } \\
\text { stamineprovocatietest via longarts } \\
\text { ppaling } \\
\text { ometrie incl. reversibilititeit } \\
\text { eer klachten eerst spirometrie }\end{array}$ \\
\hline Voorbeoordeeld paraaf...................... & & Beoordeeld & paraaf.............................. \\
\hline
\end{tabular}

\section{(Mogelijk) Astma, (Mogelijk) Mengbeeld}

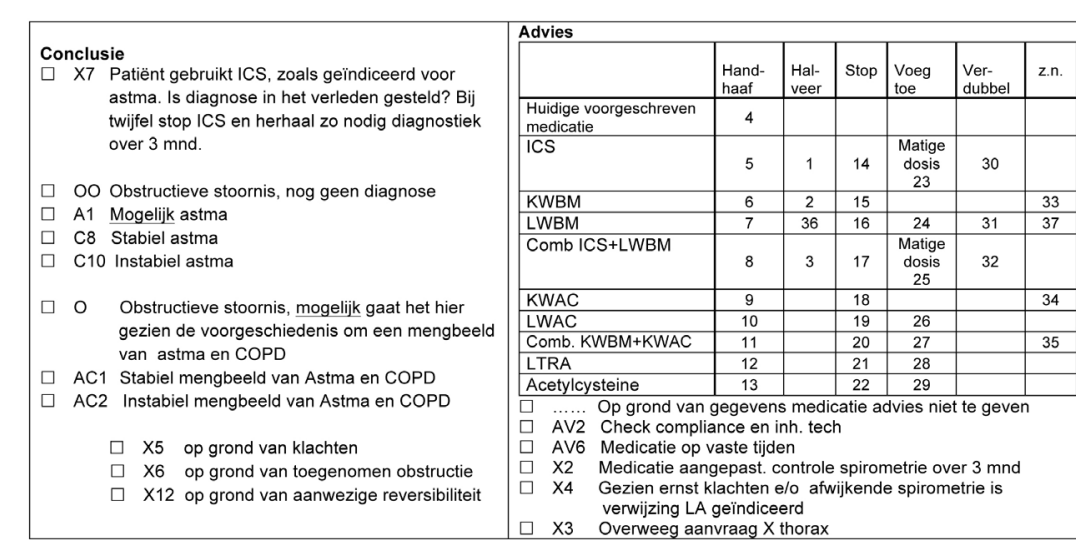

(Mogelijk) COPD

\begin{tabular}{|c|c|c|c|c|c|c|c|}
\hline \multirow{3}{*}{$\begin{array}{l}\text { Conclusie } \\
\square \quad 00 \text { Obstructieve stoornis, nog geen diagnose } \\
\square 01 \text { Obstructieve stoornis, mogelilik gaat het hier } \\
\text { gezien de voorgesshiedenis en het } \\
\text { aantal PY om COPD ICPC R } 95\end{array}$} & \multicolumn{7}{|l|}{ Advies } \\
\hline & Hüidige voorgeschreven & $\frac{\text { haaf }}{4}$ & veer & & toe & dubbel & \\
\hline & ICS & 5 & 1 & 14 & $\begin{array}{l}\text { Matge } \\
\text { dosis } \\
\text { s. }\end{array}$ & 30 & \\
\hline - C12 Stabiel COPD ICPC R 95 & KWBM & 6 & 2 & 15 & & & \\
\hline$\square$ C13 Instabiel COPD ICPC R 95 & $\begin{array}{l}\text { LWBM } \\
\text { Comb IIS }+ \text { LWBM }\end{array}$ & & 36 & & & 31 & 37 \\
\hline Ernst stadium CopD & & 8 & 3 & 17 & $\begin{array}{ccc}\text { dosis } \\
25\end{array}$ & 32 & \\
\hline $\begin{array}{l}\text { G1 Gold (mila) } \\
\square \quad \text { G2 Goldig) }\end{array}$ & $\frac{K W A C}{\text { LWAC }}$ & 99 & & 18 & 26 & & 34 \\
\hline 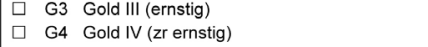 & $\begin{array}{l}\text { Comb. KWBM+KWAC } \\
\text { LTRA }\end{array}$ & $\frac{11}{12}$ & & $\frac{20}{21}$ & $\frac{27}{28}$ & & 35 \\
\hline $\begin{array}{l}\square \times 5 \text { op grond van klachten } \\
\square \times 6 \text { op grond van toegenomen obstructie }\end{array}$ & 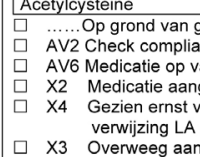 & 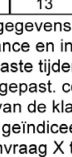 & $\begin{array}{l}\text { oththole } \\
\text { erd } \\
\text { thorot }\end{array}$ & & $\begin{array}{l}\text { ies niet } \\
\text { netrie or or } \\
\text { intende }\end{array}$ & & \\
\hline
\end{tabular}

Opmerkingen

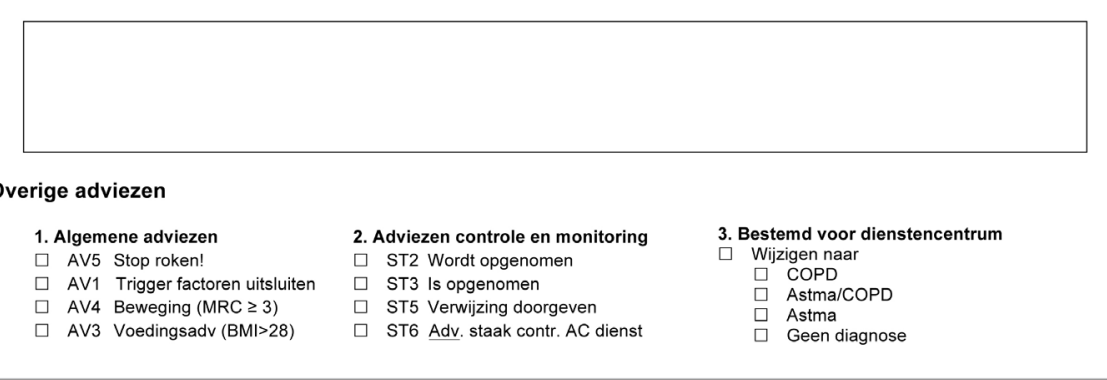




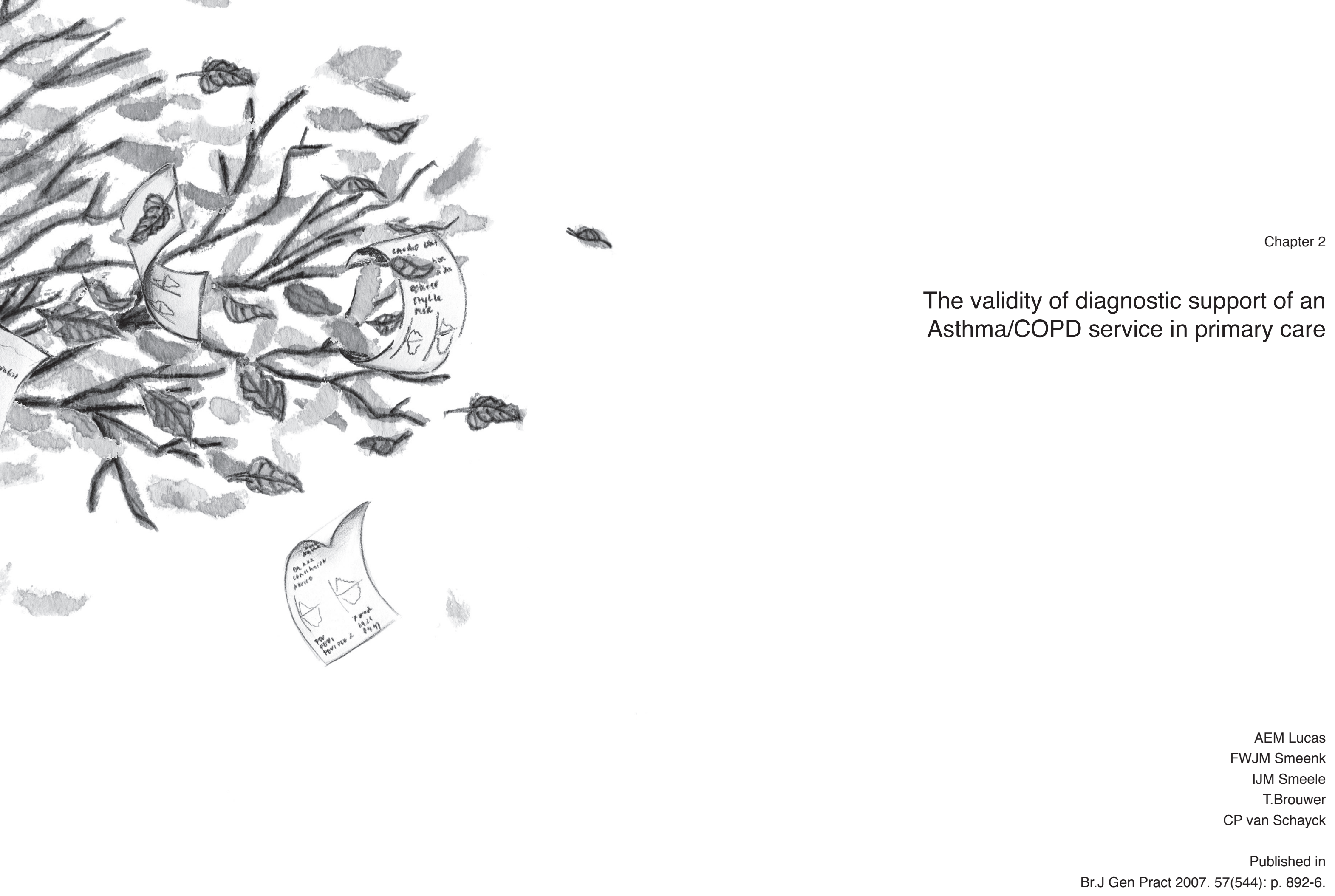


Lucas A, Smeenk F, Smeele I, Brouwer T, van Schayck O. The validity of diagnostic support of an asthma/COPD service in primary care. Br.J Gen Pract 2007. 57(544): p. 892-6.

\section{Abstract}

To support general practitioners in diagnosing and monitoring their Asthma/COPD patients "Asthma/COPD services" have been developed. Within these services, pulmonologists perform structured diagnostic and therapeutic assessments based on the combination of written history data and spirometry.

\section{Aim}

This study determines the validity of the diagnosis and advice when assessed only using written information.

\section{Design of study}

The results of the diagnostic procedures of an asthma/COPD service were compared with the results of regular office consultation by two pulmonologists who examined 80 randomly selected patients referred to an Asthma/COPD service in Eindhoven, the Netherlands, from January until August 2004.

\section{Method}

Concordance was analysed between diagnosis and advice based on written spirometry and history data with assessments based on live consultations by pulmonologists of the same patients.

\section{Results}

The validity of the assessed diagnosis was high (Cohen's Kappa $k=0.82$ ). When the diagnosis was uncertain the advice for medical treatment scored low in validity (Cohen's Kappa $\mathrm{k}=0.39$ ). The advice for additional diagnostic examinations had a high internal validity: in half of the patients, uncertainty in diagnosis turned into a definite diagnosis of asthma/COPD or another cause for the complaints of the patient was revealed; in the other half, the diagnosis of asthma/COPD could be rejected.

\section{Conclusion}

A structured Asthma/COPD service offering diagnosis and diagnostic advice assessed from written spirometry and history data is a new and valid facility that can support the general practitioner who faces the complicated diagnostic procedures in a progressive number of patients with asthma/COPD. 


\section{Introduction}

Diagnosing asthma/COPD requires the performance and interpretation of spirometry ${ }^{[1]}$. Implementation of this diagnostic instrument in primary care is considered complicated by many general practitioners ${ }^{[2,3]}$, causing incorrect use or under use of this diagnostic procedure and consequently misdiagnosis by many primary care patients $^{[4-10]}$.

Training of GPs in interpretation of spirometry can solve only part of the diagnostic and none of the practical problems ${ }^{[11]}$. Therefore, other services have been developed to support GPs in performing and interpreting spirometry and in organizing and managing asthma/COPD care. Scotland has Outreach Spirometry Services ${ }^{[12]}$, in the Netherlands there are Asthma/COPD services, and, starting from direct access to a pulmonary laboratory in $1990^{[13]}$, Open Access Spirometry is used in the UK ${ }^{[14]}$.

\section{Box 1. Asthma/COPD service, what is it?}

An Astma/COPD service can be delivered by hospitals as well as primary care facilities. The Astma/ COPD-service in this research project is part of a primary care laboratory that supports about 200 primary care practices in the region. Within this Asthma/COPD-service a protocol is developed for a structural assessment of written patient history data, patient's actual complaints and spirometry. Unique in this model is the separation of data collection and patient care. Spirometry data are interpreted by a pulmonologist in conjunction with the written clinical data of the patient. Based on this assessment, an extensive report is sent to the general practitioner as a tool to be used in the medical care for the Asthma/COPD-patient.

When actually diagnosed, the Asthma/COPD-patient is eligible for yearly monitoring. A growing number of 7000 patients out of 200 primary care practices is already added to the follow-up system of this Asthma/COPD-service (may 2007).

While retaining final responsibility for the care of their asthma/COPD patients, GPs can delegate diagnostic procedures, follow-up and monitoring procedures to these services. A main issue is whether the general practice (and the patient) can rely on the validity of this procedure. Therefore, the concordance of the ("paper") assessment by pulmonologists based on written patient data and spirometry, and the ('live") assessment in case the pulmonologists had actually seen the patient in an office consultation, were studied. 
Specifically, the study assessed the validity of:

1. the assessments of the diagnoses

2. the advice for additional examination in order to assess the definite diagnosis in new patients

3. stable or unstable condition in case of follow-up.

\section{Method}

\section{Regular routine of the Asthma/COPD service}

GPs can refer all patients with complaints suspect for obstructive pulmonary disease to the Asthma/COPD service. Lung function assistants perform spirometry and collect written medical history data, complaints, MRC-dyspnoea scale, medication and compliance. According to a structured assessment protocol, these data are assessed by pulmonologists of the local hospitals. Based on these assessments GPs receive a report containing the patient's diagnosis, advice for additional examinations in case a diagnosis cannot be assessed yet, and advice for medical and nonmedical treatment. History data and the results of spirometry (quality of the curve, obstruction, reversibility and spirometry figures) are added.

\section{Box 2. The assessment procedure of an Asthma/COPD service}

For the regular assessment a lung function assistant first performs a protocolized history taking This includes: former diagnoses and hospital admissions, family history, atopy and allergy, smoking behaviour, MRC-dyspnoea score, score of complaints (cough/dyspnoea, mucus, nightly awakening), recent exacerbations, prescribed medication and compliance. After that, spirometry is performed including reversibility testing. Prints of flow volume curve and the medical history form are weekly sent to the pulmonologists of the local hospitals. They assess diagnosis, advice for further examination, for therapy or for referral using a structured observer form, which is returned to the Asthma/ COPD-service.

Pulmonologists assess according to the guidelines of the Dutch College of General Practitioners ${ }^{1}$, based on GINA and GOLD guidelines. Within the assessment protocol the following is agreed upon:

- Reversibility is defined according to the ERS guidelines (FEV1/FVC $<70 \%$ and FEV1 reversibility $>9 \%$ of predicted value).

- The qualification "false reversibility" is given in case of improvement of FEV $1>9 \% \mathrm{PV}$ that is due to either wrong breathing manoeuvres or to volume response in case of COPD'.

- In case of new patients that have a normal lung function but also have many complaints, the diagnosis is "about normal", mostly followed by an advice to further explore the complaints.
- In case of irreversible obstruction in new patients the diagnosis COPD is postponed until a steroid test is performed that definitely shows no reversibility.

- In case of follow-up patients that have a normal lung function and use inhaled corticosteroids the pulmonologist assumes the diagnosis Asthma.

- In case of follow-up patients the main observed item is whether the patient is in stable condition, that means: no serious/new complaints, no reversibility after lung function test.

\section{Design}

The study was performed at the regional Asthma/COPD service in Eindhoven, the Netherlands, which serves 200 GPs who refer about 7,000 patients each year for diagnostic spirometry and follow-up.

The procedure involved a comparison of 80 assessment reports ("paper assessment") performed according to the regular routine of the Asthma/COPD service with the assessments of the same 80 patients after live consultation by pulmonologists ("live assessment")

\section{Participants}

Each week for six months, three to four of the weekly referred patients were randomly selected and asked to visit a pulmonologist immediately after spirometry and history taking was done by the lung function assistant. Two of five pulmonologists connected to the asthma/COPD service performed the office consultation and the "live assessment."

\section{Live and paper assessments}

To obtain a live assessment each participating patient was asked to visit a pulmonologist immediately after a regular spirometry and standardized history taking was done by the lung function assistant of the Asthma/COPD service. During this consultation, the pulmonologist himself did the history taking, examined the patient and used a copy of the spirometry test to assess the diagnosis, the need for additional examinations and therapeutic advice. A regular structured assessment form was filled in, being the live assessment. These live assessments were kept aside to be compared with the paper assessments.

The paper assessments were performed by the consulting pulmonologists and were based on the original spirometry and medical history data of the patients. To prevent recall bias, these original data were kept apart for al least three months and mixed with the routine weekly set of assessments before they were offered to the pulmonologists for regular (paper) assessment. 
Evaluation of the advice for additional examination

In case spirometry and medical history cause doubts about the diagnosis, the assessing pulmonologist can advise for additional diagnostic examinations to be performed or initiated by the patient's GP. To validate these advisories for additional examinations, the pulmonologist himself performed the additional examinations to ensure that he judged these as indicated and would normally have advised these to the GP. For this protocol, permission was granted from both the GP and the patient.

\section{Box 3. Advice for additional diagnostic examinations}

In case of unclear diagnosis after assessment of spirometry and history data by a pulmonologist an advice can be given for additional diagnostic examinations to determine the definite diagnosis and/or its severity. These advices differ for new and for follow-up patients, as is shown below:

\begin{tabular}{|c|c|c|}
\hline & Indication for additional examination & The advised additional examination \\
\hline \multirow{3}{*}{ New Patients } & $\begin{array}{l}\text { Discrepancy between complains (history) } \\
\text { and objective findings }\end{array}$ & $\begin{array}{l}\text { Look for an alternative diagnosis by } \\
\text { extending history taking, physical exami- } \\
\text { nation and/or laboratory test (BNP) }\end{array}$ \\
\hline & $\begin{array}{l}\text { normal spirometry } \\
\text { however asthma cannot be excluded. }\end{array}$ & $\begin{array}{l}\text { Consider peak flow registration according } \\
\text { to the guidelines or consider a visit to the } \\
\text { pulmonologist (histamine provocation) }\end{array}$ \\
\hline & $\begin{array}{l}\text { Spirometry shows obstruction, no } \\
\text { reversibility }\end{array}$ & $\begin{array}{l}\text { Consider a steroid test to exclude } \\
\text { asthma or determine the optimal } \\
\text { pulmonary condition (oral prednisolon } \\
30 \mathrm{mg} \text { for } 15 \text { days or } 2 \mathrm{dd} 800 \mu \mathrm{g} \text { inhaled } \\
\text { corticosteroids for } 3 \text { months) }\end{array}$ \\
\hline \multirow{2}{*}{$\begin{array}{l}\text { Follow-up } \\
\text { Patients }\end{array}$} & $\begin{array}{l}\text { Discrepancy between complains and } \\
\text { diagnosis }\end{array}$ & $\begin{array}{l}\text { Look for additional health problems by } \\
\text { extending history taking, physical exami- } \\
\text { nation and/or laboratory test (BNP) }\end{array}$ \\
\hline & $\begin{array}{l}\text { Patient uses ICS, as is indicated in } \\
\text { asthma }\end{array}$ & $\begin{array}{l}\text { When asthma is not before confirmed } \\
\text { by reversibility of obstruction consider to } \\
\text { stop the ICS and renew the diagnostic } \\
\text { procedures in } 3 \text { months }\end{array}$ \\
\hline $\begin{array}{l}\text { New and } \\
\text { Follow-up }\end{array}$ & $\begin{array}{l}\text { Severe complaints and/or severe lung } \\
\text { function pathology }\end{array}$ & Referral to a specialist is indicated \\
\hline
\end{tabular}

To assess the real impact of these additional examinations on the patient's diagnosis and treatment - and the value of the advice to perform these - the regular discharge reports of the pulmonologist that were sent to the GP were examined.

The following diagnostic tests were successively applied until the diagnosis was clear: physical examination, extensive history taking, laboratory test (BNP/Phadiatop), extensive lung function test, X-ray of chest and sinus, PC20- test (bronchial responsiveness to histamine), body box airway resistance test, and diffusion capacity test.

\section{Analyses}

To compare the paper and live assessments, descriptive statistics were used with SPSS version 11.0. Concordances between paper and live assessment in assessed diagnosis and patient condition (as a preliminary for therapeutic advices) were determined by Cohen's kappa ( $\mathrm{k}$ ). Concerning the additional diagnostic advice, we examined their internal validity by evaluating the results of the performed advice.

\section{Results}

Patients

Eighty patients were selected, and all participated; four failed to perform an adequate flow volume curve, leaving a total of 76 patients in the study. Forty-seven (male = 21) were new patients and did not use medication. Twenty-nine patients (male $=11$ ) came for follow-up of their pulmonary condition. Of these, 22 used inhaled steroids. New and follow-up patients were equally divided under and above the age of 45 : mean age was 49 , of which there was a broad range from 19 to 89 .

\section{The concordance of the diagnoses}

When regarding the main categories of diagnoses (i.e. normal lung function (no asthma or COPD), asthma, asthma with persisting obstruction, COPD, restriction), a good concordance was found between diagnoses of all patients in the paper and live assessments (table 1, $\mathrm{k}=0.82$ ). One third of all patients had no asthma or COPD and almost all were recognized as such both on paper and live.

There was a good concordance $(K=0.76)$ in the assessment of reversibility, a preliminary condition for correct diagnosis. Also, a good concordance $(k=0.78)$ was found in the diagnostic subcategories "normal" and "about normal", which lead to the distinct conclusions "no asthma" and "additional diagnostic examinations advised." 
Table 1: Concordance of diagnosis in patients being assessed using written data of spirometry and history or being assessed in a live consultation. Cohen's kappa $=0.82$

\begin{tabular}{|c|c|c|c|c|c|c|c|}
\hline & & \multicolumn{6}{|c|}{ Assessment by pulmonologist when using written patient data } \\
\hline & & Restriction ${ }^{1}$ & $\begin{array}{l}\text { (About) } \\
\text { normal }\end{array}$ & Asthma & $\begin{array}{l}\text { Asthma + } \\
\text { persisting } \\
\text { obstruction }\end{array}$ & $\begin{array}{l}\text { Obstruction } \\
\text { /COPD }\end{array}$ & total \\
\hline \multirow{6}{*}{$\begin{array}{l}\text { Assessment } \\
\text { of diagnosis } \\
\text { in live contact } \\
\text { between } \\
\text { pulmonologist } \\
\text { and patients }\end{array}$} & Restriction & 2 & & & & & 2 \\
\hline & Normal & & 26 & & & 1 & 27 \\
\hline & Asthma & & & 21 & 2 & 1 & 24 \\
\hline & Asthma+pers obstr. & & 1 & 1 & 6 & 1 & 9 \\
\hline & COPD & & 1 & & 2 & 11 & 14 \\
\hline & Total & 2 & 28 & 22 & 10 & 14 & 76 \\
\hline
\end{tabular}

${ }^{1}$ restriction: no other problem. (Minor) restriction as additional diagnosis occurred 7 times, but is not counted

Advice for additional examinations in cases of doubt about the definite diagnosis or its severity

For $57 \%$ of the patients ( $N=45$ ), additional diagnostic tests were advised, because in the assessment doubts remained about the diagnosis, most caused by discrepancies between spirometry and complaints. The concordance in advising additional tests between paper and live assessment was good (Cohen's $\mathrm{k}=0,65$ ). Of the advised tests, $62 \%(\mathrm{~N}=28)$ were performed. Previously assumed asthma or COPD could be confirmed in $35 \%$ of these patients, of which two-thirds had an additional diagnosis. In two patients, the diagnosis changed from asthma to COPD or visa versa. Alternative diagnoses were revealed in almost half of the examined patients (table 2). Alternative and additional diagnoses turned out to be mainly detectable by the general practitioner himself: they concerned sinusitis, allergic rhinitis, oesophagitis, and cardiac problems.

Between paper and live assessment there was full concordance about referral of four out of 29 follow-up patients because of COPD severity.
Table 2: Diagnostic results after performing additional diagnostic examinations as advised by the asthma/COPD service in case of primarily uncertain diagnosis.(Frequencies of finding, confirming, converting, and rejecting the diagnosis asthma and/or COPD)

\begin{tabular}{lcccccc}
\hline \multicolumn{7}{c}{ Final diagnosis after performing additional diagnostic examinations } \\
$\begin{array}{l}\text { Primarily } \\
\text { uncertain } \\
\text { diagnosis }\end{array}$ & $\begin{array}{c}\text { Newly } \\
\text { diagnosed } \\
\text { as Asthma or } \\
\text { COPD }\end{array}$ & $\begin{array}{c}\text { Diagnosis } \\
\text { Asthma or } \\
\text { COPD } \\
\text { confirmed }\end{array}$ & $\begin{array}{c}\text { Asthma } \\
\text { resp. COPD } \\
\text { converted in } \\
\text { COPD resp. } \\
\text { Asthma }\end{array}$ & $\begin{array}{c}\text { No Asthma } \\
\text { or COPD } \\
\text { but another } \\
\text { diagnosis }\end{array}$ & $\begin{array}{c}\text { COPD, but } \\
\text { also another } \\
\text { diagnosis }\end{array}$ & total \\
\hline $\begin{array}{l}\text { New patients } \\
\text { Follow-up }\end{array}$ & 5 & 3 & 2 & 3 & 6 & 14 \\
Total & 5 & 3 & 2 & 12 & 6 & 28 \\
\hline
\end{tabular}

Stable or unstable patient condition in case of follow-up

The advice to follow-up patients for adding/stopping/continuing medication were mainly based on the patient's condition, which was considered stable in case there were (almost) no complaints, no exacerbations in the last year and no conditional problems (MRC- dyspnoea scale $\leq 2$ ). Therefore, the pulmonologist assessed the stability or instability of the pulmonary condition of the follow-up patient. Only $66 \%$ agreement $(\mathrm{K}=0.39)$ was found between paper and live assessment, which did not make this differentiation meet good validity standards. 


\section{Discussion}

\section{Summary of main findings}

This study shows that in diagnostic assessments of asthma and COPD patients there is good concordance between paper consultations as performed by the Asthma/ COPD service and the live consultations by pulmonologists.

Also, advice for additional diagnostic examinations in case of unclear diagnosis can well be given from paper data. Their value is shown by the results of performing these tests: most alternative or additional diagnoses could be found by extended history taking, physical examination and eventually referral for laboratory tests or $x$-rays. GPs can manage these additional examinations when discussing the report of the asthma/COPD service with the patient. Referral to a pulmonologist was seldom necessary.

Treatment advices were not checked for their validity since they were based on the patient's clinical stability, which was found difficult to assess. Criteria for instability should be better defined ${ }^{[15]}$. Possible criteria are the number of exacerbations in the past year, dyspnoea (MRC-dyspnoea scale), increase in complaints and/or bronchodilator-use, persisting reversibility in asthma patients on maximum inhaled steroid medication and decline in FEV1 over the last three years of more than 200 $\mathrm{ml}$. Nevertheless, even with better definitions, a support service will only be able to carefully advise and cannot replace the GP's medical decision based on the live consultation and knowledge of the patient's medical and psychosocial characteristics.

\section{Comparison with existing literature}

The performance of spirometry care has been validated ${ }^{[16]}$ and interpretation of spirometry by GPs has been compared with a gold standard (in educational setting) ${ }^{[11]}$ and with the remote reportingof interpretation by respiratory specialists. However, no studies were found that validated this remote interpretation. The validity of interpretation of other complicated diagnostic procedures like $\mathrm{x}$-ray is studied more often and similar $\mathrm{K}$ are found $\mathrm{d}^{[17]}$.

\section{Strength and Limitations of this study}

For correct assessment - and for testing its validity - it is necessary to know whether a patient is referred for diagnosis or for follow-up. In this study, there was a problem with patients that already used inhaled corticosteroids without being diagnosed as having asthma (having shown reversible bronchus obstruction) or severe COPD (irreversible obstruction; more than two exacerbations in one year).
While the paper assessment tended to consider these patients as asthma patients, the live assessment more often rejected the diagnosis. Although the validity of the diagnostic assessment was adequate, we think it still can be improved when we solve this problem. Therefore, a new protocol is developed for assessment and intervention in cases of unclear diagnosis and the use of ICS, which should improve the diagnostic process and stimulate more accurate pharmacotherapy ${ }^{[18]}$.

To assess the concordance in diagnostic performances of the respiratory specialists it would have been sufficient - and easier - to only include new patients that do not use medication. However, the regular care problems, such as the issue with inhaled corticosteroids, would not have been encountered. It adds to the clinical importance of this study that all patients referred were included.

Implications for clinical practice

General practitioners as well as pulmonologists have to manage growing demands of care for asthma/COPD patients ${ }^{[19]}$. A main and complicated task is to assess the right diagnosis. It can be discussed whether all individual GPs should be able to perform and interpret spirometry, preferably combined with history data ${ }^{[20]}$. The fact is that there are many thresholds in every day practice. Access to a diagnostic support service that delivers (or rejects) a diagnosis asthma or COPD, as does a blood test for diabetes or an X-ray for pneumonia, enforces asthma/COPD disease management in primary care even when GPs themselves are not enough equipped and/or skilled or confident to do the complicated diagnostic procedure.

The present study showed that general practitioners can validly rely on the diagnostic support of respiratory specialists who only use written spirometry and medical history data. When organised in the Asthma/COPD service as described, this diagnostic support can facilitate and improve the care for asthma/COPD patients in primary care on a broad scale.

Further research will be done to determine if this approach improves diagnosis in primary care and whether it benefits primary care disease management. 


\section{Literature}

1. Pierson D. Clinical practice guidelines for chronic obstructive pulmonary disease: a review and comparison of current resources. Respir Care 2006. 51(3): 277-88

2. Poels PJ, Jacobs A, Akkermans RP, Hartman J, Bottema BJ, van Weel C. Variation in spirometry utilization between trained general practitioners in practices equipped with a spirometer Scand J Prim Health Care 2006. 24(2): 81-87

3. Caramori GB, Tosatto R, Arpinelli F, Visona G, Invernizzi G, Novelletto BF, Papi A, Adcock IM, Ciaccia A. Underuse of spirometry by general practitioners for the diagnosis of COPD in Italy. Monaldi Arch Chest Dis 2006.; 63(1): 6-12

4. Pinnock H. Respiratory Medicine. Br J Gen Prac 2004. 54(539-545)

5. Bolton CEIA, Edwards PH, Faulkner TA, Edwards SM, Shale DJ. Attaining a correct diagnosis of COPD in general practice. Respir Med 2005. 99(4): 493-500.

6. v Schayck CP, Chavannes N. Detection of asthma and chronic obstructive pulmonary disease in primary care. Eur Respir J 2003. 21(39_suppl): 16S-22

7. Marklund B, Tunsäter A, Bengston C. How often is the diagnosis bronchial Asthma correct? Fam Pract 1999. 16: 112-116

8. Bellia V, Battaglia S, Catalano F, Scichilone N, Incalzi RA, Imperiale C, et al. Aging and DisabilityAffect Misdiagnosis of COPD in Elderly Asthmatics: The SARA Study. Chest 2003. 123(4): 1066-1072

9. Martinez FJ, Gay SE. Is it asthma or COPD? The answer determines proper therapy for chronic airflow obstruction. Postgrad Med 2005. 117(3)(3): 19-26

0. Takahashi T, Ichinose M, Inoue H, Shirato K, Hattori T, Takishima T. Underdiagnosis and undertreatment of COPD in primary care settings. Respirology 2003. (8(4): 504-508

11. Chavannes N, Schermer T, et al. (2004). Impact of spirometry on GP's diagnostic differentiation and decision-making. Respir 2004 Med 98(11): 1124-30.

12. Vaughn R, Carter R, Duncan M. An outreach spirometry service for Greater Glasgow health board: does it help in the diagnosis. Eur Respir J 2004. 24: Suppl. 48, 182s

13. Kinnear W, Dennis P, Revill S, Wyatt J, Macfarlane J. Direct access for GPs to pulmonary function laboratory. Br J Gen Pract.1990. 40 (336): 304

14. Wolfende H, Bailey L, Murphy K, Partridge MR. Use of an open access spirometry service by general practitioners. Prim Care Respir J 2006.15(4): 252-255

15. Decramer M, Gosselink R, Rutten-Van Molken M, Buffels J, Van Schayck CP, Gevenois PA et al. Assessment of progression of COPD: report of a workshop held in Leuven. Thorax 2005 60(4): 335-42

16. Schermer T, Jacobs EJ, Chavannes NH, et al. Validity of spiromatric testing in a general practise population of patients with chronic obstructive pulmonary disease (COPD). Thorax 2003; 58(10):861-866

17. Wilke HJ, Rohlmann F, Neidlinger-Wilke $C$, et al. Validitys and interobserver agreement of a new radiographic system for intervertebral disc generation. Eur Spine J 2006; 15(6): 720-730

18. Lucas AEM, Smeenk FJWM, Smeele IJM, van Schayck CP. Overtreatment with inhaled corticosteroids and diagnostic problems in primary care patients, an explorative study. Fam Pract 2008. 25(2): 86-91.

19. Hoogendoorn M, Feenstra T, Schermer TR, Hesselink AE, Rutten-van Molken MP. Severity distribution of chronic obstructive pulmonary disease (COPD) in Dutch general practice. Respir Med. 2006. 100(1): 83-6.

20. Miller MR, Crapo R, Hankinson J, Brusasco V, Burgos F, Casaburi R, et al. General considerations for lung function testing. Eur Respir J 2005. 26(1): 153-161. 


\section{Abstract}

Lucas AEM, Smeenk FWJM, van den Borne BEEM, Smeele IJM, van Schayck $\mathrm{CO}$, Diagnostic assessments of spirometry and medical history data by respiratory specialists supporting primary care: are they reliable? Prim Care Resp J, 2009. 18(3): p. 177-184.

\section{Aim}

Aim to determine the intra- and inter-observer reliability respiratory specialists' diagnostic assessments of spirometry and written medical history data obtained from primary care

\section{Method}

Five respiratory specialists assessed data of spirometry and history of 156 patients randomly selected from referrals to an asthma/COPD-service. The inter-observer reliability was evaluated. After six month, all specialists repeated the assessments and the intra-observer reliability was evaluated.

\section{Results}

The diagnostic assessments for all patients had reasonable intra- and inter-observer reliability, resulting in a Cohen's kappa $\mathrm{k}=0.67$ and $\mathrm{k}=0.66$ respectively. The intraobserver reliability for assessing the need for additional diagnostic examinations had an average $\mathrm{k}=0.56$ for new patients, and an average $\mathrm{k}=0.39$ for follow-up patients. The assessment of clinical stability in follow-up patients - on which therapeutical advices are based- was inconsistent.

\section{Conclusion}

GPs who are reluctant to perform or interpret spirometry themselves, may be supported diagnostically by respiratory specialists in an asthma/COPD-service. The reliability of this advice varies. More appropriate criteria for assessing clinical stability in patients with Asthma and COPD are necessary to improve the reliability of the therapeutic advice. 


\section{Introduction}

In primary care, practical thresholds hinder the implementation of spirometry ${ }^{[1,2]}$, and many general practitioners (GPs) encounter problems in interpreting spirometry data ${ }^{[3]}$. Therefore, in several countries facilities have been developed to support general practitioners in assessing the diagnosis asthma or COPD in patients with respiratory complaints. These facilities provide spirometry testing assessed by specially interested and trained general practitioners ${ }^{[4]}$ or respiratory specialists ${ }^{[5]}$. Some services only interpret the spirometry results ${ }^{[6]}$, whereas others include $x$-ray and 02 -saturation ${ }^{[7]}$ or use medical history data ${ }^{[8]}$; furthermore, the respiratory specialists can collect data by actually seeing the patient ${ }^{[0]}$ or by assessing paperbased information only ${ }^{[10]}$. In addition, computerized data assessment is used on a wide scale[11].

The reliability and validity of these assessments may be questioned especially when a patient is not actually seen by the assessor. Therefore we studied the validity and reliability of diagnostic assessments based on spirometry results and written medical histories. In a previous study we found that these assessments had good validity, there were high similarities between the assessments of a pulmonologist based on written information and assessments of the same pulmonologist based on actual "live" contact with the patient ${ }^{[12]}$. In this paper, we examined the reliability of diagnostic assessment by different respiratory specialists who use spirometry data and written patient information. Our specific questions were:

What are the intra- and the inter-observer reliability of:

1. the actual diagnoses given to the patient?

2. the advice for additional diagnostic examinations in case of an unclear initial diagnosis?

3. the assessment of the clinical condition of the patient and the subsequent advice for adjustments in the treatment regime?

\section{Method}

Asthma/COPD-service

The study was performed at the Primary Care Diagnostic Centre in Eindhoven, the Netherlands. This Centre has developed an Asthma/COPD-service (AC-service). About 200 GPs refer their patient with respiratory problems to the centre for diagnosis and monitoring, and in 2007 approximately 6000 referrals were made. When referred, a patient fills in a structured form with questions about the medical history, smoking behaviour, fitness, complaints and compliance. This medical history is taken to the 
AC-service, where well trained lung function assistants perform spirometry including reversibility testing. The medical history form and the results of spirometry are kept together and sent to the co-operating respiratory specialists from local hospitals. They perform diagnostic assessments according to an assessment protocol that includes the following criteria:

- does the quality of the performed spirometry comply with ATS criteria[13]?

- does the flow volume curve show obstruction (FEV1/FVC $<0,70)$ and is this obstruction reversible after inhaling bronchodilator medication? (according to the Dutch standard the difference between FEV1 before and after bronchodilation should be $>9 \%$ of the FEV $1 \%$ predicted) $)^{[14]}$

- what is the conclusion based upon the patient's lung function curves:

1. No obstruction = no asthma/COPD?

2. No obstruction but decline in FEV1 and FVC = restriction?

3. Obstruction is reversible to normal lung function = asthma?

4. Irreversible obstruction = COPD?

5. Obstruction is reversible but not to a normal lung function = both asthma and COPD?

- (how) does patients medical history (allergy, family history, smoking behaviour, complaints) influence the final diagnosis - for example, in a case of normal lung function which does not exclude asthma?

- (how) does the patients' medical history (physical shape, complaints, exacerbations, use of medication, etc.) influence the assessment of stability of the disease and the patients' condition?

Following this protocol the respiratory specialists assess a diagnosis and give therapeutic advice. In case of a discrepancy between the symptoms and the spirometry results advice is given to the GP to conduct additional examinations in order to determine the final diagnosis. Referral to a pulmonologist is recommended according to the Dutch guidelines ${ }^{[15]}$.All assessment items are marked on a structured assessment form. A complete (figure 1) report is then made and sent to the patient's GP.

\section{New patients and follow-up patients}

For newly-referred patients (New Patients) the focus is on being diagnosed, or (if necessary) on obtaining advice for further diagnostic examinations. When a diagnosis of "asthma" or "COPD" is assessed, patients can be included in a monitoring program that invites them to visit the AC-service every year. For these "followup" patients, the focus is on assessing instability and progression of the disease and on providing therapeutic advice. For both new and follow-up patients the complete assessment procedure is performed: new patients also get therapeutical advice, when applicable, and follow-up patients are also checked for their diagnosis.
Patient data

During six months (January - July 2004) data records of 156 patients who were referred to the asthma/COPD-service were randomly selected (the first 7-8 patients of each week). Five respiratory specialists, who did not consult each other, assessed the spirometry results and medical history forms of the selected patients according to the regular assessment protocol. Six months later all five assessors examined copies of the same patient data for a second time. These copies were mixed in with the regular daily assessments to avoid recall bias.

\section{Intra- and inter-observer comparison method}

We first analysed the intra-observer reliability for all five observers by comparing the assessment forms of two assessments by each assessor of all patients. Only when the intra-observer reliability was reasonable for all observers $(k>0.5)$ was the interobserver reliability assessed.

Specific items for analysing the intra- and inter-observer agreement

To answer the first question about the reliability of the assessed diagnoses the scores all diagnostic options were compared. These options were:

1. "Normal'

2. "Asthma"

3. "Asthma with persisting obstruction" (i.e. mixed Asthma and COPD)

4. "COPD"

5. "Restriction" (as a single diagnosis)

The second research question was addressed by assessing the agreement in advice for additional diagnostic examinations by analysing the intra-observer reliability and the concordance in the number of patients who were given this advice by each observer.

The different types of advice were:

1. Discrepancy between spirometry results and medical history, search for an alternative diagnosis

2. Normal lung function. When considering asthma perform peak flow registration test or refer for histamine bronchoprovocation test or repeat spirometry when complains occur

3. Patient uses inhaled corticosteroid (ICS) but has a normal lung function and no complaints. If the diagnosis of asthma has not been confirmed by spirometry consider stopping the use of ICS and repeating the diagnostic spirometry after at least 3 month 
4. Discrepancy between spirometry results and medical history, search for additional diagnoses

5. Spirometry shows obstruction, no reversibility. Perform a steroid test to exclude asthma or to assess patients" personal best lung function" (at the time of the study this was according to the Dutch guidelines ${ }^{[15]}$ )

6. Patient uses ICS and has a mild obstructive lung function (COPD GOLD 1-2) When there are no frequent exacerbations and no or minor complaints consider stopping the use of ICS to be able to diagnose the actual need for ICS

To answer the third question we examined the agreement in assessing "stability" or "instability" of the clinical condition of the patient. Such reliability of assessment is a prerequisite to agreeing any adjustment in the medical treatment. Since treatment had yet to start in new patients, this part of the assessment only applied to patients who came for follow-up. The options analysed were "patient condition is stable", or "patient condition is unstable, as per the professional opinion of the respiratory specialist. They took into account the presenting complaints, physical shape, exacerbations, persisting reversibility in asthma patients, and whether or not FEV1 was declining by $>200 \mathrm{ml} /$ year.

\section{Statistical analysis}

Using SPSS 11, $\mathrm{k}$ was determined in order to qualify the intra-observer reliability. The inter-observer reliability was expressed as weighted $\mathrm{K}^{[16]}$.

\section{Results}

\section{Patients}

Seventy-two patients had been referred for diagnostic reasons ("new patients") Eighty-four patients who were considered to have asthma or COPD by their GP were referred for monitoring ("follow-up patients"). There was no information whether the diagnoses in this follow-up group were based on spirometry tests or on clinical symptoms. The patients' ages ranged from 18 to 84 years old and $46 \%$ were men. According to the pulmonologist whose report was sent to the GP, $39 \%$ of the patients had a normal lung function and had no asthma or COPD, $2 \%$ had a diagnosis of restriction $23 \%$ of the patients were diagnosed as having asthma $24 \%$ were diagnosed with COPD and $12 \%$ had a mixed diagnosis of asthma and COPD.
Quality of spirometry and the reliability of the assessment of reversibility

Before assessing the reliability of the diagnostic assessment, the quality of the performed spirometry was also assessed. According to the ATS criteria ${ }^{[17]}$ (immediate and rapid incline of the expiration curve, expiration lasting at least six seconds, no hesitation between expiration and inspiration, and uniting lines of inspiration and expiration) all but 3 of the 156 lung functions were of good or sufficient quality. There was almost complete agreement $(\mathrm{K}=0.92)$ about this. The agreement in the assessment of reversibility was also good $(\kappa=0.83)$

Reliability of the assessment of the diagnosis asthma and/or COPD

To analyse the intra-observer reliability of the assessed diagnoses, the agreement between the first and the second diagnosis of each patient was analysed for all five assessors. Cohen's kappa's for the intra-observer reliability of each assessor were $0.71 / 0.60 / 0.68 / 0.55 / 0.79$, with an average $\mathrm{k}$ of 0.67 .

The inter-observer reliability was analysed by comparing the diagnoses of all five assessors. In 114 patients (73\%) there was complete (56\%) to almost complete (16\%) agreement between all five assessors (table $1>$ )

All types of diagnosis contributed fully-agreed assessments (no asthma or COPD $\mathrm{N}=39$; asthma $\mathrm{N}=18$; COPD $\mathrm{N}=29$; asthma+COPD $\mathrm{n}=1$ ). Disagreement was likely to be caused by assessment decisions about borderline deviations from normal: asthma" or "(about) normal" (21\%), and "COPD" or "(about) normal" (12\%). In $11 \%$ of the patients there was a difference in diagnoses that was difficult to interpret. None of the assessors had a pattern of assessment that was clearly different from the others. Statistically the inter-observer reliability $(\kappa=0.63)$ approximated the reliability found in the intra-observer analysis (table $2>$ )

When comparing the diagnostic assessments of new patients and of patients that came for follow-up, higher intra-observer reliability was found for the new patients (Table 2). In addition, the intra-observer reliability was better for new patients $(\mathrm{k}=0.66)$ than for follow-up patients $(\mathrm{k}=0.56)$.

The inter-observer reliability was analysed by comparing the diagnoses of the first assessments of all five assessors. The reliability $(\mathrm{k}=0.63)$ approximated the concordance found in the intra-observers analysis. Also the inter-observer reliability was better for new patients $(\kappa=0.69)$ than for follow-up patients $(\kappa=0.48)$ 
Table 1: Patterns of, and probable causes for, differences between diagnostic assessments by five respiratory specialists of 156 primary care patients based on spirometry data and medical histories

Distribution of similar / deviant diagnoses $(n=156)$ assessed by 5 respiratory specialists

\begin{tabular}{|c|c|c|c|c|c|c|}
\hline $\begin{array}{l}\text { Pattern of assess- } \\
\text { ment: Difference }\end{array}$ & Diagnostic labels & $5 / 0^{1}$ & $4 / 1^{2}$ & $3 / 2^{3}$ & $1 / 1 / 1 / 1^{4}$ & Total \\
\hline No difference & & 87 & & & & $\begin{array}{c}87 \\
(57 \%)\end{array}$ \\
\hline $\begin{array}{l}\text { Difference in the } \\
\text { interpretation of the } \\
\text { existence of "asthma" }\end{array}$ & $\begin{array}{l}\text { No Asthma/COPD } \leftrightarrow \text { Asthma } \\
\text { or } \\
\text { Astma/COPD } \leftrightarrow \text { Asthma }\end{array}$ & & $\begin{array}{l}11 \\
4\end{array}$ & $\begin{array}{l}9 \\
7\end{array}$ & & $\begin{array}{c}31 \\
(21 \%)\end{array}$ \\
\hline $\begin{array}{l}\text { Difference in the } \\
\text { interpretation of the } \\
\text { existence of "COPD" }\end{array}$ & $\begin{array}{l}\text { No Asthma/COPD } \leftrightarrow \text { COPD } \\
\text { or } \\
\text { Asthma/COPD } \leftrightarrow \text { COPD }\end{array}$ & & $\begin{array}{l}5 \\
3\end{array}$ & $\begin{array}{l}8 \\
4\end{array}$ & & $\begin{array}{c}20 \\
(12 \%)\end{array}$ \\
\hline $\begin{array}{l}\text { Complete difference } \\
\text { between the assessors }\end{array}$ & $\begin{array}{l}\text { Asthma } \leftrightarrow \text { COPD } \\
\text { or } \\
\text { Normal } \leftrightarrow \text { Asthma } \leftrightarrow \\
\text { COPD } \leftrightarrow \text { Asthma+COPD }\end{array}$ & & 4 & 1 & 13 & $\begin{array}{c}18 \\
(11 \%)\end{array}$ \\
\hline Total & & $\begin{array}{c}87 \\
(56 \%)\end{array}$ & $\begin{array}{c}27 \\
(17 \%)\end{array}$ & $\begin{array}{c}29 \\
(19 \%)\end{array}$ & $\begin{array}{c}13 \\
(8 \%)\end{array}$ & $\begin{array}{c}156 \\
(100 \%)\end{array}$ \\
\hline
\end{tabular}

${ }^{1} 5 / 0=$ full agreement of five assessors. ${ }^{2} 4 / 1=$ agreement of 4 assessors $/ 1$ deviant assessment.

${ }_{3}^{3} / 2=$ agreement of 3 assessors $/ 2$ equal deviant assessments. ${ }^{4} 1 / 1 / 1 / 1 /=$ five deviant assessments.

Table 2: Intra- and inter-observer reliability in diagnostic assessment performed by respiratory specialists and based on written information about lung functions and medical histories

\begin{tabular}{lccc}
\hline $\begin{array}{l}\text { Agreement in diagnoses } \\
\text { (No asthma; Asthma; Asthma+COPD; COPD) }\end{array}$ & $\begin{array}{c}\text { New patients } \\
\mathbf{k}\end{array}$ & $\begin{array}{c}\text { Follow-up } \\
\text { patients } \mathbf{~}\end{array}$ & $\begin{array}{c}\text { Total group } \\
\mathbf{k}\end{array}$ \\
\hline $\begin{array}{c}\text { Intra-observer variation } \\
\text { (Mean K and range) }\end{array}$ & $\begin{array}{c}0.66 \\
(0.55-0.74)\end{array}$ & $\begin{array}{c}0.56 \\
(0.40-0.79)\end{array}$ & $\begin{array}{c}0.67 \\
(0.55-0.79)\end{array}$ \\
$\begin{array}{c}\text { Inter-observer variation } \\
\text { (Weighted } \text { ) }\end{array}$ & 0.69 & 0.48 & 0.63 \\
\hline
\end{tabular}

Assessment of the need for additional diagnostic examinations

An average of $58 \%$ of all patients was given advice to undergo additional diagnostic examinations (to be conducted by their GPs) after the first assessments and $68 \%$ after the second. The number of patients recommended for referral to a specialist because of severe problems (lung function decline and/or symptoms) was $8 \%$ $(10-25 \%)$ in the first and 7\% (5-19\%) in the second series of assessments.

The intra-observer reliabilities for advising additional diagnostic examinations had a reasonable mean Cohen's kappa $(\mathrm{k}=0.50)$ but there were big differences between the assessors, as Cohen's $\mathrm{k}$ ranged from $0.31-0.62$. The advices for new patients showed better reliability ( $\mathrm{k}=0.54-0.58)$ than the advice for follow-up patients $(\mathrm{K}=0.38$ 0.40 ) but did not meet the criteria to assess a weighted $\mathrm{k}$ (table 3 ).

Table 3: Intra-observer reliability of the advice for additional diagnostic examinations given in case of uncertainty of the diagnosis based on spirometry and written patient history data

\begin{tabular}{lc}
\hline $\begin{array}{l}\text { Advice for additional diagnostic examination } \\
\text { (Advice nr. } 1,2 \text { and } 3 \text { can be given in new patients) } \\
\text { (Advice nr. } 4 \text { and } 5 \text { can be given in case of follow-up) }\end{array}$ & $\begin{array}{c}\text { Concordance between } \\
\text { two assessments } \\
\text { mean } \mathrm{K}\end{array}$ \\
\hline $\begin{array}{l}\text { 1. Discrepancy between complaints and spirometry } \\
\rightarrow \text { check for other diagnosis }\end{array}$ & 0.54 (0.32-0.65) \\
$\begin{array}{l}\text { 2. Obstruction, no diagnosis yet } \\
\rightarrow \text { perform steroid test }\end{array}$ & $0.58(0.40-0.86)$ \\
$\begin{array}{l}\text { 3. Normal spirometry, possibly asthma } \\
\rightarrow \text { perform peakflow-registration test or }\end{array}$ & $0.56(0.24-0.75)$ \\
$\quad$ histamine provocation test & \\
4. Discrepancy between complaints and diagnosis & \\
$\rightarrow$ check for additional medical problems & $0.38(0.03-0.67)$ \\
5. Use of ICS for unclear reason & \\
$\rightarrow$ stop ICS, repeat FVM after 3months & $0.40(0.13-0.60)$ \\
\hline
\end{tabular}


Assessment of the clinical condition of the patient

Agreement in assessing the clinical stability of the follow-up patients scored low for intra-observer reliability: Cohen's kappa for each assessor: 0.64 / 0.39 / 0.35 / 0,24 / 0.28. (Mean $\mathrm{K}=0.38$ ). Based on this finding the inter-observer weighted kappa was judged of no value and was not analysed any further.

\section{Discussion}

The main finding of our study was that there was moderate agreement (inter-observer reliability) and consistency (intra-observer reliability) in the diagnostic assessments of asthma and COPD as performed by different assessors based on spirometry and written information about a patient's history, complaints and compliance.

We could not draw conclusions about the reliability of the advices for additional diagnostic examinations. The assessments of the stability of the patients' clinica condition were found to be statistically not reliable. Therefore therapeutical advice should be treated with caution by the GP.

\section{Comparable diagnostic assessments of asthma or COPD}

Intra- and inter-observer reliability in the diagnostic assessment of asthma/COPD are hardly ever discussed in the literature which is remarkable since the differential diagnostic process in asthma or COPD is complex. A previous analysis of the variability in the interpretation of spirometry results by respiratory specialists showed $63 \%$ agreement ${ }^{[18]}$. In another study, interns and respiratory specialist reached $58 \%$ agreement ${ }^{[19]}$. The concordance we found in this study $(\mathrm{K}=0.63)$ was comparable - which is remarkable since respiratory specialist combined the interpretation of medical history and spirometry data thus making the assessment more complicated. When compared to other complicated diagnostic procedures such as chest radiograph interpretation by pulmonologists $(\kappa=0.51)^{[20]}$, the diagnostic reliability of the assessments in our study is not inadequate.

What is the maximal achievable reliability?

This finding of moderately good agreement was surprising, for one would expect that diagnostic concordance would be high. To understand this better we examined in detail the discrepancies between the diagnoses assessed by the pulmonologist who had the best intra-observer reliability ( $\kappa=0,79)$. In 25 out of 156 cases $(16 \%)$ different decisions were made. Twelve cases concerned differences in diagnosing patients with lung function that was borderline to normal (FEV1 around $80 \%$, FEV1/FVC around 0,68 ). Other doubts were caused by the interpretation of an improvement in
FEV1 as a volume response or as 'real' reversible airway obstruction as is seen in asthmatics $(\mathrm{N}=5)$ and by discrepancies between complaints and spirometry results $(\mathrm{N}=3)$. The use of ICS without an obvious indication caused different diagnoses in five out of 36 of those cases. It is unlikely that these "real life problems" can be completely solved by a strict assessment protocol. This might indicate that expectations about high concordance for diagnostic support services or outpatient clinics are not realistic. An interesting question is whether GPs themselves, willing to overcome the practical problems of performing spirometry, do better. Trained GPs have been shown to identify normal and clear deviant spirometry ${ }^{[21]}$. They also had problems in interpreting the minor variations. Further research could show how GPs - be they well trained or not - diagnose the combination of spirometry and medical history and how this compares to the paper assessments of the respiratory specialists of the astma/ COPD-service

\section{Assessments in new and follow-up patients}

The reliability of the diagnostic assessments was better in new patients than in patients who came for follow-up. This can be explained by the following problem we encountered: several patients referred as new patients used ICS without a diagnosis of asthma confirmed by spirometry. In fact, because of their use of ICS, they had to be considered as follow-up patients. When their use of ICS could not be explained by the results of the actual spirometry test or the patient's medical history the assessing pulmonologist had to choose: either he accepted the presumed diagnosis (asthma or moderate COPD with recurrent exacerbations), or refused to do so and postponed the diagnosis until the use of ICS was stopped and spirometry was renewed. As we found in another study, this dilemma exists in about $20 \%$ of all patients referred to a diagnostic service ${ }^{[22]}$ and the possible conflict in decision making can influence (negatively) the reliability of the diagnostic assessment in follow-up patients..

Assessment of the need for additional diagnostic examinations

The value of additional diagnostic advices was shown in a former study where about $50 \%$ of the patients were given these advice which led to a large number of other or additional diagnoses (rhinitis, gastric asthma, cardiac problems, etc) ${ }^{[1]}$. Also, more than $50 \%$ of all patients we describe in this paper received advice regarding additional examinations. The most important effect this advice might have had is that it encouraged the GPs to explore differential considerations in case there was a discrepancy between spirometry findings and the patient's symptoms. 
Assessment of the patients clinical condition and medical advice

To classify the stability of a patient's disease one should take into account their complaints and symptoms, physical condition, exacerbation, use of reliever medication, etc. ${ }^{[23]}$. In this study we found that the clinical stability could not be assessed reliable from the written information. Consequently the (pharmacotherapeutical) treatment adjustments showed a great intra- and inter-observer variability. To improve this, a better algorithm will be needed for assessing the clinical stability. But even when there is such a protocol, the asthma/COPD-service will only be supportive to the GP in identifying instability and will not discharge the GP from taking final responsibility and consequently weighing up the therapeutical advice offered.

Difficulties encountered in the study.

In this paper we studied the regular assessment procedure of the asthma/COPDservice without making corrections for patients who were referred with a wrong indication (referred for follow-up without a diagnosis). In addition, no special instructions were given to the respiratory specialists about how to handle specific situations such as the use of ICS by patients without obvious reasons for that use. Therefore, our results reflect "every day life" reliability of the assessments of the asthma/COPD service to a greater extent than the reliability of the professional assessment skills of the pulmonologists.

Our study identified the need for properly-assessed diagnosis (before medica treatment) in order to monitor reliably an asthma or COPD patient. As a result of our study the asthma/COPD-service developed referral instructions for the GPs. In addition, regular reviewing between the respiratory specialists will be organized to develop and discuss extra guidelines for the assessments. When these changes have been implemented we intend to do a follow-up study examining the expected improvements in the reliability of the diagnostic and therapeutic assessments.

Lessons for clinical practice as a result of the study

Not all general practitioners have the facilities, the skills, or the wherewithal perform to adequately the diagnostic procedures necessary to identify correctly asthma or COPD (or its absence). GPs experience the need for ongoing support with regard to the management of the care process ${ }^{[24]}$ to start with spirometry interpretation ${ }^{[25]}$. Services offering such support need to validate their procedures and need to provide the best reliable reports to the GPs using that service. The reliability of advice varies. GPs referring to the service should realize that $100 \%$ reliability cannot be expected because of the complexity of the diagnostic procedure.
Figure 1: Report of the diagnostic assessment by a pulmonologist based on written information as sent to the general practitioner by the asthma/COPD service

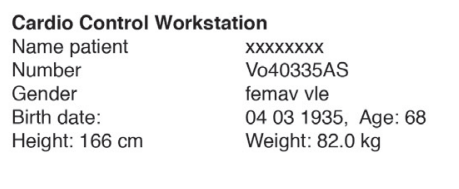

Assessment by lung specialist:
Dr. XXXXX. For questions you can contact him
at the AC-service of the Diagnostic Centre tel....

Quality Curve: reasonable, assessable
Vital capacity: NORMAL

Expiration: Moderate OBSTRUCTION improvement in FEV1 after medication, but this can be false because of a volume response CONCLUSION: moderate obstructive lung function,

ADVICE: consider diagnostic steroid test to deermine the optimal lung function and to excluce

" consider dietary advice, (BMl is too high) cheque compliance, medication to be taken daily

Patient is included in the AC-service for yearly Follow UD and will be invited for lung function test in a $\begin{array}{ll} & \\ \text { Primary Care Diagnostic Centre } \\ \text { Address } & \text { xxxxxxxx } \\ \text { Postal code } & 5641 \text { AL } \\ \text { Place } & \text { Eindhoven } \\ \text { Date of test } & 01 \text { 10 2003, 9:07:27 } \\ \text { Biometrist } & \text { JPO }\end{array}$ Notes:
General practitioner: YYrYY, address: tel:...
Code 83093, incl. revers. Reason: DIAGNOSIS PATIENT HISTORY: PATIENT HISTORY:
Known by lung specialist: Reason: brother had TBC Former X-Thorax: 25 years ago
History: Hay fever, bronchitis
Fasis Family History: positive
Smoke: STOPPED in 1990, PY: 36

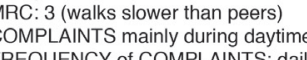
Cough and/or sputum: NO COMPLAINTS SCORE: 3 (some) (max=10) BMI: 29,7
Exacerbations: None Prescribed lung medication: tiotropium 1dd1 ago
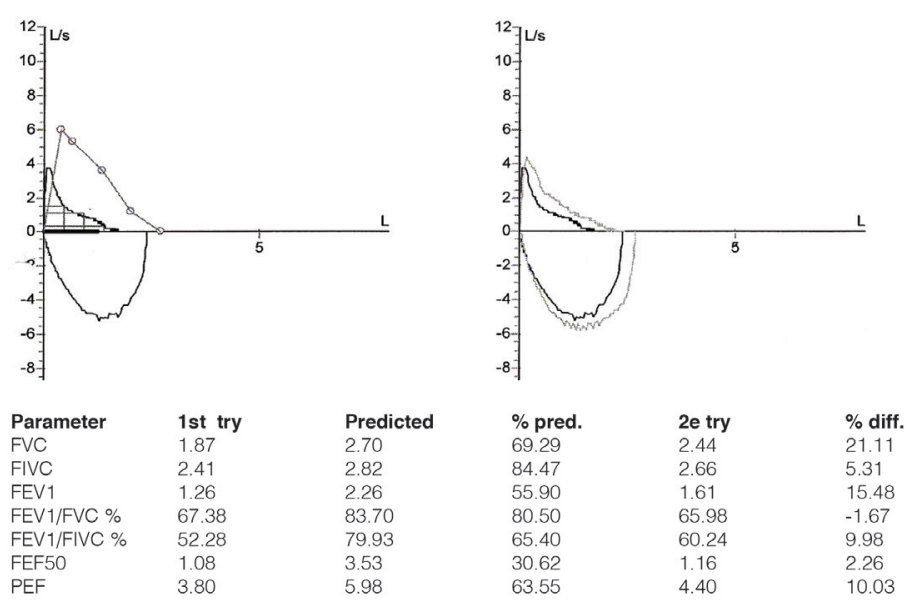


\section{Literature}

1. Walters JA, Hansen E, Mudge P, Johns DP, Walters EH, Wood-Baker R. Barriers to the use of spirometry in general practice. Aust Fam Physician 2005. 34(3): 2001-2003.

2. Frank TL, Hazell ML, Linehan MF, Frank PI. The diagnostic accuracies of chronic obstructive pulmonary disease (COPD) in general practice: the results of the MAGIC (Manchester Airways Group Identifying COPD) study. Prim Care Respir J 2006.15(5): 286-293

3. Bolton CEIA, Edwards PH, Faulkner TA, Edwards SM, Shale DJ. Attaining a correct diagnosis of COPD in general practice. Respir Med 2005. 99(4): 493-500.

4. Jones R, Whittaker M, Hanney K, Shackell B. A pilot study of a mobile spirometry service in primary care. Prim Care Respir J 2005.14(3): 169-71

5. Walker PP, Mitchell, P., Diamantea, F., Warburton, C. J., \& Davies, L. Effect of primary-care spirometry on the diagnosis and management of COPD. Eur Respir J 2006, 28(5), 945-952

6. White PW, Wong T, FIming B, Gray. Primary Care Spirometry testing: test quality and feasibility and usefulness of specialist reporting. Br.J Gen Pract 2007; 57 (542);701-5

7. Hassett R, Meade K, Partridge MR. . Enhancing the accuracy of respiratory diagnoses in primary care: a report on the establishment of a Community Respiratory Assessment Unt. Prim Care Respir J. 2006.15(6):354-61.

8. Vaughn R, Carter R, Duncan M. An outreach spirometry service for Greater Glasgow health board: does it help in the diagnosis. Eur Respir J 2004. 24: Suppl. 48, 182s

9. Wolfende H, Bailey L, Murphy K, Partridge MR. Use of an open access spirometry service by general practitioners. Prim Care Respir J 2006.15(4): 252-255

improves diagnosis and monitoring in primary care. Eur Respir J 2005., 26(suppl.49), 178s

11. Kuilboer MM, van Wijk MAM, Mosseveld M, van der Does E, Ponsioen BP, de Jongste JC, Overbeek SE, van der Lei J. Feasibility of AsthmaCritic, a decision-support system for asthm and COPD which generates patient-specific feedback on routinely recorded data in general practice. Fam Pract 2002. 19(5): 442-447

12. Lucas AEM, Smeenk F., Smeele IJ, vd Borne, B, van Schayck CP (2006). Validity of diagnostic support of an asthma/COPD-service in primary care. Submitted

13. Pauwels RA, Buist AS, Calverley P, Jenkins C, Hurd S. Global strategy for the diagnosis, management and prevention of chronic obstructive pulmonary disease. NHLBI/WHO Globa Initiative for Chronic Obstructive Lung Disease (GOLD). update 2005

14. Geijer RMM, Thiadens HA, Smeele IJ, et al. Standard of the Dutch College of General Practitioners on asthma and COPD; diagnosis (in Dutch). Huisarts en Wet 2001;44(3): 107-17

15. Geijer RMM, Thiadens HA, Smeele IJ, et al. Standard of the Dutch College of Genera Practitioners on asthma and COPD; treatment (in Dutch). Huisarts en Wet 2001;44(3): 207-19

16. Fleiss.exe V1.0 - Calcul du coefficient Kappa multi-juges d'après Fleiss ; Auteur: Philippe Bonnardel ${ }^{*}$ http://perso.worldonline.fr/kappa/

7. Miller MR, Hankinson J, Brusasco V, et al. Standardisation of spirometry. Eur Respir J 2005;26: $319 / 38$.

18. Quadrelli SA, Roncoroni AJ, Porcel G.. Analysis of variability in interpretation of spirometrc tests. Respiration 1996. 63(3): 131-136

19. Hnatiuk O, Moores L., Loughney T, \& Torrington K. Evaluation of internists' spirometric interpretations. J Gen Intern Med 1996.11(4):204-208

20. Bolton J, Padia SA, Borja MC, Becker P, Orens JB, Wiener C, et al. The predictive value and inter-observer variability of donor chest radiograph interpretation in lung transplantation. Eur Cardiothorac Surg 2003.23(4):484-487 
21. Chavannes N, Schermer T, Akkermans R, et al. The impact of spirometry on GP's diagnostic differenatioation and decision making. Respir Med 2004;98(11):1124-30.

22. Lucas AEM, Smeenk FWJM, Smeele IJM, van Schayck CP. Overtreatment with inhaled corticosteroids and diagnostic problems in primary care patients, an explorative study. Fam Pract 2008. 25(2):86-91.

23. Jones PW, Augusti AJ. Outcomes and markers in the assessment of chronic obstructive pulmonary disease. Eur Respir J 2006. 27(4): 822-832

24. Meulepas MA, Jacobs JE, Lucas AE, et al. The feasibilitys of a primary care model for the management of COPD. Prim Vare Resp J 2006;15(16):337-41

25. Poels PJ, Schermer TR, Akkermans RP, et al. General practitioners' need for ongoing support for the interpretation of spirometry tests. Eur Respir J 2007;13(1):16 -19 
Lucas AE, Smeenk FW, Smeele IJ, van Schayck CP. Overtreatment with inhaled corticosteroids and diagnostic problems in primary care patients, an exploratory study. Fam Pract 2008. 25(2): p. 86-91.

\section{Abstract}

Underdiagnosis and undertreatment of patients with asthma or COPD are widely discussed in the literature. Not much is known about the possible overdiagnosis and consequently the overtreatment with inhaled corticosteroids.

Aim

This study investigates how often inhaled corticosteroids (ICS) are prescribed without a proper indication and how big the diagnostic problem is caused by inappropriate prescription and use of ICS.

\section{Method}

All patients referred to a primary care diagnostic centre during six months who used ICS without a clear indication were included. Their GPs were questioned about the reasons for prescribing ICS. If still no diagnosis could be assessed, GPs were advised to stop ICS and renew spirometry after a steroid-free period of at least three months. After one year the use of ICS was evaluated and the diagnoses were re-assessed.

Results

1171 of all 2271 referred patients used ICS, 505 (30\%) without a clear indication. After one year final results showed that $11 \%$ of all patients originally using ICS had no indication to use ICS and had successfully ceased using this mediation. For $15 \%$ the reasons for using ICS remained unclear.

Conclusion

Overtreatment with ICS in primary care seems to be considerable, which falsely labels patients as asthmatic, and which generates unnecessary costs and possible side-effects. The awareness of GPs of the need for proper diagnostic testing before prescribing ICS needs to be improved. Overtreatment with ICS in primary care patients can be diminished by systematically supporting the general practitioner in the diagnostic procedures and decision-making. 


\section{Introduction}

Underdiagnosis and undertreatment are considered to be major problems in the management of asthma and COPD in primary care and worries exist about the consequent undertreatment of obstructive pulmonary diseases ${ }^{[1]}$. It is stressed that symptoms indicating asthma or COPD have to be interpreted more often as indicating these diseases ${ }^{[2]}$. When, according to international guidelines, a definite diagnosis is confirmed by spirometry ${ }^{[3]}$ and, consequently, proper medication is prescribed, undertreatment could be diminished. However, in daily practice, there are thresholds following this procedure ${ }^{[4]}$ and it is tempting for GPs to start medication already when a patient presents bronchial symptoms. Combined with the growing awareness of asthma/COPD in the general population, this practice could lead to too many prescriptions and to overtreatment with inhaled corticosteroids (ICS). When complaints disappear, a healthy person using ICS might be mistaken for a well regulated asthma patient and be advised to continue treatment with ICS.

The recent development of diagnostic support services ${ }^{[5.6 .7]}$ has triggered awareness of this problem.

These services offer GPs the possibility to refer all their patients with respiratory problems for diagnosis and advice. The services can be a solution for the problems GPs experience in performing good quality spirometry and good quality interpretations of results ${ }^{[8]}$.

In a region (in the Netherlands) where such a diagnostic service is part of usual care we examined the problem of overtreatment with ICS in primary care patients. We tried to answer the following questions:

1. How often are ICS prescribed without a properly assessed indication?

2. What is the magnitude of the diagnostic problem caused by the inappropriate prescription and use of ICS?

\section{Method}

Diagnostic support service

The study presented in this paper has been conducted at the Asthma/COPD service of the Primary Care Diagnostic Centre in Eindhoven, the Netherlands $\mathrm{s}^{[9]}$. This diagnostic service supports 180 GPs (population: 300.000 people), most of them with no special interest in asthma or COPD. GPs can refer all their patients with respiratory complaints to this service for diagnostic spirometry. Written spirometry data are assessed in combination with written medical history data filled in by the patients at referral. The structured history form includes smoking habits (pack years), physical 
condition (MRC dyspnoea score), respiratory complaints, exacerbations, prescribed medication and compliance. Assessments of the written data are performed by pulmonologists of the local hospitals. A diagnosis and - when indicated - advice is given about additional diagnostic examinations and about therapy and guidance. A report is then sent to the GP who is responsible for the patient's care. When a diagnosis Asthma or COPD is assessed, patients are called for a yearly follow up as recommended by the Dutch guidelines ${ }^{[10]}$.

\section{Patients}

During a six month period (April - September 2005), we examined the diagnoses of all patients referred to the asthma/COPD service. Included in the study were those patients who used ICS, had a normal or mildly obstructed lung function without reversibility and who did not have a definite diagnosis of asthma or exacerbations of COPD. The diagnosis asthma was considered definite when reversible bronchial obstruction was assessed, defined according to the Dutch guidelines as an increase in forced expiratory volume in the first second of expiration (FEV1) $>9 \%$ of the predicted value after inhalation of $400 \mu$ salbutamo ${ }^{[11]}$. An exacerbation of COPD was defined as a period of worsened complaints that needed treatment with (oral) steroids and/ or antibiotics.

\section{Questionnaire and stop-advice}

For each patient in the study the GP was asked to mark the reasons for prescribing ICS on a questionnaire that defined 6 reasons:

1. Diagnosis assessed and ICS prescribed by a lung specialist or paediatrician in the past

2. Bronchial reversibility previously shown by spirometry

3. A previously positive response to a steroid reversibility test ${ }^{2}$

4. Abnormal peak flow variability ${ }^{b}$

5. Asthma symptoms in childhood

6. Other reason to be explained by the general practitioner (e.g. bronchia symptoms, continued prescription because of start in the past, etc.)

Of these six reasons the first four reasons were considered (a priori) as "valid reasons" for the use of ICS ${ }^{[7]}$. The 5th and 6th reasons were labelled as "unclear reasons"

a steroid reversibility test": when no reversibility is found in the first spirometry test, this test is repeated after using oral steroids for 2 weeks or inhaled corticosteroids for 3 months. When in this second spirometry test the FEV 1-post bronchial dilatation( $F E V 1-P B)=>20 \%$ and $>200 \mathrm{~m}$. Compared to FEVI-PB in lhe first spirometry test, his is considered an indicalion for $>20 \%$ diagnosis Asthmal "A

政 $>20 \%$ of the mean peak flow measured on at least 2 of 14 consecutive days ${ }^{[1]}$.
The GP's explanation for the use of ICS was taken into account by the assessing pulmonologist who then reconsidered his interpretation of the patient's spirometry and medical history. When it was still not possible to diagnose asthma, GPs were advised to stop ICS and repeat the diagnostic procedure after a steroid-free period of at least three months. After three months we examined the results of this advice by checking if the patient was referred for renewal of spirometry. In addition, these patients were asked in a telephone interview:

1. Have you been given the advice to stop or step down ICS?

2. Did you do so?

3. Has this caused complaints?

4. Did you start using (more) ICS again?

One year later we evaluated the use of ICS and the number of still unclear diagnoses by examining the yearly follow-up assessments of all patients of whom the GP had not respond to the questionnaire in first instance or secondly had not followed the advice to stop ICS and renew spirometry.

\section{Results}

\section{Patients}

Over a six-month period, a total of 2271 patients were referred by their GPs for lung function tests. $36 \%$ were diagnosed as Asthma patients, $19 \%$ as COPD patients. $6 \%$ had both COPD and asthma. 20\% had neither asthma nor COPD. In 19\% the diagnosis was unclear (table 1).

Reasons for prescribing ICS

Of all referred patients 1177 (52\%) used ICS (figure: 1st assessment). The reasons for this use were clear in 572 patients with the diagnostic assessment Asthma or (severe) COPD (table 1). In 505 patients the use of ICS did not match the results of the spirometry test or the medical history. These patients were included in our study.

The size of overtreatment

GPs received a questionnaire for the included 505 patients about their reasons for prescribing ICS. 282 GPs responded (58\%). As a second assessment the answers of the GPs were evaluated (figure): the pulmonologists assessed a diagnosis for 173 additional patients (62\%). Of those, 128 asthma patients and 5 COPD patients were advised to continue ICS. In 149 patients doubts remained about the reason for the use (or the continuation of formerly indicated use) of ICS and the advice was given to stop (table 2). 
Table 1: Characteristics of all patients ( $\mathrm{n}=2271$ ) referred to an Asthma/COPD-service during six months: Spirometry results, assessed diagnosis, use of ICS and validity of indication for ICS

\begin{tabular}{|c|c|c|c|c|}
\hline $\begin{array}{l}\text { Spirometry Results } \\
\text { (medical history) }\end{array}$ & Diagnosis & Patients (\%) & $\begin{array}{c}\text { Patients } \\
\text { using ICS } \\
\text { (N) }\end{array}$ & $\begin{array}{l}\% \text { clear } \\
\text { reasons } \\
\text { for the use } \\
\text { of ICS }\end{array}$ \\
\hline $\begin{array}{l}\text { Normal, no reversibility } \\
\text { (reversibility shown in the past) } \\
\text { (history of asthma complaints) }\end{array}$ & $\begin{array}{l}\text { No asthma, } \\
\text { No COPD } \\
\text { Asthma }\end{array}$ & $\begin{array}{l}462 \text { (20\%) } \\
214 \text { (10\%) }\end{array}$ & $\begin{array}{l}0 \\
0\end{array}$ & $\begin{array}{l}\text { no ICS } \\
\text { (does not } \\
\text { apply) }\end{array}$ \\
\hline Obstruction reversible to normal & $\begin{array}{c}\text { Asthma } \\
\text { Asthma and COPD } \\
\text { COPD, GOLD 1(?)-2 } \\
\text { COPD, GOLD 3-4 }\end{array}$ & $\begin{array}{ll}589 & (26 \%) \\
128 & (6 \%) \\
344 & (15 \%) \\
29 & (1 \%)\end{array}$ & $\begin{array}{l}489 \\
108 \\
61 \\
14\end{array}$ & $\begin{array}{c}\text { Yes } \\
(572=57 \%)\end{array}$ \\
\hline $\begin{array}{l}\text { Normal lung function no } \\
\text { reversibility } \\
\text { (no former reversibility known, } \\
\text { no suspect complaints, } \\
\text { patient uses ICS) }\end{array}$ & No clear diagnosis & 434 (19\%) & 434 & $\begin{array}{c}\text { Unclear } \\
(505=43 \%)\end{array}$ \\
\hline $\begin{array}{l}\text { Mild obstruction, } \\
\text { (no exacerbations, } \\
\text { patient uses ICS) }\end{array}$ & COPD GOLD 1 & $71 \quad(3 \%)$ & 71 & \\
\hline
\end{tabular}

Total

$2271(100 \%) \quad 1177(52 \%) \quad(100 \%=1177)$

In all, 71 (of 149) patients followed the advice to stop the use of ICS and came to the asthma/COPD-service for renewed spirometry testing after a steroid-free period of at least three months. Then a third assessment (figure) was done: 5 patients had developed asthma symptoms and had started ICS again. 6 COPD patients could stop ICS without any problem, as could 60 persons with normal lung function.

One year after referral patients of whom GPs did not respond to the questionnaire or did not follow the advice to renew the diagnostic procedure (283) were invited for follow-up spirometry (figure: 4th assessment). 49 had stopped using ICS without problems, 43 of them had normal lung functions and 6 were mild COPD-patients.
60 asthma patients continued using ICS on indication, as did 6 COPD patients because of exacerbations. 89 patients still used ICS for unclear reasons and 79 did not show upon invitation or recall.

Through telephone interviews with the patients after their GPs completed the questionnaire, we found that, except for the patients who definitely stopped ICS, 43 of the 128 diagnosed as ICS-dependent asthma patients had reduced their dose of ICS without experiencing respiratory problems again

Table 2: Reasons for prescribing ICS by GPs to patients showing a normal lung function or a medical history without severe complaints compared with the diagnostic assessments of pulmonologist who take these reasons into account

\begin{tabular}{|c|c|c|c|c|c|}
\hline \multirow{2}{*}{$\begin{array}{l}\text { Reasons named by GPs } \\
\text { for prescribing ICS to patients } \\
\text { who show a normal lung } \\
\text { function or } \\
\text { a medical history without } \\
\text { (severe) complaints }\end{array}$} & \multicolumn{5}{|c|}{$\begin{array}{l}\text { nostic assessment by a pulmonologist based on spirometry, } \\
\text { edical history and the reasons named for prescribing ICS }\end{array}$} \\
\hline & $\begin{array}{l}\text { Diagnosis } \\
= \\
\text { Asthma }\end{array}$ & $\begin{array}{l}\text { Diagnosis } \\
= \\
\text { Unclear }\end{array}$ & $\begin{array}{l}\text { Diagnosis } \\
\quad= \\
\text { COPD }\end{array}$ & $\begin{array}{l}\text { no Asthma } \\
\text { no COPD }\end{array}$ & TOTAL \\
\hline Obvious reasons, total & 119 & 18 & 13 & 2 & 152 \\
\hline $\begin{array}{c}\text { Previously shown reversible } \\
\text { bronchial obstruction }\end{array}$ & 39 & 6 & 5 & 1 & 51 \\
\hline $\begin{array}{l}\text { Peak flow registration test } \\
\text { shows Asthma }\end{array}$ & 10 & 4 & & & 14 \\
\hline $\begin{array}{l}\text { Steroid test } \\
\text { shows Asthma }\end{array}$ & 6 & & & & 6 \\
\hline $\begin{array}{l}\text { Diagnosis previously } \\
\text { assessed by paediatrician/ } \\
\text { pulmonologist }\end{array}$ & 56 & 5 & 8 & 1 & 70 \\
\hline Severe Asthma in childhood & 8 & 3 & & & 11 \\
\hline Unclear reasons, total & 13 & 91 & 10 & 16 & 130 \\
\hline $\begin{array}{l}\text { History of complaints from } \\
\text { allergy or hyperactivity/ smo- } \\
\text { king habits and dyspnoea, }\end{array}$ & 8 & 24 & 9 & 4 & 39 \\
\hline ICS prescribed by former GP & 3 & 27 & 1 & 3 & 34 \\
\hline Reason unclear to prescribing GP & 2 & 40 & & 9 & 51 \\
\hline Total & $\begin{array}{c}133 \\
(47 \%)\end{array}$ & $\begin{array}{c}108 \\
(38 \%)\end{array}$ & $\begin{array}{c}23 \\
(8 \%)\end{array}$ & $\begin{array}{c}18 \\
(7 \%)\end{array}$ & $\begin{array}{c}282 \\
(100 \%)\end{array}$ \\
\hline (advised to stop ICS) & 5 & 108 & 18 & 18 & 149 \\
\hline
\end{tabular}


Figure 1: Results of assessments to clarify the reasons for using ICS and to define the magnitude of overtreatment in all patients referred for spirometry to a diagnostic support service in a period of 6 months

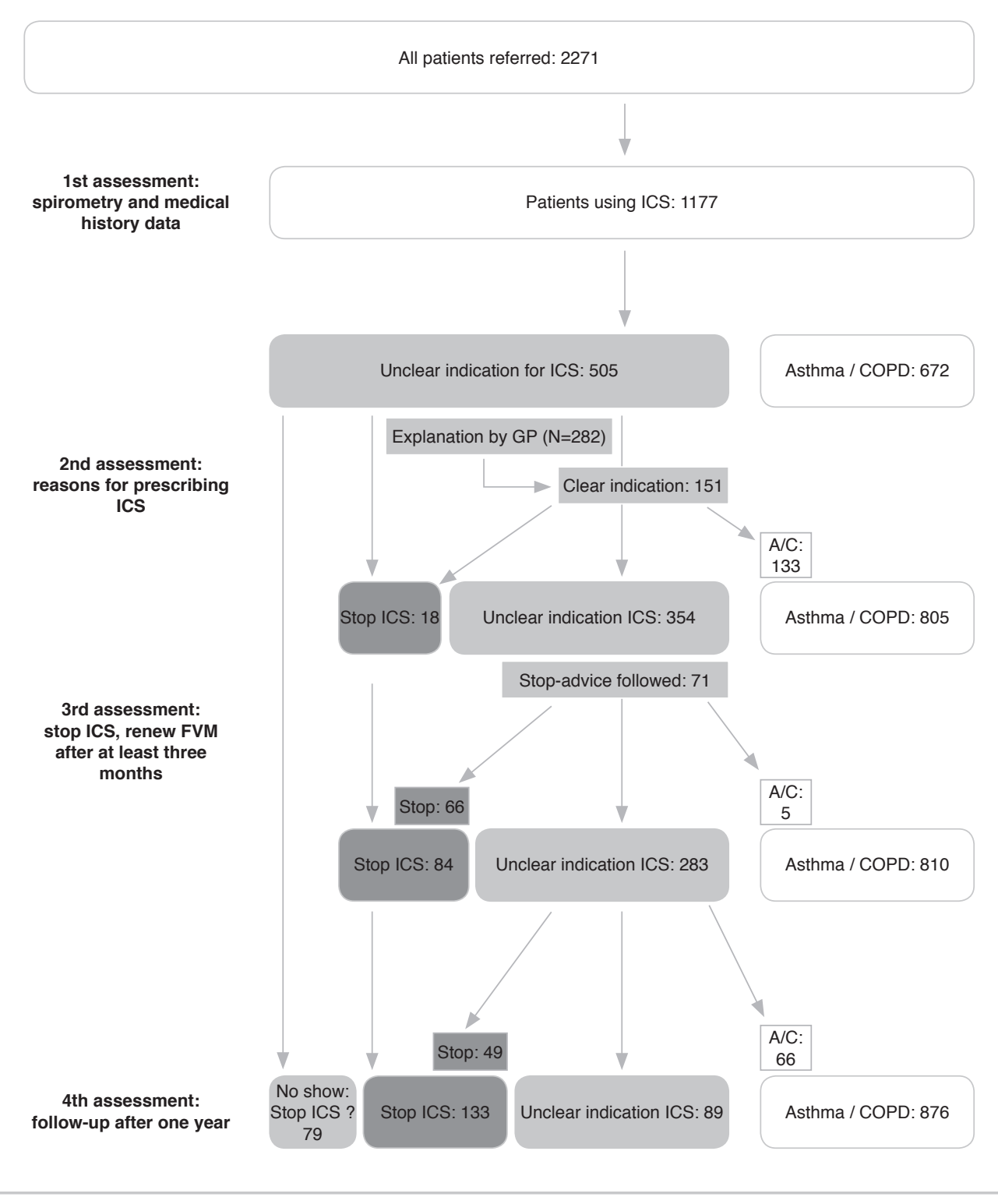

Use of ICS because of obvious reasons (diagnosis asthma (A) or moderate COPD(C)). Use fiCS for unclear reasons causing diagnostic problems (Overtreatment?). Use of ICS not necessary, could be stopped without regaining respiratory problems.

\section{Discussion}

Use of ICS in primary care patients with respiratory problems

The first finding of this study is that about $50 \%$ of all patients referred to the asthma/ COPD-service for diagnostic assessment used inhaled corticosteroids. For $43 \%$ of these patients the assessing pulmonologist did not understand the reason for this use, since all these patients had a normal or only mildly obstructed spirometry and none had complaints or a history suggesting asthma or exacerbations.

During the study the referral of all primary care patients with respiratory problems had become standard practice. However there remained a number of eligible patients who were not referred yet. The patients referred were distributed over all primary care practices and there were no reasons to assume priority selection in referrals. Therefore we believe that the research population represents the total population of primary care patients with respiratory problems fairly well.

Inappropriate use of ICS

Half of the GPs who responded to the questionnaire about the reason for the prescription of ICS could not provide valid arguments for this. When they followed the advice to have their patients stop the ICS and to repeat the diagnostic tests after a steroid-free period of three months, almost all of these patients could stop using ICS without regaining respiratory complaints. This was the first indication that ICS were not appropriate for all of the patients who used them.

One year after referral we studied all patients who originally used ICS for unclear reasons, to also learn about the patients whose GP did not answer the questionnaire or who did not repeat spirometry because of cessation of ICS use. We found that $11 \%$ of the patients who originally used ICS had successfully stopped the medication and could be discharged from follow-up.

For $15 \%$ of the patients the reason for the use of ICS at referral remained not clarified: $8 \%$ continued to use ICS for unclear reasons even after the GP had been questioned and advised to stop the prescription, and $7 \%$ of the patients that originally used ICS for unclear reasons did not come for follow-up. Since, according to the protocol of the asthma/COPD-service, these patients were called twice and because regular follow-up discipline is high, this could indicate that they were no longer considered to be patients and had stopped using medication.

The findings show that of all patients using ICS at the beginning of the study, at least $11 \%$, probably $19 \%$ and maybe up to $26 \%$ of the patients could stop using these drugs because there was no proper indication 
Reasons for prescribing ICS

It is clear that there is no good reason to continue a prescription without a diagnosis or clear indication; yet many GPs will admit that these things "just happen". Sending the questionnaire induced awareness in GPs. This was indeed necessary: patients that came for follow-up spirometry continued to use ICS without an obvious reason for many years. A yearly assessment reporting normal spirometry was not a sufficient reason for the GP to reconsider the use of ICS, even when a regular reminder was added to the report which read: "Is it really asthma? When there is any doubt, stop ICS and renew spirometry. In case asthma has been diagnosed, ICS can be continued".

The GPs could mark - and comment upon- six reasons for prescribing ICS. The assessing pulmonologists did not discuss the diagnoses formerly given by a lung specialist or a paediatrician (25\% of the patients). Also "Shown Reversibility" (in $16 \%$ ) was most often considered a valid reason for using ICS no matter whether spirometry was performed and/or interpreted by a respiratory specialist or by the GP. This might have biased the number of valid reasons, since interpretation of spirometry is found to be difficult by $\mathrm{GPs}^{[12]}$ and supervision of interpretation is advisable ${ }^{[13]}$ "Abnormal peak flow variability", even though this is less reliable in daily primary care practice ${ }^{[14]}$, was more often accepted as a diagnostic for asthma. A "positive response to a steroid reversibility test", being a diagnostic recommendation in the Dutch guidelines, was considered a valid reason for the use of ICS. We realise that if we had been able to validate the interpretations of these tests, the number of patients with a doubtful indication for ICS could have been even higher. This emphasizes the importance of quality assurance in primary care diagnostic assessment of asthma and/or COPD, which is not the same as following the guidelines, and which requires support and feedback ${ }^{[15]}$

\section{Diagnostic problems because of the use of ICS}

The magnitude of the diagnostic problem could be reduced from $43 \%$ at the start to $15 \%$ at follow-up. This required active participation of the asthma/COPD service in the diagnostic process. This does not mean that responsibility for diagnosis is taken over from the GP. The final responsibility belongs to the GP, who should always judge whether the assessed diagnosis and advices given fit in the clinical profile of the patient ${ }^{[16]}$. Our study shows that this is not a natural attitude. Some gentle force was needed to make GPs reconsider the use of ICS and to follow the diagnostic advice to stop the treatment. On the other hand, GPs did appreciate this type of support. After the study period we continued to send questionnaires, when indicated, and the response continued to increase. It will be interesting to examine if this way of providing feedback adds to the diagnostic knowledge and self-confidence of the GP.

Shortcomings of this study

A relatively high percentage of the GPs did not respond to the questionnaire. We do not know if this means that the GPs were triggered sufficiently to reconsider the use of ICS and the diagnoses of their patients or that they ignored the questionnaire. We tried to discover this by studying the patients at the yearly follow-up, but also at that time we could not be sure whether no responds means good effect or no effect.

We could not prevent the possible bias introduced by asking the GPs to justify their own prescription behaviour. Nor could pulmonologists exclude the "benefit of the doubt" when diagnosing asthma in patients using ICS who had a normal lung function and only minor complaints. For at least $30 \%$ of these patients it was possible to decrease their dose of ICS without problems, which could indicate either achieved asthma control[17] or - in some patients- misdiagnosed "asthma".

These facts suggest a higher number of patients using ICS unnecessarily and an underestimation of the problem we examined.

\section{Conclusion}

In primary care, inhaled corticosteroids are frequently prescribed in patients having respiratory complaints but who have not had a proper diagnosis or indication for this kind of therapy. More than $10 \%$ of our patients on ICS used these drugs unnecessarily, leading to unnecessary costs. More important is the consequence that many healthy people risk by being labelled as asthmatic. This diagnosis is hard to turn back since the same ICS lead to misdiagnoses when spirometry shows a normal flow curve that fits to asthma in a stable condition.

Our study emphasises the importance of adding medical history data to spirometry in the assessment of asthma and COPD. Diagnostic support, as given by an asthma/COPD-service, can be further improved by an appropriate feedback system that should make GPs more aware of the importance of clear diagnosis before prescribing ICS. 


\section{Literature}

1. V Schayck CP, v d Heijden FMMA, vd Boom G, Tirimanna PRS, v Herwaarden CLA. Underdiagnosis of asthma: is the doctor or the patient to blame? The DIMCA project. Thorax 2000. 55:562-565

2. V Schayck $\mathrm{CP}$, Chavannes NH. Detection of asthma and chronic obstructive pulmonary disease in primary care. Eur Respir J 2003. 21(39_suppl):16S-22

3. Vander Molen T, Østrem A Stallberg B, Ostergaard MS, Singh RB. International Primary Care Respiratory

4. Bolton CE lonescu AA, Edwards PH, Faulkner, TA, Edwards SM, Shale DJ Attaining a correct diagnosis of COPD in general practice. Respir Med. 2005. 99(4):493-500

5. Walker PP, Mitchell P, Diamantea F, Warburton CJ, Davies L. Effect of primary-care spirometry on the diagnosis and management of COPD. Eur Respir J 2006. 28(5): 945-952

6. Vaughn R, MacIntyre D. An outreach Spirometry service for Greater Glasgow health board: does it help in diagnosis. Eur Respir J 2004. 24(suppl. 48), 182s

7. Wolfenden H, Baily L, Murphy K, Partridge MR. Use of an open access spirometry service by general practitioners. Prim Care Respir J 2006. 15(4): 252-255

8. Frank TL, Hazel ML, Lineham MF, Frank PI. The diagnostic accuracies of chronic obstructive pulmonary disease (COPD) in general practice: the results of the MAGIC (Manchester Airways Group Identifying COPD) study. Prim Care Respir J 2006. 15 (5): 286-93.

9. Lucas AEM, Smeenk FJWM, Smeele IJ, Brouwer T, van Schayck CP. Validity of diagnostic support of an asthma/COPD-service in primary care. Br J Gen Pract 2007. 57(544): 892-896

10. Geijer RMM, Thiadens HA, Smeele IJM, et al. Standard of the Dutch College of General practitioners on Astma and COPD: treatment (in Dutch). Huisarts Wet 2001;44(5):207-19.

11. Geijer RMM, Thiadens HA, Smeele IJM, et al. Standard of the Dutch College of General practitioners on Astma and COPD: diagnostics (in Dutch). Huisarts Wet 2001;44(3):107-17.

12. Kaminsky DA, Marcy TW, Bachand M, Irvin CG. Knowledge and use of office spirometry for the detection of chronic obstructive pulmonary disease by primary care physicians. Respir Care 2005. (12): $1639-48$

13. White P, Wong W, Flemming T, Gray B. Primary Care Spirometry. Test quality and the use of specialists reporting. Br J Gen Pract 2007. 57(542): 701-5.

14. Thiadens HA, De Bock GH, Van Houwelingen JC, Dekker FW, De Waal MWM, Springer MP et al. Can peak expiratory flow measurements reliably identify the presence of airway obstruction and bronchodilator response as assessed by FEV1 in primary care patients presenting with a persistent cough? Thorax 1999. 54(12): 1055-1060

15. Hassett R, Meade K, Partridge MR. Enhancing the accuracy of respiratory diagnoses in primary care: a report on the establishment of a Community Respiratory Assessment Unit. Prim Care Respir J 2006. 15(6): 354-61.

6. Miller MR, Crapo R, Hankinson J, Brusasco V, Burgos F, Casaburi R, et al. General considerations for lung function testing. Eur Respir J 2005. 26(1): 153-161

17. Hawkins G, McMahon AD, Twaddle S, Wood SF, Ford I, Thomson NC. Stepping down inhaled corticosteroids in asthma: randomized controlled trial. BMJ 2003. 326(7399):11-15 
Lucas Annelies E, Smeenk Frank J, Smeele Ivo J, van Schayck Onno P. Diagnostic accuracy of primary care asthma/COPD working hypotheses, a real life study. Respiratory Medicine 2012. 106(8): p. 1158-1163.

\section{Abstract}

Misdiagnoses are inevitable when working hypotheses of asthma and COPD of General Practitioners (GPs) are not checked by spirometry. To reduce misdiagnoses, Asthma/COPD-support services (AC-services) offer validated diagnostic support by performing spirometry assessed together with written medical history data by consulting pulmonologists.

Research questions

Which criteria do GPs use to justify their asthma/COPD working hypotheses? How do diagnostic assessments by an AC-service change GPs' working hypotheses? Do GPs' justifications for their working hypotheses influence the extent to which working hypotheses correspond with diagnoses given by an AC-service?

\section{Method}

We investigated the working hypotheses of 17 GPs for 284 patients with respiratory problems and their justifications: "clinical symptoms", "office spirometry", or "specialist's correspondence". The working hypotheses were compared with the diagnoses given by an AC-service, and the influence of the different justifications categories on diagnostic accuracy of the working hypotheses was described.

\section{Results}

$49 \%$ of the working hypothesis were only based on clinical information, $21 \%$ were also based on office spirometry. For $30 \%$ additional specialist information was available. $50 \%$ of the working hypotheses were confirmed by the AC-service. The working hypothesis asthma was confirmed more frequently (62\%) than the working hypothesis COPD (40\%). The justifications for the working hypotheses given by GPs did not influence these results.

\section{Conclusion}

Diagnostic assessments of the AC-service differed significantly from the working hypotheses of GPs, even when these were based on previous specialists' correspondence or on office spirometry. To optimize the diagnoses in primary care, diagnostic support of an AC-service is recommended for all primary care patients with respiratory problems. 


\section{Introduction}

Decision making in asthma/COPD-care should start with at least a provisional diagnosis, a "working hypothesis", most often assessed in primary care from the patients' complaints and symptoms at consultation. Sometimes a working hypothesis can be supported by information from previous specialists' correspondence. Many studies have shown that spirometry is required to gain more diagnostic certainty in asthma/COPD ${ }^{[1-4]}$. The implementation of office spirometry in primary care is growing, although internationally barriers still exist in organizing and performing spirometry, ${ }^{15}$, ${ }^{6]}$ to the implementation and maintenance of quality ${ }^{[7,8]}$ and to accurate interpretation of the results ${ }^{[9]}$.

To overcome either organizational and / or quality problems, GPs can refer their patients with respiratory problems to an Asthma/COPD-service (AC-service) to have their working hypothesis confirmed or adjusted by expert assessment. In the Netherlands, there are 10 such services, organized as private institutions or connected to a hospital. At these AC-services, consulting pulmonologists perform diagnostic assessments of spirometry and written medical history data according to a standardized protocol. GPs receive a report of the diagnosis, recommendations for further diagnostic examinations (if indicated) and medical treatment and lifestyle $\left.{ }^{[10}\right]$. The validity and reliability of this diagnostic procedure (protocolized written assessments by different pulmonologists) has been tested and confirmed by previous research ${ }^{[11,12]}$. Therefore in real life the assessments of the AC-service are used as a gold standard in primary care diagnostic procedures.

In this study we examined to what extent there was concordance between the diagnoses assessed by an AC-service and the working hypotheses of GPs. Furthermore we examined whether the justification for the working hypothesis, such as clinical symptoms, spirometry performed in the GP's office (office spirometry) or information previously provided by correspondence of a lung specialist or pediatrician (specialist information) might be of influence on the level of concordance. Our research questions were:

1. Which criteria are being used by GPs to justify their working hypotheses?

2. How often are working hypotheses of GPs confirmed by validated diagnostic assessments of consulting lung specialists at an AC-service using spirometry and written medical history?

3. Does the justification given by the GP for the working hypothesis influence the extent to which the working hypothesis corresponds with the assessment of the AC service? 


\section{Method}

Setting

The study was performed as part of an evaluation program that examined the support of an AC-service given to GPs in and around Eindhoven, the Netherlands, in their care for asthma and COPD-patients (trial ID NTR324). The AC-service in this study is part of a primary care diagnostic centre that offers laboratory facilities, X-ray/ echo, and function tests. The AC-service supports about $300 \mathrm{GPs}$ and performs up to 10.000 lung function tests a year.

\section{Population}

From 1-1-2006 until 1-7-2008 GPs were asked to participate in the evaluation program. Eligible were GPs who had no former experience in working with the AC-service, who had no Practice Nurses participating in asthma/COPD care processes and who were willing to (re-) organize their care for asthma and COPD patients starting with more accurately diagnosing eligible patients with the help of the AC-service.

Eligible patients were selected from the medical records by searching for ICPCcodes R95 (COPD), R96 (asthma), R91 (bronchitis) ${ }^{[13]}$ and for ATC-code R03 (inhaled medication $)^{[14]}$ registered during the last 2 years. As part of standard procedure the AC-service supported this search, where after the GPs screened the listed patients for mis-registrations and, when indicated, added patients. This resulted in lists of patients with a reasonable suspicion of asthma/COPD. GPs invited these patients to have spirometry tests at the AC-service as part of the regular care program. Informed consent was obtained for taking part in the evaluation study.

\section{Regular procedures of the $A C$-service}

Spirometry including reversibility testing is performed during a standard visit to the AC-service, according to ATS/ERS standard procedures. Patients also fill in a structured questionnaire about their medical family history, their complaints (cough/dyspnoea mucus, nightly awakenings), atopy, allergies, smoking habits, MRC-dyspnoea score, exacerbations, use of medication, compliance and co-morbidity. Length and weight are measured. Data are assessed by consulting respiratory specialists according to a standardized protocol[11]. Medical and organizational protocols are based on the guidelines of the Dutch General Practitioners for asthma and COPD ${ }^{[15]}$.

At first visits the emphasis is on establishing a (working) diagnosis and, when appropriate, on diagnostic and/or therapeutic recommendations. The diagnosis - and possibly its adjustment - is still important at follow-up but the focus shifts to therapeutic advice.
Working hypotheses and diagnoses

GPs were asked to formulate their working hypotheses, prior to the patients' visit to the AC-service and to explain which arguments contributed to these hypotheses: clinical assessment, office spirometry performed, or information from lung specialist's correspondence.

Diagnoses reported by the $\mathrm{AC}$-service were classified as:

1. No Asthma or COPD: lung function is (near) normal.

2. Asthma

3. Asthma and COPD

4. COPD

5. Diagnosis is uncertain because of ICS use in very mild COPD or ICS without prior proven reversible airway obstruction ${ }^{[16]}$

We examined the concordance between the working hypotheses and the diagnoses assessed by the AC-service, which we considered "gold standard" because of their shown validity ${ }^{[11,12]}$. As a second step we examined how the justification for the working hypotheses influenced the extent to which these working hypotheses correspond with the diagnoses given by the AC service.

\section{Results}

Seventeen GPs with a total population of 39.640 patients participated in the study. Eight of them worked in single practices, 3 were duo-practices, and 3 GP's worked in a healthcare center. Of 904 patients selected for spirometry, $461(51 \%)$ agreed to take part in the study. Average age was 51 years (12-88), 55\% was female. Working hypotheses were available for 312 patients (67\%). Of those, 28 patients did not show up for spirometry, leaving 284 patients for the study (figure 1). 
Figure 1: Diagram showing inclusion of patients and data collection

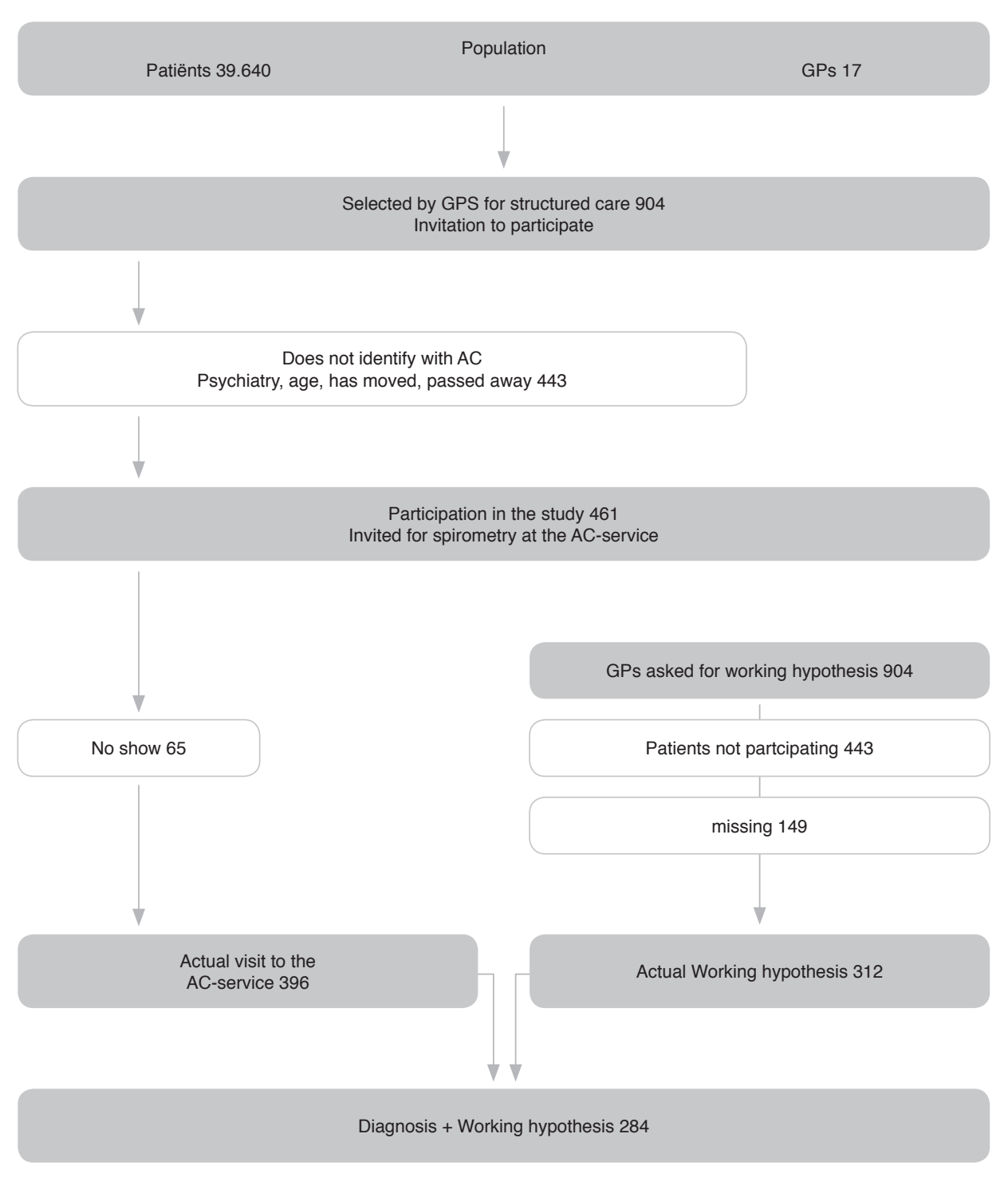

Criteria for setting the working hypotheses

$65 \%$ of the patients received a clear working hypothesis (No asthma or COPD/asthma/ COPD/asthma+COPD) (table1). For 140 patients (49\%) the GPs' working hypothesis was based on clinical assessment (medical history and physical examination). For a minority of these patients $(n=52)$ this resulted in a clear working hypothesis of asthma, COPD or both asthma and COPD. For 58 patients (20\%) office spirometry was performed which resulted in $39(68 \%)$ clear working hypotheses. $31 \%(n=86)$ of all working hypotheses were adopted from the correspondence of lung specialists, most of those $(74=86 \%)$ were clear to the GP.

Table 1: Arguments on which GPs establish their working hypothesis for patients with respiratory complaints eligible for AC-diagnostic procedure

\begin{tabular}{|c|c|c|c|c|c|c|}
\hline \multirow[b]{2}{*}{$\begin{array}{l}\text { Arguments for establishing a } \\
\text { working hypothesis }\end{array}$} & \multicolumn{6}{|c|}{ Working hypothesis } \\
\hline & $\begin{array}{l}\text { "I am } \\
\text { in doubt" }\end{array}$ & $\begin{array}{l}\text { "I expect } \\
\text { no asthma } \\
\text { or COPD" }\end{array}$ & Asthma & $\begin{array}{l}\text { Asthma + } \\
\text { COPD }\end{array}$ & COPD & Total \\
\hline Clinical assessment & 72 & 16 & 36 & 4 & 12 & 140 \\
\hline Office spirometry & 18 & 1 & 17 & 4 & 18 & 58 \\
\hline Correspondence of a lung specialist & 12 & 0 & 34 & 13 & 27 & 86 \\
\hline Total & 102 & 17 & 87 & 21 & 57 & 284 \\
\hline
\end{tabular}

Diagnostic accuracy of GPs' working hypotheses

For $34 \%(n=102)$ of all patients referred to the AC-service, the GPs were uncertain about the working hypothesis even when office spirometry was performed $(n=18)$ or when there was correspondence of a lung specialist $(n=12)$ (Table 1). For $95 \%$ of those patients, the AC-service provided a diagnosis (figure 2$): 42 \%$ ( $n=40)$ was diagnosed as asthma, 14\% ( $n=13)$ COPD, 10\% ( $n=9)$ asthma and COPD, 34\% $(n=34)$ neither asthma nor COPD (table 2).

Seventeen patients (6\%) had the working hypothesis "no asthma/COPD", 2 of them were diagnosed "asthma" and 2 as "COPD". 
Table 2: Working hypothesis of the GP and the diagnosis assessed by patients' first visit to the AC-service

\begin{tabular}{lccccccc}
\hline \multicolumn{7}{c}{} & \multicolumn{7}{c}{$\begin{array}{c}\text { Diagnosis assessed by AC-service } \\
\text { Working hypothesis }\end{array}$} & ICS? & $\begin{array}{c}\text { No Asthma } \\
\text { or COPD }\end{array}$ & Asthma & $\begin{array}{c}\text { Asthma + } \\
\text { COPD }\end{array}$ & COPD & $?$ & Total \\
\hline "I am in doubt" & 2 & 34 & 40 & 9 & 13 & 4 & 102 \\
"I expect no AC" & 0 & 13 & 2 & 0 & 2 & 0 & 17 \\
Asthma & 2 & 18 & 54 & 9 & 2 & 2 & 87 \\
Asthma+COPD & 0 & 4 & 12 & 2 & 2 & 1 & 21 \\
COPD & 1 & 9 & 17 & 3 & 23 & 4 & 57 \\
Total & 5 & 78 & 125 & 23 & 42 & 11 & 284 \\
\hline
\end{tabular}

The GPs set a clear working hypothesis (asthma, COPD and asthma+COPD) for 165 patients (table 2). $21 \%$ of them $(n=57)$ were supposed to have COPD and another $8 \%(n=21)$ both COPD and asthma. Of $31 \%$ of the patients $(n=87)$ the GP was sure of the diagnosis asthma. Figure 2 shows that these working hypotheses did correspond with the diagnoses of the AC-service in 40\% ("COPD"), $10 \%$ ("asthma and COPD"), and $73 \%$ ("asthma") of cases. The overall concordance between clear working hypotheses and diagnoses assessed by the AC-service was $48 \%(79 / 165)$.

\section{Diagnostic accuracy influenced by justification of the working hypotheses}

Figure 3 shows how the justifications for the working hypotheses were related to the outcome of the assessments of the AC-service. Information from correspondence of lung specialists gave 86 working hypotheses of which $35(41 \%)$ were confirmed. Office spirometry gave 60 working hypotheses of which 20 (33\%) were confirmed. Clinical assessment gave 138 working hypotheses of which $37(27 \%)$ were confirmed.
Figure 2: Working hypotheses of the GP and diagnoses assessed by the AC-service: how often do they correspond

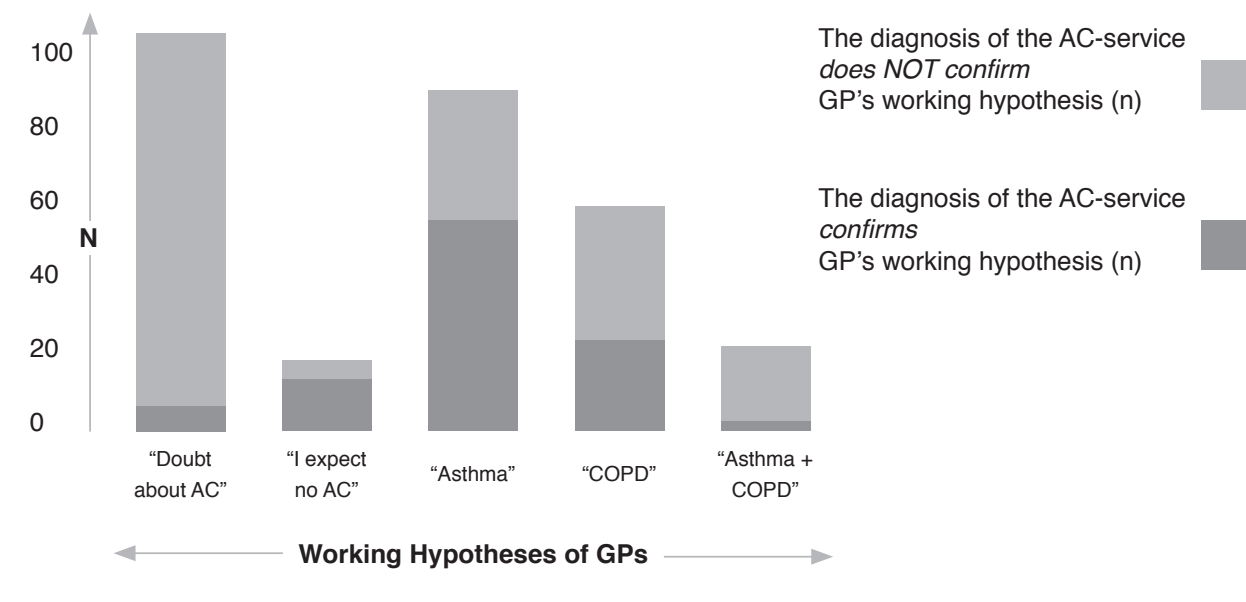

Figure 3: Change of working hypotheses into diagnoses assessed by the AC-service: outcome related to the criteria for establishing a working diagnosis (correspondence of a lung specialist, related to the criteria for establishing
office spirometry, clinical assessment

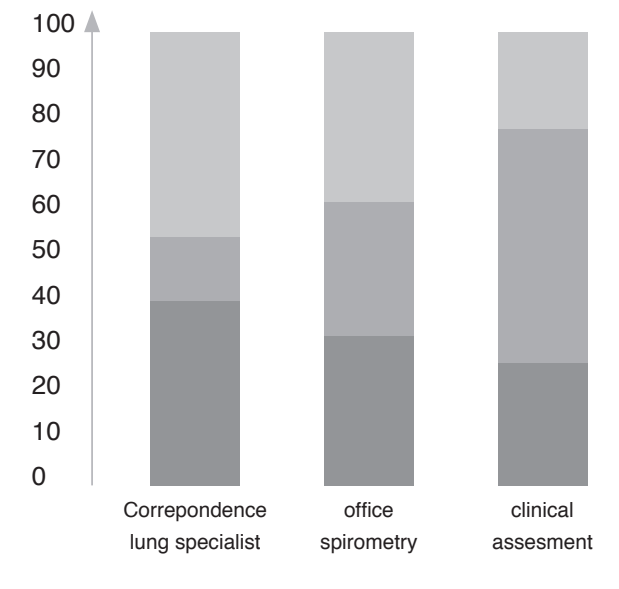

The diagnosis of the AC-service does NOT confirm GP's working hypothesis (\%)

The AC-service gives a new diagn working hypothesis) (\%

The diagnosis of the AC-service confirms
GP's working hypothesis (\%) 


\section{Discussion}

Our study shows that the working hypotheses of the participating GPs offered limited certainty about an accurate diagnosis of respiratory problems. Approximately half the working hypotheses were confirmed by diagnostic assessment by an asthma/COPD service. Neither office spirometry nor interpretation of historical information from lung specialists' letters improved this outcome, although in total they contributed to a higher number of described working hypotheses (68\% in case of office spirometry, $89 \%$ in case of specialists' correspondence) than clinical arguments alone (50\%).

Of course patient outcome is not only dependent from the accuracy of the diagnosis but is influenced by many factors like GP's performance, patient adherence to advice and treatment, the disease itself and the circumstances of all these factors. However, a correct diagnosis attributes to correct care from which patients should benefit, at least those who might have received an asthma/COPD diagnosis incorrectly

Our findings reflect the difficulty of making a diagnosis in asthma and COPD in daily clinical practice, going from symptoms (allergy) lifestyle habits (smoking) or from complaints that are not sufficiently specific, or going from spirometry results that are often hard to interpret, if at all obtained correctly ${ }^{[5,6,9]}$. Misdiagnoses (under-diagnoses, but also over-diagnoses) occur, as is reflected in the working hypotheses in this study.

Few studies compare expert spirometry with office spirometry by GPs without training the GPs or without protocolizing the performance or interpretation of spirometry. In an experimental setting but without training, GPs and specialists disagreed in $38 \%$ of spirometry interpretations of patients diagnosed with asthma or COPD, and only fully agreed in $20 \%{ }^{[9]}$. Our research question was not to compare the expertise of GPs and pulmonologists, but to find out whether patients with a working hypothesis asthma/ COPD given after (unprotocolized/untrained) spirometry could enroll in disease management programs without further diagnostic assessment. In our study, working hypotheses were registered for care purposes and not for research purposes which influences their accuracy ${ }^{[17]}$. Inconsistent registrations reflect "carelessness" as well as daily practice diagnostic uncertainty ${ }^{[18]}$ and misdiagnoses ${ }^{[19]}$ all contributing to the low concordance of working hypotheses with expert diagnoses. This is a problem not uncommon in primary care: our results are in line with a Swedish study showing that only $30 \%$ of clinical diagnoses of COPD were confirmed by spirometry ${ }^{[4]}$.

The low impact of office spirometry for accuracy of working hypotheses stresses the importance of quality equipment, performance skills and knowledge of and experience in interpretation of lung function measurements. It was shown that GPs, when minimally trained, can distinguish normal from abnormal lung functions ${ }^{[20]}$. Through thorough training GPs can - in experimental settings - assess lung function as accurate as lung specialists ${ }^{[2]}$ or an expert system ${ }^{[22]}$. In every day practice however, there is a need for ongoing diagnostic support ${ }^{[23]}$ as well as for the assistance of trained practice nurses ${ }^{[24]}$.

Pulmonologists correspondence generally concerns long time care and/or extended diagnostic assessments. Therefore it was surprising that the information in the correspondence from the pulmonologist or pediatrician did not improve the predictive value of the working hypothesis for the diagnosis of the AC-service. An important reason for this is that the Information from older letters might not be appropriate anymore because of changed disease definition (in the past asthma and COPD were often combined in the Netherlands in the diagnosis "chronic nonspecific lung disease", CNSLD ${ }^{[25]}$ ), changed and classification (using a fixed FEV1/FVC ratio or low limit of normal FEV1/FVC to define airway obstruction ${ }^{[26]}$ ), changed interpretation of presented complaints and the evolution of the patient's disease. The indefinite character of respiratory diagnoses was shown in a follow up study of the DIMCA program ${ }^{[2]}$ that showed that 10 years after extended diagnostic screening in research setting, $50 \%$ of the diagnoses were neither definite nor stable in time but were renewed after reassessment by lung specialists ${ }^{[28]}$. GPs should be aware of this phenomenon and realize that information from old correspondence can be outdated and might not be reliable anymore.

In addition, professionals should communicate as clearly as possible, leaving no room for interpretation and prevent definitions like "unstable COPD, characterized by chronic asthmatic bronchitis" (referral letter from pulmonologist, 2007).

Limitations of the study

Working hypotheses for 149 patients were missing. We choose not to specifically remind the GPs in order not to bias this study and our other studies focusing on un-intervened regular care. Therefore we examined the 284 records available. We assume that working hypotheses most often were missing because of diagnostic doubts. That means that the percentage of uncertain working hypotheses could be twice as high (up to $56 \%$ instead of $35 \%$ ). Since this category was excluded for the examination of diagnostic certainty of the working hypothesis, this part of our results is not influenced. Furthermore, patients without a working hypothesis resembled the study population in diagnoses assessed by the AC-service suggesting no selective recruitment bias. 
The limited diagnostic certainty of working hypotheses based on specialists' correspondence was unexpected and we did not collect date data about the correspondence. Further research should clarify whether specialists' correspondence in more recent years offers the expected certainty for the GP's working hypothesis.

We cannot conclude that the AC-services diagnosis is incontestable since for assessments of asthma and COPD a single gold standard test is missing. In research situations optimal accuracy can be obtained by performing additional tests such as whole body pletysmography and histamine provocation tests, and HRCT thorax ${ }^{[7,28]}$. For daily care the assessments of the AC-service are as good as life consultation of a patient by a pulmonologist (Cohen's $k=0,82)^{[11]}$ and its assessments have a fairly good inter-observer reliability $(k=0,67)^{[12]}$. Furthermore, the AC-service warrants quality diagnostics by peer review of assessments in the team of consulting lung specialists. Therefore we consider an AC-service to be "best practice" for reviewing working hypotheses but we recommend follow-ups for more diagnostic certainty.

\section{Conclusion}

Working hypotheses of General Practitioners offer limited certainty about the correct diagnosis of respiratory problems, independent from the justifications that they are based on. Clinical symptoms often leave uncertainty about the accuracy of the working hypotheses. In addition, working hypotheses based on (outdated) specialis correspondence might not be reliable anymore and should be updated regularly by spirometry and medical history taking. Expert diagnostic support of an Asthma/ COPD service is recommended to optimize the diagnoses in primary care for all primary care patients. 


\section{Literature}

1. Levy ML, Quanjer Ph, Booker H, Cooper R, Holmes BG, Small S. Diagnostic Spirometry in Primary Care: Proposed standards for general practice compliant with American Thoracic Society and European Respiratory Society recommendations. Prim Care Resp J 2009. 18(3): 130-147.

2. Yawn BP. Optimizing Chronic Obstructive Pulmonary Disease Management in Primary Care. Southern Medical Journal, 2011. 104(2):121-127

3. Walker PP, Mitchell P, Diamantea F, Warburton CJ, Davies L. Effect of primary-care spirometry on the diagnosis and management of COPD. Eur Respir J 2006. 28(5): 945-952.

4. Arne M, Lisspers K, Ställberg B, Boman G, Hedenström H, Janson C, Emtner M. How often is diagnosis of COPD confirmed with spirometry? Respir Med 2010.104(4):550-556.

5. Bolton C E, lonescu AA, Edwards PH, Faulkner TA, Edwards SM, Shale DJ Attaining a correct diagnosis of COPD in general practice. Respir Med 2005. 99(4): 493-500.

6. Buffels J, Degryse J, Liistro G. Diagnostic certainty, co-morbidity and medication in a primary care population with presumed airway obstruction: the DIDASCO2 study. Prim Care Resp J 2009. 18(1): 34-40.

7. White P, Wong W, Fleming T, Gray B.Primary care spirometry: test quality and the feasibility and usefulness of specialist reporting. Br J Gen Pract 2007. 57: 701-705.

8. Schermer T, Crockett A, Poels P, van Dijke J, Akkermans R, Vlek H, Pieters W, Quality of routine spirometry tests in Dutch general practices. Br J Gen Prac 2009. 59: e376-e382.

9. Raghunath AS, Innes A, Norfolk L, Hannant M, Greene T, Greenstone M, Morice AH. Difficulties in the interpretation of lung function tests in the diagnosis of asthma and chronic obstructive pulmonary disease. J Asthma.2006. 43(9): 657-60.

10. Smeele I, Hennekam M. Papieren Consultatie (article in Dutch). Med Contact 2002 (57): 43.

11. Lucas A, Smeek F, Smeele I, Brouwer T, van Schayck O. The validity of diagnostic support of an asthma/COPD service in primary care. Br.J Gen Pract 2007. 57(544): 892-6.

12. Lucas AEM, Smeenk FJWM. van den Borne BEEM, Smeele IJM, van Schayck CO, Diagnostic assessments of spirometry and medical history data by respiratory specialists supporting primary care: are they reliable? Prim Care Resp J 2009. 18(3): 177-184.

13. International Classification of Primary Care: short titles and Dutch subtitles. Utrecht; Nederlands Huisartsen Genootschap; 1995.

14. WHO. The Anatomical Therapeutical Chemical Classification System with Daily Doses (ATC-DDD).http://www.who.int/classifications/atcddd/en/ 2007.

15. Geijer RMM, Thiadens HA, Smeele IJM. Standard of the Dutch College of General practitioners on asthma and COPD: diagnostics (in Dutch). Huisarts en Wet, 2001. 44(3): 107-117.

16. Lucas AE, Smeenk FJWM., Smeele IJM, van Schayck CP. Overtreatment with inhaled corticosteroids and diagnostic problems in primary care patients, an exploratory study. Fam Pract 2008. 25(2): 86-91.

17. Khan NF, Harrison SE, Rose PW. Validity of diagnostic coding within the General Practice Research Database: a systematic review. Br J Gen Pract 2010. 60: e128-e136.

18. Jones RC, Dickson-Spillmann M, Mather MJ, Marks D, Shackell BS. Accuracy of diagnostic registers and management of chronic obstructive pulmonary disease: the Devon primary care audit. Respir Res, 2008. 18: 9-16.

19. Tinkelman DG, Price DB, Nordyke RJ, Halbert R. Misdiagnosis of COPD and asthma in primary care patients 40 years of age and over. J Asthma 2006. 43(1): 75-80.

20. Chavannes N, Schermer T, Akkermans R, Jacobs JE, van der Graaf G, Bollen R, van Schayck O, Bottema B. Impact of spirometry on GPs' diagnostic differentiation and decision-making. Respir Med 2004. 98(11): 1124-30. 
21. Yawn BP, Enright PL, Lemanske RF, Israel E, Pace W, Wollan P, Boushey H, Spirometry Can Be Done in Family Physicians' offices and Alters Clinical Decisions in Management of Asthma and COPD. Chest 2007. 132(4): 1162-1168.

22. Poels P. Schermer TRJ, Schellekens DPA, Akkermans RP, de Vries Robbe PF, Kaplan A Bottema BJAM, van Weel C. Impact of a spirometry expert system on general practitioners' decision making. Eur Respir J 2008. 31(1): 84-92.

23. Poels P.Schermer RJ, Akkermans RP, Jacobs A, van den Bogart-Jansen M. Bottema BJAM, van Weel C. General practitioners' needs for ongoing support for the interpretation of spirometry tests. Eur J Gen Pract 2007. 13(1): 16-19.

24. Walters JA, Hansen EC, Johns DP, Blizzard EL, Walters EH, Wood-Baker R. A mixed methods study to compare models of spirometry delivery in primary care for patients at risk of $\mathrm{COPD}$. Thor 2008 . 63(5): $P$. $408-414$. .

A "splitting" look at chronic nonspecific lung disease (CNSLD): common features but diverse pathogenesis. Eur Respir J 1991. 4(4): 490-496.

26. Schermer TRJ, Smeele IJM, Thoonen BPA, Lucas AEM, Grootens JG, van Boxem TJ, Heijdra YF, van Weel C. Current clinical guideline definitions of airflow obstruction and COPD overdiagnosis in primary care. Eur Respir J 2008. 32(4): 945-952.

27. van den Boom G, van Schayck CP, van Möllen MP, Tirimanna PR, den Otter JJ, van Grunsven $\mathrm{PM}$, et al. Active Detection of Chronic Obstructive Pulmonary Disease and Asthma in the General Population. Results and Economic Consequ Respir. Cric Care Med., 1998. 158(6): 1730-1738.

28. Albers, M.,SchermerT, Molema J,Kloek C,Akkermans R,Heijdra Y, van Weel, C. Do family physicians' records fit guideline diagnosed COPD? Fam Pract 2009. 26(2): 81-87. 


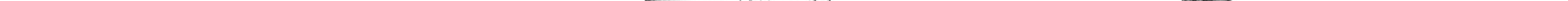


Lucas AEM, Smeenk FWJM, Smeele IJM, van Schayck CP. Diagnostic advice by Astma/COPD-services and its usefulness to reduce diagnostic uncertainty for respiratory problems in primary care. Submitted

\section{Abstract}

Asthma/COPD-services (AC-services) support primary care diagnostic process. If consulting pulmonologists cannot ascertain a diagnosis they recommend additiona diagnostic examinations to confirm/exclude asthma or COPD, or to find alternative/ additional diagnoses.

\section{Aim}

Aim of the study is the evaluation of the feasibility and usefulness of diagnostic advice of an AC-service in primary care daily practice.

\section{Method}

Of 383 patients referred to an AC-service by $17 \mathrm{GPs}$ we compared the assessed diagnoses at first visit and at follow-up. Adjustments at follow-up were examined of patients with and without diagnostic advice at first visit. GPs' adherence to advice was examined by observing GP practice and the need for diagnostic advice at follow-up.

\section{Results}

$59 \%$ of the diagnoses given at first visit to the AC-service were confirmed at followup. $62 \%$ of the patients received advice for additional diagnostic examinations at firs visit. For those, diagnoses changed at follow-up in 51\%. Diagnoses changed significantly less frequent for patients without diagnostic advice ( 51 vs. $31 \%$; $p=0,007$ ).

Diagnostic recommendations were badly followed by GPs (e.g. histamine provocation tests, stop ICS when these cause diagnostic problems). Adjustments of diagnoses were mostly due to accurate assessments by the pulmonologists at follow-up. Most recommendations were restated at follow-up.

\section{Conclusion}

Diagnostic advice of an AC-service is useful for GPs as a warning of diagnostic uncertainty. However, GPs' adherence to the advice was low. Mutual feedback between GPs and pulmonologists is recommended to improve the diagnostic process by GPs as well as to evaluate the added value in daily practice and the feasibility of diagnostic advice. 


\section{Introduction}

Many studies have shown the complexity of the diagnostic process in patients with respiratory problems ${ }^{[1-3]}$. Patients' presentation of complaints can be unspecific or complaints are not recognized as asthma or COPD ${ }^{[4,5]}$, clinical diagnoses are not always confirmed by spirometry and if so, performance and interpretation of spirometry are not always adequate ${ }^{[6]}$. Misdiagnoses in medical records become apparent when patients are re-assessed by protocolized assessment and spirometry performed by trained GPs or respiratory specialist ${ }^{[7]}$. However, even trained specialists show diagnostic doubts and can disagree about the nature of the respiratory problem ${ }^{[8]}$. Especially in primary care this is an understandable phenomenon since most patients have mild problems and diagnostic findings might differ only minimally from normal. In addition, criteria to define asthma or COPD, like (ir)reversible obstruction, are not unconditional disease characteristics ${ }^{[0]}$. Furthermore symptoms frequently seen in asthma and COPD, like shortness of breath, cough, and phlegm production, are relatively unspecific and are seen in virtually all other respiratory diseases.

To come as close as possible to a correct diagnosis, patients' complaints should be assessed taking into account the medical history and lifestyle as well as the results of optimally performed and interpreted spirometry. Nevertheless this can still lead to a suggested diagnosis which may not always be correct. For example: an initially fixed bronchial obstruction (suggesting COPD) may, in time, prove to be fully reversible (suggesting asthma) after treatment. Therefore, follow-up should not only address treatment and condition, but should also reconsider the initial diagnosis. Whether untrained or trained, GPs experience ongoing need for support in managing asthma/ COPD diagnostic assessments ${ }^{[10,11]}$. As in other countries, primary care based Asthma/COPD-services (AC-services) in the Netherlands offer such support ${ }^{[12,13]}$. These services perform spirometry and take a structured medical history of patients referred for protocolized assessment by consulting lung specialists. GPs receive reports on all spirometry and history measurements, a possible diagnosis, and recommendations for treatment and lifestyle. In case of significant diagnostic doubts, advice for additional diagnostic examinations is included. This advice is applicable in almost $50 \%$ of all referred patients ${ }^{[7,14,15]}$. Most of the additional diagnostic examinations can be conducted by GPs themselves to find diseases other than pulmonary problems that might cause symptoms of cough and dyspnoea (hay fever, gastric reflux, cardiac problems, etc). 
In this study we explored the usefulness and added value of additional diagnostic advice by examining:

- adjustments at follow-up of diagnoses given by an asthma/COPD service at first visit

- the relationship between advice for additional diagnostic examinations given at first visit and these adjustments

- the remaining diagnostic uncertainty at follow-up as measured by the need for diagnostic advice

- the adherence of GPs to diagnostic advice of an asthma/COPD-service in real life.

\section{Method}

\section{Setting}

This research was part of a study to evaluate the effectiveness of the support of an AC-service in Eindhoven, the Netherlands, in improving the quality of care by GPs for their patients with respiratory problems. In 2006-2008, 17 primary care practices without experience in spirometry selected respiratory patients with a clinical diagnosis (ICPC-code R95, R96, ${ }^{[16]}$ ) or prescribed medication (ATC-code R03 $\left.{ }^{[17]}\right)^{[18]}$. Patients were referred to the AC-service for diagnostic assessment and - when a diagnosis of Asthma or COPD was assessed - for follow up each year. For $330 \mathrm{GPs}$ in the Eindhoven region this working practice has become regular care since 2004.

Diagnoses and diagnostic advice given by the AC-service

According to the protocol, referred patients fill out a structured medical history form and have spirometry performed at the AC-service. Consulting pulmonologists assess these written data according to a protocol and conclude one of the following diagnostic categories:

1. Asthma (reversible obstruction or medical history including reversibility in the past)

2. Asthma and COPD (reversible but persistently obstructed flow volume curve)

3. COPD (irreversible obstruction and medical history)

4. No asthma/COPD (normal spirometry (minor restriction), no specific complaints); Since inhaled corticosteroids (ICS) might cause diagnostic problems in patients having no complaints and a normal spirometry ${ }^{[19]}$ a sub-category is added:

4a. "Normal spirometry. Patient uses ICS: is a diagnosis of asthma confirmed by former reversibly obstructive lung function?"
In case of discrepancies between medical history/complaints and spirometry results, uncertainty can remain about diagnostic accuracy, and additional diagnostic examinations can be advised according to the Dutch General Practitioners guidelines used at the time ${ }^{[20]}$. This advice is included in the report sent to the GP.

When advice is taken up a diagnosis can change ("look for an alternative diagnosis"), can become more accurate ("confirm asthma/COPD") or more comprehensive ("consider an additional diagnosis"). A positive impact of this advice should be apparent at follow up: patients without proven asthma or COPD should not show up for follow-up nor should there be a need for further diagnostic advice (figure 1). Furthermore, diagnoses should be adjusted more often when a diagnostic advice was given, compared to diagnoses without additional advice.

Data and analyses

We compared the diagnoses at first visit and at follow-up of all patients excluding patients that were not eligible for follow-up because they were not asthma or COPD patient.

We anticipated that the diagnoses of patients who got diagnostic advice at first visit would change more often compared to those patients who had not had this advice. Therefore we compared the level of change in diagnoses in both groups.

Furthermore we evaluated to what extent advice was followed by GPs by studying, when possible, the effect at follow-up (figure 1).

The remaining diagnostic uncertainty was measured by evaluating whether or not diagnostic advice was still given at follow up.

Diagnoses and diagnostic advice were collected from the assessment protocols filled in by the consulting pulmonologists. Frequencies after first visit and follow-up and their correlations (chi-square) were analyzed using SPSS 17. 


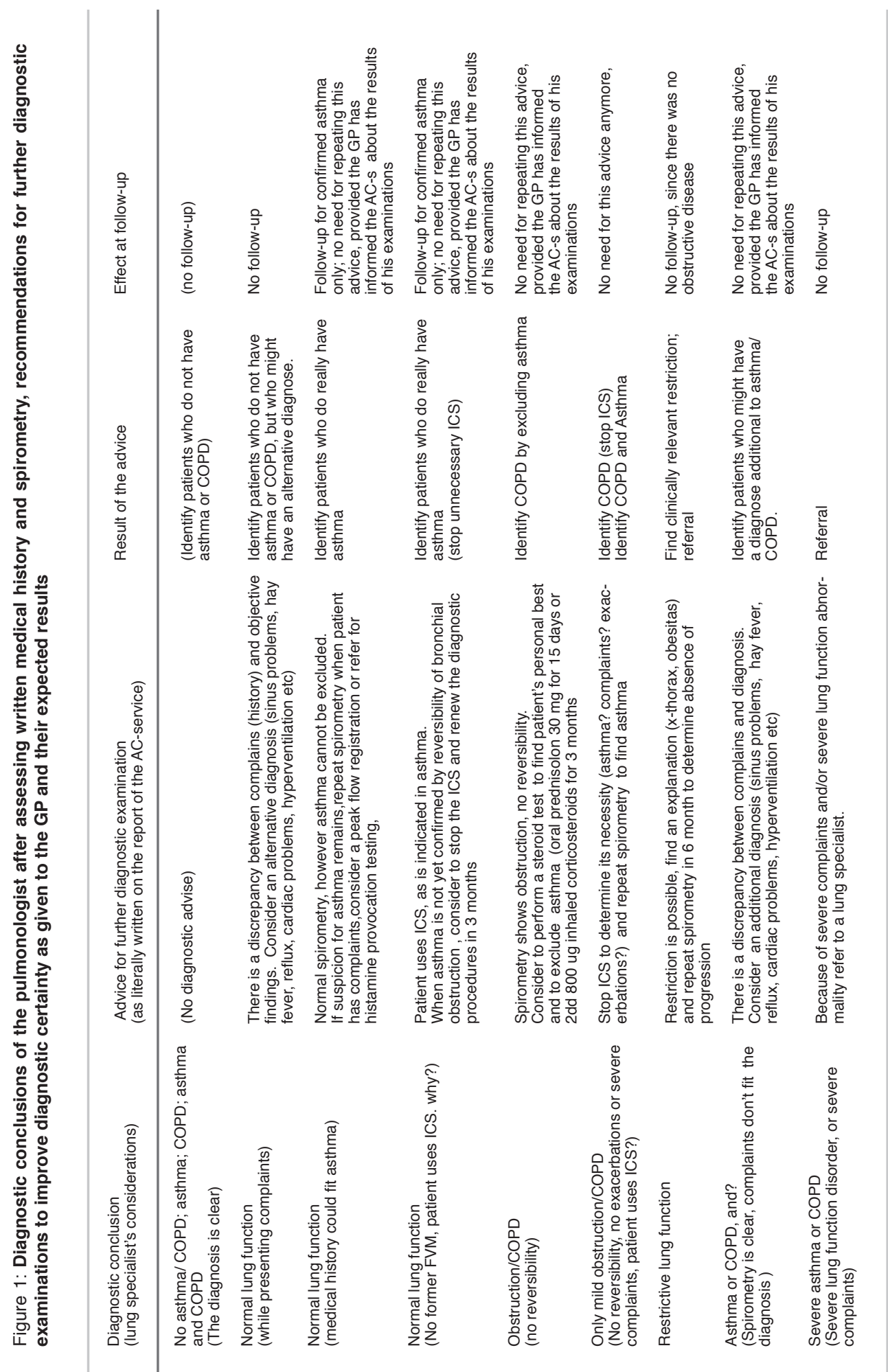

\section{Results}

Patients

Of 461 patients who agreed to participate, $396(86 \%)$ actually came in for spirometry (mean age 51 yrs, range 12-88, 55\% female). 13 patients were excluded because of badly performed spirometry. Of the remaining 383 patients, 229 came for follow-up. When patients with no indication for follow up are excluded ( $N=106)$, the actual "no show" at follow-up was $19 \%(n=48)$ (table 1$)$.

Diagnoses at first visit to the AC-service and at follow up

At first visit, $35 \%(n=133)$ had a normal lung function and did not get a diagnosis of asthma or COPD, $43 \%$ were diagnosed as asthma, $15 \%$ as COPD and $7 \%$ were diagnosed having asthma and COPD.

For "asthma", no show at follow up was 16\%, for "COPD" 29\%. 59\% of the 229 follow-up patients received the same diagnosis from the assessing pulmonologist ("Asthma", Asthma+COPD" and "COPD") (table 1). COPD was a stable diagnosis for $80 \%$. The initial diagnosis of asthma changed in 55\%, mostly to "normal why ICS?" ( $n=34,25 \%$ ) or to "no asthma/COPD ( $n=15,11 \%)$. Despite not being eligible 24 "normal" patients also came for follow up. 19 patients were again diagnosed as "normal", 3 changed to COPD, and 1 patient to asthma, and 1 to "FVM normal why ICS".

Table 1: Diagnoses assessed by consulting lung specialist at patients' first visits to the AC-service and one year later at follow-up visits

\begin{tabular}{|c|c|c|c|c|c|c|c|c|}
\hline \multirow[b]{2}{*}{ Diagnosis at first visit } & \multicolumn{8}{|c|}{ Diagnosis at follow-up visit } \\
\hline & $\begin{array}{c}\mathrm{FVM}= \\
\text { normal } \\
\text { Why ICS? }\end{array}$ & $\begin{array}{c}\text { No } \\
\text { Asthma / } \\
\text { COPD }\end{array}$ & Asthma & $\begin{array}{l}\text { Asthma + } \\
\text { COPD }\end{array}$ & COPD & Total & $\begin{array}{l}\text { No show } \\
\text { at } \\
\text { follow-up }\end{array}$ & $\begin{array}{l}\text { All patients } \\
\text { at first visit }\end{array}$ \\
\hline FVM=normal, why ICS? & 3 & 0 & 0 & 0 & 0 & 3 & & $3(1 \%)$ \\
\hline $\begin{array}{l}\text { FVM=normal, no Asthma/ } \\
\text { COPD }\end{array}$ & 1 & 19 & 1 & 0 & 3 & 24 & 106 & $130(34 \%)$ \\
\hline Asthma & 34 & 15 & 75 & 8 & 4 & 136 & 27 & $163(43 \%)$ \\
\hline Asthma + COPD & 2 & 2 & 11 & 6 & 3 & 24 & 4 & $28 \quad(7 \%)$ \\
\hline COPD & 1 & 6 & 2 & 0 & 33 & 42 & 17 & $59(15 \%)$ \\
\hline Total patients for follow-up & 41 & 42 & 89 & 14 & 43 & 229 & 154 & $383(100 \%)$ \\
\hline
\end{tabular}


Table 2: Diagnoses assessed by lung specialist from written medical history and lung function at patients first visit to the asthma/COPD-service and recommendations for further diagnostic examinations to gain more diagnostic certainty

\begin{tabular}{|c|c|c|c|c|c|c|c|}
\hline \multirow[b]{2}{*}{$\begin{array}{l}\text { Recommendations for further } \\
\text { diagnostic examination }\end{array}$} & \multicolumn{5}{|c|}{ Diagnosis at first visit to the $A C$-service } & \multirow{2}{*}{\multicolumn{2}{|c|}{ Total }} \\
\hline & $\begin{array}{r}\mathrm{Nc} \\
\mathrm{FVM} \\
\mathrm{res}\end{array}$ & $\begin{array}{l}\text { ormal } \\
1 / \text { some } \\
\text { itriction }\end{array}$ & Asthma & $\begin{array}{l}\text { Asthma \& } \\
\text { COPD }\end{array}$ & COPD & & \\
\hline Total number (\%) of patients & 133 & $(35 \%)$ & $163(43 \%)$ & $28(7 \%)$ & $59(15 \%)$ & 383 & $(100 \%)$ \\
\hline $\begin{array}{l}\text { Total number (\%) of patients receiving } \\
\text { one or more recommendations }\end{array}$ & 98 & $(37 \%)$ & $104(40 \%)$ & $10(4 \%)$ & 50 (19\%) & 262 & $(100 \%)$ \\
\hline $\begin{array}{l}\text { 1. Normal lung function. } \\
\text { Consider an alternative diagnosis }\end{array}$ & & $(30 \%)$ & $x$ & $x$ & $x$ & 39 & $(12 \%)$ \\
\hline $\begin{array}{l}\text { 2. Normal lung function. Asthma? } \\
\text { Repeat spirometry, consider peak } \\
\text { flow registration or referral for a } \\
\text { histamine provocation test }\end{array}$ & & $(46 \%)$ & $1(1 \%)$ & $x$ & 1 (1\%) & 62 & $(18 \%)$ \\
\hline $\begin{array}{l}\text { 3. Normal lung function, ICS. } \\
\text { Asthma? If uncertain, stop ICS } \\
\text { to find Asthma }\end{array}$ & 8 & $(6 \%)$ & $93(74 \%)$ & $9(45 \%)$ & $x$ & 110 & $(32 \%)$ \\
\hline $\begin{array}{l}\text { 4. Obstruction. } \\
\text { Consider a steroid test to exclude } \\
\text { asthma/find personal best }\end{array}$ & & $x$ & $x$ & $x$ & $36(62 \%$ & 36 & $(11 \%)$ \\
\hline $\begin{array}{l}\text { 5. Mild obstruction, ICS. } \\
\text { Asthma? If uncertain, stop ICS to } \\
\text { also find asthma }\end{array}$ & & $x$ & $x$ & $x$ & $13(22 \%)$ & 13 & $(4 \%)$ \\
\hline $\begin{array}{l}\text { 6. Restriction? } \\
\text { Find an explanation an check for } \\
\text { progression }\end{array}$ & 17 & $(13 \%)$ & $7(6 \%)$ & $2(10 \%)$ & $1(2 \%)$ & 27 & $(8 \%)$ \\
\hline $\begin{array}{l}\text { 7. Complaints don't fit lung function. } \\
\text { Consider an additional diagnosis. }\end{array}$ & 4 & (3\%) & $18(14 \%)$ & $3(15 \%)$ & $2(1 \%)$ & 27 & $(8 \%)$ \\
\hline $\begin{array}{l}\text { 8. Severe complaints / lung function } \\
\text { disorder } \\
\text { Refer to a lung specialist. }\end{array}$ & 3 & (2\%) & $6(5 \%)$ & $6(30 \%)$ & $7(12 \%)$ & 22 & $(7 \%)$ \\
\hline
\end{tabular}

Total number (\%) of recommendations $131(100 \%) 125(100 \%) 20(100 \%) \quad 60(100 \%) \quad 336(100 \%)$ for further diagnostic examination
Diagnostic advice

$68 \%(n=262)$ of the patients received additional diagnostic examination advice (one or more recommendations) (table 2). $37 \%$ of all recommendations were given to patients with a normal spirometry, $40 \%$ to asthma patients, $19 \%$ to COPD-patients, and $4 \%$ to patients with a double diagnosis of asthma and COPD. Most advice (65\%) was oriented towards finding or excluding asthma: repeat spirometry, peak flow or a histamine provocation test $(18 \%)$ in case of a normal lung function, a steroid test in case of persistent obstruction (11\%), advice to stop unexplained use of ICS when FVM was normal (36\%). $20 \%$ of the recommendations were related to suspicion of an alternative or additional diagnosis.

Table 3a: Asthma/COPD diagnoses with or without diagnostic advice at first visit to the AC-service and their relationship with diagnostic certainty (diagnosis confirmed at follow-up) at follow-up (Significant difference in diagnostic certainty: $p=0,007$. X2)

\begin{tabular}{|c|c|c|c|}
\hline \multirow[b]{2}{*}{ Diagnostic advice } & \multicolumn{3}{|c|}{ Diagnoses of first visits confirmed or adjusted at follow-up } \\
\hline & $\begin{array}{l}\text { Confirmed } \\
\text { diagnosis }\end{array}$ & $\begin{array}{l}\text { Adjusted } \\
\text { diagnosis }\end{array}$ & Total \\
\hline No diagnostic advice given at first visit & $53(69 \%)$ & $24(31 \%)$ & $77(100 \%)$ \\
\hline Diagnostic advice given at first visit & $61(47 \%)$ & $64(53 \%)$ & $125(100 \%)$ \\
\hline Total & $114(56 \%)$ & $88(44 \%)$ & $202(100 \%)$ \\
\hline
\end{tabular}

Table 3b: Need for another diagnostic advice in follow-up assessments of confirmed or adjusted asthma/COPD diagnoses and diagnostic advice previously given at first visit

New or restated advice for further diagnostic examination at follow-up

\begin{tabular}{|c|c|c|c|}
\hline Diagnostic advice & $\begin{array}{l}\text { No Diagnostic } \\
\text { Advice } \\
\text { at follow up }\end{array}$ & $\begin{array}{l}\text { Diagnostic advice } \\
\text { at follow up }\end{array}$ & Total \\
\hline No diagnostic advice ad first visit & $63(82 \%)$ & $14(18 \%)$ & $77(100 \%)$ \\
\hline Diagnostic advice ad first visit & $66(52 \%)$ & $59(48 \%)$ & $125(100 \%)$ \\
\hline Total & $129(64 \%)$ & $73(36 \%)$ & $202(100 \%)$ \\
\hline
\end{tabular}


Diagnoses and diagnostic advice

Figure 2 (at the end of this article) shows the diagnoses at first visits, additional diagnostic advice, and the reassessments at follow-up.

No advice for diagnostic examination: a certain diagnosis?

When at first visit no advice for further examinations was added to the diagnosis, the initial diagnosis asthma was confirmed at follow up for $80 \%$, COPD for $88 \%$ and "astma+COPD" only for $30 \%$ (figure 2 ). In total, $69 \%$ of all asthma/COPD diagnoses without diagnostic advice after first visit was confirmed at follow-up (table 3a).

A minority of the follow-up patients (18\%) received new diagnostic advice, mostly to look for an additional diagnosis (table $3 b$ ).

Advice for diagnostic examinations: adjustment of diagnosis at follow-up?

In total, $53 \%$ of the diagnoses that were accompanied by additional diagnostic examination advice were adjusted at follow-up. This was significantly more than for diagnoses without this additional advice ( $p=0,007 \times 2)$ (table 3a). The initial diagnosis "asthma+COPD" was adjusted for $85 \%$, "asthma" for $60 \%$ and "COPD" for $24 \%$. In total, $48 \%$ of the patients receiving an advice for further diagnostic examination after first visit to the AC-service needed a restated or a new advice at follow-up.

The overall frequency of diagnostic advice as an indicator for diagnostic uncertainty diminished from $62 \%(n=125)$ to $36 \%(n=73)$ for patients that came for follow-up (table 3b).

Adherence to the advice for additional diagnostic examinations

Results of the diagnostic recommendations and the actual adherence of GPs are described in the box (page 125). We found that:

- $25 \%$ of the patients came for follow-up without an indication (no asthma/COPD)

- No histamine provocation test was performed

- $67 \%$ of "Asthma (since using ICS)?" was adjusted to "normal why ICS": ICS was not stopped

- Steroid tests were performed only twice (7\%), changing "COPD" into "asthma"

- $68 \%$ of the patients advised to be referred to a pulmonologist came for follow-up to the $\mathrm{AC}$-service and were not referred

\section{Diagnostic recommendations and GPs' adherence}

Exclude patients who do not have asthma or COPD, or who might have an alternative diagnosis: no show at follow-up.

66 patients had no astma/COPD (39) or a minor restriction (27). Nevertheless $25 \%$ came for followup: no astma/COPD diagnosis was assesses. The advice to look for restriction was repeated twice.

Exclude or confirm supposed asthma in case of normal lung function by spirometry when having complaints, or perform peak flow registration or a histamine provocation test. At follow up "asthma" patients should not need this advice anymore provided it was followed and the GP informed the $A C$-service about the results.

Of the 62 patients who received this advice, $20 \%$ came for follow-up. All of them were diagnosed as normal. No histamine provocation test was performed. The advice to do so was repeated once at follow-up.

Exclude misdiagnosis or confirm asthma in patients who use ICS for unclear reasons: they should stop ICS and not get this advice any more at follow-up, independent from their new diagnosis (normal or astma/COPD or uncertain).

This most frequently given advice was received by 123 patients, 13 of them being diagnosed as mild COPD. Diagnoses were adjusted in $67 \%$, mostly to "normal (why ICS?)". The advice was repeated for 27 patients.

Prevent missing asthma in patients with obstructive lung function: when performing a steroid test, reversibility (to normal) should be excluded. This advice should not be necessary anymore at follow-up.

36 steroid tests were advised for patients with obstructive lung function. Two were performed, changing the diagnosis COPD in asthma. Of the other 25 patients that were given this advice, 6 patients changed to "no asthma/COPD" and 17 kept the diagnosis COPD. Nine of them were again advised to perform the steroid test.

Complete a diagnosis by confirming or rejecting an additional diagnosis: this advice should only be given once, provided that the GP informs the AC-service about his findings.

24 out of 27 patients that had received this advice came back for follow-up. Advices were repeated for 3 patients. When this advice was given, a follow-up diagnosis was adjusted 4 times more than without this advice.

Extending diagnostic procedures in case of severe respiratory problems: patients should be referred. Follow-up should be at pulmonologist office, or when follow-up at the AC-service, problems should be under control, no further advice.

22 patients got this advice, 15 came for follow-up, 2 again received the advice for referral. No diagnostic or referral advice was applicable anymore in 8 follow-up patients. 


\section{Discussion}

Our results show that diagnoses assessed at the first diagnostic visit to the AC-service were often indefinite, even when no advice was given for additional diagnostic examinations. Although significantly less than amongst patients that received diagnostic advice, change at follow up still occurred in $31 \%$ of the initial diagnoses without diagnostic advice.

Many studies have shown that clinical diagnoses change when they are tested by spirometry ${ }^{[21-25]}$. In addition we found that one spirometry test, even when clinical information was added, does not guarantee diagnostic certainty in all patients. Expert assessors as well as clinicians have to take into account a natural variability of patients' lung function characteristics $s^{[9]}$ and clinical symptoms. Patients in primary care show a small assessment range between normal/healthy and abnormal/sick, causing more diagnostic uncertainty than severe patients in secondary care do, and differentiation between asthma and COPD can be difficult ${ }^{[2]}$. These phenomena could explain the change of diagnoses even when an initial diagnosis was given with apparent certainty, i.e. with no need for further diagnostic examinations at the time of its assessment.

We found that for $68 \%$ of the initial diagnoses there was diagnostic uncertainty, expressed by advice for further diagnostic examinations to discriminate between asthma and COPD, or to explain respiratory complaints not necessarily caused by asthma or COPD ${ }^{[26]}$. The correlation between diagnostic uncertainty and diagnostic advice was emphasized by the fact that an initial diagnosis accompanied by diagnostic advice changed at follow-up significantly more often than an initial diagnosis without diagnostic advice.

We could not conclude that a diagnostic advice at first visit to the AC-service led to a definite diagnosis, making additional diagnostic advice superfluous at follow-up. Additional advice was given again at follow-up for half of the patients, independent from change of diagnosis, indicating that diagnostic uncertainty diminished but still was considerable at follow-up.

Change of diagnosis after diagnostic advice occurred after following diagnostic advice, but also independent form GPs' adherence to the advice. Consulting pulmonologists decided themselves what the most likely diagnosis was, for example in patients who initially were diagnosed with "asthma" because of use of ICS and still used ICS after being advised to stop - showed a normal spirometry at follow-up without asthma complaints in the past year (diagnosis: "normal FVM, why ICS?"), or in older patients having a FEV1/FVC close to lower limit of normal without obvious COPD characteristics (diagnosis: no COPD). Advice to find proof for the new diagnosis was added for half the patients, again indicating diagnostic uncertainty to be resolved by the GP. Our study showed that GPs' adherence to diagnostic advice was low. It is questionable whether this was because of negligence, because of disagreement or because of feasibility problems:

- we found in another study ${ }^{[19]}$ that the advice to stop ICS - in case of doubt about the diagnosis "asthma" - was neglected unless the AC-service explicitly asked for justification of the use of ICS before assessment by the consulting pulmonologist;

- at the time of the study, a steroid test was advocated for irreversible obstructive lung functions ("COPD?") to exclude asthma ${ }^{[27]}$. We cannot conclude about its usefulness but it is obvious that the test was badly accepted by GPs and/or patients. When the Dutch guidelines were updated the steroid test was deleted, not for lack of diagnostic use but due to lack of proof for therapeutic effects of ICS after a steroid test was positive ${ }^{[28]}$. The advice is now only given when clinical symptoms are suspected for "fixed asthma" which should improve its acceptability amongst GPs;

- when the lung function was normal and medical history was suspected for asthma renewed spirometry at the moment of complaints, peak flow registration or histamine provocation tests were advised. No intermediate spirometries were reported by the AC-service and according to pulmonologists' records no patient was referred for histamine provocation tests, indicating that there were problems in realizing these tests.

Consulting pulmonologists are increasingly interested in getting feedback from GPs about the effects of diagnostic advice. A closer collaboration between primary and secondary care could meet this demand, and provide more insight in the reasons for non adherence and the feasibility of the recommendations.

Relation to other studies

Van den Bemt showed that amongst long time stable COPD-patients there is little patient adherence to (lifestyle and pharmacotherapeutical) recommendations of an AC-service ${ }^{[14]}$. Our findings suggest that GPs' adherence to (diagnostic) advice also needs to be improved.

Even with low adherence to advice, the AC-service contributed considerably to the diagnostic process. This is an important contribution to the discussion, in literature and in real life, about whether expert diagnostic support systems like AC-services have a positive influence on GPs' decision making and on patient outcome in 
asthma/COPD care. Studies show that when GPs perform badly remote pulmonologist support was feasible and necessary ${ }^{[25]}$. Positive effects of expert support were not found in an experimental setting when GPs are intensively trained ${ }^{[29]}$ or when only spirometry data are assessed by experts ${ }^{[21]}$. This study shows that for GPs with an average interest in Asthma/COPD-care and without special training the quality of the diagnostic process can be improved considerably by (repeated) support of an A/C service.

At the AC-service diagnostic recommendations should continuously be reviewed for their feasibility and when necessary be reconsidered. Thus, the peak flow registration test and the steroid test are not recommended anymore as standard diagnostic procedures. The histamine provocation test, frequently advocated for more diagnostic certainty after a first undecided spirometry test ${ }^{[23,24]}$, can be protocolized better in the diagnostic process of asthma in primary care. As a first step pulmonologists in Eindhoven have organized a special office hour offering a one visit consultation for primary care patients including the histamine provocation test.

\section{Strength and limitations}

The study was performed without interference in the usual care of the AC-service or primary care practices. This means we learned about the everyday threats and opportunities in primary care asthma/COPD diagnostics. The consequence was that we could neither evaluate the exact way in which GPs handle diagnostic advice, nor ask for their arguments to ignore them. Since the AC-service always sends reports including all advices, it also was not possible to compare the effect of AC-support with and without a specific diagnostic advice. Finally there was no gold standard for the diagnoses given by pulmonologists nor for diagnostic advice ${ }^{[8]}$. Therefore, the study shows the real life problems a well developed and sustained support system can encounter.

\section{Conclusion}

Diagnostic advice given by pulmonologists assessing spirometry and medical history for an AC-service underlines the complexity of the dynamic diagnostic process of asthma/COPD. When this advice was given, diagnoses more often were revised at follow-up, indicating diagnostic uncertainty that should trigger GPs to reconsider their working diagnosis. However, GPs' adherence to diagnostic advice was low. Adjustments of diagnoses diminishing the diagnostic uncertainty were mainly due to the accuracy of the assessing pulmonologist, most frequently because they did not accept the initial diagnosis anymore when spirometry and medical history or medication were incongruent.

Advice for additional diagnostic examinations can be useful only if more attention is paid to implement diagnostic strategies. Histamine provocation should be easily available; mutual feedback about diagnostic decisions might improve the non-adherence of GPs as well as the quality of diagnostic advice by pulmonologists.

Our study emphasizes that it takes time to reach a definite diagnosis. Because of this complexity expert diagnostic support including additional diagnostic advice should be continued at least until diagnostic doubts have diminished. When GPs are supported by an AC-service this means: until the diagnosis of their patients is repeatedly confirmed and diagnostic advice is not given anymore.

Figure.2: Patients diagnosed as Asthma, COPD or Asthma+COPD after their first diagnostic visit to the AC-service (A), diagnostic advice given (B) and confirmed or adjusted diagnoses at follow-up (C)

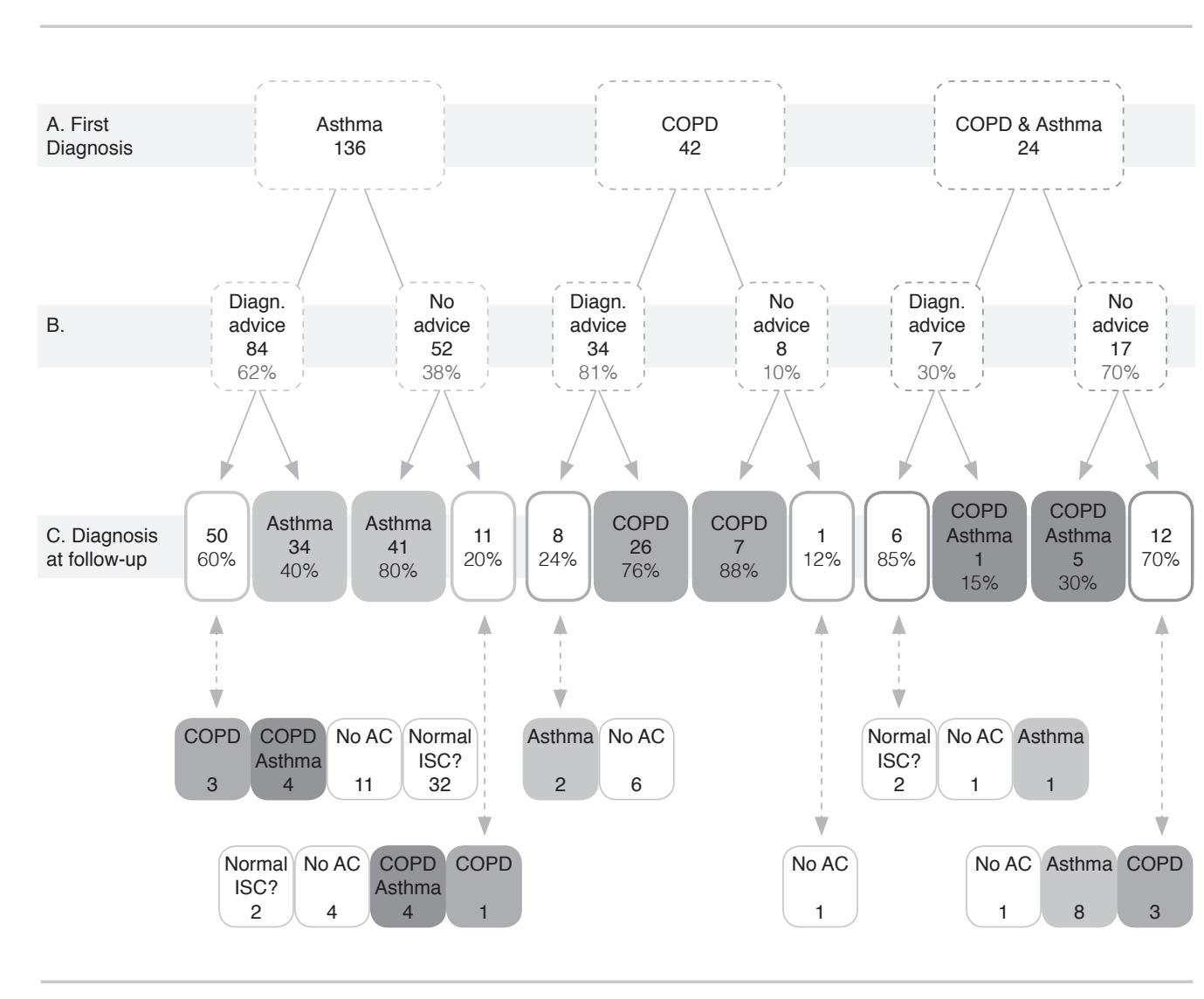




\section{Literature}

1. Bolton CE, lonescu AA, Edwards PH, Faulkner TA, Edwards SM, Shale DJ. Attaining a correct diagnosis of COPD in general practice. Respir Med 2005. 99(4): 493-500.

2. Tinkelman DG , Price DB., Nordyke RJ, Halbert RJ Misdiagnosis of COPD and asthma in primary care patients 40 years of age and over. J Asthma, 2006. 43(1): 75-80.

3. Yawn BP. Optimizing Chronic Obstructive Pulmonary Disease Management in Primary Care. Southern Medical Journal, 2011. 104(2): 121-127

4. van Schayck CP. van der Heijden FMMA, van den Boom G, Tirimanna PRS, van Herwaarden CLA. Underdiagnosis of asthma: is the doctor or the patient to blame? The DIMCA project. Thorax 2000. 55(7): 562-565

5. van Weel C. Underdiagnosis of asthma and COPD: is the general practitioner to blame? Monaldi Arch Chest Dis 2002. 57(1):: 65-8.

6. Arne M, Lisspers K, Ställberg B, Boman G, Hedenström H, Janson C, Emtner M. How often is diagnosis of COPD confirmed with spirometry? Respir Med 2010. 104(4): 550-556.

7. Albers, M., Schermer T, Molema J, Kloek C, Akkermans R, Heijdra Y, van Weel, C. Do family physicians' records fit guideline diagnosed COPD? Fam Pract 2009. 26(2): 81-87.

8. Lucas AEM, Smeenk FWJM, van den Borne BEEM, Smeele IJM, van Schayck CP. Diagnostic assessments of spirometry and medical history data by respiratory specialists supporting primary care: are they reliable? Prim Care Resp J 2009. 18(3): 177-184.

9. Calverley PMA, Burge PS, Spencer S, Anderson JA, Jones PW. Bronchodilator reversibility testing in chronic obstructive pulmonary disease. Thorax 2003. 58(8): 659-664.

10. Poels PJP. Schermer TRJ, Akkermans RP, Jacobs A, van den Bogart-Jansen M. Bottema BJAM, van Weel C. General practitioners' needs for ongoing support for the interpretation of spirometry tests. Eur J Gen Pract 2007. 13(1): 16-19.

11. Kaminsky D, Marcy TW, Bachand M, Irvin CG. Knowledge and use of office spirometry for the detection of chronic obstructive pulmonary disease by primary care physicians. Respir Care, 2005. 50(12): 1639 - 48

12. Smeele IJM, Hennekam M. Papieren Consultatie (article in Dutch). Med Contact 2002(57): 43.

3. Worth, A., Pinnock H,Fletcher M, Hoskins G, Levy ML, Sheikh A., Systems for the managemen of respiratory disease in primary care - an international series: United Kingdom. Prim Care Resp J 2011. 20(1): 23-32.

14. van den Bemt LST. Smeele IJM, Boonman-de Winter LJ, van Boxem T, Denis J, GrootensStekelenburg JG, et al. An expert-supported monitoring system for patients with chronic obstructive pulmonary disease in general practice: results of a cluster randomised controlled trial. Med J Aust. 2009. 191(5): 249-254.

15. Lucas A, Smeenk F, Smeele I, Brouwer T, van Schayck O. The validity of diagnostic support of an asthma/COPD service in primary care. Br.J Gen Pract 2007. 57(544): 892-6.

16. International Classification of Primary Care: short titles and Dutch subtitles. Utrecht; Nederlands Huisartsen Genootschap; 1995

17. WHO, The Anatomical Therapeutical Chemical Classification System with Daily Doses (ATC-DDD).http://www.who.int/classifications/atcddd/en/. 2007.

18. Lucas AEM, Smeenk FWJM., Smeele IJM, van Schayck CP. Diagnostic accuracy of primary care Asthma/COPD working hypotheses, a real life study. Respir Med 2012.106;1158-63.

19. Lucas AE, Smeenk FWJM., Smeele IJ, van Schayck CP. Overtreatment with inhaled corticosteroids and diagnostic problems in primary care patients, an exploratory study. Fam Pract 2008. 25(2): 86-91.

20. Geijer RMM, T.H., Smeele IJM et al., Standard of the Dutch College of General practitioners on asthma and COPD: diagnostics (in Dutch). Huisarts en Wet 2001. 44(3): 107-117. 
21. Poels, PJP, Schermer TRJ, Thoonen BPA, Jacobs J E, AkkermansRP, de Vries Robbe PF, Quanjer PH, Bottema BJAM, van Weel C., Spirometry expert support in family practice: a cluster-randomised trial. Prim Care Respir J 2009. 18(3): 189-197.

22. Walker PP,. Mitchell P, Diamantea F, Warburton CJ, Davies L., Effect of primary-care spirometry on the diagnosis and management of COPD. Eur Respir $\mathrm{J}$ 2006. 28(5): 945-952.

23. Schneider A, Tilemann L, Schermer T, Dinant GJ, Meyer FJ, Szecsenyi J, Diagnostic accuracy of spirometry in primary care. BMC Pulm med 2009. 9(31).

24. Luks VP, Vandemheen Kl, Aaron SD. Confirmation of asthma in an era of overdiagnosis. Eur Respir J 2010. 36(2): 255-260.

25. White P, Wong W, Fleming T, Gray B. Primary care spirometry: test quality and the feasibility and usefulness of specialist reporting. Br J Gen Prac 2007. 57: 701-705.

26. Lucas AEM, Uncertainty about the diagnosis Astma/COPD (article in Dutch). Tijdschrift v Praktijkondersteuning 2011. 6(7): 49-54.

27. Broekhuizen BDL, Sachs AP, Hoes AW, Moons KG, van den Berg JW, Dalinghaus WH, Lammers E, Verheij TJ. Diagnostic Value of Oral Prednisolone Test for Chronic Obstructive Pulmonary Disorders. Ann Fam Med, 2011. 9(2): 104-109.

28. Chavannes NH, Schermer TR., Wouters EFM, Akkermans RP, Dekhuijzen PNR, Muris JWM, van Weel, van Schayck OC. Predictive value and utility of oral steroid testing for treatment of COPD in primary care: the COOPT study. Int J Chron Obstruct Pulmon Dis 2009. 4: 431-6.

29. Yawn BP, Enright PL, Lemanske RF, Israel E, Pace W, Wollan P, Boushey H. Spirometry Can Be Done in Family Physicians' offices and Alters Clinical Decisions in Management of Asthma and COPD Chest, 2007. 132(4): 1162-1168. 
Lucas EM Annelies, Derckx WCC Emmy, Meulepas A Marianne, Smeele JM Ivo, Smeenk WJM Frank and van Schayck P Onno. Consultation performance of general practitioners when supported by an asthma/COPDC-service. BMC Research Notes 2012, 5:368

\section{Abstract}

General practitioners (GPs) can refer patients to an Asthma/COPD service (AC-service) for diagnostic assessment of spirometry and medical history and for asthma or COPD monitoring. The AC-service reports diagnostic results and additional information about disease burden (BORG-score for complaints, MRC-dyspnoea score, exacerbation rate), life style, medication and compliance, to the patient's GP. This study explores how GPs use this additional information when discussing the patient's disease burden and how this influences GPs' information and education provision during consultations with asthma/COPD patients.

\section{Method}

Patients with (a suspicion of) asthma or COPD were referred to an AC-service and consulted their GPs after they had received a report from the AC-service. Retrospectively patients answered questions about their GPs' performance during these consultations. Performances were compared with performances of the same GPs during consultations without support of the AC-service (usual care), earlier that year.

\section{Results}

Of consultations not initiated by an AC-service check-up, $91 \%$ focussed on complaints, the initial reason for the consultation. In AC-service supported follow-up consultations, GPs explored disease burden when the (BORG-)score for complaints was high - as reported by the AC-service - even when patients themselves thought it was irrelevant. GPs put significantly less effort in exploring disease burden when the Borg-score was low (BORG 3-4: 69\%; BORG1-2: 51\%, p=0,01). GPs mostly ignored MRC-dyspnoea scores: attention to dyspnoea was $18 \%$ for MRC-score $<3$ and $25 \%$ for MRC-score $>3(p=0,63)$. GPs encouraged physical fitness in $13 \%$ of patients. Smoking behaviour was discussed with $66 \%$ of the actual smokers but only $14 \%$ remembered a stop smoking advice. Furthermore, pharmacotherapeutic management education in AC-service supported consultations did not differ from performance in usual care according to patient evaluations.

\section{Conclusion}

Other than taking into account the severity of complaints, there was no difference between GPs' performance in AC-service supported and in usual care consultations AC-service reports are thus not effective by themselves. GPs should be encouraged to use the information better and systematically check all relevant aspects that characterize the disease burden of their patients. 


\section{Introduction}

Self management and individual action plans are important issues in effective care for asthma and COPD patients ${ }^{[1-3]}$. Patient information and education are prerequisites for successful implementation. Through a multifaceted approach, patients should be educated about all aspects of their disease, the influence of lifestyle and medication ${ }^{[4]}$. They should be supported to implement this knowledge and to adopt a healthier life style. In every day practice this ideal situation is hard to realize. New guidelines focus on the individual burden of the disease for which many factors (e.g. respiratory complaints and disabilities, co-morbidity, social restrictions) have to be explored ${ }^{[5]}$. However, only a limited number of issues can be discussed in one consultation. In addition, addressing lifestyle behaviour is not part of GPs' routine procedures $^{[6]}$. Research is needed to determine which management model offers the best support to improve this ${ }^{[7]}$ and to provide good instruments to routinely inform and educate patients.

One of the models is the support of an Asthma/COPD service (AC-service), an efficacious working method in The Netherlands for obtaining best quality diagnosis of asthma/COPD for all patients with respiratory problems in a primary care practice ${ }^{[8]}$. The service's main task is to perform diagnostic spirometry on patients referred by their GPs. To improve assessment quality, consulting pulmonologists use structured medical history data in addition to spirometry data. This protocolized approach of the AC-service gives valid diagnostic results ${ }^{[8,9]}$ and provides a lot of additional information to GPs which they can use in consultations with their patients.

Consultation support by reports of the AC-service

The AC-service sends diagnostic reports to GPs which include history data. GPs can use this information to structure consultation communication. Communication starts with exploring complaints to understand patient's disease burden followed by patientdoctor conversations. The AC-service reports a Borg-score (0 to 10) for respiratory complaints, a frequency score for exacerbations per year, the MRC-dyspnoea score (1 to 5) and weight problems (BMI) (figure 1). These data can help the GP to discuss disease burden, something not always spontaneously reported by the patient ${ }^{[10]}$ or noticed by the GP ${ }^{[11]}$. Disease burden might get less attention at follow-up visits that focus on spirometry results even when complaints and scores are substantial.

Tailored recommendations for medical treatment and lifestyle adaptations, i.e. stopping smoking and improving physical condition, are also added to the report of the AC-service. Especially when the disease burden indicates the need for therapeutic action these recommendations should be discussed in the next part of the consultation. 
Unknown is to what extent GPs use the information of the AC-service in their consultations and whether this influences patients' knowledge and attitudes towards lifestyle adaptations.

We studied this by exploring the consultation performance of GPs - as perceived by their patients with respiratory problems - when a report of the AC-service was available and compared this with the performance of GPs in usual care consultations. We focused in detail on the extent to which GPs addressed the experienced burden of the disease (complaints, MRC, exacerbations), the diagnosis, the impact of lifestyle on the disease (smoking, lack of exercise), inhalation technique, and compliance.

\section{Method}

\section{Setting}

This study was part of an extensive research project that evaluated the "Asthma/ COPD-service" for its validity and reliability ${ }^{[8,9]}$ and diagnostic and therapeutic support offered to GPs in their care for patients with respiratory complaints ${ }^{[12-14]}$. The research project was conducted at the AC-service in Eindhoven, the Netherlands, established in 2001 for the purpose of supporting asthma/COPD care in 300 primary care practices in the region. When the research started, AC-service was already part of regular care for some GPs but not all primary care practices in the region were enrolled.

\section{Participants in the study}

From May 2005 until December 2007 GPs from Eindhoven city and surrounding areas who had no experience of working with the AC-service were asked to participate in the research project. This meant that GPs would start with the regular support of the AC-service and agree to have its effect evaluated by their patients. To be able to collect consultation data without and with support of the AC-service from the same GPs, GPs were asked to postpone the actual partnership with the AC-service for one year after they agreed to participate.

\section{Regular support of the AC-service}

Regular support of the AC-service starts with the screening of primary care office registers. Patients (12 years and older) with respiratory problems are selected who are eligible for diagnostic assessment and/or follow-up in order to enrol in their GP's monitoring program. Selection criteria are the use of inhaled medication in the last two years (ATC-code R03) and/or a registered diagnosis "COPD" "asthma" or "bronchitis" (ICPC-codes R95, R96 and R91, $\left.{ }^{(15)}\right)$. GPs can send all these patients
- including all new respiratory patients - to the AC-service for written medical history taking and spirometry. GPs decide about the (very) old, immobile, or psychiatric patients for which these referrals not automatically apply.

After each visit to the AC-service, GPs receive a report with the results of spirometry, the medical history and diagnostic and therapeutic advice (figure 1). The GP remains fully responsible for the interpretation of the report and for the patient's care process.

\section{Design}

Office registers of participating practices were screened by the AC-service as described. Selected patients were asked to participate in the evaluation of their GP's care process and to answer questionnaires at the start and at the end of the research period. GPs were informed about which patients were selected only at the end of the research period.

At the start of the study data were collected about GPs' performances in consultations without support of the AC-service (i.e. usual care) (figure 2). Participating patients received a questionnaire eight weeks after their practice enrolled in the study. The questionnaire addressed the consultations patients might have had in these eight weeks related to respiratory problems. Patients were asked whether they had discussed the following care issues with their GPs in detail:

- their personal disease burden (complaints, dyspnoea, exacerbations)

- their diagnosis

- the impact of lifestyle on their disease (smoking, lack of exercise)

- medication, inhalation technique and compliance.

At the end of the one year research period, GPs asked the selected patients to visit the AC-service as part of their new asthma/COPD disease management and to discuss results during consultation.

GPs' performances during these consultations (supported by a report of the $\mathrm{AC}$-service) were examined with the same questionnaire as used at the start of the study, which was sent to the patients eight weeks after the invitation to visit the AC-service. By that time the actual visit to the AC-service should have taken place, as well as the patient-doctor consultation discussing the results.

In order not to interfere with regular care, no special research protocols were written for neither the AC-service nor the GPs. 
Data from usual care consultations were compared to data from consultations supported by information from the AC-service. The influence of this information was examined by taking into account the specific data given to the GP by the AC-service (see figure 1).

\section{Data Analysis}

We compared the frequencies of each issue discussed (means per GP) during usual care and after support of the AC-service (SPSS 17, paired samples test).

The relevance of discussing specific issues could be assessed in AC-service supported consultations by studying impact scores as reported by the AC-service (SPSS 17, $\mathrm{X} 2$ test)

\section{Ethical Approval}

Participants were offered the usual care common in the local area and in other Dutch regions. At first this was without support of an AC-service. During the research period this support was introduced as part of the new usual care procedure. No ethical approval was needed in this case.

Informed consent was obtained from the participants to analyze the questionnaires as well as the data of the AC-service. Participants answered the questionnaire anonymously.
Figure 1: Chapters of information given in the report of the AC-service

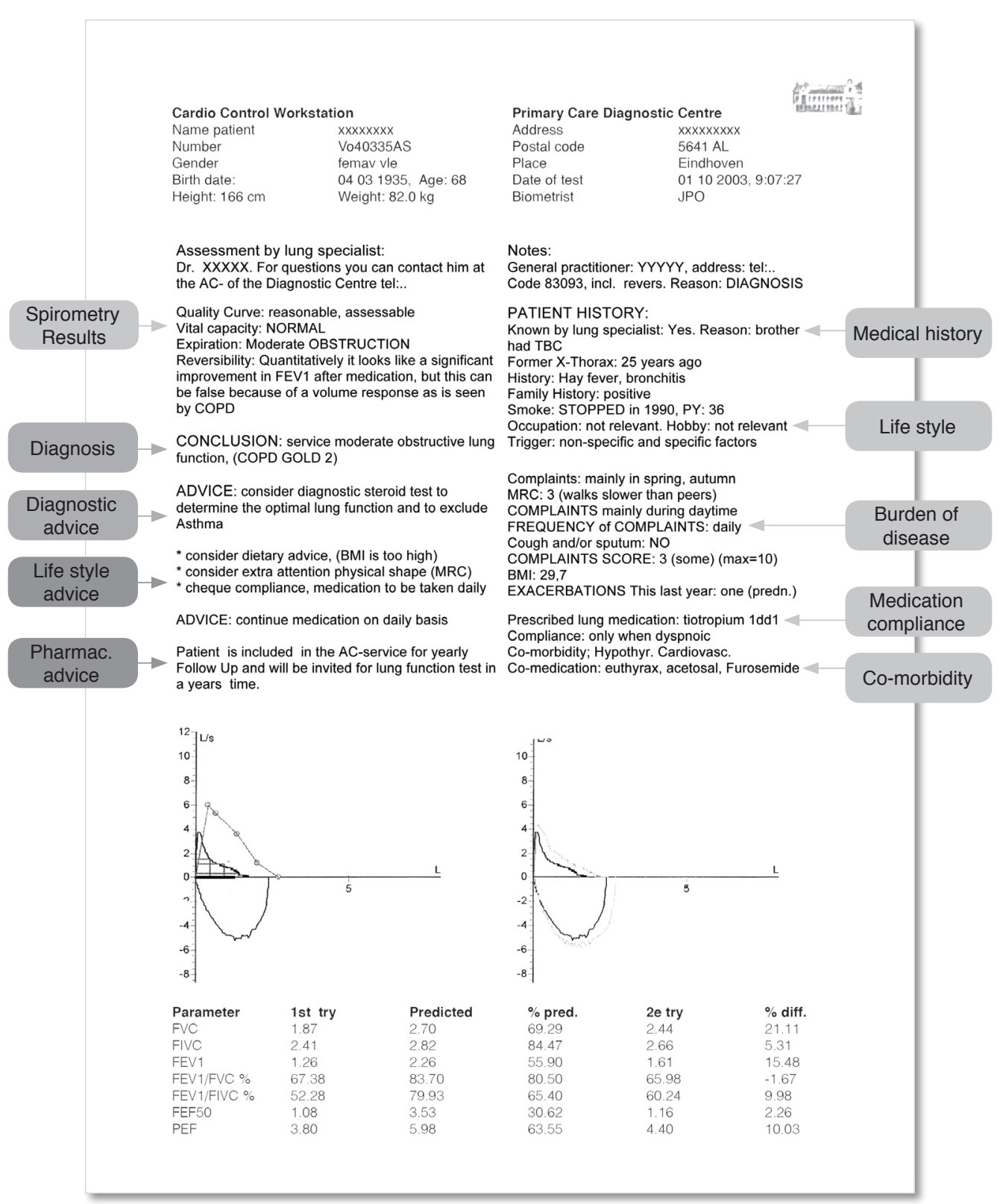




\section{Results}

Participating GPs

16 GPs participated in the study. GPs were on average 48 years of age, 30\% were female, and $40 \%$ of the practices were urban. The total patient population per GP ranged from 1135 to 2987 (Total: 37.949 patients),

\section{Figure 2: Participating Patients}

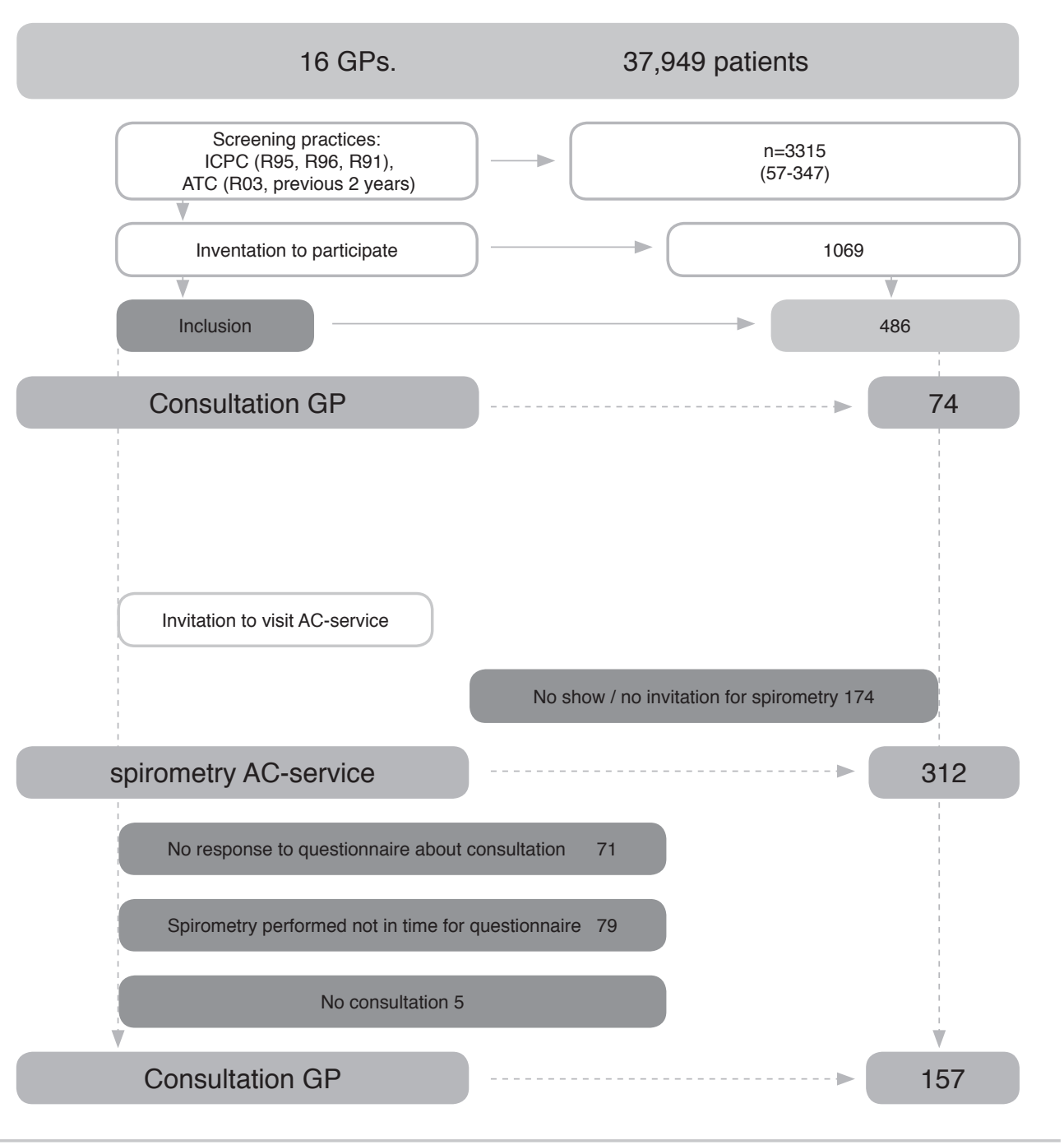

Participating patients

Of 1069 patients selected for the study, 486 agreed to participate (18-63 patients per GP. Mean: 30$)$. In the first 8 weeks of the study 74 patients (2-13 patients per GP) visited their GP for usual care and responded to the questionnaire. At the end of the study, after one year, 312 patients visited the AC-service.

157 (49\%) went for a consultation to their GP (6-23 patients per GP) and answered the questions about their GP's performance. These patients had baseline characteristics comparable to all patients visiting the AC-service: COPD prevalence: $17 \%$ $>1$ exacerbation/year: 22\%; smoking: 24\%: MRC-dyspnoea score $\geq 3$ : $17 \%$; using inhaled corticosteroids: $48 \%$; co-morbidity reported: $17 \%$.

Exploring the patients' disease burden

$85 \%$ of the patients consulting their GP after a visit to the AC-service did not mention complaints as a reason for consultation but $60 \%$ had a BORG $>3$ score for complaints. GPs discussed complaints in $77 \%$ and exacerbations in $78 \%$ of the AC-service supported consultations according to their patients (table 1). Complaints did get less attention (55\%) in telephone consultations (34\% of AC-supported consultations).

Table 1: Usual care consultations and AC-supported consultations (mean \% per GP) in which the burden of the respiratory disease was discussed with the patient (GPs: $n=16$. Patients "no ACs-support" $n=5-10 /$ GP, total 74. Patients "ACs-support": $n=9-21 / G P$, total 157)

\begin{tabular}{lccc}
\hline & $\begin{array}{c}\text { No support AC-s } \\
\text { Item discussed }\end{array}$ & $\begin{array}{c}\text { Support AC-s } \\
\text { Item discussed }\end{array}$ & $\begin{array}{c}\text { Paired t-test } \\
\text { means/GP }\end{array}$ \\
\hline Complaints & $91 \%$ & $77 \%$ & $p=.75 ; 95 \%$ C.I. $-24 /+.34$ \\
Exacerbations & $91 \%$ & $78 \%$ & $p=.79 ; 95 \%$ C.I. $-21 /+.34$ \\
Dyspnoea total & $25 \%$ & $31 \%$ & $p=1,00 ; 95 \%$ C.I. $-26 /+.26$ \\
Weight problems total & $14 \%$ & $6 \%$ & $p=0,57.95 \%$ C.I. -.24/+.14 \\
& & & \\
\hline
\end{tabular}


Overall, in consultations without AC-service support (16\% were telephone consultations) complaints were discussed more often (mean score GPs: 91\%). However, a paired sample test for means per GP showed no significant difference between discussion of complaints with and without AC-services support because some GPs discussed less complaints when supported by the AC-service and others discussed more $\left(t_{21}=.32, p=.75 .95 \%\right.$ c.i. $\left.-.24 \% / .34\right)$. This was due to differences in complaint severity between patients of different GPs (BORG>4: ranged $10 \%-60 \%$ per practice), which was significantly related to the frequency of discussing complaints $(\mathrm{p}=0,01, \mathrm{x} 2)$, (table 2)

There was no difference in frequency of discussing dyspnoea (31\% of the consultation; $\mathrm{t}_{19}=.00, \mathrm{p}=1,00 ; 95 \%$ C.I. 0,26/+0,26) between usual care and AC-supported care (table 2). GPs did not consider the exact MRC-dyspnoea score for discussing dyspnoea (table 2). $17 \%$ of the patients scored $\geq 3$ on the MRC-dyspnoea scale. Of those, $28 \%$ said it was not a relevant issue.

GPs paid some attention to overweight problems but not to underweight issues even when this was advised by the AC-service (table 2). Overall, weight problems only got attention in $6 \%$ of the consultations, there was no difference between usual care and AC-supported care ( $t_{18}=.-.56, p=0,57 ; .95 \%$ C.I.-.24/+.14). 50\% of the underweight persons thought it was not a health problem as did $25 \%$ of the overweight patients.

Giving information about the diagnosis

After receiving reports from the AC-service, 39\% of GPs discussed the diagnosis with their patients. Two thirds of the patients received a "clear explanation" regarding their diagnosis. Only half of them remembered their GP mentioning the name of their diagnosis. Lack of a diagnosis ("no asthma or COPD") was hardest to explain ("clear information" in 37\%). Asthma (70\%) and COPD patients (72\%) reported to be rather well informed about their diagnosis.

\section{Lifestyle recommendations}

According to the patients, GPs discussed smoking cessation with $66 \%$ of smokers after a visit to the AC-service (range $40-100 \%$ ) and with $71 \%$ in usual care (range $50-100 \%$ ) (table 3 ). $14 \%$ of smokers in the AC-supported consultations and $19 \%$ of smokers in usual care did not recall a smoking advice but answered that the issue was irrelevant. There was no significant difference for remembering stop smoking recommendations $(\mathrm{t}-2,3=.20, \mathrm{p}=0,34 ; 95 \%$ C.I. $-.14 /+0.05)$.
When the MRC-dyspnoea score was provided by the AC-service, GPs advised $13 \%$ of the patients with a MRC $\geq 3$ to improve their physical fitness (table 3 ). No significant difference between consultations was found for MRC scores and discussing fitness $(\mathrm{t}-2,3=.21 \mathrm{p}=0,42 ; 95 \%$ C.I. $-.32 /+.14)$

Table 2: Mean \% of GPs' consultations in which the burden of the respiratory disease was discussed with the patient, the actual prevalence of the problem as reported by the AC-service and severity weighting for whether or not discussing the item (GPs: $n=16$. Patients "ACs-support": $n=9-21 / G P$, total

\begin{tabular}{lccc}
\hline & \multicolumn{2}{c}{ Support AC-service } & \\
& $\begin{array}{c}\text { Prevalence of } \\
\text { item } \\
\text { reported by AC-s }\end{array}$ & $\begin{array}{c}\text { Item } \\
\text { discussed }\end{array}$ & $\begin{array}{c}\text { Weighting } \\
\text { severity }\end{array}$ \\
\hline BORGscore 0-21 & $49 \%$ & $51 \%$ & $P=$ \\
BORGscore 3 & $18 \%$ & $69 \%$ & 0,01 \\
BORGscore >4 & $33 \%$ & $90 \%$ & \\
$\quad$ Complaints total & $100 \%$ & $77 \%$ & \\
\hline Exacerbations n=0/yr & $78 \%$ & $72 \%$ & $P=$ \\
Exacerbations n>1/yr & $22 \%$ & $90 \%$ & 0,04 \\
$\quad$ Exacerbations total & $100 \%$ & $78 \%$ & \\
\hline MRC-dyspnoea 0-1-2 & $83 \%$ & $29 \%$ & $P=$ \\
MRC-dyspnoea 3-4-5 & $17 \%$ & $40 \%$ & 0,24 \\
Dyspnoea total & $100 \%$ & $31 \%$ & \\
\hline BMI <21 & $9 \%$ & $0 \%$ & $P=$ \\
BMI 21-30 & $75 \%$ & $4 \%$ & 0,06 \\
BMI > 30 $\quad 16 \%$ & $18 \%$ & \\
Weight problems total & $100 \%$ & $6 \%$ & \\
\hline
\end{tabular}

BORG-score: respiratory complaints: 0-2: no or few complaints 3: complaints; > 4: considerable/many complaints

Exarion: need for prednisolon/antibiotics because of respiratory complaints

$3=$ unable to walk up with people of same age, same sex, without dyspnoea; $4=d y$ sonc $5=$ dyspnoea in self care 
Table 3: Table 3. Lifestyle advice by GPs: mean percentage of consultations in which recommendations for improving lifestyle were given and their relevance according to the report of the AC-service. Overall difference between support and no support $(p)$

\begin{tabular}{|c|c|c|c|c|c|c|c|c|c|}
\hline \multirow[b]{2}{*}{ Available information } & \multicolumn{5}{|c|}{ Advice: stop smoking (mean/GP) } & \multicolumn{4}{|c|}{ Advice: improve condition } \\
\hline & $\begin{array}{l}\text { Actual } \\
\text { smoker }\end{array}$ & $\begin{array}{l}\text { Stoped } \\
\text { smoking }\end{array}$ & $\begin{array}{l}\text { Never } \\
\text { smoked }\end{array}$ & Overall & & $\begin{array}{c}\text { MRC } \\
0-2\end{array}$ & $\begin{array}{c}\text { MRC } \\
\geq 3\end{array}$ & Overall & \\
\hline No ACs-support & $71 \%^{1}$ & $7 \%$ & $0 \%$ & $31 \%$ & $P=$ & $13 \%$ & $17 \%^{3}$ & $17 \%$ & $P=$ \\
\hline ACs- support & $66 \%^{2}$ & $10 \%$ & $0 \%$ & $21 \%$ & 0,34 & $10 \%$ & $13 \%^{4}$ & $13 \%$ & 0,42 \\
\hline
\end{tabular}

1,2 in addition $14 \%^{1}$ and $19 \%^{2}$ of the smokers said it was irrelevant to discuss stop smoking

3,4 in addition $14 \%^{3}$ and $40 \%^{4}$ of the patients MRC $\geq 3$ said it was irrelevant to discuss how to improve physical shape

\section{Managing medication}

Patients in usual care and patients with a visit to the AC-service were similarly advised on how they should manage medication (table 4). At the start of the study $75 \%$ of all patients gave themselves 8 points on a 10-point scale for adequately using medication. Only $5 \%$ thought they should do better. This figure did not improve.

Table 4: Mean \% of consultations in which the compliance to prescribed medication and inhaling technique was discussed, instruction was given in inhaling medication and in adapting medication in case of more respiratory problems

A

\begin{tabular}{|c|c|c|c|c|c|}
\hline Available information & $\begin{array}{c}\text { Compliance } \\
\text { discussed }\end{array}$ & $\begin{array}{l}\text { Inhalation } \\
\text { technique } \\
\text { discussed }\end{array}$ & $\begin{array}{l}\text { Inhalation } \\
\text { instruction } \\
\text { given }\end{array}$ & $\begin{array}{l}\text { Correct dosis/ } \\
\text { use } \\
\text { explained }\end{array}$ & $\begin{array}{l}\text { Self manage- } \\
\text { ment instruction }\end{array}$ \\
\hline No ACs-support & $39 \%$ & $26 \%$ & $29 \%$ & $25 \%$ & $28 \%$ \\
\hline ACs- support & $42 \%$ & $31 \%$ & $29 \%$ & $28 \%$ & $43 \%$ \\
\hline
\end{tabular}

\section{Discussion}

It is known that the support of AC-services improves the diagnostic process as well as the logistic organization of asthma/COPD management in primary care ${ }^{[16]}$. An AC-service's report does not only provide a diagnosis but also a more complete set of data about a patient's respiratory condition. We examined whether these reports had a positive influence on the consultation performances of GPs. Our findings, based on patient recall, showed that GPs supported by an asthma/COPD-service did not conduct more comprehensive consultations than GPs who delivered usual care. Van den Bemt found this result for consultations with long time monitored, stable COPD patients ${ }^{[17]}$. We could not find evidence for her expectation that results should be better for patients recently referred to the AC-service.

AC-service supported consultations were delivered by phone more often than usual care consultations. It is known that telephone consultations are shorter and contain less data-gathering and counselling/advice ${ }^{[18]}$. This might contribute to but should not be a justification for the lack of improvement, i.e. more extensive consultations when more information is available.

A positive finding was that issues discussed were tailored to the scores reported by the AC-service, even when patients had bad scores and thought that this discussion was irrelevant. In addition, GPs were able to address patients who might not have come for follow up, even if they had complaints, without the invitation to visit the AC-service.

Regular follow up of patients with chronic conditions such as asthma and COPD is recommended by the guidelines. The AC service supports an active follow up system by monitoring asthma and COPD patients upon request of their GPs, thus guaranteeing as much as possible regular follow up independent from complaint presence.

COPD patients in particular are badly informed about their disease ${ }^{[19]}$. In our study only a minority of the patients could name their diagnosis, and amongst these one third had not clearly understood their GP's explanation. Patients particularly did not understand their GP's explanation when the diagnosis asthma or COPD was still uncertain which occurs for $50 \%$ of the patients visiting the AC-service for the first time ${ }^{[13]}$. This stresses the importance for GPs as well as their patients to understand their health problem. Therefore, we recommend to have patients monitored by the AC-service at the very least until their diagnosis is clear before monitoring is decreased or even stopped as suggested by the literature ${ }^{[17,20]}$. 
Studying GPs' performances in detail we found that a stop-smoking advice was adequately given by all GPs independent from the support of the AC-service. Of course it requires a bigger effort to get patients, especially those with $\mathrm{COPD}^{[21]}$, to actually stop smoking. Overall, smoking habits in the study population hardly changed: $12 \%$ of the smokers stopped in both usual care and ACs-supported practices but $8 \%$ of the non-smokers started smoking during the research period.

Advice to improve physical fitness was rarely given. Since one third of the patients with a MRC-dyspnoea score $\geq 3$ did not think improving physical fitness was an issue to discuss, GPs should be instructed to pay more attention to the MRC-dyspnoea score as a first step in implementing this important life style item ${ }^{[22]}$.

In usual care and in ACs-supported consultations, GPs gave similar advice on how to manage medication, indicating that triggering by the AC-service was as effective as being triggered by existing complaints. As shown in other research ${ }^{[23]}$ there is much room for improvement. GPs' awareness should grow but it is probably more effective to delegate patient information and education to nurse practitioners ${ }^{[24]}$ who are known to work in a more structured way ${ }^{[25]}$ and who appreciate protocol support ${ }^{[26]}$.

We realize that diagnostic spirometry results as a reason for consultation could distract GPs and patients from clinical issues. Patients in our extensive research project reported no clinically relevant differences between experienced attention in usual care and in AC-services supported consultations. This part of the study showed that consultations following a visit to an AC-service were at least as complete as consultations in usual care because of complaints.

\section{Limitations of the study}

The subject of our study was consultation behaviour of general practitioners. We could not question the GPs themselves about their care process and the effect of the AC-service support. In order not to interfere with medical routines, we instead chose to question their patients after consultation. Patients questioned at the start and at the end of the study might not have been the same persons. Although GP behaviour cannot be independent from a specific consulting patient, it should be possible to examine general behaviour patterns in GPs consultations with all their patients and the influence of AC-service support on this pattern.

Recall bias was reduced as much as possible through questionnaire timing. Nevertheless, recall bias cannot be excluded entirely because patients' perceptions about issues being addressed or being important to recall might differ from actual actions taken. However, the final result should be that the patients benefit from the support of an AC-service. This justifies using patients' answers as measures in our study, acknowledging that patients might have to visit their GP more often before all issues are discussed and / or remembered.

In our study, not only the introduction of consultation support to GPs was new but also the invitation for patients to visit the AC-service and their GP's office. We chose to study the new situation and compare it with the usual one. Through this design, a difference became apparent between patients in usual care and patients consulting their GP after a visit to the AC-service: in usual care patients only named "complaints" as a reason for the encounter while patients that had visited the AC-service mostly mentioned consulting their GP to discuss the results of their spirometry test. They were more likely to have a telephone consultation.

Since complaints and face-to-face visits are likely to trigger GPs to inform and educate patients more comprehensively, we are pleased to find that there was no difference between usual care (complaints) and AC-supported care (often no complaints). We might have found a more positive influence of the AC-service report if we had compared follow-up consultations fully supported by the AC-service and follow-ups supported only by spirometry results, excluding telephone consultations. Both situations were artificial, and therefore were not chosen for this real life study.

\section{Conclusion}

An AC-service can support GPs in structuring communication with their patients about many aspects of their disease but no significant communication differences were found for consultations supported by AC-service reports compared to usual care consultations.

GPs should be encouraged to use the information and advice given by the AC service and to discuss this with their patients in a structured manner. Awareness about the full content of the report should be given sufficient attention by all Asthma/COPD services supporting GPs. 


\section{Literature:}

1. Gallefoss, $F$, the effects of patient education in COPD in a 1 year follow-ip randomised controlled trial. Patient education and counselig, 2004. 52(3): 259-266.

2. Bourbeau, J,. van der Palen J, Promoting effective self-management programmes to improve COPD. Eur Resp J 2009. 33(3): 461-463.

3. Trappenburg, J, Koevoets L, de Weert-van Oene G, Monninkhof E, Bourbeau J, Troosters T,et al. Action Plan to enhance self-management and early detection of exacerbations in COPD patients; a multicenter RCT. BMC Pulmonary Medicine, 2009. 9(1): p. 52.

4. Walters JAE, Turnock A, Walters EH, Wood-Baker R. Action plans with limited patient education only for exacerbations of chronic obstructive pulmonary disease. . Cochrane database of systematic reviews 2010(5): CD005074.

5. LAN, Long Alliantie Nederland, Zorgstandaard COPD (Dutch standard for COPD Management and Care). www.longalliantie.nl, 2010.

6. Noordman J, Verhaak P, van Dulmen S. Discussing patient's lifestyle choices in the consulting room: analysis of GP-patient consultations between 1975 and 2008. BMC Fam Pract, 2010. 11(1): 87.

7. Cranston JM, Crockett AJ., Moss JR, Pegram RW, Stocks NP. Models of chronic disease management in primary care for patients with mild-to-moderate asthma or COPD: a narrative review. Med J Aust. 2008. 188(8 suppl):. s50-2.

8. Lucas A, Smeenk F, Smeele I, Brouwer T, van Schayck O., The validity of diagnostic support of an asthma/COPD service in primary care. Br.J Gen Pract. 2007. 57(544):. 892-6.

9. Lucas AEM, Smeenk F., van den Borne BEEM, Smeele IJM, van Schayck CO, Diagnostic assessments of spirometry and medical history data by respiratory specialists supporting primary care: are they reliable? Prim Care Resp J 2009. 18(3): 177-184.

10. van Schayck C P, vd Heijden FM, van den Boom G, Tirimanna PRS, van Herwaarden $\mathrm{CL}$, Underdiagnosis of asthma: is the doctor or the patient to blame? The DIMCA project. Thorax, 2000. 55(7): 562-565.

11. van Weel, C. Underdiagnosis of asthma and COPD: is the general practitioner to blame? Monaldi Arch Chest Dis, 2002. 57(1):. 65-8.

12. Lucas AEM, Smeenk F, Smeele I, van Schayck O., Diagnostic accuracy of primary care Asthma/ COPD working hypotheses, a real life study. acceted for publication by Resp. Med 2012.

13. Lucas AEM, Smeenk FW, Smeele IJ, van Schayck CP. Diagnostic advice by Astma/COPDservices and its usefulness to reduce diagnostic uncertainty in primary care (submitted), 2011

14. Lucas AE, Smeenk F, Smeele IJ, van Schayck CP. Overtreatment with inhaled corticosteroids and diagnostic problems in primary care patients, an exploratory study. Fam Pract.2008. 25(2): 86-91.

15. International Classification of Primary Care: short titles and Dutch subtitles. Utrecht; Nederlands Huisartsen Genootschap; 1995

16. Meulepas MA, Jacobs.JE., Lucas AE, Smeenk FW, Smeele I, Bottema BJ, Grol RP., The feasibility of a primary care model for the management of COPD. Prim Care Respir J, 2006. 15(6) 337-41.

17. van den Bemt L, Schermer T., Smeele IJ, Boonman-de Winter LJ, van Boxem T, Denis J, et al., An expert-supported monitoring system for patients with chronic obstructive pulmonary disease in general practice: results of a cluster randomised controlled trial.. Med J Aust. , 2009. 191(5): 249-254.

18. McKinstry, B, Hammersley V, Burton C, Pinnock, H, Elton R, Dowell J, et al., The quality, safety and content of telephone and face-to-face consultations: a comparative study. Quality and Safety in Health Care 2010. 19(4): 298-303. 
19. Hernandes P, Balter M., Bourbeau J, Hodder R, Living with chronic obstructive pulmonary disease: A survey of patients' knowledge and attitudes, 2009 Resp Med 103(12): 1004-1012.

20. Abramson M, Schattner.R., Sulaiman D, Birch K, Simpson P, Del Colle E, Aroni R, et al. Do spirometry and regular follow-up improve health outcomes in general practice patients with asthma or COPD? A cluster randomised controlled trial. Med J Aust., 2010. 193(2): 104-109.

21. Wilson S Elborn JS, Fitzsimons D. 'It's not worth stopping now': why do smokers with chronic obstructive pulmonary disease continue to smoke? A qualitative study. Journal of Clinical Nursing, 2011. 20(5-6): 819-827.

22. van Wetering C, van Nooten F, Mol S, Hoogendoorn M, Rutten-van Molken M, Schols A Systemic impairment in relation to disease burden in patients with moderate COPD eligible for a lifestyle program. Findings from the INTERCOM trial. Int J Chron Obstruct Pulmon Dis 2008. 3: $443-451$.

23. Braido F, Baiardinil, Menoni S, Brusasco V, Centanni S, Girbino G,et al. Asthma management failure: a flaw in physicians' behaviour or in patients' knowledge? J Asthma 2011. 48(3): 266-74.

24. Hesselink, A. Penninx B, Windt D, van Duin B, de Vries P, Twisk J, et al, Effectiveness of an education programme by a general practice assistant for asthma and COPD patients: results from a randomised controlled trial. Patient Educ Couns, 2004. 55(1): 121 - 128.

25. Meulepas MA, Jacobs JE., Smeenk FW, Smeele I, Lucas AE, Bottema BJ, Grol RP, Effect of an integrated primary care model on the management of middle-aged and old patients with obstructive lung diseases. Scand J Prim Health Care 2007 25(3):186-92.

26. Zakrisson $A B$, Hägglund $D$. The asthma/COPD nurses' experience of educating patients with chronic obstructive pulmonary disease in primary health care. Scand J Caring Sci 2010. 24(1): $147-55$. 


\section{General discussion}

This thesis gives more insight into the quality of the diagnostic and therapeutic support offered by an Astma/COPD-service to general practitioners delivering primary care to patients with respiratory problems. In this chapter we present the main findings of our studies and the methodological considerations, and summarize the overall conclusions. Next we discuss the implications of our research for primary care daily practice, and, at the end, we recommend further research topics.

\section{Main results}

Chapter 1 describes the development, workup, and protocols of the evaluated astma/COPD-service. The asthma/COPD-service performs spirometry on patients referred by their GPs and consulting pulmonologists assess the written spirometry data according to a protocol. To improve the diagnostic quality of the assessments, structured medical histories are added to the spirometry results. These also enable the pulmonologists to include additional diagnostic advice, as well as life style and pharmacotherapeutic advice. When asthma or COPD is diagnosed (or cannot be excluded) GPs can have their patients called up by the service for yearly follow up.

In chapter 2 we showed that diagnostic assessment based on spirometry and written structured medical histories gives results equal to face-to-face diagnostic assessment during specialist consultation. This means that the AC-service diagnosis can more or less be considered best practice for daily practice primary care diagnostic support.

Since the AC-service performs about 10.000 assessments each year, a team of assessors is needed. In chapter 3 we examined the intra- and inter-observer variability of the given diagnoses and additional diagnostic advice. A team of five expert assessors showed good intra- and inter-assessor reliability for the diagnosis and a fair reliability for the additional diagnostic recommendations (diagnostic advice). This means that results of diagnostic assessments can be considered to be independent from the assessing specialist. This could not be concluded for the pharmaco-therapeutic recommendations. These were related to the assessments of patients' disease stability; a feature based on a complex combination of clinical characteristics and therefore leading to classification disagreements between assessors.

Chapter 4 addresses one of the reasons for diagnostic uncertainty amongst assessors, which was the use of inhaled corticosteroid (ICS) by patients who were not diagnosed as asthma patients yet and who did not have lung function characteristics or a medical history suspect for asthma. Should they be diagnosed with asthma or was this diagnosis justifiably doubted? We found that the majority of the patients 
using ICS without a clear reason (25\% of all ICS-users) did not get respiratory problems or exacerbations after stopping use of ICS. They remained symptom-free and did not show (progressive) airway obstruction after a one-year follow-up period. This indicates that they did not have (ICS-dependent) asthma or severe COPD with recurrent exacerbations. It also made clear that overtreatment is a serious problem in primary care asthma/COPD-patients.

Thus, being confident about the validity and reliability of the AC-service's diagnostic support and knowing the important assessment pitfalls, we proceeded to evaluate the results of this support for the GPs' diagnostic processes.

In Chapter 5 it is explored how the AC-service influenced GPs' working hypotheses for all patients with (possible) asthma or COPD selected by screening the office registers. We found that the diagnostic support of the AC-service was helpful for all these patients independent of their working hypothesis and the way this hypothesis was developed (clinical symptoms, spirometry, and specialists' correspondence). When GPs did not have a working hypothesis all patients were given a new diagnosis. Half of the existing working hypotheses were confirmed, the other half changed. In case of uncertainty about the (complete) diagnosis, GPs were advised to perform additional diagnostic examinations. We assumed that fresh diagnoses as well as confirmed working hypotheses, with or without additional advice, were diagnostic improvements, since they were given by expert assessors.

In chapter 6 the diagnostic results were examined during a follow-up visit to the AC-service after one year. $44 \%$ of the diagnoses originally given by the AC-service were adapted. Adaptations were related to diagnostic uncertainty expressed by additional diagnostic advice given after the first visit to the AC-service. Diagnostic uncertainty still remained to a certain extent at follow-up: GPs did not adhere very well to additional diagnostic recommendations and more diagnostic adaptations could be expected at follow-ups to come.

Chapter 7 describes whether patients experience changes in the consultation skills of their GPs when they use reports of an Asthma/COPD service. In these reports the AC-service's structured medical history taking is recorded as well as the diagnosis and diagnostic advice. GPs can use this information to get a complete picture of a patient's disease burden and lifestyle which should be addressed in consultations according to guidelines for patient information and (self management) education. When asked, patients did not report a difference in GPs' education performance between usual care consultations and AC-service supported consultations.

\section{Methodological considerations}

The ultimate research question should be whether the support of an Asthma/COPDservice given to GPs is beneficial to the well-being of asthma and COPD patients in real life. To be able to answer that question the content and quality of the support first has to be clear. Therefore in our study we focused on understanding the support process (validity, reliability) and the different aspects that might be most successful in influencing its effect. We choose to examine the usual care procedures without structuring or guiding the process. This led to several methodological complications.

\section{Study design}

When studying the impact of an intervention the quality of this intervention (in our study the support of an Asthma/COPD-service) should be uncontestable. We therefore studied the validity and reliability of the support of the AC-service. As expected the validity and reliability were proven sufficient and comparable to other complicated diagnostic procedures but they were not perfect. For daily practice this means that GPs should not automatically accept but consider carefully the assessments and take final responsibility for diagnosis and treatment. In our effect study we ignored this phenomenon, realizing that the assessments of the AC-service offer best practice support (chapter 2) and are closer to best practice than the average GPs assessments.

To study the effects of the Asthma/COPD-service intervention we described what happened diagnostically in practices supported by the asthma-COPD/service (chapter 4, 5): how did working hypotheses change into diagnoses assessed by the AC-service, and how did diagnostic advice influence these first diagnoses to gain more certainty at follow-up assessment? It was not possible to compare this with the diagnostic process in unsupported practices since for those no outcome data (of the AC-service) were available. We examined AC-service support induced changes in GPs' consultation performance in a before-after study in practices receiving support at the end of the study period (chapter 7).

Except in the study of inappropriate use of ICS (chapter 4), we did not influence usual care by research protocols. We only asked GPs for their working hypotheses (chapter 5) and, to prevent a learning effect in GPs, we collected data about effects of the intervention from other sources. Diagnoses and results of diagnostic advice were obtained from the Astma/COPD-service; information about GPs' consultation performance was given by their patients. We realize that patients' information might be subject to recall bias ${ }^{[1]}$. 
Similarly, to prevent influence on usual care, we did not add research protocols to the regular working methods of the pulmonary specialists (chapter $2,3,5,6$ ) or of the general practitioners (chapter 4, 5, 6, 7). Nor did we offer special training to assess spirometry and medical history accurately or to fully use the reports of the AC-service. Because of this design we examined both the quality of AC-service intervention and the adherence of specialists, GPs and patients to the protocols.

As in most studies we lost data in our study. This was due to registration inaccurateness in GPs' medical records, complexity of enrollment in the study, non response to questionnaires and to invitations for spirometry tests and because of less effective consultations with limited interventions by GPs when patients turned out to be "normal", i.e. did not have asthma or COPD. Taking this, and the other considerations into account this research gives insight into the real life feasibility of improving the process and the quality of primary care for asthma/COPD-patients through valid and reliable AC-service support. Insight into the maximum possible quality improvement, when desired, should be obtained by strictly protocolized and controlled research.

\section{Overall conclusions}

Overall the conclusions of this thesis are

1. an asthma/COPD service gives best practice diagnostic support to GPs, offering valid and reliable diagnoses and useful additional diagnostic advice

2. additional advice in case of diagnostic uncertainty can be more effective when GPs adhere better to the given diagnostic recommendations

3. All patients selected by screening medical records on asthma and COPD can benefit from diagnostic assessment by an AC-service

4. the diagnostic process should be conducted before prescribing ICS, to prevent diagnostic assessment problems, incorrectly labeling patients as asthma patients and to prevent overtreatment with ICS

5. pharmacotherapeutic advice based on a patient's clinical condition cannot reliably be given from the written data now available in the astma/COPD service report

6. the additional asthma/COPD service diagnostic support does not lead to measurable improvements in GPs performance in asthma and COPD, patients disease knowledge and (self-) management than after usual care consultations

\section{Implications for daily primary care practice}

We examined the support of the AC-service in all its details and in the different chapters of this thesis we also discussed results of each part in detail. To further understand the implications for daily practice we address the questions that originally inspired our study, deriving answers from our own results and from the literature:

- "Support services for GPs: a threat to GPs' autonomy or a good idea?"

- "Spirometry in primary care, who should do it?"

- "Diagnostic quality improvement, how to achieve it?"

- "Support of an asthma/COPD-service, to what extent?"

- "How to continue diagnostic support in the near future?"

\section{Support services for GPs: a threat to autonomy or a good idea?}

As occurs for other fields in general practice, there is a discussion about GPs autonomy in caring for asthma/COPD patients and about the need for support, for example in diagnostic procedures. However, history tells us that GPs should not be allergic to support as it develops alongside of the development of our professional maturity.

\section{An overview:}

General Practice as a medical discipline developed at lightning speed in the Netherlands from the late seventies onwards, when a one year course was introduced for medical masters to emphasize that general practice was a specialization within medical practice. This course, currently a three year curriculum, was the first support for doctors who practiced family medicine until then on their own merit. In 1989, the first standard for general practice was edited by the "NHG" (Nederlands Huisartsen Genootschap, = the Dutch Association of Family Doctors), addressing diabetes mellitus type $2^{[2]}$. Close to 100 standards followed and were regularly updated ${ }^{[3]}$. At first the NHG-standards met quite some resistance because of "handing over autonomy" and "enforcing uniformity" ("eenheidsworst"), but soon the standards were welcomed by all GPs as a supportive source of knowledge and evidence based practice, leaving enough possibilities for variation according to the individual patient's health care.

NHG-standards made clear that practices had to be re-organized to meet the implicit quality standards required. More tasks were delegated to practice assistants and in 2001 practice nurses ("praktijkondersteuners") were introduced. Disease 
management models describing the cooperation between GPs, practice nurses, specialists and facilitating services were the next step in supporting primary care ${ }^{[4]}$. These models stimulated facilitating services to develop from diagnostic services into services offering extended support for disease management. At first, this development encountered criticism; did those diagnostic services interfere with the professional autonomy in screening, diagnosing and monitoring patients? After a while the practical value of a protocolized diagnostic process was understood, especially when patients adhered better to the care process and better results of care were shown in a research program ${ }^{[5,6]}$

Some skepticism was also related to the introduction of specialist expertise meant to support the care process ${ }^{[7]}$. GPs and specialists had to establish correct notions about each other's competence. Concerns about financially driven competition were fed by specialist consultation hours offered for minor (primary care) complaints ${ }^{[8,9]}$ These obstacles had to be cleared to improve GPs' confidence in new supportive, cooperative care structures. Confidence is positively influenced by initiatives shared by GPs and specialists that meet the professional (support) needs of GPs.

An important stimulus for implementation of disease management programs was the new system for financing medical care, the "DBC", introduced in 2003. (DBC= payment for the full program from diagnosis to treatment: Diagnose-Behandel-Combinatie). To be eligible for payment for delivering care to chronically ill patients this care had to be contracted by GPs and health insurance companies. Insurance companies only offered contracts to GP-cooperations thus GPs had to organize themselves as a group and agree about the content and quality of care they would contract. Health insurance companies more or less forced the GPs to carefully consider quality and costs of care. In return for the payments for care they asked for process transparency and results of the care process which should guarantee better health for the patients and lower costs for society. Although not experienced in that way, these regulations certainly were an important support for GPs to improve their care, as is confirmed by the data reported to the health insurance companies.

While all these developments occurred, much effort was put into improving GPs skills and knowledge to keep up with the professional and social requirements Continuing education became obligatory for at least 40 hours per year. GPs had to come together and discuss their knowledge ("DKB") diagnostic skills ("DTO"), and pharmacotherapy ("FTO"). For this, specialist support was given by professional organizations and by the pharmaceutical industry, both strictly bound to primary care professional standards and to objectivity and regulations about conflict of interest. GPs were supported to implement knowledge, skills, and disease management systems by their own cooperative organization and by external providers. Specialized nurses were sent to screen registration systems to find patients eligible for chronic care program. Office registration systems were improved to monitor care. IT-communication between primary care offices and diagnostic laboratories and hospitals became usual practice. Specialists and hospitals intended to support primary care by organizing one stop hospital visits and single patient consultations. Furthermore, professional responsibilities were to be shared functionally instead of disciplinarily between specialists and general practitioners.

Support also focused on patients who increasingly became partners in care. The most recent developments are the Zorgstandaarde ${ }^{[10]}$ in which patients and professionals can find all information about the disease and about what to expect of each participant in the care process, including the patient and the specialist expert. As a logical consequence, patient portals now receive much attention.

This overview shows that professional support and stimulus has become an essential and natural part of primary care daily practice. As long as the GPs as professionals initiate their own support there should be no fear of losing control. On the contrary, support can make it possible to meet the high quality standards in health care and to handle the heavy workload in general practice better.

\section{Spirometry in primary care, who should do it?}

The allocation of spirometry in primary care is an interesting issue. There are 3 options: - primary care offices organize, perform, and interpret spirometry themselves

- primary care offices are supported by diagnostic facilities like an asthma/COPDservice described in this thesis

- pulmonologists supervise the primary care diagnostic and also the therapeutic process by means of joined consultations, proved to be efficient in other disciplines in medicine like orthopedics ${ }^{[11]}$, cardiology ${ }^{[12]}$, rheumatism ${ }^{[13]}$

Many issues contribute to this discussion. GPs who want to perform their own diagnostic procedure accept the challenges of organizing the complex diagnostic, monitoring and registration procedures and keeping spirometry performance skills of their practice nurses as well as their own interpretation skills up to date.

The advantage of this model is a one-stop service to the patient, professional autonomy, and business-like autonomy. However, concern arises about the quality of the diagnostic process. Even though spirometry as point of care testing (POCT) has become more popular ${ }^{[14]}$ not much is known about its quality in daily primary care. In 
study sites, $90 \%$ of the primary care lung function tests were sufficiently accessible after intensive training, especially in patients with few dyspnoea problems ${ }^{[15]}$. When trained, primary care practice nurses' skills in performing spirometry were as good as the skills of clinical lung function assistants ${ }^{[16]}$. However, in real life, only $30 \%$ of the routine spirometry tests in general practice fully met the ATS-criteria ${ }^{[17]}$. Nevertheless, some $84 \%$ of the lung function tests were clinically usefu[ ${ }^{[18]}$. In comparison, primary care asthma/COPD diagnostic centers reached $60 \%$ perfect tests, which nevertheless could be used for assessments in $97 \%$ This is better than the internationally accepted figure which lies around $70 \%$ usefulness ${ }^{[19]}$.

Another issue is the performance of GPs in interpreting spirometry results and in assessing a diagnosis. In research settings, GPs can be trained to recognize normal and obviously obstructive lung functions but rare and mixed pathologies were often missed $^{[20]}$. In real life, participation in interpretation courses is high ${ }^{[21]}$, however, the need for support remains ${ }^{[22,23]}$ and also the need for feedback and discussions. GPs who feel confident about their interpretation skills and about how they keep those updated, can choose to organize the lung function tests in their own office. A choice that, in the near future, might be influenced by quality requirements as a condition for receiving payment for this diagnostic task ${ }^{[24]}$.

Diagnostic support delivered by an Asthma/COPD service-like facility solves the practical problems of purchasing, maintaining, and calibrating spirometers, of organizing spirometry in the office and of managing the follow-up of asthma/COPD patients ${ }^{[4]}$. Most important is the validity of the diagnostic assessments (chapter 2), and the trigger to critically consider diagnostic uncertainty (chapter 5), even when GPs occasionally complain about inconsistencies which are inevitable because of the complex procedures as shown in our reliability study (chapter 3$)^{[25]}$.

When a diagnosis is set - for which some more lung function tests might be necessary (chapter 5, 6) - patients need follow-up spirometry to monitor their disease. GPs can decide to continue the performance and interpretation of the lung function tests in their own office, using spirometry tests of the AC-service as reference tests. However for practical, disease management, and quality reasons, continuing follow-up by an Asthma/COPD-service is an alternative that is at least as good as POCT.

Pulmonologists concerns about diagnostic problems in primary care are caused by their experiences with patients that were referred too late or inadequately. Of course pulmonologists should be consulted in time. However, the majority of primary care respiratory patients can be taken care of by GPs with no special need for supervision as given in joined consultations (GP and expert). This is especially the case when pulmonologists are already involved as diagnostic consultants for an asthma/COPDservice in the daily diagnostic process ${ }^{[2,27]}$.
To summarize, it is recommend that primary care spirometry is performed and interpreted by an asthma/COPD-service at least until the diagnosis is most certain. After that it depends on the preference of the GP or its cooperative organization based on practical and quality arguments, whether follow-up spirometry is continued as POCT or by the asthma/COPD-service.

\section{Considerations on achieving diagnostic quality improvement}

Many studies (amongst which ours, see chapter 4) show that over- and under diagnoses in primary care respiratory patients occur due to basing a diagnosis solely on medical history ${ }^{[28]}$ or due to poor spirometry quality ${ }^{[26]}$. Besides improved spirometry performance adding to diagnostic accuracy, efforts are made to find additional diagnostic tools for detecting (COPD-) patients ${ }^{[29]}$ and to better characterize respiratory diseases and their severity ${ }^{[10]}$. However, spirometry performed and interpreted correctly is decisive. The first step in improving diagnostic quality is to make quality spirometry - not only spirometers - available to all primary practices ${ }^{[2]}$, defining quality for performance as well as for interpretation,

Diagnostic accuracy is improved by adding medical history to the results of lung function tests. Besides assessing the test quality, restriction, obstruction, and reversibility, the medical history data make it is possible - also for the asthma/COPD service consultants - to obtain a diagnostic assessment of the patient's clinical condition ${ }^{[30}$, ${ }^{31]}$. This is especially important for normal spirometry test results and inconsistent medical histories, like suspect complaints (chapter 6) or the use of ICS (chapter 4). Additional diagnostic advice could be given. However, GPs' adherence to advice needs improvement. A possibility is to send reminders to the GPs to first give information about the assumed diagnosis or the reason for prescription in case of ICS use without an obstructive lung function ${ }^{[3,32,31]}$. Another effective and efficient way of addressing this and other diagnostic questions might be organizing regular feedback and consultation meetings between pulmonologists and GPs. If implemented, an Asthma/COPD service should be able to provide relevant feedback data, initiate, and logistically support these consultation sessions.

GPs who perform and interpret spirometry have to keep their skills up to date and so do the consulting pulmonologists. Our study showed sufficient inter-assessor reliability. However, we also found some discrepancies between assessors. To some extent, these are inevitable due to differences in interpreting minor lung function deviations and different perceptions of patient's complaints, data on which a diagnosis is based. However, as we experienced, discussions between colleagues 
about interpretation and about accurate assessment according to the primary care guidelines are useful - when not necessary - to keep the assessments as close as possible to a gold standard, which unfortunately is not available. Asthma/COPD services can call attention to assessment disagreements and provide cases for consultation meetings between colleagues.

Furthermore, diagnostic quality can be improved by using "time" as an additional diagnostic tool, as is often used in primary care ${ }^{[3]}$. After a single visit to the Asthma/ COPD service a certain diagnosis is only given for half of the patients (chapter 2,3,5) and even then a diagnosis can change over time as this reflects a disease characteristic $^{[33]}$. Following the results of different tests over time gives a better insight into the real nature of the problem and former tests should be available to the interpreter.

Last but not least, the quality of the diagnostic process can be improved by easy referral of a patient to pulmonologist's consultation when uncertainty or other diagnostic problems persist. Thresholds to refer, if possible to one stop consultations, should be removed as much as possible. Pilot studies of pulmonologists' consultations in primary care settings are promising ${ }^{[7]}$.

\section{Support of an asthma/COPD-service, to what extent?}

After the Asthma/COPD service set its first goal - improving the diagnosis of asthma/ COPD in primary care - other targets developed more or less automatically. The question addressed here is to what extent the intervention of an asthma/COPD service (and a diagnostic facility for primary care in general) can be efficient, effective, and thus acceptable? Some answers can be derived from our study.

From the beginning the Asthma/COPD service collected medical history and life style data to better identify the patient's diagnosis. Smoking behavior and age could make a difference for COPD or fixed asthma; information about the use of ICS should ascertain the diagnosis asthma in normal lung functions. However, the data were not only used for setting a diagnosis, they also triggered advice for additional diagnostic examinations. So, diagnostic recommendations became part of the AC-service protocol. The advice to stop ICS and renew the diagnostic procedures not only clarified misdiagnosis of asthma, it also prevented unnecessary use and treatment costs for at least $15 \%$ of the former users (chapter 4). Also in Canada about $20 \%$ of the ICS-users could stop using ICS $^{[34]}$, indicating that misuse might be a worldwide problem. We conclude that effective support of an asthma/COPD-service goes beyond diagnostic assessment and that additional diagnostic advice, especially about (un-clarified) use of ICS, is a valuable surplus.
The question is whether this is also true for lifestyle advice and medical treatment. In addition to a diagnosis and diagnostic advice, the asthma/COPD service always gives life style advice when applicable. Patients, however, did not recall more life style information and life style advice when their GP used the astma/COPS service report (chapter 7). It is likely that there is more effect of this support when extra attention is given through coaching. However, it has been shown that extra coaching of practice nurses in using the recommendations from the Asthma/COPD service did not lead to greater success, at least not for long term COPD patients ${ }^{[35]}$.

Medical treatment advice is given dependent on disease (un-)stability and on already prescribed and/or used medication. This advice has been included in the support of the Asthma/COPD-service right from the start. It can be debated whether this has been a good decision. We did not find reliable judgment of disease stability (chapter 3), assessors disagreed too much. As a consequence reliable advice (i.e. independent from the assessing pulmonologist) is hard to give, making it problematic to blame GPs when they do not follow a treatment advice. The most important - but immeasurable - effect should be that GPs use the advice as a trigger to reconsider the pharmacotherapeutic treatment critically.

The debate is now about trying to improve the assessment of disease stability by adding additional measurements to the astma/COPD service protocols like a CCQ or $A C Q^{[36]}$, which in fact are instruments to be used by practice nurses when they evaluate the outcome of care with their patients and make decisions about next treatment steps and self management ${ }^{[37,38]}$.

Other discussions about the extent of support concern the duration of monitoring patients by an asthma/COPD service. For diagnosed asthma-patients, yearly lung function tests, including reversibility, are recommended to detect and prevent remodeling because of under-treatment ${ }^{[39]}$ and were found to be effective ${ }^{[40]}$. For diagnosed COPD-patients lung function tests do not contribute much to guidance ${ }^{[35]}$ but it is important to monitor disease burden regularly ${ }^{[4]}$. Spirometry frequency can be cut down to once in three years when there is no extraordinary loss of $\mathrm{FEV}_{1}$ or when patients have stopped smoking ${ }^{[10,42]}$. Spirometry tests might be stopped for COPD patients who have a long time stable clinical condition. Less stable or more severe COPD patients and asthma patients (using ICS) stay eligible for yearly spirometry monitoring.

We conclude that the common yearly follow-up routine should change to follow-up according to disease characteristics and the patient's needs. 


\section{How to continue diagnostic support in near future: recommendations}

As long as there are GPs who experience practical thresholds for spirometry in primary care practices ${ }^{[14,43]}$ and as long as GPs are not trained enough ${ }^{[31]}$ or do not feel confident about their diagnostic skills ${ }^{[22]}$, an asthma/COPD service can contribute to the diagnosis of asthma/COPD in primary care, especially since we have shown its validity and reliability.

We strongly recommend continuing this service, provided the asthma/COPD service puts effort into guaranteeing quality as close as possible to a - desired but utopian - gold standard for diagnosis and diagnostic advice. In addition, effort should be put in improving the adherence to and the effects of diagnostic advice by providing feedback to GPs as well as to assessors.

Follow-up of asthma/COPD-patients should focus on measuring disease progression and a decision has to be made about adding CCQ or ACQ to spirometry and medical history.

Furthermore, new ICT provisions will make it possible to call patients for spirometry follow up according to their own frequency requirements and to develop discriminative electronic pathways for new and follow-up patients, for asthma and COPD patients and for children and adults.

\section{Recommendations for further research}

Our research raises many questions concerning the asthma/COPD service that should be further examined:

- can interdisciplinary consultations by pulmonologists improve the reliability of the assessments and come closer to a "gold standard" for diagnosis in primary care?

- does feedback of (non-)adherence to diagnostic recommendations makes these recommendations more feasible? Does this feedback improve the quality of the recommendations of the pulmonologists and the adherence of GPs to (improved) recommendations? Does this affect the overall quality of diagnostic support as provided by the asthma/COPD service?

- do practice nurses make better use of the full report of the asthma/COPD service when offered only the reports or when trained, especially for new patients? Does this improve patients' knowledge and self management? Does this influence exacerbation frequency, smoking habits and lifestyle? Does this improve patient's quality of life?
Other research questions are raised by new developments:

- currently, one third of the Dutch practices has followed courses to improve their spirometry performance and interpretation skills like CASPIR ${ }^{[21]}$. Interest in office spirometry ("point of care") is growing. The quality of diagnostic assessments of these practices should be examined: how does this compare to the quality of assessments of consulting pulmonologists of an asthma/COPD service?

- is there a difference between diagnostic support by tele-consultation (un-protocolized) and (tele-) diagnostic support by an Asthma/COPD service (protocolized)?

- for which patients does live consultation by a pulmonologist add to the overall quality of asthma/COPD diagnostics in primary care?

- how do effectiveness and cost-effectiveness of the different diagnostic assessment possibilities in primary care compare?

Last but not least there is a need for a cost-benefit analysis, which should include not only the comparison of costs of different diagnostic routes but also their economical effect of wellbeing, morbidity, and mortality rates of astma/COPD-patients. 


\section{Literature}

1. Selic P, Svab I, Repolusk M, Gucek N. What factors affect patients' recall of general practitioners' advice? BMC Fam Pract 2011. 12(1): ;141.

2. Rutten G, de Grauw W. Nijpels G, Goudzwaard A, Uitewaal P, van der DOES F et a NHG-standaard Diabetes Mellitus type 2. Huisarts Wet 2006. 49(3):137-152.

3. Wiersma T, Boukes FS, Geijer RMM, Goudszwaard AN, NHG-standaarden voor de huisarts. Nederlands Huisartsen Genootschap, 2006 www.nhg.org.

4. Meulepas MA, Jacobs .J, Lucas AE, Smeenk FW, Smeele I, Bottema BJ, Grol RP., The feasibility of a primary care model for the management of COPD. Prim Care Respir J 2006. 15(6): 337-41.

5. Meulepas MA, Jacobs J., Smeenk FW, Smeele I, Lucas AE, Bottema BJ, et al, Effect of an integrated primary care model on the management of middle-aged and old patients with obstructive lung diseases. Scand J Prim Health Care 2007. 5(3):186-92.

6. Meulepas MA, Braspenning JC, de Grauw WJ, Lucas AE, Wijkel D, Grol RP... Patient-oriented intervention in addition to centrally organised checkups improves diabetic patient outcome in primary care. Qual Saf Health Care 2008. 17(5): 324-8.

7. Wesseling G, Vaassen MAP. Ketenpoli COPD Maastricht, lessons learnt. . (presentation of first results of a pilot) 2011

8. O'Dowd A., Darzi's five pledges fail to quell doctors' anxieties about polyclinics. BMJ 2008. 336(7653): 1090

9. Sheaff R. Medicine and Management in English Primary Care: A Shifting Balance of Power? Jnl Soc Pol 2009. 38(627-47).

10. LAN, Long Alliantie Nederland, Zorgstandaard COPD (Dutch standard for COPD Management and Care). www.longalliantie.nl, 2010

11. Vierhout WP, Knottnerus JA, van OOij A, Crebolder HF, Pop P, Wesselingh-Megens AM,et al. Effectiveness of joint consultation sessions of general practitioners and orthopaedic surgeons for locomotor-system disorders. Lancet. 1995. 346(8981):990-4.

12. Vlek J, Vierhout W, Knottnerus JA, Schmitz JJ, WinteR J, Wesselingh-Megens AMK, Crebolder HFM. A randomised controlled trial of joint consultations with general practitioners and cardiologists in primary care. Br J Gen Pract 2003. 53(487):108-112.

13. Schulpen GJ , Vierhout WP , van der Heijde DM , Landewé RB , Winkens RA, van der Linden $S$. Joint consultation of general practitioner and rheumatologist: does it matter? Ann Rheum Dis 2003. 62(2): 159-61.

14. Schellekens D, Poels P, Pellegrino A, Cretier R, Smeele I, Schermer T. Spirometry in Dutch general practice: Results of a national survey. Huisarts Wet 2008. 51(9): 434-9.

15. Enright P, Vollmer WM, Lamprecht B, Jensen R, Jithoo A, Tan W.et al. Quality of Spirometry tests performed by 9893 adults in 14 countries: The BOLD Study. Respir Med 2011. 105(10): 1507-1515.

16. Schermer TR, Jacobs JE, Chavannes NH, Hartman J, Folgering HT, Bottema BJ, et al. Validity of spirometric testing in a general practice population of patients with chronic obstructive pulmonary disease (COPD). Thorax 2003. 58(10): 861-866.

17. ATS, American Thoracic Society Official Statement. Standardization of Spirometry. 1994 Update. Am J Respir Crit Care Med 1995. 152: 1107 - 1136.

18. Landman M, Gilissen T, Grootens-Stekelenburg J, Akkermans R, Schermer T.The quality of spirometry in primary care. Huisarts Wet 2011. 54(10): 536-42.

19. Yawn B, Enright PL, Lemanske RF, Israel E, Pace W, Wollan P, Boushey H, Spirometry can be done in family physicians' offices and alters clinical decisions in nanagement of asthma and COPD. Chest 2007; 132(4). 1162-1168. 
20. Chavannes N, Schermer T, Akkermans R, Jacobs JE, van der Graaf G, Bollen R, et al. Impact of spirometry on GPs' diagnostic differentiation and decision-making. Respir Med 2004. 98(11): 1124-30.

21. Denis J, Smeele I, Van Gijsel H, Verschuur M, Heydra Y, Steenbruggen I, et al. CASPIR: Practical spirometry for primary care, a nation wide programme. Utrecht: CAHAG, 2010.

22. Poels P, Schermer RJ, Akkermans RP, Jacobs A, van den Bogart-Jansen M. Bottema BJAM, van Weel C. General practitioners' needs for ongoing support for the interpretation of spirometry tests. European Journal of General Practice 2007. 13(1): 16-19.

23. Walters JA, Hansen EC, Johns DP, Blizzard EL, Walters EH, Wood-Baker R,. A mixed methods study to compare models of spirometry delivery in primary care for patients at risk of COPD. Thorax 2008. 63(5): 408-414.

24. Nederlandse Zorgautoriteit. Advies Eerstelijnsdiagnostiek, diagnostiek onderzocht $2011 \mathrm{http}: / /$ www.nza.nl/104107/139830/465987/Advies_eerstelijnsdiagnostiek.pdf.

25. Lucas A, Smeek F, Smeele I, Brouwer T,van Schayck O Het klopt heel aardig!' Validiteit van het diagnostisch advies dat astma/COPD-diensten aan huisartsen geven (article in Dutch). Huisarts Wet 2008. 51(10): 479-84

26. White P, Wong W, Fleming T, Gray B. Primary care spirometry: test quality and the feasibility and usefulness of specialist reporting. Br J Gen Pract 2007. 57: 701-705.

27. Enright P. Provide GPs with spirometry, not spirometers. Thorax 2008. 63(5):387-388

28. Sandelowsky H, Stallberg B, Nager A,Hasselstrom J. The prevalence of undiagnosed chronic obstructive pulmonary disease in a primary care population with respiratory tract infections - a case finding study. BMC Fam Pract 2011. 12(1): 122.

29. Broekhuizen BD, Sachs AP, Oostvogels R, Hoes AW, Verheij TJ, Moons KG., The diagnostic value of history and physical examination for COPD in suspected or known cases: a systematic review. Fam Pract 2009. 26(4): 260-268.

30. Levy M, Quanjer Ph, Booker H, Cooper R, Holmes BG, Small S.Diagnostic Spirometry in Primary Care: Proposed standards for general practice compliant with American Thoracic Society and European Respiratory Society recommendations. Prim Care Respir J. 2009. 18(3): 130-147.

31. Price DB, Yawn BP, Jones RCM. Improving the Differential Diagnosis of Chronic Obstructive Pulmonary Disease in Primary Care. Mayo Clinic Proceed, 2010. 85(12): 1122-1129.

32. Lucas AE, Smeenk F, Smeele IJ, van Schayck CP. Overtreatment with inhaled corticosteroids and diagnostic problems in primary care patients, an exploratory study. Fam Pract 2008. 25(2): 86-91.

33. Calverley PMA, Burge PS, Spencer S, Anderson JA, Jones PW. Bronchodilator reversibility testing in chronic obstructive pulmonary disease. Thorax 2003. 58(8):659-64.

34. Pakhale S, Sumner A, Coyle D, Vandemheem K. (Correcting) misdiagnoses of asthma: a cost effectiveness analysis. BMC Pulm Med 2011. 11(1): p. 27.

35. van den Bemt L, Schermer T., Smeele IJ, Boonman-de Winter LJ, van Boxem T, Denis J, et al.An expert-supported monitoring system for patients with chronic obstructive pulmonary disease in general practice: results of a cluster randomised controlled trial. Med J Aust 2009 191(5): 249-254.

36. Van der Molen T, Willemse BW, Schokker S, ten Hacken NH, Postma DS, Juniper EF.Development, validity and responsiveness of the clinical COPD questionnaire. Health Qual Life Outcomes 2003. 1(1): 13.

37. Trappenburg JC, Monninkhof EM, Bourbeau J,Troosters T, Schrijvers AJ, Verheij TJ, Lammers JW. Effect of an action plan with ongoing support by a case manager on exacerbation-related outcome in patients with COPD: a multicentre randomised controlled trial. Thorax 2011. 66(11): 977-984.
38. McGeoch GR, Willsman KJ, Dowson CA, Town GI, Frampton CM, McCartin FJ, et al.Selfmanagement plans in the primary care of patients with chronic obstructive pulmonary disease. Respirology 2006. 11: 611 - 618 .

39. Geijer RMM, Chavannes NH, Muris JWM, Sachs APE, Schermer T, Smeele IJM, et al. Standard of the Dutch College of General Practitioners on asthma (NHG-Standaard Astma bi) volwassenen,article in Dutch). Huisarts Wet. 2007(11): 537-551.

40. Oei S, Thien F, Schattner RL, Sulaiman ND, Birch K, Simpson P, et al. Effect of spirometry and medical review on asthma contro in patients in general practice : A randomised controlled trial. Respirology 2011. 16(5): 803-810.

41. Tsiligianni I, Kocks JW, Tzanakis N, Siafakas N, van der Molen T. Factors that influence diseasespecific quality of life or health status in patients with COPD: a review and meta-analysis of Pearson correlations. Pr Care Resp J 2011. 20(3):257-268.

42. Smeele IJM, Van Weel C, Van Schayck CP, Van der Molen T, Thoonen B, Schermer T, Sachs APE, Muris JWM, Chavannes NH, Kolnaar BGM, Grol MH, Geijer RMM, Standard of the Dutch College of General Practitioners on COPD (NHG-Standaard COPD, article in Dutch). Huisarts Wet 2007. (8): 362-370.

43. Bolton C E, lonescu AA, Edwards PH, Faulkner TA, Edwards SM, Shale DJ. Attaining a correct diagnosis of COPD in general practice. Respir Med 2005. 99(4): 493-500. 



\section{Summary}

We know from epidemiology that about $2 \%$ of the population suffers from COPD and $3-4 \%$ has asthma. Disease burden differs for individual patients. Especially for COPD patients the disease can hinder patients to take part in everyday life activities, sometimes while they are unaware of their diagnosis or its severity. The diagnosis asthma is easily given because of cough, dyspnoea or wheezing. This might incorrectly label patients as chronically ill. Therefore, managing the problem of asthma and COPD starts with assessing the right diagnosis and identifying the patients who need care. This thesis evaluates a support system for general practitioners to handle this important but complex task. This support system is called the "asthma/COPD support service".

In chapter 1 the "asthma/COPD service" and its rationale is introduced. First, professionals developed guidelines that defined the diagnostic process for individual primary care asthma and COPD patients and introduced spirometry as a primary care facility. Then disease management models were needed to organize the process. For practical and for quality reasons, GPs, together with pulmonologists, invented a support system called the asthma/COPD service. Asthma/COPD services are private institutions or institutions connected to hospitals that offer diagnostic and therapeutic support to GPs who refer their patients for spirometry and medical history taking. Based on this written information, consulting pulmonologists perform protocolized assessments. Of those the Asthma/COPD service makes structured reports which are sent to the GPs, who are responsible for the patients care process. Diagnostic advice for further examinations as well as therapeutic advice is given in addition to the diagnostic assessments. A full report from the AC-service offers a complete set of data which the GP can use to systematically check all relevant aspects that characterize the disease burden of the patient. Asthma/COPD services can be asked to perform yearly follow-up to patients who are diagnosed with asthma or COPD to ensure continuity of care for these patients.

To evaluate the effect of the asthma/COPD service for the whole primary care practice population, we first had to find the patients eligible to visit the asthma/COPD service. Chapter 1 describes that only one third of the patients registered with asthma or COPD or pulmonary medication met the clinical criteria of asthma or COPD when screened for eligibility to undergo diagnostic spirometry by the asthma/COPD service. This finding addressed one of the problems concerning asthma/COPD misdiagnoses for which asthma/COPD-service support can be helpful. 
Chapter 2 evaluates the validity of the asthma/COPD-service as a diagnostic instrument for primary care. Testing of this validity was necessary before we could examine the results of asthma/COPD-service support being the intervention in our research project.

We compared the results of the asthma/COPD-service diagnostic procedures for 80 patients with the results of regular office consultation by 2 pulmonologists of the same patients. The concordance of the diagnoses of two different assessments for one patient was high (Cohen's kappa $\mathrm{k}=0.82$ ). This means that it is possible to assess the right diagnosis from written information without actually seeing the patient, and that the diagnosis of an asthma/COPD service can be considered to be best practice diagnostic support for the general practitioner.

Advice for additional diagnostic examinations had a high internal validity: when carried out, for half of the patients that were given this advice uncertainty in diagnosis turned into a definite diagnosis of asthma/COPD or another cause for the complaints of the patient was revealed. For the other half the diagnosis of asthma/COPD could be rejected.

Chapter $\mathbf{3}$ explores whether GPs can rely on the diagnosis a pulmonologist gives following a structured assessment protocol for spirometry and written patient data as used by asthma/COPD-services. We knew from chapter 2 that a specific pulmonologist reaches a similar diagnosis during live consultation as when using written spirometry and medical history data. In this part of the study we found that (five) different respiratory specialists performed comparable diagnostic assessments of written data of 156 patients, and were consistent in their assessments when these were repeated after six months (Cohen's kappa $\mathrm{K}=0.63$ and 0.67 for inter- and intraobserver reliability). This means that the asthma/COPD service provides reliable diagnoses. GPs have to take into consideration that sometimes assessment inconsistencies can occur when history results and/or spirometry results are borderline to normal, when discrepancies exist between complaints and spirometry results, or when there is use of inhaled steroids without an obvious indication. These "real life problems" cannot be solved completely by diagnostic support services. GPs, knowing their patients best, will always have to think along with using the reports of the asthma/COPD service. This is also true when advice for additional diagnostic examination is given. Cohen's kappa for its reliability reached a mean $\mathrm{k}=0.56$ for new patients. Therapeutic recommendations - based on assessments of stable o in-stable conditions in follow-up patients - were inconsistent.

Chapter $\mathbf{4}$ addresses an important problem that we encountered in our validity and reliability studies: the prescription of inhaled corticosteroids (ICS) without a proper indication and the diagnostic problem caused by inappropriate prescription and use of ICS.

We found that 1171 of all 2271 patients referred in a period of six months used ICS, 505 (43\%) without a clear indication. Their GPs were questioned about the reasons for prescribing ICS. If after this no diagnosis could be assessed, GPs were advised to stop ICS and renew spirometry after a steroid-free period of at least three months. After one year final results showed that $11 \%$ of all patients originally using ICS had no indication to use ICS and had successfully ceased using this mediation. For $15 \%$ the reasons for using ICS remained unclear.

Overtreatment with ICS in primary care seems to be considerable, which falsely labels patients as asthmatic, and which generates unnecessary costs and possible side-effects. The awareness of GPs of the need for proper diagnostic testing before prescribing ICS needs to be improved. Overtreatment with ICS in primary care patients can be diminished by systematically supporting the general practitioner in the diagnostic procedures and decision-making.

Chapter 5 explores the effects of the diagnostic assessments of the consulting pulmonologists on GPs working hypothesis for their patients with respiratory complaints referred to the asthma/COPD service. We took the arguments on which these working hypotheses were based into account: $49 \%$ of the working hypothesis were only based on clinical information, $21 \%$ were also based on office spirometry. For $30 \%$ additional specialist information was available. The asthma/COPD service confirmed half of the working hypotheses, more often when the working hypothesis was asthma (62\%) than when it was COPD (40\%). These results were not influenced by the three mentioned justifications for the working hypothesis. This means that all working diagnoses, also those based on specialist correspondence, should regularly be updated by qualified spirometry and medical history taking. Office spirometry without thorough training in performing and interpreting lung function tests did not improve the accuracy of the working hypothesis and might even cause misinterpretations. To optimize the diagnoses in primary care, the diagnostic support of an Asthma / COPD service can be recommended for all primary care patients with respiratory problems, no matter what arguments are given for the patient's working hypotheses.

Chapter 6 studies the usefulness of the diagnostic advice given by the Asthma/ COPD-services in reducing diagnostic uncertainty for respiratory problems in primary care. When consulting pulmonologists of asthma/COPD services cannot ascertain a diagnosis they recommend additional diagnostic examinations (e.g. histamine provocation tests, stop ICS when these cause diagnostic problems) to confirm or exclude asthma or COPD, or to find alternative or additional diagnoses. This should lead to 
adjustments of diagnoses at follow-up. We evaluated these adjustments and their relationship with the diagnostic advice given at first visit for 383 patients. $62 \%$ of the patients received advice for additional diagnostic examinations at first visit. Amongst those patients, diagnoses changed at follow-up for $51 \%$. Diagnoses changed significantly less frequent for patients without diagnostic advice ( $51 \mathrm{vs.} 31 \%$; $p=0,007$ ).

In our validation study a consequently followed diagnostic advice solved diagnostic uncertainties when the advised examination was performed by the pulmonologist during office consultation. Adherence of GPs to the diagnostic advice in this part of the study was low and diagnostic uncertainty was not solved at follow-up: half of the diagnostic recommendations were restated at follow-up. Our results indicate that diagnostic advice of an AC-service is useful at least as a warning of diagnostic uncertainty.

Chapter 7 explores whether patients are aware of GPs' use of additional information from the asthma/COPD service reports during office consultations. These reports include information about disease burden (BORG-score for complaints, MRC-dyspnoea score, and exacerbation rate), life style, medication, and compliance. Patients visited the AC-service when GPs had received the reports. They could discuss the results with their GP during office consultation. Afterwards, patients answered questions about their GP's information and education performance. This performance was compared with GP's performance in consultations without the availability of AC-service reports (usual care), earlier that year. We found no difference between GPs' consultation performance in AC-service supported and usual care consultations. Smoking behavior was discussed with $66 \%$ of the actual smokers; only $14 \%$ of the smokers remembered a stop smoking advice. However, there was some influence of the Asthma/COPD-service reports: supported GPs took the severity of complaints as reported by the AC-service into account when discussing disease burden. They also discussed this when patients thought it was not relevant. GPs mostly ignored the MRC-dyspnoea score: attention for dyspnoea was only $18 \%$ $25 \%$, physical fitness was encouraged in $13 \%$. Our conclusion was that offering AC-service reports did not influence the performance of GPs during consultations, at least not enough to be recalled by their patients. More or other incentives are needed to make GPs effectively use patient information and systematically check all relevant aspects that characterize the disease burden of their patients.

In Chapter $\mathbf{8}$ the relevance of our study is discussed, as well as its implications for daily practice and for further research.
Overall the following conclusions can be drawn from this thesis:

1. an asthma/COPD service gives best practice diagnostic support to GPs, offering valid and reliable diagnoses and useful additional diagnostic advice

2. additional advice in case of diagnostic uncertainty can be more effective when GPs adhere better to the given diagnostic recommendations

3. all patients selected by screening medical records on asthma and COPD can benefit from diagnostic assessment by an AC-service

4. the diagnostic process should be conducted before prescribing ICS, to prevent diagnostic assessment problems, incorrectly labeling patients as asthma patients and to prevent overtreatment with ICS

5. pharmacotherapeutic advice has to be based on a patient's clinical condition and cannot be reliably given from the written data now available in the astma/ COPD service report

6. going from patients' recall, the additional asthma/COPD service diagnostic support does not lead to measurable improvements in GPs performance in asthma and COPD care, patients' disease knowledge and (self-) management than after usual care consultations

Given the variable nature of especially asthma and the diagnostic difficulties, regular follow up assessment and critical appraisal of the need for inhaled steroids are added values of an asthma/COPD service. For daily primary care practice the asthma/ COPD service has shown to be a best practice diagnostic support for patients with respiratory problems. 



\section{Samenvatting}

COPD is een chronische aandoening van de longen die voor komt bij ongeveer $2 \%$ van alle mensen. De aandoening wordt vrijwel altijd veroorzaakt door roken. Patiënten hebben problemen met name met de uitademing (t.g.v. "luchtwegobstructie") waardoor hun conditie in meer of mindere mate beperkt kan worden. $3-4 \%$ van de mensen heeft astma. Dit is een aandoening die deels erfelijk bepaald is en samenhangt met overgevoelige luchtwegen (o.a. voor sigarettenrook) en allergieën zoals hooikoorts. Astma-patienten kunnen veel last hebben van benauwdheid als ze aan prikkels worden blootgesteld. Benauwdheid en piepen zijn in de regel met medicijnen geheel op te heffen. Bij COPD zijn medicijnen niet zo effectief en is de ziektelast vooral te beïnvloeden door leefregels: stoppen met roken en lichaamsbeweging.

De mate van ziektelast is verschillend voor elke patiënt. Vooral COPD patiënten kunnen door de aandoening zeer beperkt worden in hun dagelijkse activiteiten, soms meer dan dat ze zelf of hun huisartsen in de gaten hebben. Nauwkeurige inkaarting van aandoening en klachten is daarom heel belangrijk.

Als iemand hoest, benauwd is of piept, wordt al snel aan astma gedacht, maar dit hoeft niet altijd de juiste diagnose te zijn. Daardoor kunnen patiënten onterecht een etiket krijgen van chronische (astma-)patiënt.

Het organiseren van goede zorg begint dus met het stellen van de juiste diagnose en het opsporen van patiënten die daadwerkelijk zorg nodig hebben. Dit proefschrift onderzoekt een model dat de huisarts ondersteunt bij deze belangrijke maar complexe taak. Dit model is de astma/COPD-dienst.

In hoofdstuk 1 maakt de lezer kennis met de astma/COPD-dienst en wordt toegelicht hoe deze past in de ontwikkelingen in de gezondheidszorg. Als eerste stap naar betere zorg werden door de beroepsorganisatie van huisartsen richtlijnen ontwikkeld die beschreven hoe een diagnose gesteld moest worden bij een patiënt in de huisartsenpraktijk. Binnen deze richtlijnen was plaats voor longfunctiemetingen (spirometrie) en het advies was deze toegankelijk te maken voor de huisarts. Een volgende stap was de behoefte aan organisatiemodellen waarbinnen goede zorg voor elke patiënt geleverd kon worden. Om praktische redenen en omdat men kwaliteit belangrijk vond, hebben huisartsen samen met longartsen de astma/ COPD-dienst bedacht die een dergelijk organisatiemodel zou kunnen ondersteunen. Astma/COPD-diensten zijn onderdeel van eerstelijns diagnostische centra of zijn georganiseerd binnen een ziekenhuis. Ze bieden ondersteuning aan de huisartsenpraktijk bij de diagnostiek en behandeling van patiënten die naar de dienst verwezen worden voor een longfunctiemeting. Patiënten vullen daarbij ook een lijst in met 
gestandaardiseerde vragen over hun klachten en hun voorgeschiedenis (anamnese) Verslagen van longfunctiemetingen met bijbehorende anamnese worden beoordeeld door longartsen die als consulent werken voor de astma/COPD-dienst. Dit gebeurt volgens een speciaal ontwikkeld beoordelingsprotocol. De beoordelingen van de longarts worden door de astma/COPD dienst verwerkt tot een rapportage die aan de huisarts wordt gestuurd (zie figuren in hoofdstuk 1). Het is de verantwoordelijkheid van de huisarts om door gebruik te maken van deze rapportage de patiënt de juiste zorg te geven.

In de rapportage aan de huisarts wordt de door de longarts gestelde diagnose vermeld. Daarnaast worden, als dat van toepassing is, adviezen gegeven voor verder onderzoek evenals adviezen voor medicamenteuze behandeling en voor het aanpassen van de leefstijl. De rapportage van de astma/COPD-dienst biedt aan de huisarts een compleet overzicht over alle belangrijke zaken die de ziektelast voor de patiënt bepalen en die besproken zouden moeten worden tijdens het spreekuur. Op verzoek van de huisarts kunnen patiënten waarbij de diagnose astma of COPD is gesteld, jaarlijks worden opgeroepen voor een follow-up.

Om te onderzoeken wat het effect van de ondersteuning door de astma/COPD dienst is voor de hele praktijkpopulatie was het belangrijk eerst alle patiënten te vinden die in aanmerking komen voor onderzoek bij de astma/COPD dienst.

Hoofdstuk 1 beschrijft de uitkomst van het opsporen door de astma/COPD dienst van mogelijke astma/COPD-patiënten in de registratiesystemen van huisartsen: slechts een derde van alle patiënten die een code hadden voor astma of COPD, of die astma- of COPD-medicatie gebruikten, bleken te voldoen aan de criteria die de aandoeningen kenmerken en op grond waarvan patiënten bij de astma/COPD dienst nader onderzocht zouden moeten worden. Het werd duidelijk dat dit een van de problemen is waardoor er veel misdiagnostiek bestaat bij astma en COPD.

In hoofdstuk 2 wordt beschreven hoe "valide" de diagnostische beoordelingen van de astma/COPD-dienst zijn, ofwel: kloppen de beoordelingen wel? Achterliggende vraag is: is het wel mogelijk uit gegevens op papier (longfunctie en anamnese) te concluderen welke aandoening de patiënt heeft. Het was belangrijk om daar zekerheid over te hebben voordat we deze beoordelingen gingen onderzoeken als instrument voor betere zorg.

De validiteit is als volgt onderzocht: van 80 patiënten werden de diagnostische beoordelingen door de astma/COPD-dienst vergeleken met beoordelingen die 2 longartsen gaven nadat deze patiënten bij hen op het spreekuur waren geweest. Het bleek dat de beoordelingen goed overeen kwamen (Cohen's Kappa $(\kappa)=0.82)$. Dit betekent dat het mogelijk is om een goede diagnose te stellen zonder de patiënt zelf te zien, gebruik makend van de longfunctiegegevens en de anamnese. Het betekent ook dat de diagnostische ondersteuning door de astma/COPD dienst te beschouwen is als de beste manier voor de huisarts om een goede diagnose te krijgen. Daarbij gaan we uit van de longarts als expert.

Het advies om aanvullend diagnostisch onderzoek te doen had een hoge "interne validiteit". De longarts beoordeelde in zijn spreekkamer de patiënt eerst zoals hij dat voor de AC-dienst zou doen, dus volgens protocol. Als daar uit kwam dat er aanvullend onderzoek nodig was dan voerde hij dat, volgens afspraak met de huisarts van de patiënt, uit. Bij de helft van de patiënten kon hij dan astma of COPD definitief uitsluiten, bij de andere helft kon de diagnose (astma en/of COPD of een alternatieve diagnose) met zekerheid gesteld worden.

Hoofdstuk 3 beantwoordt de vraag of de diagnose zoals de Astma/COPD dienst die levert, betrouwbaar is, d.w.z. onafhankelijk van de longarts die de beoordeling verricht heeft. We wisten al, zie hoofdstuk 2, dat een longarts op grond van papieren gegevens hetzelfde beoordeelt als wanneer hij de patiënt in de spreekkamer ziet. In dit dee van het onderzoek hebben we de longfunctiegegevens en bijbehorende anamnese van 156 patiënten laten beoordelen door 5 verschillende longartsen De onderlinge vergelijkbaarheid van de gestelde diagnoses was redelijk tot goed (Cohen's Kappa $\mathrm{K}=0.63$ ). Zes maanden later hebben de longartsen deze beoordelingen overgedaan. Hun diagnostische conclusies kwamen redelijk overeen met die van de eerste serie beoordelingen (Cohen's Kappa $\mathrm{k}=0.67$ ). Deze inter- en intra-beoordelaar betrouwbaarheid van de methode van de astma/COPD-dienst zijn vergelijkbaar met die van andere complexe diagnostische onderzoeken waar huisartsen gebruik van maken. Huisartsen moeten er wel rekening mee houden dat beoordelingen soms lastig zijn, bijvoorbeeld als anamnese en longfunctie gegevens maar net afwijken van normaal, of als ze discongruent zijn. Ook als de patiënt medicijnen gebruikt en een normale longfunctie heeft is het voor de longarts lastig om te komen tot een goede beoordeling (zie hoofdstuk 4). Huisartsen kennen hun patiënten het beste en moeten kritisch blijven meedenken met de longarts. Dat moeten ze ook doen als er advies gegeven wordt voor extra diagnostisch onderzoek (intra-beoordelaar betrouwbaar bij nieuwe patiënten: Cohen's kappa $\mathrm{K}=0.56$ )

Longartsen waren het onderling te vaak oneens over de stabiliteit van de aandoening van de patiënt. Omdat medicamenteuze adviezen gebaseerd worden op ziekteinstabiliteit kan de huisarts daar niet goed op varen. 
Hoofdstuk 4 behandelt een belangrijk probleem in zorg voor astma en COPDpatiënten: het gebruik van inhalatie corticosterö̈den (ICS) zonder dat daar een duidelijke indicatie voor is. ICS zijn medicijnen die ontstekingsmechanismen opheffen bij astma-patienten, waardoor deze weer een normale longfunctie kunnen krijgen. Omdat klachten van patiënten vaak lijken op astma (hoesten, benauwd) worden ICS wel voorgeschreven op proef. Als het goed gaat, gaat de patiënt er dan vaak mee door, ook al is de diagnose astma twijfelachtig. Patiënten met een normale longfunctie die ICS gebruiken en waarbij niet eerder een diagnose werd gesteld kunnen óf goed behandelde astmapatiënten zijn, óf geen astma hebben en ten onrechte ICS gebruiken. Dan is er dus sprake van een diagnostisch probleem.

In dit hoofdstuk wordt dit fenomeen beschreven: van alle 2271 patiënten die in een periode van 6 maanden de astma/COPD dienst bezochten, gebruikten 1171 patiënten ICS. Bij 505 (43\%) van hen was de reden daarvoor onduidelijk. Aan hun huisartsen werd gevraagd welke verklaring zij konden geven. $\mathrm{Na}$ antwoord op die vraag bestond in veel gevallen nog steeds twijfel aan een mogelijke diagnose "astma". In dat geval kregen de huisartsen expliciet het advies om de ICS te stoppen en de patiënt na een wachttijd van minstens 3 maanden een nieuwe longfunctie te laten blazen.

Bij follow-up na een jaar bleek dat $11 \%$ van alle patiënten die oorspronkelijk ICS gebruikten, daartoe blijkbaar geen reden hadden en zonder problemen met deze medicatie gestopt waren. Voor nog eens $15 \%$ bleef de reden voor ICS gebruik onduidelijk.

De conclusie uit dit onderzoek is dat ICS overmatig veel gebruikt worden in de huisartsenpraktijk waardoor veel patiënten ten onrechte het label astma krijgen en waardoor er onnodig veel kosten gemaakt worden voor farmacotherapie. De huisartsen moeten zich meer bewust worden van het belang om eerst de diagnostiek goed af te ronden voordat patiënten ICS krijgen voorgeschreven. Astma/COPDdiensten kunnen bijdragen aan de oplossing van het geconstateerde probleem door huisartsen daarbij met feedback te ondersteunen en kritisch te blijven beoordelen.

In hoofdstuk 5 wordt een tweede resultaat van de ondersteuning door de astma/ COPD-dienst beschreven, namelijk hoe de diagnostische beoordeling door de astma/COPD-dienst de werkdiagnoses van de huisartsen veranderden. $49 \%$ van de huisartsen hanteerden een werkdiagnose op grond van klachten van de patiënt. $21 \%$ van de huisartsen beschikten over een eigen longfunctiemeter en betrokken de resultaten van een longfunctietest in hun werkhypothese. Bij 36\% van de huisartsen kwam de werkhypotheses tot stand op grond van gegevens uit specialistenbrieven. Patiënten met als werkhypothese (mogelijk) astma of COPD werden verwezen naar de astma/COPD dienst om de diagnose te bevestigen of te verwerpen.

De astma/COPD-dienst bevestigde de helft van de werkhypotheses, iets vaker als het om astma ging (62\%) dan om COPD (40\%). Opvallend was dat het niet uitmaakte hoe de werkhypothese tot stand gekomen was. Dit betekent dat alle werkhypotheses, ook als ze gebaseerd zijn op specialistenbrieven regelmatig gecontroleerd moeten worden met behulp van gekwalificeerd diagnostisch onderzoek zoals longfunctiemeting en anamneses bij een astma/COPD-dienst. Longfunctiemeting in eigen praktijk zonder degelijke training in uitvoering en interpretatie gaf geen betere werkdiagnoses en kon zelfs tot verkeerde diagnoses leiden. Om de kwaliteit van de diagnoses in de eerste lijn te bevorderen is het aan te bevelen voor alle patiënten met luchtwegproblemen de diagnostische ondersteuning van de astma/COPD dienst in te zetten ongeacht de argumenten voor de werkdiagnose van de huisarts.

Hoofdstuk 6 beschrijft de resultaten van een studie naar de betekenis van adviezen voor aanvullende diagnostiek. Deze adviezen geven de longartsen als ze geen duidelijke diagnose kunnen stellen op grond van de beschikbare longfunctie en anamnese. Bijvoorbeeld: als een longfunctie normaal is en de klachten wijzen toch op astma, dan kan het advies zijn een zgn. histamine provocatie test aan te vragen. Deze test kan astma uitsluiten of zeer waarschijnlijk maken. Het advies aan de huisarts kan ook zijn om zelf te zoeken naar een alternatieve of aanvullende diagnose, door bijvoorbeeld anamneses en lichamelijk onderzoek uit te breiden om aandoeningen op een ander gebied dan de luchtwegen te vinden, zoals zuurbranden, hartfalen, hyperventilatie.

Aanvullende diagnostische adviezen zouden moeten leiden tot aangepaste diagnoses bij follow-up door de astma/COPD-dienst. Bij 383 patiënten zijn deze aanpassingen onderzocht gerelateerd aan de diagnostische adviezen. $62 \%$ van de patiënten kreeg een advies voor nader onderzoek bij het eerste bezoek aan de astma/COPD-dienst. Bij $51 \%$ van hen veranderde de diagnose. Bij patiënten die geen advies kregen kon de diagnose ook veranderen, maar dat gebeurde significant minder (31 vs. $51 \%$; $\mathrm{p}=0,007$ ).

In het onderzoek naar de validiteit van de beoordelingen bleek het opvolgen van diagnostisch advies de onzekerheid over een diagnose weg te nemen, maar in die studie werd het aanvullend onderzoek uitgevoerd door de longarts tijdens of aansluitend aan het consult. In de dagelijkse praktijk volgden de huisartsen de adviezen, voor zover controleerbaar, niet zo goed op. Bij 30\% van de patiënten was opnieuw een diagnostisch advies nodig bij follow-up. De diagnoses bij follow-up werden wel aangepast, vooral omdat de longartsen bij follow-up strenger waren en twijfelachtige diagnoses niet meer accepteerden. Onze conclusie is dat diagnostisch advies gegeven door de astma/COPD-dienst de huisarts waarschuwt voor diagnostische onzekerheid en dat de huisarts beter gevolg zou moeten geven aan het advies om die diagnostische onzekerheid op te lossen. 
In hoofdstuk $\mathbf{7}$ is onderzocht of en hoe de huisartsen gebruik maken van alle extra informatie geleverd in de rapportages van de astma/COPD-dienst. Het gaat daarbij om een zgn. BORG-score voor klachten, een score op de MRC-dyspnoe schaal, de frequentie waarin een verergering van klachten (exacerbatie) optreedt; rookgedrag en lichamelijke conditie, medicatievoorschrift en het daadwerkelijk gebruik ervan. Deze informatie kan de huisarts gebruiken om systematisch de ziektelast en de leefstijl van patiënten te bespreken tijdens zijn consult.

In dit onderzoek werd aan patiënten gevraagd een vragenlijst in te vullen na het consult met hun huisarts waarin deze de beschikking had over de rapportage van hun bezoek aan de astma/COPD-dienst. Gescoord werden de onderwerpen die besproken werden, en de wijze waarop de kwalificatie daarvan in de rapportage mee gespeeld had. De antwoorden werden per huisarts vergeleken met de antwoorden van patiënten op vragen over consulten waarin nog geen rapportage beschikbaar was, eerder in het jaar.

Huisartsen bleken rekening te houden met de klachtenscore in de rapportage van de astma/COPD-dienst. Ook als de patiënten het zelf onbelangrijk vonden (en mogelijk spontaan niet hadden vermeld) werden hoge klachtenscores toch besproken. Verder vonden we geen verschil in communicatie tijdens consulten met en consulten zonder ondersteuning middels een verslag van de astma/COPD-dienst. Huisartsen bespraken het rookgedrag van patiënten bij $66 \%$ van de rokers. Hiervan herinnerde zich $14 \%$ dat men een stop-roken advies gekregen had. Huisartsen negeerden veelal de MRC-dyspnoe score: de aandacht voor benauwdheidklachten bij inspanning was er slechts in $18 \%-25 \%$ van de consulten. Conditieverbetering werd aangemoedigd bij $13 \%$ van de patiënten, voor zover zij zich dat herinnerden. Onze conclusie was dat de uitgebreide rapportages van de astma/COPD-dienst geen invloed hadden op de manier waarop huisartsen informatie en voorlichting gaven aan hun patiënten, tenminste niet zodanig dat de patiënten zich dat herinnerden. Er is blijkbaar meer of andere aanmoediging nodig voor huisartsen om systematisch alle aspecten na te lopen die te maken hebben met de ziektenlast van de patiënt.

Hoofdstuk 8 bespreekt de resultaten van de studies in breed perspectief en de consequenties daarvan voor de dagelijkse praktijk en voor vervolgonderzoek.
Samenvattend zijn de volgende conclusies te trekken:

1. een astma/COPD-dienst kan borg staan voor "best practice" diagnostische ondersteuning aan huisartsen door valide en betrouwbare diagnoses te stellen en bruikbare adviezen te geven voor aanvullende diagnostiek

2. adviezen voor aanvullende diagnostiek in geval van diagnostische onzekerheid kunnen pas daadwerkelijk effect hebben als huisartsen deze adviezen beter opvolgen

3. alle "astma" en "COPD" patiënten die door screenen van huisartsinformatiesystemen worden opgespoord kunnen baat hebben bij een diagnostische beoordeling door een astma/COPD-dienst

4. het diagnostisch onderzoek moet worden afgerond voordat er inhalatiecorticosteroïden worden voorgeschreven om te voorkomen dat de diagnostiek tgv deze medicatie wordt bemoeilijkt, dat patiënten onterecht het etiket "astma" krijgen en dat patiënten onnodig worden behandeld

5. farmacotherapeutisch advies moet gebaseerd zijn op de klinische conditie van de patiënt en kan met de nu beschikbare informatie niet betrouwbaar worden gegeven door de astma/COPD-dienst

6. het opnemen van alle gegevens uit anamneses en voorgeschiedenis als toevoeging aan de diagnostische beoordeling en advisering lijkt niet wezenlijk bij te dragen aan de aandacht van de huisarts voor ziektenlast en leefstijl

Vanwege de lastige diagnostiek en vanwege de natuurlijke ziektebeeldvariatie vooral bij astma is regelmatige follow-up samen met de astma/COPD-dienst zeer waardevol voor de huisartsenpraktijk, temeer daar de kritische beoordeling van het gebruik van inhalatiesteroïden tot zinvolle diagnostische en therapeutische adviezen leidt. Voor de dagelijkse diagnostische ondersteuning van de astma/COPD-zorg in de eerste lijn levert de Astma/COPD-dienst daarom een "best-practice" bijdrage. 


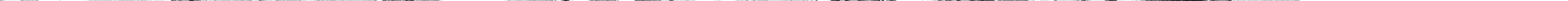


De complexe weg naar de diagnose astma of COPD

Annelies Lucas

\section{De kern}

- de diagnostiek van COPD en vooral van astma is complex en heeft tijd nodig.

- Systematisch aanpakken van de diagnostiek is belangrijk om een verkeerde diagnose te voorkomen

- het is belangrijk om geen inhalatiesteroïden voor te schrijven voordat de diagnose astma rond is

- de diagnostiek van astma is gebaat bij afspraken met de longarts over het uitvoeren van een histaminedrempelbepaling

- het bewaken van het diagnostische traject bij astma en COPD is een belangrijke taak voor de praktijkondersteuner. Een praktijkondersteuner kan er namelijk voor zorgen dat dit traject goed doorlopen wordt

\section{Inleiding}

De diagnostiek van astma en COPD is niet gemakkelijk. Er is geen eenduidige maat voor, zoals een $\mathrm{HbA} 1 \mathrm{c}$ voor diabetes, of een bloeddrukmeting voor hypertensie. De diagnose wordt gesteld door een aantal gegevens te combineren. Het verzamelen van deze gegevens gaat meestal stap voor stap, en onderweg is er een aantal valkuilen. Geen wonder dat er al veel geschreven is over misdiagnostiek bij astma en COPD: de diagnose wordt zowel te vaak als te weinig gesteld.1 Praktijkondersteuners lopen daar bijvoorbeeld tegenaan als ze hun praktijken gaan opschonen. En eenmaal bezig met de zorg voor astma/COPD-patiënten blijkt hoe je moet blijven oppassen: klopt het allemaal nog wel?

Het stellen van de juiste diagnose is de verantwoordelijkheid van de huisarts, maar de praktijkondersteuner is er meestal vanaf het begin al bij betrokken: bij het uitdiepen van de anamnese en het uitvoeren van longfunctiemetingen of ander aanvullend onderzoek. Inzicht in de complexiteit van de diagnostiek is ook voor de praktijkondersteuner belangrijk. En minstens zo belangrijk is begrip van het hele diagnostische traject, om dit samen met de huisarts goed te kunnen managen.

Dit artikel beschrijft dit diagnostische traject bij astma en COPD in de praktijk en gaa in op de struikelblokken die je onderweg kunt tegenkomen. Een volgend artikel gaat over aandoeningen waaraan je moet gaan denken als de diagnose astma of COPD geen, of onvoldoende verklaring is voor de klachten van de patiënt.

\section{Een casus}

Mevrouw Joosten, 46 jaar, klaagt over hoesten en ook wel benauwdheid. Ze heeft wel vaker last van bronchitis, en hoesten, tja, ze rookt ook wel af en toe een sigaretje. Of de huisarts even wil luisteren. Misschien heeft ze een kuurtje nodig. Tot haar opluchting vindt de huisarts geen afwijkingen en geen aanwijzingen voor longontsteking. De huisarts legt uit dat een kuurtje niks toevoegt aan de spontane genezing.

Klaar is Kees... Of toch niet? Het addertje zit natuurlijk in de mededeling dat ze 'wel vaker' last heeft van haar luchtwegen. De huisarts kan een chronische aandoening niet uits/uiten: is er misschien sprake van astma of COPD?

\section{Diagnostiek bij vermoeden van astma of COPD}

Mevrouw Joosten uit de casus heeft een leeftijd waarop zowel astma als COPD voorkomt. Bijzonder is dat vrij ernstig astma zich bij vrouwen kan openbaren na de menopauze.2 Je kunt je afvragen of dat bij mevrouw Joosten het geval is. Maar het 
feit dat mevrouw Joosten rookt, maakt haar kandidaat voor COPD. Hoe specifiek zijn de klachten en kenmerken van COPD of astma eigenlijk? Hoe kunnen we komen tot een definitieve diagnose? Daarvoor gaan we stap voor stap te werk:

1. klachtenpresentatie bij astma of COPD;

2. lichamelijk onderzoek;

3. uitdiepen van de anamnese;

4. meer zekerheid krijgen over de diagnose met een longfunctieonderzoek.

\section{Klachtenpresentatie bij astma of COPD}

De COPD-patiënt heeft een chronische beschadiging van de luchtwegen (inflammatie) en dat komt vooral door roken. Dit gaat gepaard met bronchusobstructie en hypersecretie van slijm. Chronisch hoesten is daarom onvermijdelijk, net als chronisch aanwezige benauwdheidklachten.

Bij astma is er sprake van een verhoogde gevoeligheid van de luchtwegen voor allergische en niet-allergische prikkels. Door deze verhoogde gevoeligheid ontstaat een ontstekingsreactie die kan leiden tot hoestklachten, maar hoesten alleen is geen hoofdsymptoom. Meer kenmerkend voor astma is de meestal periodiek optredende bronchusobstructie. Deze zorgtvoor detypisch symptomenvan astma:naastbenauwdheid is dat de piepende ademhaling ${ }^{[3]}$.

\section{Tabel1: Diagnostiek in de spreekkamer: onderscheid tussen astma en COPD}

\begin{tabular}{lll}
\hline & Astma & COPD \\
\hline Leeftijd & Jongere leeftijd, en na de menopauze! & Ouder dan 40 jaar \\
Hoesten, slijm & Zelden & Chronisch \\
Kortademig & Soms, met piepen & Voortdurend \\
24-uursritme van de klachten & 's Nachts meer last & Continu \\
Rookgedrag & Zoals voorkomt in bevolking & Bijna allemaal rokers \\
Allergie & Hooikoorts, inspanning & Nee \\
Niet-allergische prikkels & Gevoeligheid & Niet bijzonder \\
Familiair voorkomen & Ja, ook atopie, eczeem & Nee \\
\end{tabular}

Bijzonder is dat in de spreekkamer relatief vaak aan astma wordt gedacht. Dit is duidelijk geworden nu praktijkondersteuners in zorggroepen hun populatie gaan opschonen als voorbereiding op ketenzorgprogramma's en dbc-afspraken. In de HIS'en worden veel meer ICPC-codes voor astma (R96) en meer recepten voor inhalatiemedicatie gevonden dan men zou verwachten op grond van epidemiologische cijfers $^{[4]}$. Zo lastig is dus de diagnose. Om een verkeerde diagnose te voorkomen, kunnen praktijkondersteuners samen met de huisartsen bewaken dat patiënten pas een ICPC-code krijgen als de diagnose rond is. Dit is meestal nog niet het geval na de eerste klachtenpresentatie.

\section{Lichamelijk onderzoek}

Indien er sprake is van periodiek optreden van benauwdheid, piepen op de borst en productief hoesten, mag de werkdiagnose astma gesteld worden ${ }^{[6]}$. Als een patiënt komt met een echte astma-aanval, zijn deze kernsymptomen inderdaad aanwezig: bij auscultatie van de longen is dan piepen te horen en is een verlengd exspirium vast te stellen, als uiting van de bronchusobstructie. Bij nachtelijke klachten of bij inspanningsastma wordt een aanval niet altijd 'gevangen', en levert auscultatie onvoldoende op. Ook bij COPD is auscultatie geen betrouwbaar diagnostisch gegeven ${ }^{[5]}$. Patiënten met ernstige COPD met emfyseem hebben vaak een hee 'stille' ademhaling. Bij patiënten als mevrouw Joosten is daarom nadere diagnostiek aangewezen, ter ondersteuning van de diagnose. Dit begint bij het uitdiepen van de anamnese.

\section{Uitdiepen van de anamnese}

De voorgeschiedenis (atopie, eczeem) en familieanamnese zijn vooral van belang als astma wordt overwogen (tabel 1). Gevoeligheid voor inhalatieallergenen (hooikoorts, huisdieren, dekbedden) kan in de richting van astma wijzen, evenals benauwdheidsaanvallen bij aanvang van sporten. ledereen kan op aspecifieke prikkels reageren, maar de echte astmapatiënt is er veel gevoeliger voor en raakt benauwd bij virusinfecties en van verflucht en parfum. Ook van sigarettenrook, maar helaas voorkomt dit niet dat (jonge) astmapatiënten gaan roken ${ }^{[6]}$. Langdurig roken leidt bij $15-20 \%$ van de mensen tot COPD. Van alle COPD-patiënten heeft $95 \%$ een rookhistorie. De beroepsanamnese (verf, stof) is zeker ook van belang bij een vermoeden van COPD.

Specifieke vragenlijsten kunnen astma en COPD beter in kaart brengen: de Asthma Control Questionnaire (ACQ), de Clinical COPD Questionnaire (CCQ), de Respiratory Illness Questionnaire Monitoring 10 (RiqMon-10), en de MRC-dyspnoescore ${ }^{[7]}$. Bij de eerste diagnostiek worden deze vragenlijsten nog niet veel gebruikt. Als de diagnose helder is kan het beloop van de aandoening ermee worden gevolgd en kunnen ze 
van dienst zijn bij het maken van zorgplannen op maat. Het is dan ook belangrijk gericht te vragen naar gevolgen van de aandoening voor school, werk, vrije tijd, en relaties. De nieuwe zorgstandaard COPD gaat daar zeer expliciet op $\mathrm{in}^{\left[{ }^{[8]}\right.}$.

\section{Meer zekerheid krijgen over de diagnose: longfunctieonderzoek}

Als er voldoende anamnestische aanwijzingen zijn om aan astma of COPD te denken, is de volgende stap het longfunctieonderzoek (figuur 1). Zowel astma als COPD zijn obstructieve longaandoeningen en een longfunctiemeting is bedoeld om een eventuele obstructie aan te tonen. Criterium voor obstructie is de forced expiratory ratio $(F E R=F E V 1 / F V C)$. De normale waarde daarvan is bij ouderen lager dan bij jongeren. Globaal is het afkappunt 0,7 of $70 \%$.

Belangrijk voor de diagnostiek is of de bronchusobstructie blijvend is of reversibel. Criterium voor reversibiliteit is een verbetering van de FEV1 met $\geq 12 \%$ ten opzichte van de uitgangswaarde en $\geq 200 \mathrm{ml}$, na inhalatie van een bronchusverwijder.

Bij astma is de reversibiliteit zodanig dat de bronchusobstructie na inhalatie van de bronchusverwijder is opgeheven. Soms is er sprake van een partiële reversibiliteit: de bronchusobstructie vermindert na bronchusverwijding weliswaar zoveel dat aan het criterium van reversibiliteit is voldaan, maar er blijft nog steeds obstructie bestaan. In dat geval heeft de patiënt waarschijnlijk zowel COPD als astma.

Omdat bij de eerste diagnostiek nog niet duidelijk is of en van welke obstructieve longaandoening er sprake is, voeren we altijd een longfunctiemeting uit met reversibiliteitbepaling. Longfunctieonderzoek kan de praktijkondersteuner zelf uitvoeren. Voorwaarde is wel dat deze een goede instructie en training heeft gekregen zoals de CASPIR-training (COPD, astma en spirometrie), ontwikkeld door de COPD en Astma Huisartsen Advies Groep (CAHAG), en dat de vaardigheden worden onderhouden door het uitvoeren van voldoende spirometrieën per jaar en door follow-uptraining.

\section{Longfunctieonderzoek bij COPD}

Als de kwaliteit van de verkregen longfunctie goed is en je vindt zowel voor als na inhalatie van een bronchusverwijder dezelfde obstructieve longfunctie, dan is de diagnose COPD rond. Uiteraard als dat past bij de anamnese, klachten, en het rookgedrag.De aanbeveling van de NHG-Standaard is om de longfunctiemeting jaarlijks te blijven herhalen. In de praktijk blijkt dat reversibiliteit niet zo'n absoluut begrip is als we zouden willen ${ }^{19}$. Daarom is het verstandig om een aantal jaren achter elkaar de longfunctiemeting inclusief reversibiliteitbepaling uit te voeren. Als blijkt dat er inderdaad geen reversibiliteit gevonden wordt, kan men besluiten om de reversibiliteitbepaling achterweg te laten en de longfunctiemeting alleen te gebruiken om te snelle progressie van de obstructie te kunnen opsporen.

\section{Longfunctieonderzoek bij de dubbele diagnose COPD en astma}

Ongeveer 15\% van de COPD-patiënten heeft ook astma. Bij hen wordt weliswaar een obstructieve longfunctie gevonden voor en na bronchusverwijding, maar is er tevens een verschil tussen voor- en nameting dat voldoet aan de criteria voor reversibiliteit. Belangrijk is om daarbij niet alleen op de FEV1 te letten, maar ook op de FER. Bij COPD (zonder astma) kan namelijk zowel de FEV1 als de FVC groter worden, zodat de FER gelijk blijft. Dan is er sprake van zogenoemde volumerespons met valse of schijnreversibiliteit.

\section{Longfunctieonderzoek bij astma}

De diagnostiek bij astma is meestal niet rond met één longfunctieonderzoek. Een patiënt met ernstig astma, nog onbehandeld, zal op elk willekeurig tijdstip een reversibele luchtwegobstructie hebben en dan is de diagnose helder. Echter, voor veel astmapatiënten geldt dat de longfunctie variabel is, net als de klachten. Voer je tussen de aanvallen een longfunctieonderzoek uit, dan vind je niet de reversibele obstructieve afwijking waar je naar zoekt, maar een volstrekt normale longfunctie. Hoe moet je dan handelen?

\section{Vervolgonderzoek bij vermoeden van astma}

Meer zekerheid over de diagnose krijg je door systematisch te werk te gaan. Op de eerste plaats is het zinvol om opnieuw de anamnese uit te diepen voor de luchtwegproblemen. Blijft er een vermoeden van astma bestaan, vraag dan, als dat nog niet gedaan is, een allergietest aan, bijvoorbeeld de Phadiatop. Is het resultaat van de screeningstest positief, dan versterkt dit het vermoeden dat er astma in het spel is. Voor de keuze voor een volgende stap in het diagnostische traject (figuur 1) overleg je als praktijkondersteuner in de regel met de huisarts. Die kan als volgt besluiten.

- de patiënt krijgt de instructie om zich bij klachten meteen te melden. Er kan dan op dat moment een longfunctiemeting verricht worden om te beoordelen of er inderdaad bronchusobstructie bestaat en of deze werkelijk reversibel is. Als opnieuw geen reversibiliteit aangetoond wordt, dan is de diagnose astma onwaarschijnlijk. Blijt de verdenking desondanks bestaan, dan kan de patiënt naar een longarts worden verwezen voor een histamineprovocatietest;

- det aanvragen van een histamineprovocatietest kan in sommige regio's ook meteen. Dit onderzoek wordt meestal uitgevoerd onder toezicht van de longarts: de patiënt ondergaat longfunctiemetingen terwijl hij histamine in toenemende dosering toegediend krijgt. In geval van astma (bronchiale hyperreactiviteit) treedt er bij een lage dosis histamine al bronchusobstructie op, hetgeen niet gebeurt bij mensen zonder astma 


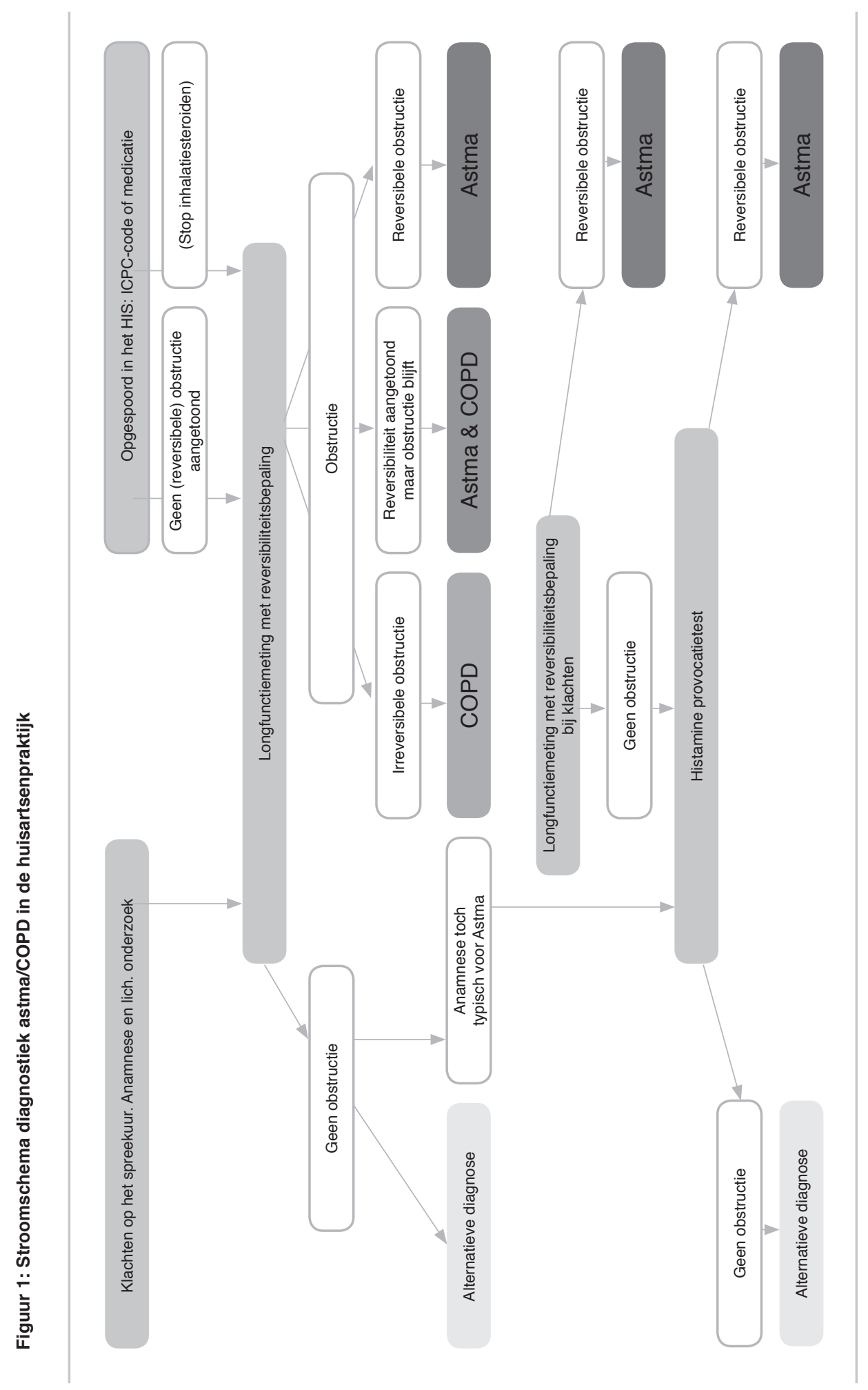

Gezamenlijke diagnostiek

Een positieve reversibiliteittest bij klachten levert meestal voldoende bewijs op voor astma, maar een positieve histamineprovocatietest wordt beschouwd als de gouden standaard. Deze test wordt in de regel in de tweede lijn uitgevoerd. In diverse regio's bestaan afspraken over een diagnostische verwijzing: specifiek voor dit onderzoek kan verwezen worden naar een longarts die de patiënt met de uitslag van de test en eventueel een advies terugverwijst naar de huisarts. Hierna is het diagnostische traject helemaal doorlopen en is het vrij zeker of er wel of geen sprake is van astma.

\section{Obstakels in het diagnostische traject}

Een paar factoren zorgen ervoor dat het diagnostische traject niet altijd even gladjes verloopt: problemen bij het uitvoeren en interpreteren van longfunctiemetingen, medicatie die al is voorgeschreven voordat de diagnose rond is, en de vraag of er niet een alternatieve of aanvullende diagnose is.

Problemen bij uitvoeren en interpreteren van longfunctiemetingen

Het spreekt voor zich dat we longfunctiemetingen volgens de kwaliteitseisen ${ }^{[10]}$ moeten uitvoeren en deskundig moeten interpreteren. Deze vaardigheden vergen onderhoud. De praktijkondersteuner of huisarts die zich niet voldoende vaardig en deskundig acht, of opziet tegen de praktische organisatie, kan de diagnostische longfunctiemetingen uitbesteden aan een astma/COPD-dienst ${ }^{[11]}$.

Medicatie voorschrijven voordat de diagnose rond is

Als een patiënt met klachten komt, is het begrijpelijk dat de huisarts daar meteen iets aan wil doen. Gebleken is dat dan nogal eens een inhalatiecombinatiepreparaat (luchtwegverwijder en inhalatiecorticosteroïde) wordt voorgeschreven, al dan niet na eerst een proeftherapie met alleen een luchtwegverwijder. Dan is het moeilijk om nog betrouwbare longfunctiediagnostiek te doen. Immers, een normale longfunctie zonder reversibiliteit bij een patiënt die een inhalatiecorticosteroïde gebruikt, kan twee dingen betekenen:

- de patiënt heeft een goed behandeld astma en gebruikt de medicatie terecht - de patiënt heeft geen astma en gebruikt de medicatie ten onrechte Degene die de longfunctie beoordeelt, zal ervan uitgaan dat een patiënt die inhalatiemedicatie gebruikt, daadwerkelijk astma heeft. We weten uit onderzoek dat daardoor $15-20 \%$ van de patiënten ten onrechte te boek blijt staan als astmapatiënt (kader 1).

Alternatieve of aanvullende diagnoses

Bij bijna de helft van de patiënten die bij een astma/COPD-dienst komen, adviseert de beoordelend longarts om aanvullend diagnostisch onderzoek te doen omdat de 
klachten niet passen bij de longfunctie van de patiënt: er zou sprake kunnen zijn van een alternatieve of een aanvullende diagnose bij astma of COPD ${ }^{[10]}$. Dat maakt dat de diagnose niet eenduidig is en per keer, bij elke jaarcontrole, net iets anders geformuleerd kan worden. Het opsporen van een eventuele andere oorzaak voor de klachten van de patiënt is dan ook van wezenlijk belang.

\section{Samenvattend}

De diagnostiek van COPD en vooral van astma is een proces dat tijd nodig heeft. De in figuur 1 voorgestelde systematische werkmethode kan een verkeerde diagnose voorkomen. Heel belangrijk is om te beginnen met kwalitatief goed uitgevoerde en goed geïnterpreteerde longfunctiemetingen, en om geen inhalatiesteroïden voor te schrijven voordat de diagnose zeker is. Samenwerkingsafspraken tussen huisartsenpraktijken en longartsen over het kunnen laten uitvoeren van een histamineprovocatietest zijn aan te bevelen.

Ten slotte: alternatieve of aanvullende diagnoses bij klachten die op astma of COPD lijken, komen veel voor. Daarover gaat een volgend artikel.

\section{Kader 1: Onderzoek en praktijk: diagnostische problemen bij gebruik van inhalatiesteroïden}

Praktijk

De huisartsen uit de regio Eindhoven sturen al hun patiënten met luchtwegklachten naar een astma/ COPD-dienst voor diagnostiek. Patiënten krijgen bij deze dienst een longfunctiemeting en vullen een anamneseformulier in. Longartsen beoordelen op papier de longfunctie samen met de anamnestische gegevens. De astma/COPD-dienst stuurt hierover een rapport naar de huisartsenpraktijk. Patiënten waarbij astma of COPD niet wordt uitgesloten, worden jaarlijks opgeroepen voor follow-up, waarbij opnieuw de longfunctie en de anamnese wordt beoordeeld.

\section{Onderzoek}

Gedurende een halfjaar zijn de beoordelingen geëvalueerd bij patiënten die inhalatiesteroïden gebruikten. Dit waren bijna 50\% (1.200 patiënten) van alle patiënten die in dit halve jaar naar de astma/COPD-dienst kwamen. Van hen bleek $15-25 \%$ met dit medicijn te kunnen stoppen zonder astmatische klachten te krijgen en zonder dat de longfunctie obstructief werd.11

Beleid

Als een patiënt inhalatiesteroïden gebruikt bij een normale longfunctie en er is niet eerder een obstructieve, reversibele longfunctie gevonden, stelt de longarts bij de astma/COPD-dienst geen diagnose, maar adviseert hij te stoppen met inhalatiecorticosteroïden. Drie maanden later (of eerder bij klachten) kan dan een betrouwbare diagnostische longfunctietest worden uitgevoerd die past in het beschreven diagnostische traject. 


\section{Literatuur}

1. Tinkelman DG, Price DB, Nordyke RJ, Halbert RJ. Misdiagnosis of COPD and asthma in primary care patients 40 years of age and over. J Asthma 2006;43:75-80

2. Troisi RJ, Speizer FE, Willett WC, Trichopoulos D, Rosner B. Menopause, postmenopausal estrogen preparations, and the risk of adult-onset asthma. A prospective cohort study. Am J Respir Crit Care Med 1995;152:1183-8.

3. Geijer RMM, Chavannes NH, Muris JWM, Sachs APE, Schermer T, Smeele IJM, et al. NHG-Standaard Astma bij volwassenen. www.nhg.org.

4. Jones RCM, Dickson-Spillmann M, Mather MJC, Marks D, Shackell BS. Accuracy of diagnostic registers and management of chronic obstructive pulmonary disease: the Devon primary care audit. Respir Res 2008;9:62.

5. Jansen D, Cardol M, Spreeuwenberg P, Heijman MJWM. Preventie en gezond gedrag bij mensen met astma [Rapport]. Utrecht: Nivel, 2009.

6. Smeele IJM, Van Weel C, Van Schayck CP, Van der Molen T, Thoonen B, Schermer T, et al. NHG-Standaard COPD. www.nhg.org.

7. Voorstel voor de zorgstandaard COPD. Amersfoort: Long Alliantie Nederland, 2009.

8. Calverley PMA, Burge PS, Spencer S, Anderson JA, and Jones PW. Bronchodilator reversibility testing in chronic obstructive pulmonary disease. Thorax 2003;58;659-64.

9. Miller MR, Hankinson J, Brusasco V, Burgos F, Casaburi R, Coates A, et al. Standardisation of spirometrie. Eur Respir J 2005;26:319-38.

10. Lucas AEM, FWJM Smeenk, IJ Smeele, T Brouwer, CP van Schayck. 'Het klopt heel aardig!' Validiteit van het diagnostisch advies dat astma/COPD-diensten aan huisartsen geven. Huisarts Wet 2008;51:479-84.

11. Lucas AEM, Smeenk FWJM, Smeele IJ, Van Schayck CP. Overtreatment with inhaled corticosteroids and diagnostic problems in primary care patients, an exploratory study. Fam Pract 2008;25:86-91. 


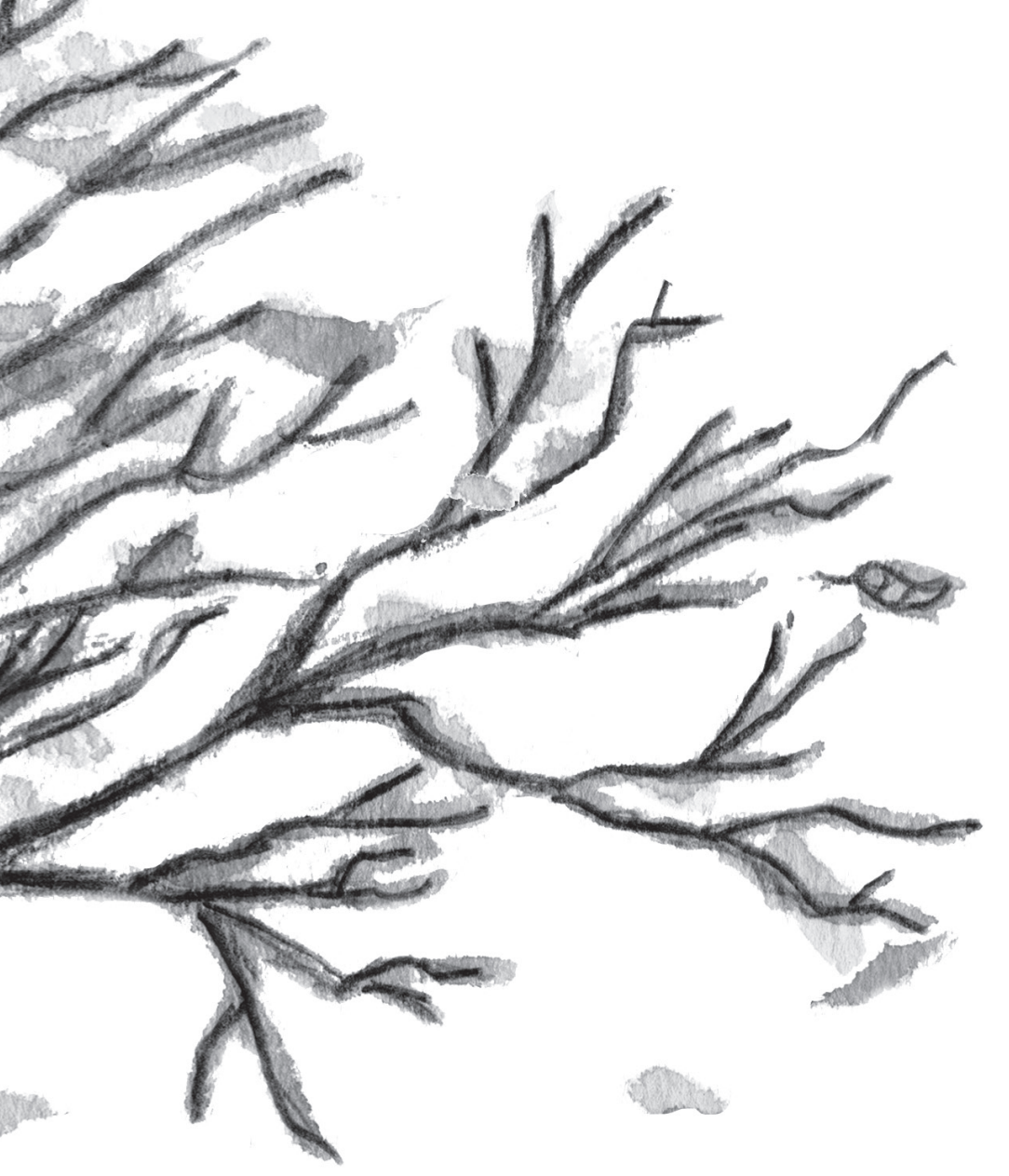

Twijfel aan diagnose astma of COPD?

matipe

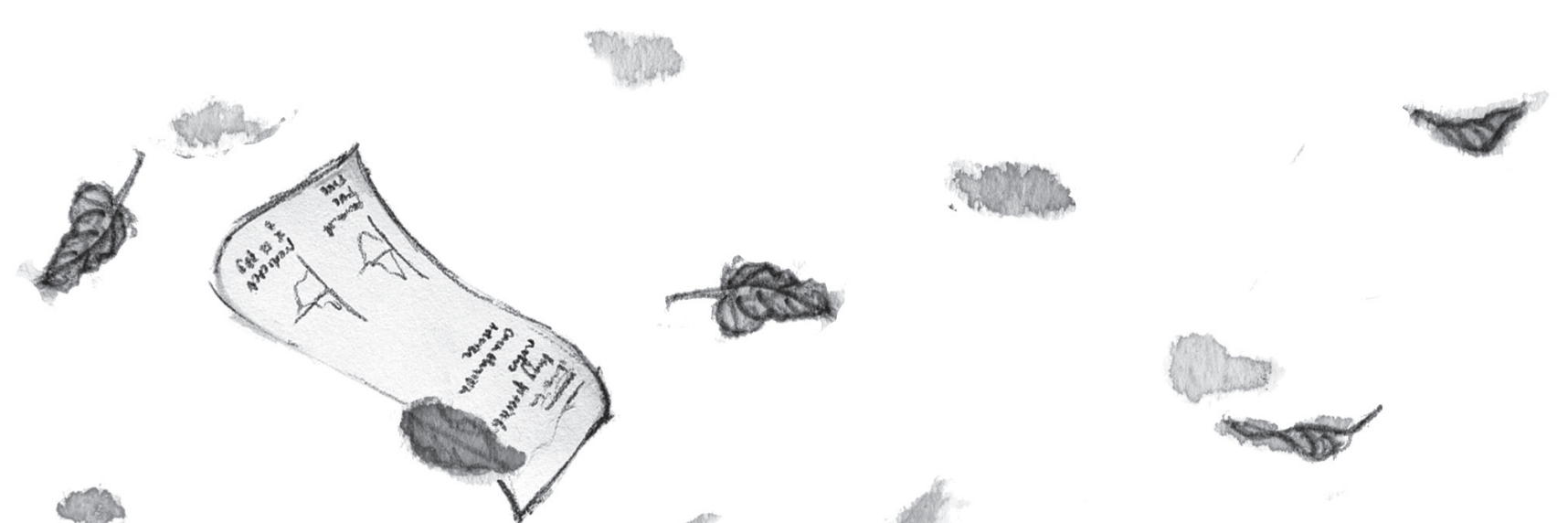


Twijfel aan diagnose astma of COPD?

Annelies Lucas

\section{De kern}

- bij veel patiënten waarbij de arts diagnostiek van astma of COPD uitvoert, bestaat twijfel over een definitieve of complete diagnose

- naast astma en COPD gaan verscheidene andere aandoeningen gepaard met hoesten en/of benauwdheidsklachten

- door systematisch de anamnese uit te diepen, soms aangevuld met simpel onderzoek, kan de arts de diagnose in de regel aanscherpen

- de praktijkondersteuner ondersteunt de huisarts daadwerkelijk door diagnostisch voorwerk te doen als twijfel ontstaat over de diagnose astma of COPD

\section{Inleiding}

De diagnostiek van astma en COPD kan lastig zijn. Bij een patiënt met klachten die passen bij astma en/of COPD kan longfunctieonderzoek helpen om de diagnose te bevestigen ${ }^{[1]}$. Soms echter ontstaat er twijfel: de longfunctie kan bijvoorbeeld normaal zijn, of weliswaar afwijkend maar niet passend bij de klachten. Is er dan toch sprake van astma of COPD, of is er (nog) iets anders aan de hand?

Recentelijk heeft de astma/COPD-dienst in Eindhoven wetenschappelijk onderzoek naar gedaan naar dit fenomeen De huisartsen uit de regio verwijzen al hun patiënten met luchtwegproblemen naar deze dienst voor een longfunctieonderzoek om astma en/of COPD te diagnosticeren. Longartsen beoordelen op papier de longfunctie en het door de patiënt ingevulde anamneseformulier en rapporteren de diagnose en adviezen aan de huisartsenpraktijk.

Uit evaluatieonderzoek van deze astma/COPD-dienst bleek dat bij ruim de helft van de patiënten die de dienst bezochten, de beoordelende longarts twijfels had over de diagnose omdat bevindingen bij longfunctieonderzoek niet overeenkwamen met de anamnese. De longartsen gaven dan aan de huisarts het advies om aanvullend onderzoek te doen naar een alternatieve of een aanvullende diagnose ${ }^{[2]}$. De volgende zaken waren aanleiding voor de diagnostische twijfel.

- ongeveer $25 \%$ van de patiënten die een advies kregen voor aanvullend onderzoek, had een normale longfunctie en geen klachten op het moment van het longfunctieonderzoek. De vraag was of er toch sprake was van astma. Voor deze patiënten gold het advies het diagnostisch traject af te maken zoals eerder beschreven in dit tijdschrift ${ }^{\left[{ }^{[3]}\right.}$ opnieuw een longfunctieonderzoek uitvoeren bij klachten, of een histamineprovocatietest aanvragen;

- nog eens $25 \%$ van deze patiënten had eveneens een normale longfunctie, maar zij noemden juist wel klachten op het moment van het longfunctieonderzoek. De bedoeling van het advies voor aanvullend onderzoek bij deze patiënten was na te gaan of er een andere diagnose dan astma of COPD in het spel kon zijn;

- de overige patiënten hadden weliswaar een diagnose astma en/of COPD gekregen, maar de longfunctieafwijking verklaarde de ernst of de aard van de klachten niet. De vraag was of er sprake kon zijn van een aanvullende diagnose.

Wat kan er in deze situaties met de patiënten aan de hand zijn, en hoe komen we daarachter? 


\section{Discrepantie}

De klachten die in eerste instantie reden zijn voor het vermoeden van astma/COPD, zijn piepen, hoesten, slijm, benauwdheid en kortademigheid. Als het erop lijkt dat niet, of niet alleen astma of COPD deze klachten veroorzaken, hoef je natuurlijk niet altijd de hele differentiële diagnostiek na te lopen. Het klinische beeld van de patiënt wijst meestal al de weg. Soms is het lastiger en daarom zet ik de verschillende mogelijkheden op een rij in dit artikel.

Veel van de aandoeningen die in aanmerking komen, zijn echte huisartsgeneeskundige gezondheidsproblemen. Ingewikkeld onderzoek is daarvoor niet nodig. Belangrijk is vooral om goed uit te vragen wat de patiënt bedoelt met de klacht en welke andere klachten er nog blijken te bestaan. De vragen die een ingang kunnen zijn om een aanvullende diagnose op het spoor te komen, staan in tabel 1. De antwoorden van de patiënt zullen aanleiding geven om meer vragen te stellen en aanwijzingen te vinden voor de diagnose. In het volgende licht ik toe hoe je als praktijkondersteuner te werk kunt gaan.

Overigens is het stellen van de uiteindelijke diagnose de verantwoordelijkheid van de huisarts. De praktijkondersteuner kan actief meedenken en alert zijn op discrepanties tussen klachten en bevindingen bij longfunctieonderzoek zoals ik in de inleiding al vermeldde. Het loont zeker de moeite: uit al het genoemde onderzoek bleek dat de helft van de adviezen voor verdere diagnostiek een nieuwe of extra diagnose opleverde.

\section{Hoesten}

Bij de hoofdklacht ‘hoesten' kunnen de volgende problemen spelen.

\section{Acute hoest}

Acute hoest (hoestklachten met een duur tot drie weken) is de meest voorkomende klacht in de huisartsenpraktijk: per 1000 patiënten hebben 152 deze klacht. Dat is heel wat meer dan de 28 astmapatiënten die er onder deze 1000 patiënten voorkomen. Acute hoestklachten betreffen meestal onschuldige virale of bacteriële infecties van de bovenste luchtwegen waarmee patiënten naar de huisartsenpraktijk gaan: ongeveer 34 per 1000 mensen bezoeken jaarlijks de huisarts met 'acute hoest $^{\lceil[4]}$. Er is pas reden om aan astma te denken bij frequente hoestklachten. Omdat 'frequent' een lastig begrip is, kan een patiënt met 'acute hoest' het diagnostisch traject ingaan, een longfunctiemeting krijgen en voor de uitslag op het spreekuur van de praktijkondersteuner komen. Wellicht zijn de klachten dan voorbij. De praktijkondersteuner breidt in elk geval de anamnese uit:

- vraagt nog eens na hoe lang de klachten duren of geduurd hebben, en hoe vaak hoestklachten voorkomen. Houd je een vermoeden van astma, volg dan het diagnostisch traject zoals besproken in het artikel 'De complexe weg naar de diagnose astma of COPD'

- vraagt na of er koorts en/of keelpijn aanwezig is of was

- overlegt met de huisarts indien het hoesten deze keer heftig is of erg lang duurt, want dan zou het kinkhoest kunnen zijn

- doet dit ook als de patiënt ziek is, als hij pijn heeft die vastzit aan de ademhaling, of als hij bij het hoesten bloederig slijm opgeeft

\section{Chronische sinusitis}

Een rinosinusitis is in de regel na 2-3 weken voorbij en gaat vooral gepaard met hoofdpijn, een verstopte neus en koorts ${ }^{[5]}$. Hoesten ontstaat door de zogeheten postnasal drip of postnasal reflux: de slijmsliert die soms achterin de keel te zien is, bevat inflammatoire mediators die de hoestreflex opwekken. Vooral bij chronische klachten is het onderscheid met astma van belang. De praktijkondersteuner:

- vraagt naar een verstopte neus, naar hoofdpijn, en naar hoofdpijn bij het bukken - vraagt ook naar het gebruik van neusspray met xylometazoline om de neus weer doorgankelijk te krijgen. Bij misbruik (gebruik langer dan vijf dagen) werkt die averechts en verstopt de neus des te meer. De klacht? Behalve hoesten ook benauwdheid!

\section{Passief roken}

Passief roken kan de oorzaak zijn van chronisch hoesten. Denk ook aan beroepen waarbij de patiënt in aanraking komt met andere prikkelende zaken zoals fijn stof, verflucht, dieren. De praktijkondersteuner:

- vraagt naar het rookgedrag van de patiënt en dat van zijn huisgenoten en collegae. Deze vraag zou routine moeten zijn

- vraagt naar het beroep en de hobby's van de patiënt

\section{Hoesten door reflux van maagzuur}

De typische verschijnselen van reflux zijn brandende pijn achter het borstbeen, zuur oprispen, hartwater, zure smaak, boeren en herkauwen (regurgitatie). Klachten kunnen vooral 's nachts, in liggende houding, optreden. Soms ontbreken al deze maagverschijnselen en moeten zaken als heesheid, een gevoel van een prop in de keel (globusgevoel) en ja: hoesten, ons op het spoor zetten van reflux. De praktijkondersteuner:

- vraagt naar zuurbranden, ook naar gebruik van Rennies

- adviseert de patiënt bij nachtelijke klachten om 's avonds niet te veel te eten, en het hoofdeinde van het bed wat hoger te zetten

- overlegt de met huisarts of de patiënt maagzuurremmers moet gaan gebruiken 
Het verband tussen reflux en hoesten is niet waterdicht: mensen die hoesten bij door gastroscopie aangetoonde reflux houden soms toch hun hoestklacht ondanks medicatie. Maar er zijn ook succesverhalen en het is terecht om zuurremmers voor te schrijven bij hoesten en reflux.

\section{Medicatie}

Berucht is hoesten als bijwerking van de zogeheten ACE-remmers (enalapril, lisinopril enzovoort). Een paar uur tot een aantal weken na eerste inname kan een heel hinderlijke prikkelhoest optreden. In de praktijk leidt dit er vrijwel altijd toe dat de patiënt met het middel moet stoppen. Angiotensine-II-antagonisten zijn goede vervangers voor de ACE-remmers. De praktijkondersteuner:

- vraagt naar medicatie, en overleg met de huisarts als daar ACE-remmers bij zitten (je herkent die aan de uitgang '-pril')

- overlegt met de huisarts wie de controle uitvoert: als de huisarts de medicatie verandert, volgt een controle waardoor jij of de huisarts behalve het hoesten ook de bloeddruk en eventuele cardiale klachten kunnen evalueren

\section{Benauwdheid}

Ook als de hoofdklacht benauwdheid is, kunnen andere aandoeningen in het spel zijn. Niet altijd zal de patiënt klagen over 'benauwdheid', maar wel over bijvoorbeeld moeheid, conditieverlies, of kortademigheid. Welke problemen moeten jij en de huisarts dan in elk geval overwegen?

\section{Hartfalen}

Hartfalen staat op de eerste plaats ${ }^{[6]}$. Hartfalen komt bij 20\% van de COPD-patiënten voor, ongeacht hun GOLD-classificatie, dus ook al bij GOLD ${ }^{\left[{ }^{[7]}\right.}$. Hartfalen is een symptoom dat optreedt als het hart op de een of andere manier schade heeft opgelopen (klepproblemen, infarct, hypertensie enzovoort). Bij hartfalen ontstaat hoesten doordat er vocht achterblijft in het longweefsel ten gevolge van een verminderde pompfunctie van het hart. Kernsymptomen zijn dyspnoe of moeheid bij een normale of geringe inspanning of zelfs in rust, en oedeem in de benen. De patiënt kan 's nachts benauwdheidsaanvallen krijgen en moet dan rechtop in bed gaan zitten (orthopnoe). Patiënten slapen op meerder kussens, of zetten het hoofdeinde van het bed omhoog.
De praktijkondersteuner:

- vraagt naar de volgende symptomen; die zijn de belangrijkste pijler voor de diagnostiek van hartfalen:

- 'vocht vasthouden', dat wil zeggen 's avonds dikke enkels, 's nachts vaak plassen

- hoesten bij plat liggen, meer rechtop moeten slapen

- moe en/of kortademig bij inspannen

- overlegt met de huisarts of er aanvullend een BNP of NT-proBNP-bepaling in het bloed moet plaatsvinden

Als deze (NT-pro)BNP-bepaling een normale waarde laat zien, is hartfalen uit te sluiten. Een verhoogde waarde zegt echter niet veel, omdat een verhoogde waarde ook bij COPD past. Als er een vermoeden blijft bestaan van hartfalen, is het aan de huisarts om verder het beleid te bepalen. Deze kan een ecg en een echocardiogram laten maken, of verwijzen. Het verdere beleid en de begeleiding van de patiënt met hartfalen staan buiten het bestek van dit artikel, maar ook daarbij kan de praktijkondersteuner een belangrijke rol hebben.

\section{Hooikoorts}

Hooikoorts en andere vormen van allergische rinitis8 horen voor de volledigheid in deze differentiële diagnose thuis, maar die herken je meestal wel meteen. Een loopneus en tranende, jeukende ogen zijn de meest hinderlijke verschijnselen. Door de verstopte neus kan de patiënt klagen over benauwdheid en piepen. Bij auscultatie van de longen hoort de huisarts geen afwijkingen.

De praktijkondersteuner:

- vraagt naar niezen, loopneus, jeuk in neus en ogen

- vraagt naar de omstandigheden waaronder de klachten voorkomen. Die zetten je op het spoor van de allergenen waarvoor de patiënt gevoelig is: pollen, huisstof, huisdieren

- overlegt met de huisarts of de anamnese voldoende aanwijzing geeft voor hooikoorts, of dat een allergietest wenselijk is

\section{Neuspoliepen}

Neuspoliepen zijn vaak een gevolg van chronische slijmvliesprikkeling zoals bij heftige allergische rinitis. Patiënten klagen over een verstopte neus en nachtelijke ademhalingsproblemen. Een inhalatiecorticosteroïde is in deze gevallen wel geïndiceerd, maar voor de neus, en (zonder astma) niet voor de longen! Soms kun je neuspoliepen zien bij inspectie van de neus met een neusspeculum. Dat zal de huisarts voor zijn rekening nemen. 
De praktijkondersteuner:

- vraagt naar (te) langdurig gebruik van xylometazoline (Otrivin) en Nasivin

Psychische aandoeningen

Hyperventilatie geeft bij uitstek benauwdheid, en kan een gevolg zijn van een paniekstoornis. Vaak maken de klachtenpresentatie en bijkomende verschijnselen de diagnose wel duidelijk: patiënten ervaren angst, hartkloppingen, tintelingen in de armen en rond de mond, wazig zien enzovoort. Klachten treden vaak op in spannende situaties.

De praktijkondersteuner:

- kijkt goed naar de patiënt en vraag welke klachten hij allemaal ervaart

- leest samen met de patiënt de NHG-Patiëntenbrief Hyperventilatie: de informatie kan de verschijnselen verhelderen, en dat werkt vaak geruststellend

- kan aan de patiënt vragen om een tijdje snel te ademen. Patiënten herkennen de klachten namelijk als je hyperventilatie provoceert. Voor deze test zou je in overleg met de huisarts de fysiotherapeut kunnen inschakelen, die vervolgens ademhaling- en ontspanningstherapie kan geven

\section{Depressie}

komt bij chronische ziekten, ook bij COPD, frequent voor. Als inactiviteit en moeheidsklachten niet door de ernst van de COPD te verklaren zijn, kun je aan depressie als bijkomende klacht denken.

De praktijkondersteuner:

- gebruikt de CCQ bij de controle van alle COPD-patiënten. Deze vragenlijst bevat twee vragen waarmee je de stemming meet. Doorvragen blijt belangrijk: COPDpatiënten hebben niet het hart op de tong!

\section{Medicatie}

Berucht is aspirine (acetylsalicylzuur) als uitlokker van soms heftige astmaklachten. Het is geen allergische reactie, maar de astmatische reactie is het gevolg van een toename van leukotriënen. Ook NSAID's kunnen op deze wijze astmatische klachten veroorzaken. Nog enkele andere medicijnen zijn niet handig bij astma of COPD en kunnen klachten eventueel versterken: bètablokkers, morfine en valium.

De praktijkondersteuner:

- gaat na wat de patiënt aan medicatie gebruikt, en vraag ook naar zelfmedicatie, bijvoorbeeld Ascal ('aspirientje') bij keelpijn of hoofdpijn

- overlegt zo nodig met de huisarts of deze de medicatie wil aanpassen

\section{Andere (luchtweg)problemen}

Pas altijd op voor andere (luchtweg)problemen. Er bestaan natuurlijke veel meer longproblemen dan astma of COPD. Houd daar rekening mee en pas op voor valkuilen.

\section{a-1-antitrypsinedeficiëntie}

Een voorbeeld is de patiënt met een zogeheten a-1-antitrypsinedeficiëntie. Deze heeft een longfunctie zoals past bij 'echte' COPD.

De praktijkondersteuner:

- is alert op het volgende: als de patiënt een longfunctie heeft die past bij COPD, maar nooit heeft gerookt en/of jonger is dan 40 jaar, mag je die niet zomaar in je COPD-controleprogramma opnemen. Er kan sprake zijn van deze erfelijke, ernstige aandoening, of iets anders, bijvoorbeeld gefixeerde astma. Hoe dan ook, in dit geval moet de longarts de patiënt verder onderzoeken

- overlegt met de huisarts

\section{Restrictieve longfunctie}

Van een restrictieve longfunctie kan sprake zijn bij een te lage FVC samen met een te lage FEV1, een vrijwel normaal FEV1 en een vrijwel normale FVC. Strikt genomen kun je de diagnose restrictie niet op grond van longfunctiemeting in de huisartspraktijk stellen. Restrictie past bijvoorbeeld bij longweefselaandoeningen als sarcoïdose en voor deze diagnose moet de patiënt voor uitgebreider pathofysiologisch onderzoek naar de longarts. Er kan wel enige afname van de longvolumina optreden bij (ernstige) abdominale adipositas, die inderdaad ook vaak met kortademigheid en conditieverlies gepaard gaat, of bij ernstig, acuut, hartfalen.

De praktijkondersteuner:

- gaat, als de longfunctie restrictieve kenmerken heeft, na of de patiënt erg dik is, of dat er afwijkingen zijn in lichaamsbouw zoals kippenborst

- gaat, als dat niet zo is, na of de patiënt enigerlei beperkingen of klachten ervaart. Zo ja, dan waarschuwt zij de huisarts, die de diagnostiek verder kan uitvoeren, of kan verwijzen

- overweegt, als de patiënt geen beperkingen ervaart, in overleg met de huisarts een X-thorax te laten maken en/of de longfunctiemeting over 3-6 maanden te herhalen. Als de X-thorax geen afwijkingen laat zien en de longfunctie hetzelfde blijtt, lijkt er geen sprake van pathologie en past deze longfunctie bij de patiënt. Maar laat je huisars deze conclusie trekken! 


\section{Andere longproblemen}

Andere longproblemen kunnen met hoesten en of benauwdheid samengaan, maar dat hoeft niet per se. De NHG-standaard beveelt aan om bij patiënten ouder dan 50 jaar een $\mathrm{X}$-thorax aan te vragen bij eerste diagnostiek. Dit is vooral om andere aandoening aandoeningen (dan COPD) uit te sluiten, zoals longcarcinoom. Het gaat immers om rokende patiënten!

De praktijkondersteuner:

- is samen met de huisarts attent op het maken van een röntgenfoto bij een oudere patiënt met luchtwegklachten, zoals de standaard aanbeveelt

\section{Ernstige aandoeningen}

Ernstige aandoeningen mag je niet over het hoofd zien. Veel aandoeningen gaan gepaard met moeheid, een gebrekkige conditie of ademtekort.

De praktijkondersteuner:

- let ook op alarmsignalen als zich ziek voelen, afvallen, pijn, enzovoort. Er zou sprake kunnen zijn van een nieuwe aandoening, of een al bekende aandoening die opspeelt

\section{Samenvattend}

$\mathrm{Er}$ is een aantal alternatieve of aanvullende aandoeningen die een rol kunnen spelen bij de astma- of COPD-diagnostiek. De meeste daarvan kan de praktijkondersteuner samen met de huisarts, zelf op het spoor komen, vooral door de anamnese uit te breiden, evenals het lichamelijk onderzoek, en beperkt laboratorium- of röntgenonderzoek. Als we er niet uitkomen, is een verwijzing op zijn plaats. De longarts heeft een uitgebreid arsenaal aan diagnostische mogelijkheden en uiteraard zijn er legio problemen die je in de huisartsenpraktijk niet goed kunt behandelen, zoals bronchiëctasieën en longfibrose. Omdat deze patiënten in de thuissituatie ook een beroep doen op de huisartsenpraktijk, is het voor de huisarts, maar óók voor de praktijkondersteuner, belangrijk het veld van hoest- en benauwdheidsklachten te overzien.
Tabel 1: Astma-COPD-diagnostiek: op zoek naar een alternatieve of aanvullende diagnose.

\begin{tabular}{ll}
\hline Oriënterende vraag & Mogelijk probleem \\
\hline Hoe lang en hoe vaak hoesten? & Incidenteel (hoesten bij spirometrie) \\
Hoofdpijn, ziek? & Chronische sinusitis \\
Loopneus, jeuk ogen, neus? & Allergische rinitis, hooikoorts \\
Verstopte neus, benauwd? & Neuspoliepen \\
Vocht vasthouden: Orthopnoe? & Hartfalen \\
Benauwd bij inspanning? Dikke enkels? & \\
Zuurbranden? Oprispingen? & Reflux \\
Rookomgeving? Beroepsomstandigheden? & Reactief hoesten \\
Nooit gerookt? & a1-antitrypsinedeficiëntie \\
ACE-remmers? & Bijwerking medicijnen \\
Aspirine/salicylaten/NSAID's? & Bijwerking medicijnen \\
Te zwaar? & Beperkte longinhoud, restrictie \\
Stress, paniek? & Hyperventilatie \\
Moe = down, lusteloos? & Depressie \\
Recentelijk X-thorax gehad? & Longproblematiek \\
Ziek, afvallen, pijn? & Alarmsignalen voor ernstige aandoeningen \\
\hline
\end{tabular}




\section{Literatuur}

1. Geijer RMM, Chavannes NH, Muris JWM, Sachs APE, Schermer T, Smeele IJM, et al. NHG-Standaard Astma bij volwassenen. www.nhg.org.

2. Lucas A, Smeenk F, Smeele I, Brouwer T, Van Schayck O. 'Het klopt heel aardig!' Validiteit van het diagnostisch advies dat astma/COPD-diensten aan huisartsen geven. Huisarts Wet 2008; $51: 479-84$.

3. Lucas AEM. Diagnostiek van astma en COPD in de praktijk. Tijdschr praktijkonderst 2011;6:17-22.

4. Verheij ThJM, Salome PhL, Bindels PJ, Chavannes AW, Ponsioen BP, Sachs APE, et al. NHG-Standaard Acuut hoesten. www.nhg.org.

5. De Sutter A, Burgers JS, De Bock GH, Dagnelie CF, Labots-Vogelesang SM, Oosterhuis WW, et al. NHG-Standaard Rhinosinusitis. www.nhg.org.

6utten FH, Walma EP, Kruizinga Gl, Bakx HCA, Van Lieshout J. NHG-Standaard Hartfalen www.nhg.org.

7. Rutten FH, Cramer MJ, Grobbee DE, Sachs AP, Kirkels JH, Lammers JW, et al. Unrecognized heart failure in elderly patients with stable chronic obstructive pulmonary disease. Eur Heart J 2005;26:1887-94.

8. Sachs APE, Berger MY, Lucassen PLBJ, Van der Wal J, Van Balen JAM, Verduijn MM. NHG-Standaard Allergische en niet-allergische rinitis. www.nhg.org. 



\section{Dankwoord}

Op 11 december 2001 zat ik in het vliegtuig van New York naar Amsterdam en spelend met mijn New York Marathon-medaille bedacht ik dat het nu wel eens tijd werd voor een andere soort topprestatie. Racefiets aan de haken, hardloopschoenen in de kast, tijd om de belofte aan mijn middelbare school leraren in te lossen en mijn hersenen uit te dagen. Alsof die niet genoeg aan hun trekken kwamen in de huisartsenpraktijk, als nascholingscoördinator, als ontwerper van modellenwegwijzers voor praktijkondersteuning, en niet te vergeten als moeder van twee slimme kids. Toch, iets ontbrak nog..

Dat iets kwam op mijn weg, en nu is het af, mijn eigen promotieonderzoek. Niet dat het ongemerkt voorbij is gegaan. Niet voor mezelf, ook niet voor mijn omgeving. Maar het is echt afgekomen, dankzij...

Mijn begeleidingscommissie prof. Dr. Onno van Schayck, Dr. Frank Smeenk, Dr. Ivo Smeele. Dank voor jullie lange adem! Toen we aan het traject begonnen hadden we geen idee dat we er bijna 9 jaren mee bezig zouden zijn. Voor 3 jaar was er, waarvoor dank, financiële ondersteuning van Pfizer Inc. and Boehringer Ingelheim Inc. Drie jaar was dus in principe de termijn die in ons hoofd zat, wetend dat het kort was in combinatie met 0,7 huisartsenpraktijk. Het doorgaan zonder financiële verplichtingen na die 3 jaren gaf mij lucht, maar gaf ook ruimte aan de vele beren die op mijn weg kwamen. Een aantal waren gerelateerd aan het onderzoek: minder instroom, designproblemen, de gebruikelijke hobbels. Een groter aantal "beren" had niet te maken met het onderzoek. En tja, ik ging deze niet uit de weg, jullie hoofdschudden voor lief nemend: de introduktie van de ketenzorg, het schrijven van DBCs en het onderhandelen daarover, automatiseringsperikelen, implementatie van de BeweegKuur en de beweegconsulent. Dat alles tijdens zeer roerige jaren binnen de SGE, en met ook nog eens, voor jullie niet herkenbaar maar voor mijn lotgenotes des te meer: de confrontatie met de "hormonologen".

Jullie hebben telkens geduldig gewacht tot ik weer een familieberaad belegde per telefoon en er weer een stapje gezet werd. Uiteindelijk hebben we de eindstreep gehaald! 
Onno, met al mijn ervaring als huisarts moest ik het vak van wetenschapper van de grond af leren. Jij bleef erin geloven, lastige extraneus die ik was. Als ik thuis me voornam om ermee te stoppen wist jij het zo te draaien dat ik naar huis ging met nieuwe moed. De uitroeptekens in je reply als ik weer iets had gemaild gaven moed om toch weer te proberen de door jou geconstateerde "chaos" te ordenen. Chaos was ook een uiting van mijn worsteling tussen wetenschap en praktijk. Een combinatie die jij heel waardevol vond, en zo gaf je me weer zelfvertrouwen. Ik heb het onderzoek doen van jou geleerd, Onno. Dank daarvoor, voor alle steun en voor de prioriteit in je agenda bij de eindspurt.

Frank, jii zei: "iemand die een marathon kan lopen kan ook promoveren", en ja, je wilde me begeleiden. De Astma/COPD-dienst was jouw kindje, je wilde daar graag een wetenschappelijke evidence aan koppelen. Zouden we bijvoorbeeld jouw eigen stelling bij je proefschrift "De huidige (1998) ontwikkelingen rondom de invoering van de spirometrie als diagnosticum in de huisartsenpraktijk zullen leiden tot overbehandeling van patiënten" kunnen ontkrachten? Jouw kennis van de ins en outs van de Astma/COPD-dienst, jouw positieve betrokkenheid bij het onderzoek en je enthousiasme voor de boodschap in onze artikelen waren mij zeer tot steun. En ja, er blijft nog veel werk aan de winkel, leuk om daar met jou de schouders onder te kunnen blijven zetten!

Ivo, we zijn al heel lang vrienden, en ik verheug me erg op de vriendschap nu voort te kunnen zetten zonder dat 'het onderzoek' ertussen staat.

Jij was het die me uitnodigde de astma/COPD-dienst wetenschappelijk te evalueren. Wat een worsteling dat zou zijn, hebben we allebei op dat moment maar half beseft. Jij bent een pure wetenschapper, gaat voor de absolute waarheid ook al doet die het ideale klinische concept geweld aan. Je moest me vaker met twee benen op de grond zetten. Jouw wens, jouw eis, om steeds gestructureerd, efficiënt en kort te overleggen vond ik niet gemakkelijk. Gevecht tussen Mars en Venus. Maar ook ji hebt engelengeduld gehad. Dank daarvoor! We heffen snel weer het glas, op de boo of, wie weet, op de rand van ons zwembad.

Prof. Dr. GJ Wesseling, Dr. J. Muris en Prof. Dr. T. Van der Molen vormden samen de beoordelingscommissie aan wie ik tenslotte mijn manuscript kon toesturen GeertJan, Jean, Thys, dank dat jullie mijn proefschrift wilden lezen en ook nog mij zo snel groen licht gaven om het af te maken.

Anderen wil ik graag min of meer chronologisch bedanken. Beginnend bij het begin zijn dat de huisartsen en de patiënten die deelnamen aan het onderzoek.
Huisartsen, jullie deelname was een cadeautje aan mij, meer dan een hommage aan de wetenschap, en dat maakte dat mijn onderzoek een echte real life study kon zijn. Mijn heel hartelijk dank voor jullie bereidwilligheid in je keuken te laten kijken!

En patiënten, dank voor het taaie invullen van alwéér een vragenlijst. Vaak schreven jullie je eigen ervaringen in de zorg erbij. Wat kunnen wij dokters nog veel leren over hoe wij (zouden moeten) communiceren, wat een misverstanden. Dank voor de wijze lessen! Het onderzoek draaide om de beoordelingen "door de astma/COPD-dienst", feitelijk beoordelingen door de longartsconsulenten van het Catharina ziekenhuis en Maxima Medisch Centrum.

Frank, Ben, Pascal en Jacques, jullie staken er samen met Maria van de Boogaard dubbel tijd in om je als beoordelaar te laten valideren. Heldhaftig, dank! En ik maak heel graag van deze gelegenheid gebruik om alle betrokken longartsen te bedanken voor de vanzelfsprekendheid waarmee ze dagelijks de huisartsen ondersteunen in hun diagnostiek, zonder discussies over belangen en lijnen.

Maria, je naam is al genoemd: wie astma/COPD(-dienst) zegt, zegt Maria van den Boogaard. Jij bent mede-oprichter en ambassadeur van de dienst, niet alleen vanwege de borging van diagnostische kwaliteit maar ook vanwege de extra ondersteuning, in het bijzonder het opschonen van HIS-sen. We hadden daar samen nog een artikel over willen schrijven, maar practici als we zijn ging het dagelijkse zorgen voor. Jouw bevlogenheid heeft bij mij altijd alle twijfel weggenomen over de zin van mijn onderzoek. We gaan samen verder, voor CASPIR, voor PoZoB, leuk!

Dank aan mijn onderzoeksassistenten, de echte harde werkers: Marion Drietelaar, Tim Brouwer, Gerrie Brouwer, Sandra Horrocks, Karin Aretz.

Marion, in de eerste uren zorgde je minutieus voor de vragenlijsten, de reminders, de binnenkomende data en de protocollenboeken, de basis voor het werk van alle volgende jaren. We verloren elkaar uit het oog toen je de universiteit verliet, maar dit boekje is zeker ook een hommage aan jou. Tim, als jochie deed je samen met mijn zoon Charles aan hoogspringen, nu vond ik je een echte hoogvlieger toen je geïnstrueerd door Arnold Kesters je tanden zette in de Fleiss-analyses voor de eerste artikelen. En heel bijzonder: het was Gerrie, je moeder, die bij de astma/ COPD-dienst alle casuïstiek hiervoor verzamelde. Gerrie, Manuella, Friek, Yvonne, super-enthousiaste en dito-gezellige AC-dienst van nu, wat is het leuk om, na alle monnikenwerk, samen met jullie en helemaal bij de (ICT-)tijd, verder te werken aan efficiëntere en daardoor betere ondersteuning voor onze huisartsen! 
Sandra, wat was het fijn dat je in Eindhoven bij Meetpunt Kwaliteit zo'n groot stuk van de dataverwerking mocht doen. Kon ik even tussendoor langs komen, gemakkelijk en gezellig bovendien. Mocht jouw scriptie ervan komen, ik sta bij je in het krijt!

Karin, stevige professional, wat had ik gemoeten zonder jou? Gepuzzel met SPSS, onderzoeksvragen, zoeken naar antwoorden en daardoor creëren van nieuwe vragen, heerlijk om met jou te sparren! Wel pas nadat we heel de week doorgenomen hadden, met als achtergrond op je PC de fraaie foto's van Oostenrijkse landschappen en bloemenpracht. Helaas paste die ene tabel die ons en Bjorn Winkens grijze haren kostte, toch niet in het boekje. That's all in the game, toch? Er bleef genoeg moois over, waarvoor heel veel dank!

Hoe blijf je je wetenschapper voelen zonder een pied à terre op het instituut? Doo er toch, zij het met beperkte regelmaat te komen en de lucht te op te snuiven van de academische werkplaats. Even bij tanken door me soulmates te weten me Marc, Daniel, Carolien, Luc, Merijn, collega-onderzoekers voor wie juist de SGE een uitstap was. Deed goed, zoals ook de contacten in CaHag-verband. Tjard, Philippe, zonder de anderen te kort te willen doen, dank ik jullie voor de gelegenheid te kunnen bijdragen in de discussie rondom LLN en zorgstandaarden.

En ja, het was allemaal niet gelukt zonder de medewerking van de fantastische collega's in de Orion. Af en toe moest ik tijd maken, goochelen met spaarverlof en levensloopregelingen. Marlieke en Marjolein, mijn respectievelijke duo-maatjes, ik heb er geen onvertogen woord over gehoord, integendeel. Net zo min als van jullie, Pieter, DirkJan, Wies, John, Marie-Louise, assistentes. Alleen die éne hoopvolle zucht van jou, Carin, toen ik er eens het bijltje bij neer dreigde te gooien "want dan zou ik voor de Orion ook nog...". Eén voordeel dat het toch af kwam: nu heb ik weer iets om over te schijven in het Groene Boekje, als ik nog mag!

Marjolein, dat jij ook aan een promotietraject bent begonnen vind ik geweldig, en voor het geval je niet meer weet hoe in PubMed te komen, ik help je wel!

Praktijkondersteuners van de SGE en PoZob, Hanneke in het bijzonder, Katinka, Arnold, Colette, jullie gaven me alle gelegenheid om als kaderarts astma/COPD de wetenschap aan de praktijk te toetsen. Voor jullie zijn de laatste hoofdstukken in dit boekje!

En dan waren- en zijn - jullie er, mijn vrouwengroep, Marijke, José, Thea, Marlie, Annette. Al zo veel jaren hebben we onze avondjes intervisie, bijpraten, what's in a name. Weten dat we van elkaar weten, dat is zó kostbaar. Jullie vingen mijn steunen en zuchten op alsof promoveren net zo'n existentieel probleem was als al het andere wat ons overkwam. En spiegelden: "Eigen keuze toch? Dan moet je daar achte gaan staan, positie kiezen". En zo is het. Noblesse oblige, het ei is gelegd! Enorm bedankt voor jullie empowerment, lieve ladies!

Een keuze waar ik geen moment over getwijfeld heb was de keuze voor mijn klankbordgroepje. Marianne en Emmy, dat jullie hier pas genoemd worden heeft te maken met chronologie, niet met belangrijkheid, absoluut niet. Het bleek goud waard jullie in de laatste periode te vragen met mij te brainstormen ter voorbereiding voor de vergaderingen met de heren van mijn promotiecommissie. Marianne, natuurlijk wist ik al hoe secuur je wetenschap bedrijft. Methodologisch en inhoudelijk hield je me scherp. En Emmy, jou sms-jes hielden de vaart erin. "Enne Lieske? Waird t neet weer ens tied?" De 11e van de 11e in 2011 zat er niet in, maar krap een jaartje later staan jullie aan mijn zijde als paranimfen waar ik helemaal op durf te vertrouwen. Ik ga, als ik dit schrijf, er zelfs vanuit dat we het shoppen er goed vanaf gaan brengen! Nu jij nog, Emmy, at your service!

Wie ooit zelf promoveerde weet dat dit zo met je leven is verweven dat alles bijdraagt aan het halen van de eindstreep. Ook, misschien wel vooral, de tijd die je er NIET aan besteedt, even iets heel anders doet. Zie daar het levensbelang van mijn clubjes. Mijn fietsclub Velo l'eauloo, mijn zwemgroep, mijn filmclub, mijn leesclub, mijn kookclub. Dank dat jullie er zijn! Wie weet kom ik nu wel tot heel creatieve fietsroutes en recepten, exotischer boeken en films, in elk geval zal ik een stuk lichter mee kunnen doen en genieten!

Natuurlijk zou ik dit hoofdstuk, dat, o heerlijk, niet beperkt hoeft te zijn tot 2000 woorden, lekker lang uit willen breiden. Dat is niet moeilijk, ik wil graag íedereen bedanken die met me mee leefde. Luc (Harms) bijvoorbeeld. Je was mijn collega bij groep IV / de Orion en bent mijn voorganger bij Diagnostiek voor U. In jouw tijd richtten we de astma/COPD-dienst op, zo zie je maar! Jules, dank voor je geduldig wachten, zó zeer niet-jou, op het Hora Est. Je hebt net als mijn andere "nieuwe" collega's bij Diagnostiek voor U er vast naar uitgekeken dat ik me vol kon concentreren op mijn nieuwe functie, nu is het zover!

Aan alle vrienden, familie (als ik geen naam noem kan ik niemand vergeten) wil ik bekennen dat "aan het onderzoek moeten werken" vaak mijn sociale agenda blokkeerde, op zijn minst in mijn hoofd. Dank voor jullie begrip, heerlijk om weer meer tijd met jullie te kunnen delen! 
En dan tot slot het allerbelangrijkste, mijn dank-je-wel aan mijn naasten. Zo jammer dat $\mathrm{u}$ het niet meer lezen kunt, Mama. Dank je wel voor uw aanmoediging elke dinsdag, bij ons wekelijkse etentje samen, maar meer nog dank je wel dat $u$ er was, was zoals u was, er voor mij was.

En wat is het bijzonder om gecoacht te worden door je eigen dochter! Ellen, vanaf mijn coschappen al mijn maatje, wie heeft beter ervaren hoe ik als "student" in elkaar steek! Jij wist hoe frustrerend promoveren kan zijn, en natuurlijk kon ik met persoonlijk geworstel bij je terecht. Maar ook professioneel stond je me bij, waar je ook zat op de wereld. Methodologische vraagstukken, statistiek, en als ik bij de 10e, 11e, 12e, 13e versie van een artikel was dan ging je er steeds weer geduldig, als inmiddels native speaker, met het rode potlood overheen. Dan zuchtte ik maar weer eens, stiekem heel trots op jou! Gelukkige delen we zoveel meer dan wetenschap, lieve dochie van me. Wat denk je, Cappadocie op de fiets, om dit nu in alle rust samen te vieren?

Charles, zoonlief, je hebt me ingehaald, en me daarmee enorm geholpen. Ik hoefde nog maar na te doen wat jij deed: tanden op elkaar, nachten doorwerken, paniek te boven komen, de stress eruit rammen op de fiets en uiteindelijk slagen! Maar zonder gekheid, jouw WAAAAAuuuw-mailtjes als ik succesjes te vieren had, je steun en je vanzelfsprekende vertrouwen dat het zou lukken, dat alles was een geweldig stimulans om er net als jij eens te staan. En om mijn handen vrij te krijgen voor die andere rol waarmee jij en Julia me over de streep hebben gelokt! Dus.. wanneer kan de oma van Sam komen oppassen???

En dan Benno, lieve supporter van me. Jij en ik zijn twee heel verschillende mensen. Je hebt vaak gezegd dat je niks jaloers was op mijn gedrevenheid. Je bent een levensgenieter, en ja, je wist inderdaad vaak beter dan ik wat goed voor me was. Hup, gaan hardlopen, fietsen. Maar ook: nog even doorgaan, hoe laat het ook was, je bracht me koffie met een wafel erbij, en een nachtzoen. Je hebt eindeloos veel geduld gehad, daarvoor ben ik je heel dankbaar

En nu is "het onderzoek" af. We hebben er samen lang naar uitgekeken. De belofte van weer echte weekenden, weer echt vakantie. De rust hebben om naast je in de Topolino te zitten, of in de Austin 7, het zou zomaar kunnen zijn. lief maatje van me, heerlijk!

Mijn slotzin is voor Papa
Papa, ooit verzuchtte $u$ : nu wordt het toch geen dokter Lucas. U maakte niet mee dat het wel weer dokter Lucas werd. En nu, 20 jaar na uw overlijden, is het niet alleen dokter Lucas maar ook doctor Lucas. Wat zou u dat graag meegemaakt hebben, wat had ik u graag erbij gehad. Zoals Stef Bos zegt: "papa, ik lijk steeds meer op jou". Ik ben $u$ heel dankbaar voor de ambities en het doorzettingsvermogen dat $u$ aan me heeft doorgegeven. Aan wie anders dan aan u zou ik dit boekje opdragen? 


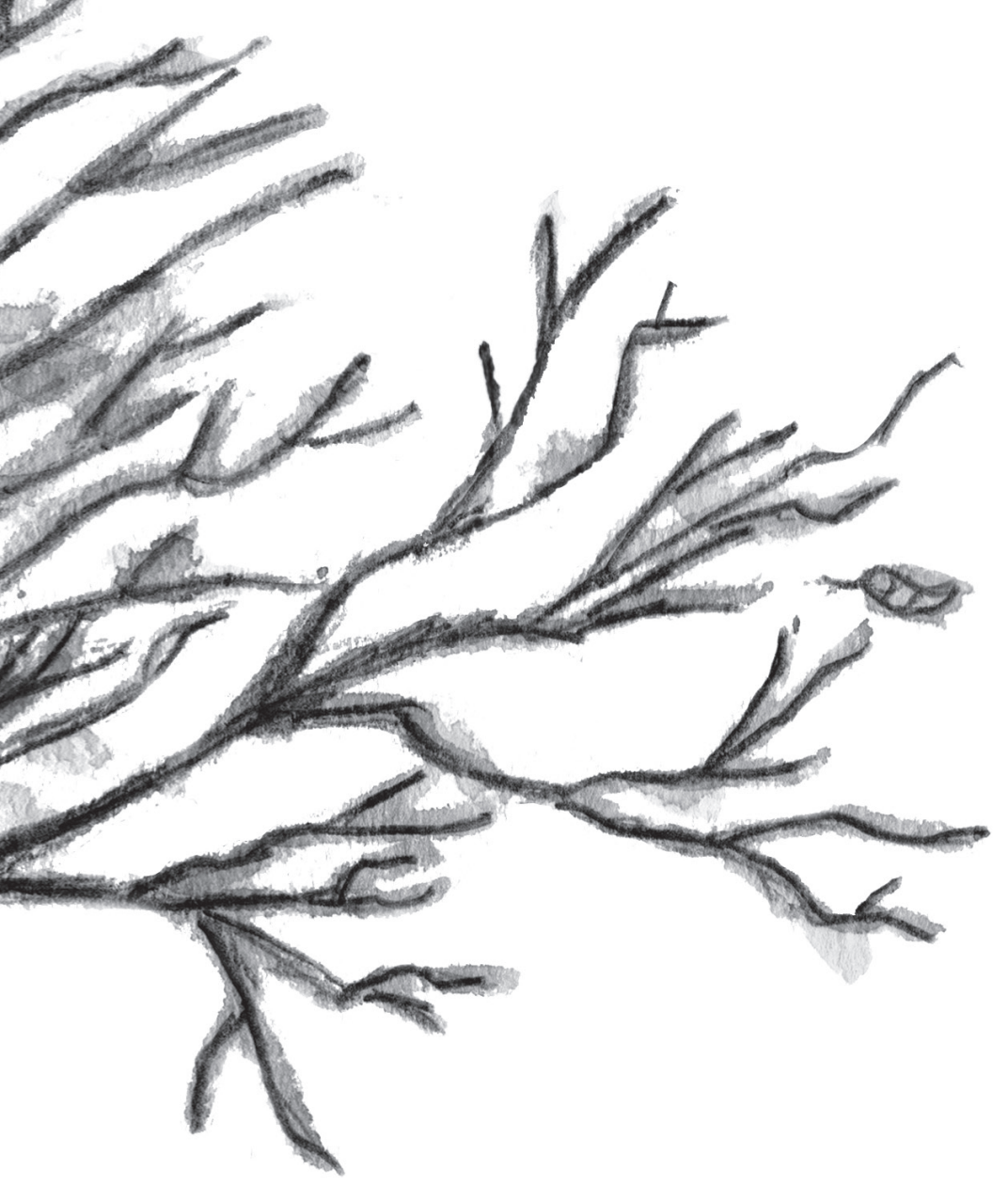




\section{Author, co- author}

1. Gabriel Smilkstein, Annelies Helsper-Lucas, Clark Ashworth, Dan Montano, Mark Paget. Prediction of pregnancy, complications: an application of the biopsychosocial model. Soc.Sci. Med. vol. 18 no 4, 315-321, 1984.

2. Helsper-Lucas AEM, van Lammeren DJ. Opvang slachtoffers van sexueel geweld. Medisch Contact 1986,$41 ; 182-184$

3. Bulte, J, van de Ende J, Helsper-Lucas A, Visser S. De beroepsopleiding tot huisarts, evaluatie van de op de preventieve taak van de huisarts gerichte onderwijsprogramma's. S.1988 ISBN 90-367-0077-9

4. Helsper-Lucas A, Bulte J, Grol R, Visser S. De inhoud van het terugkomdagonderwijs in de Nijmeegse en Groningse opleiding tot huisarts. Huisarts Wet 1987; 30: 318-324

5. Helsper-Lucas A, Grol R. Attitudeontwikkeling tijdens de beroepsopleiding tot huisarts in Nijmegen en Groningen. Huisarts en Wetenschap 1987; 30:357-359

6. Bulte J, Helsper-Lucas A, van de Ende J, Visser S. Evaluatie-onderzoek naar de huisartsenopleiding in Nijmegen en Groningen. Huisarts Wet 1987; 30: 317

7. Helsper-Lucas AEM, Grol RPTM Grol, Mokkink HGA. Effecten van de opleiding tot huisarts: veranderingen in consultvoering. Huisarts en Wetenschap 1988 ; 31: 407-411

8. Grol R, Mokkink H, Helsper-Lucas A, Tielens V, Bulte J. Effects of the vocational training of general practice consultation skills and medical performance. Med Educ. 1989;23(6):512-21

9. Helsper-Lucas A, Mokkink H, Grol R. Veranderingen in de medisch-technische vaardigheden bij arts-assistenten tijdens de eenjarige beroepsopleiding tot huisarts in Nijmegen en Groningen. in: de beroepsopleiding tot huisars, Groningen/Nijmegen 1988

10. Marianne Meulenpas, Joze Braspenning, Hans Vlek, Annelies Lucas, Wim de Grauw, Richard Grol. Eerste lijns zorgmodel voor diabetes type 2: toepasbaar en haalbaar. Huisarts Wet. 2006 49 (7) $356-60$

11. Meulepas MA, Jacobs JE, Lucas AE, Smeenk FW, Smeele IJ, Bottema BJ, Grol RP. The feasibility of a primary care model for the management of COPD. Prim Care Respir $\mathrm{J}$. 2006;15(6):337-41

12. Meulepas MA, Braspenning JC, de Grauw WJ, Lucas AE, Harms L, Akkermans RP, Gro RP. Logistic support service improves processes and outcomes of diabetes care in genera practice. Family Practice 2007; 24(1)20-25

13. Meulepas MA, Jacobs JE, Smeenk FW, Smeele IJ, Lucas AE, Bottema BJ, Grol RP. Effect of an integrated primary care model on the management of middle-aged and old patients with obstructive lung diseases. Scand J Prim Health Care. 2007;25(3):186-92.

14. Lucas AEM, Smeenk FWJM, Smeele IJ, Brouwer T, van Schayck CP. Br J Gen Pract. The validity of diagnostic support of an asthma/COPD service in primary care. 2007; 57(544):892-6.

5. Meulepas M A, Braspenning J C C, de Grauw W J, Lucas A E M, Wijkel D, Grol R P T M. Patient-oriented intervention in addition to centrally organised checkups improves diabetic patient; outcome in primary care. Qual of Health Care 2008;000:1-6
16. Lucas AEM, Smeenk FWJM, Smeele IJ , van Schayck CP. Overtreatment with inhaled corticosteroids and diagnostic problems in primary care patients, an exploratory study. Fam Pract. 2008 25(2): 86-91.

17. Schermer TRJ, Smeele IJM, Thoonen BPA, Lucas AEM, Grootens JG, van Boxem TJ, Heijdrae YF, van Weel C. Current clinical guideline definitions of airflow obstruction and COPD, overdiagnosis in primary care. Eur Respir $\mathrm{J}$ 2008; 32: 945- 952

18. Annelies Lucas, Frank Smeenk, Ivo Smeele, Tim Brouwer, Onno van Schayck. Het klopt heel aardig!' Validiteit van het diagnostisch advies dat astma/COPD-diensten aan huisartsen geven. Huisarts Wet 2008:51(10):479-84

19. Lucas AEM, Smeenk FWJM, Smeele IJ , van Schayck CP. Diagnostic assessments of spirometry and written medical history data by respiratory specialists supporting primary care: are they reliable? Prim Care Respir J.(2009); 18(3): 177-184

20. Annelies Lucas. De complexe weg naar de diagnose astma of COPD. Tijdschrift voor Praktijkondersteuning 2011,(6), februari, pag. 17-22.

21. Annelies Lucas. Twijfel aan de diagnose astma of COPD? Tijdschrift voor Praktijkondersteuning (6) april 2011 blz. 49-54. Tijdschr v Praktijkondersteuning 2011 (7), april, bldz 49-54

22. Linmans J, Spigt M, Deneer L, Lucas A, de Bakker M, Gidding L, et al. Effect of lifestyle intervention for people with diabetes or prediabetes in real-world primary care: propensity score analysis. BMC Family Practice. 2011;12(1):95.

23. Lucas AEM, Smeenk FWJM, Smeele IJ, van Schayck CP. Diagnostic accuracy of primary care Asthma/COPD working hypotheses, a real life study. Respir Med 2012.106;1158-1163

24. Akkermans RP, Berrevoets MA, Smeele I, Lucas A, Thoonen B, Grootens-Stekelenburg J, et al. Lung function decline in relation to diagnostic criteria for airflow obstruction in respiratory symptomatic subjects. BMC Pulmonary Medicine, 2012. 12(1): 12

25. Lucas EM Annelies, Derckx WCC Emmy, Meulepas A Marianne, Smeele JM Ivo, Smeenk WJM Frank and van Schayck P Onno. Consultation performance of general practitioners when supported by an asthma/COPDC-service. BMC Research Notes 2012, 5.368 

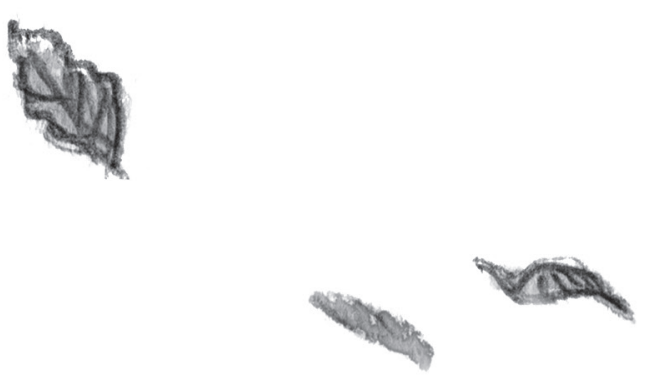

\section{Annelies Lucas}

is geboren in Swalmen op 26 juli 1953. Ze behaalde in 1971 haar gymnasium- $\beta$ diploma, de basis voor "medicijnen gaan studeren", (toen) vanzelfsprekend aan de katholiek Universiteit Nijmegen. Daags na haar artsexamen in 1979 vertrok ze naar de Verenigde Staten (Pullman, Washington State). Gedurende twee jaar werkte ze daar als consulent voor studenten en zwangeren bij Familiy Planning en onder steunde ze revalidatieprogramma's voor MS-patienten. Ze voerde er een wetenschappelijk onderzoek uit naar de invloed van biopsychosociale factoren op verloop van zwangerschap en bevalling, onder leiding van Prof. Dr. Gabriel Smilkstein.

In oktober 1981 kwam ze terug naar Nederland om de eenjarige huisartsenopleiding te volgen aan het huisartseninstituut te Nijmegen. Aansluitend nam ze deel aan de wetenschappelijke evaluatie van de beroepsopleidingen van Nijmegen en Groningen onder leiding van prof. Dr. Richard Grol. Dit combineerde ze met huisartsenwaarnemingen, totdat ze in 1986 haar eigen praktijk kon starten in "Groep 4", een van de gezondheidscentra van de SGE (Stichting Gezondheidscentra Eindhoven. Van 1994 tot 2000 was ze daarnaast nascholingscoördinator bij de WDH Eindhoven (Werkgroep Deskundigheidsbevordering Huisartsen, later Stichting $\mathrm{KOH}$ ). Naast scholingen voor huisartsen, assistentes en paramedici werkte ze aan samenwerkingsafspraken tussen huisartsen en specialisten. "Groep 4" verhuisde en werd gezondheidscentrum Orion. In "de Orion" deelde Annelies vanaf 2001 haar praktijk met een collega.
Ter voorbereiding op de komst van de praktijkondersteuner ontwikkelde Annelies in 2000, in opdracht van de DHV (Districts Huisartsen Vereniging) ZuidOost Brabant, de Modellenwegwijzers Diabetes Mellitus type 2 en Astma/ COPD. Een logisch vervolg was de uitbouw tot de eerste eerstelijns DBC Diabetes, die ze schreef in 2003 namens de SGE samen met de zorggroep Pozob. Annelies was nauw betrokken bij de ontwikkeling van de facilitaire diensten voor chronisch zieken en accepteerde in 2003 de uitnodiging om één van deze, de astma/ COPD-dienst, wetenschappelijk te evalueren. Ze introduceerde ondertussen bij de SGE de Beweegconsulent in de BeweegKuur en werd kaderarts astma/COPD. Als zodanig is ze nu docent en adviseur voor regionale zorggroepen.

Nadat ze haar 25 jarig praktijkjubileum heeft gevierd in augustus 2011 heeft Annelies de praktijk overgedragen en werd ze medisch directeur bij Diagnostiek voor $U$, het eerstelijns diagnostisch centrum in de regio Eindhoven, den Bosch en Limburg.

Annelies heeft een dochter Ellen en een zoon Charles, haar soul mates in de sport en in de wetenschap waarin beiden haar een voorbeeld stelden door (eerder en sneller!) te promoveren. En sinds kort is er kleinzoon Sam! Annelies woont samen met haar sparring partner Benno, op de mooiste plek op aarde: Swalmen. 
